\title{
Libro Actas
}

Comunicación TEerologín

Docencia

XIT

Jornadas de Innovación Docente e Investigación Educativa UZ

Facultad de Filosofía y Letras de la Universidad de Zaragoza

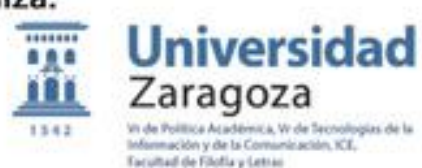

Colabora:

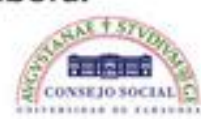

\section{Innovación}

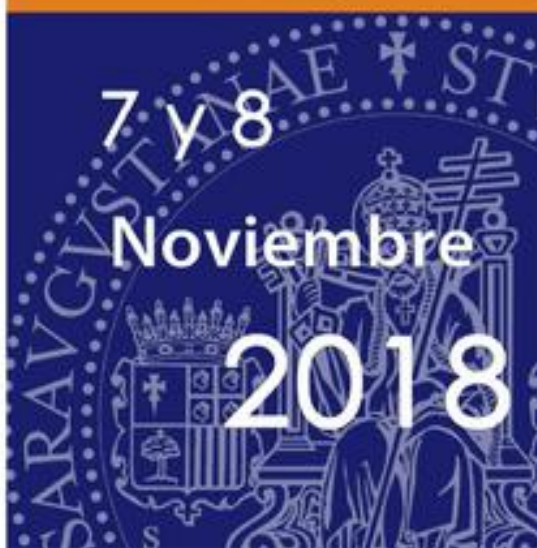






\section{Libro Actas de las XII Jornadas de Innovación Docente e Investigación Educativa de la Universidad de Zaragoza}

$$
\begin{aligned}
& \text { ㅍ.: Universidad }
\end{aligned}
$$

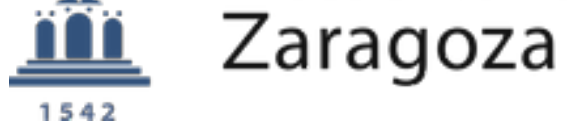

Zaragoza, 7 y 8 de noviembre de 2018 
Jornadas de Innovación Docente e Investigación Educativa UZ (12ª 2018. Zaragoza)

Libro de Actas de las XII Jornadas de Innovación Docente e Investigación Educativa UZ, Zaragoza, 7 y 8 de noviembre de 2018 / Universidad de Zaragoza. Vicerrectorado de Política Académica. Vicerrectorado de Tecnologías de la Información y de la Comunicación. Instituto de Ciencias de la Educación (coord.).-Zaragoza: Universidad de Zaragoza, 2018. - 237 p

Recurso Electrónico

ISBN 978-84-09-06315-4

https://zaguan.unizar.es/

I. Universidad de Zaragoza. Vicerrectorado de Política Académica, coord. II. Universidad de Zaragoza. Vicerrectorado de Tecnologías de la Información y de la Comunicación, coord. III. Universidad de Zaragoza. Instituto de Ciencias de la Educación, coord. 1.- Universidad de Zaragoza - Innovación docente - Congresos 2.-Enseñanza superior - Innovaciones - Congresos 3.- Enseñanza superior - Investigación - Congresos

4.- Tecnología educativa - Enseñanza superior - Congresos 5.- Difusión de la innovación - Enseñanza superior - Congresos

Primera edición: 29 de octubre de 2018

\section{(c) $(1)(9)$}

(C) Los autores, XII Jornadas de Innovación Docente e Investigación Educativa de la Universidad de Zaragoza 2018

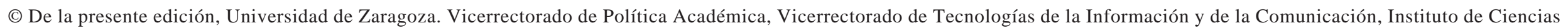
de la Educación.

Diseño gráfico y maquetación: María Teresa Pérez Yago 




\section{Índice}

Presentación

Programa

Mesas:

I. Aplicación de metodologías activas |

II. Evaluación del aprendizaje

III. Experiencias de mejora de la calidad de las titulaciones

IV. Aplicación de metodologías activas II

V. Experiencias de coordinación entre el profesorado

VI. Aplicación de metodologías activas III 



\section{Presentación}

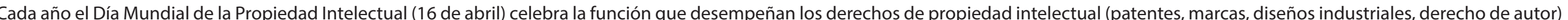

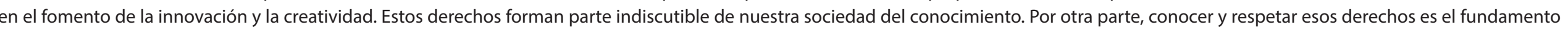
de la gestión del conocimiento generado durante la docencia en las universidades, tanto si queremos difundirlo en abierto, como de otras formas.

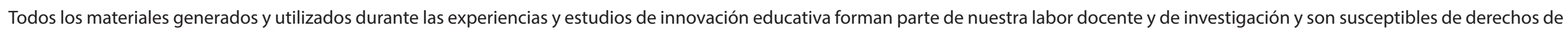
autor, propios y ajenos. Adicionalmente, estos materiales se difunden entre alumnado y profesorado, por ello es importante asegurar su buena definición y uso.

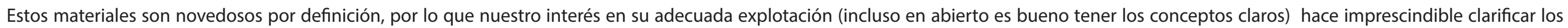

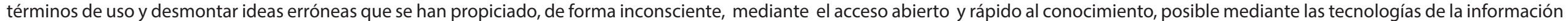

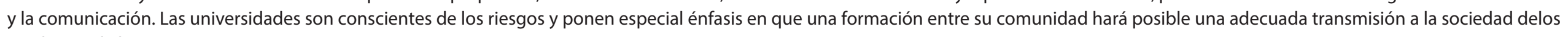
productos de la innovación.

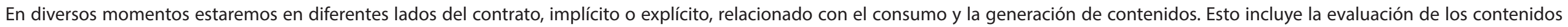
generados por otras personas. En este sentido parece necesario conocer nuestro marco de referencia para poder actuar de acuerdo a nuestros intereses y los de la institución.

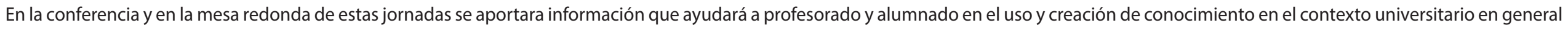
y en los proyectos de innovación educativa en particular.

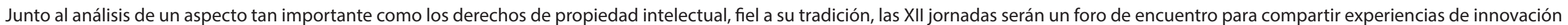

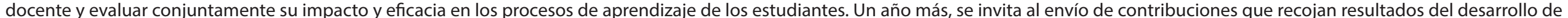
proyectos de innovación docente.

\section{Gerardo Sanz Saiz}

Vicerrector de Política Académica

Presidente del Comité Organizador 


\section{PROGRAMA}

XII Jomadas de Innovación Docente e Investigación Educativa

$09: 00 \mathrm{~h}$. a 09:30 h.

$09: 30 \mathrm{~h}$. a $11: 30 \mathrm{~h}$.

$11: 30 \mathrm{~h}$. a $12: 00 \mathrm{~h}$.

12:00 h. a $12: 30$ h.

$12: 30 \mathrm{~h}$, a $14: 00 \mathrm{~h}$

14:00 h. a $16: 00 \mathrm{~h}$

$16: 00$ h. a $19: 00$ h.
Entrega documentación. (Facultad de Derecho. Sala de Grados)

Mesas temáticas | y |I.

- Mesa temática I: Aplicación de metodologías activas I. (Facultad de

Derecho. Sala de Juntas)

Coordinadora: D." Estrella Escuchuri Aisa.

- Mesa temática II: Evaluación del aprendizaje. (Biblioteca Maria Moliner.

Salón de Actos)

Coordinador: D. Javier Usoz Otal

Pausa café. (Facultad de Derecho. Cafeteria)

Bienvenida e Inauguración. (Biblioteca María Moliner. Salón de Actos)

- D. Gerardo Sanz Sáiz.

Sr. Vicerrector de Politica Académica. Universidad de Zaragoza.

- D. Fernando Tricas Garcia.

Sr. Vicerrector de Tecnologias de la Información y de la Comunicación.

Universidad de Zaragoza

- D. Manuel Serrano Bonafonte.

Sr. Presidente del Consejo Social de la Universidad de Zaragoza

- D. Eliseo Serrano Martín.

Sr. Decano de la Facuitad de Filosofia y Letras. Universidad de Zaragoza.

Conferencia. (Biblioteca Maria Moliner. Salón de Actos)

- La gestión de la propiedad intelectual en las aulas virtuales.

Ponente: D. Andrés Marzal Varó. Gerente y Catedrático de Lenguajes y

Comida. (Facultad de Derecho. Cafetería)

Mesa temática III.

- Mesa temática III: Experiencias de mejora de la calidad de las titulaciones.

(Biblioteca Maria Moliner. Salón de Actos)

Eniversidad

iii Zaragoza

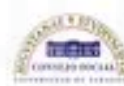

Facultad de Filosofia y Letras, Universidad de Zaragoza 


\section{PROGRAMA}

XII Jomadas de Innovación Docente e Investigación Educativa

$09: 30 \mathrm{~h}$ a $11: 30 \mathrm{~h}$.

11:30 h. a 12:00 h

12:00 h. a $14: 00$ h.

$16: 00$ h. a $19: 00 \mathrm{~h}$.

19:00 h. в 20:00 h.

Mesas temáticas IV y V

- Mesa temática IV: Aplicación de metodologías activas II. (Facultad de Derecho. Sala de Juntas)

Coardinador: D. Iván Lidón López.

- Mesa temática V: Experiencias de coordinación entre el profesorado.

(Biblioteca María Moliner. Salón de Actos)

Coordinadora: $D .^{a} M{ }^{a}$ lsabel Ubieto Artur.

Pausa café. (Facultad de Derecho. Cafetería)

Mesa Redonda (Biblioteca Maria Moliner. Salón de Actos)

- Fomento de buenas prácticas en el uso de la propiedad intelectual. Participantes:

-D. Pedro Bueso Guilìnen. Universidad de Zaragoza.

- D. a Lola Hernández Ara. Universidad de Zaragoza

- D. Clara Ubieto Avtur. Universidad de Zaragoza

- Da Isabel Ubieto Artur Universidad de Zaragoza

Mesa temática VI y VII.

- Mesa temática VI: Aplicación de metodologias activas III. (Biblioteca Maria Moliner. Salón de Actos:

Coordinador: $D$. Rubén Rebollar Rubio.

- Mesa temática VII: Acciones de integración y orientación de estudian-

tes. (Facultad de Derecho. Sala de Juntas)

Coordinadora: $D^{a} M^{\circ}$ Dolores Cepero Ascoso.

Acto de clausura. (Biblioteca Maria Moliner. Salón de Actos)

- D. Gerardo Sanz Sáiz

Sr. Vicerrector de Politica Académica. Universidad de Zaragoza.

- D. Manuel Serrano Bonafonte.

Sr. Presidente del Consejo Social de la Universidad de Zaragoza.

- D. Eliseo Serrano Martín.

Sr. Decano de la Facuitad de Filosofia y Letras Universidad de Zaragoza.

FI Universidad

Zaragoza

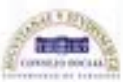





\author{
I \\ Aplicación de \\ metodologías activas I
}




\section{Aplicación de metodologías activas I}

1. López-Forniés, L.; Manchado Pérez, E.; Biel lbáñez, P.;Sanz Segura, R.

10 años de Semana del Diseño. Generar conocimiento más allá de la docencia reglada

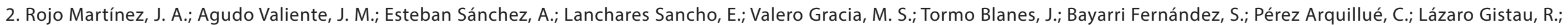
Valero-Gil, J.; Sayago García, F. J.

Aprender preguntando online. Realizar cuestionarios y actividades utilizando la plataforma Moodle

3. Gállego Lanau, M

Aprendiendo Derecho de la competencia a través de la metodología de role playing

4. Alzueta Anía, M. U.; Abián Vicén, M.

Control de la contaminación en un sistema industrial

5. Zabalza Bribián, I.; Peña Pellicer, B.; Llera Sastresa, E. M.; Usón Gil, S.; Martínez Gracia, A.; Romeo Giménez, L. M. Creación de un curso ADD en abierto con material audiovisual de apoyo al estudio de la termodinámica y la ingeniería térmica

6. Murillo Esteban, M. B.; Callejas Bermejo, A.; Gil Lalaguna, N.; Leris López, D.; Atienza Martínez, M. Desafío para la sostenibilidad: aprendizaje cooperativo y colaborativo mediante el trabajo en grupo de tipo caja blanca

7. Allueva Pinilla, A. I.; Alejandre Marco, J. L.

Elaboración de videotutoriales con ScreenCast-O-Matic para la clase invertida y el aprendizaje personalizado

8. Artero Escartín, I.; López Sánchez, C.; Villagrasa Rozas, M. M.; Rico Letosa, S.; Lobera Viñau, E. Gamificación con Kahoot en el Grado en Gestión y Administración Pública

9. Íñiguez Berrozpe, L.; Melero Polo, I.

Flipped Teaching como herramienta para la didáctica de Historia del Arte en el Grado de Turismo

10. Carrasquer Álvarez, B.; Ponz Miranda, A.

La elaboración de conservas y dulces en la formación de maestros/as de Educación Infantil 
11. Revilla Carrasco, A.; Cadena González, A.; Laliena Cantero, D.

La enseñanza de las artes visuales a través del taller para Educación Visual y Plástica; taller expositivo de luz y color

12. Carretero Calvo, R.; Criado Mainar, J.

Los dioses en el arte. Adaptación del estudio de casos a la iconografía de las divinidades de la Antigüedad como instrumento para la comprensión de las culturas del pasado

13. Abrego Garrués, J.; Callejas Bermejo, A.; Matute Najarro, R. P.; Mosteo Abad, R.; Murillo Esteban, M. B.; Sarasa Alonso, J. Retos para la sostenibilidad: los estudiantes de primero de ingeniería tienen algo que contarte

14. Carreras Manero, O.; de Miguel Arias, S.; López Pérez, F .

Role playing en la práctica contencioso-administrativa del Máster Universitario en Abogacía

15. Luzón Marco, M. J.; Velilla Sánchez, M. A.; Albero Posac, S.

Uso de vídeos disciplinares en inglés para el diseño de material docente en las asignaturas de Biología Humana en los grados de Medicina y Enfermería 


\section{0 años de Semana del Diseño. Generar conocimiento más allá de la docencia reglada}

López-Forniés, L.;Manchado Pérez, E.; Biel Ibáñez, P.;Sanz Segura, R.

\section{Palabras clave}

Charlas abiertas, aprendiendo del exterior, actividades paralelas, competencias transversales.

\section{Resumen}

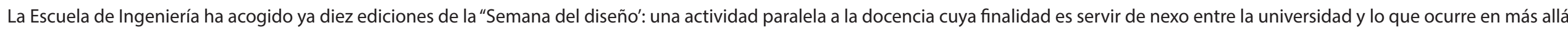

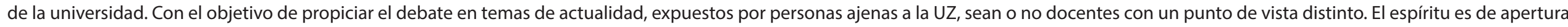
con voluntad de oír nuevas ideas. El proyecto sigue una metodología tipo foro y taller, cada año se mantienen dos tipos de actividades:

- Charlas y conferencias de divulgación sobre diseño con temas tratados de un modo abierto y transversal desvinculados de las materias de la titulación.

- Talleres impartidos por un profesional invitado, los participantes experimentan en la práctica algún aspecto tratado previamente

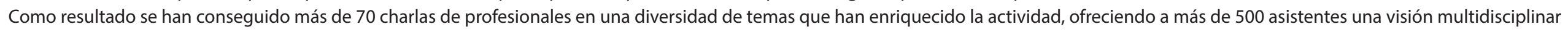

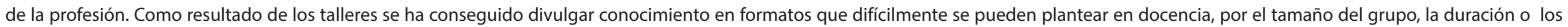
medios materiales.

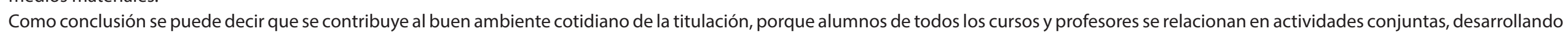

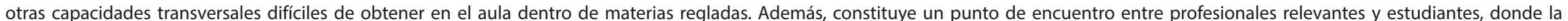

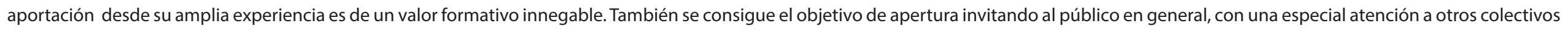
del diseño en Aragón como el Cadi, la DIN-A y a otros centros de formación. 


\title{
Generar conocimiento más allá de la docencia reglada.
}

\author{
Relación de autores: López-Forniés, I.; Manchado Pérez, E.; Biel Ibáñez, P.; Sanz Segura, R.
}

Departamento Ingeniería de Diseño y Fabricación, Departamento de Historia del Arte. ignlopez@unizar.es

La actividad propuesta desde la coordinación del Grado en Ingeniería en Diseño Industrial y Desarrollo de Producto, abierta a todos los cursos del grado y resto de titulaciones en ingeniería y UZ en general. No se vincula a ninguna materia concreta o asignatura, aportando conocimientos transversales por medio de charlas y talleres.

La Semana del Diseño en la EINA ha cumplido 10 ediciones. Los temas han sido: Cultura, Sociedad, Naturaleza, Imagen, Ciencia, Creatividad, Fabricación, Empleabilidad, Nuevas oportunidades y Reflexión.

Miradas acerca del diseño, que van más allá de la cuestión docente, poniendo el foco en la reflexión y el análisis a lo largo de una década en temas emergentes.

La Semana del Diseño ha tenido un formato de conferencias, más reflexivas y vinculadas con la teoría del diseño, talleres relacionados con la actualidad del diseño y basados en experiencias, y en ocasiones, actividades paralelas que tienen el objetivo de despertar el ánimo lúdico y crítico de los asistentes y del alumnado en general.

La Semana del Diseño ha sido apoyada por la dirección de la EINA, del Vicerrectorado de Cultura y Proyección Social, del Departamento de Ingeniería de Diseño y Fabricación y de la Cátedra HMY-Yudigar.

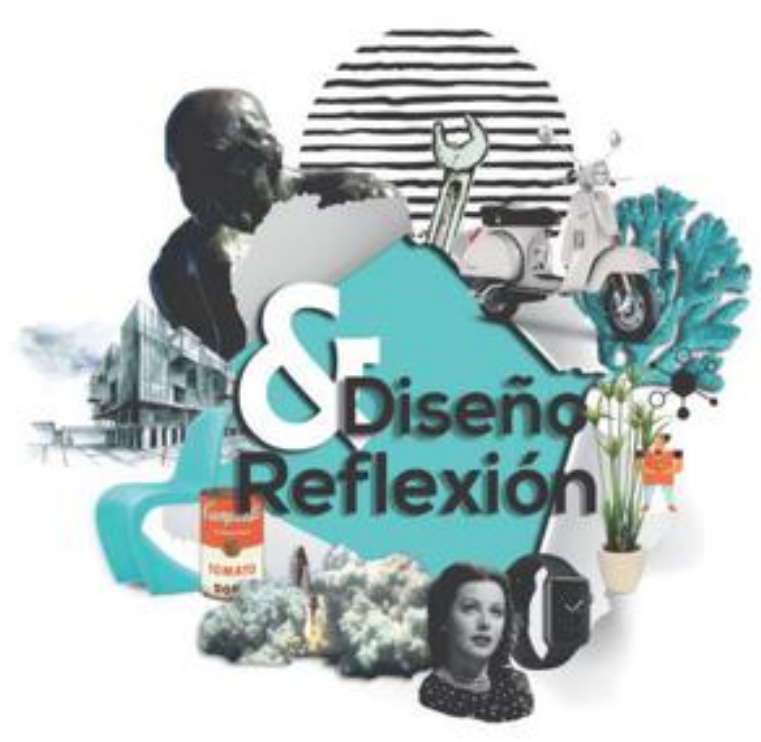

$X$ Semana del Diseño Universidad de Zaragoza - Eina 15 y 16 de Mayo de 2018 Compus Rio Ebro

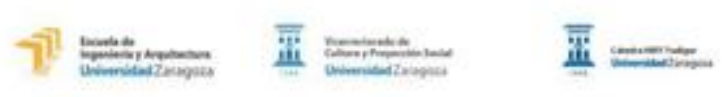

Se ha conseguido generar un foro de debate y conocimiento relacionado con otros aspectos de diseño no reglados en los estudios, difundiendo un conocimiento multidisciplinar propio de la empresa y el ámbito profesional, vinculando al alumnado de la EINA con la realidad laboral que afrontaran en un futuro próximo.

Se ha fomentado la curiosidad en el alumnado por llegar al conocimiento más allá de la universidad, interactuando en la exposición de opiniones y de la interacción con profesionales ajenos al mundo universitario. También se lleva al alumno a la reflexión en torno a la presencia del diseño en la vida cotidiana y en su capacidad de innovación a través del debate.

La participación activa en la semana del diseño hace que el buen ambiente y funcionamiento de la titulación se afiance, contribuyendo a una interacción entre estudiantes, PDI y PAS difícil de conseguir en el día a día de sus estudios. Finalizan 10 años en el libro Diseño y Reflexión y la futura formación de una nueva cátedra UZ. 


\section{Aprender preguntando online. Realizar cuestionarios y actividades utilizando la plataforma Moodle}

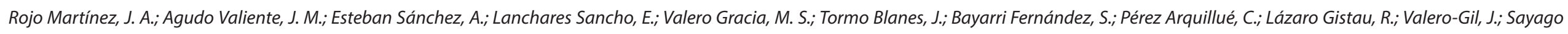
García, F.J.

\section{Palabras clave}

Aprendizaje continuo, Clase magistral, Flipped classroom, Evaluación continua, Cuestionarios de 5 minutos

\section{Resumen}

Contexto:

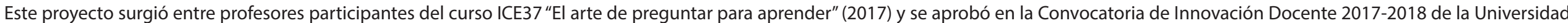

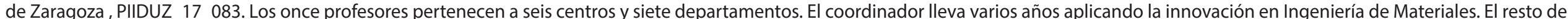
equipo ha empezado la innovación este curso en diversas asignaturas de grado y de máster de áreas distintas.

Objetivos:

1. Lograr una mayor motivación, dedicación y profundidad en el aprendizaje del estudiante

2. Crear una red de aprendizaje on-line entre los miembros del equipo.

3. Aprender a elaborar preguntas: fáciles ( $1^{\circ}$ nivel de la taxonomía de Bloom: recordar), normales ( $2^{\circ}$ nivel: entender) y difíciles ( $3^{\circ}$ nivel: aplicar).

4. Preparar lecturas y actividades previas a la clase presencial de unos 10 minutos que haga el estudiante en su casa.

5. Elaborar cuestionarios de 5 minutos que contesta el estudiante en su casa y en la clase presencial.

Metodología:

1. Se creó un curso en el ADD donde los miembros del equipo han compartido materiales, cuestionarios y experiencias.

2. e han diseñado cuestionarios de 5 minutos, que contesta el estudiante al final de la clase presencial y tras la mini flipped classroom.

3. Cada profesor ha adaptado estas actividades a su experiencia previa, contenido de sus asignaturas y nivel inicial de sus estudiantes.

4. Se han compartido en Moodle los resultados obtenidos por cada profesor del equipo y una valoración de los mismos. Resultados:

1. Aumento del porcentaje de estudiantes que asisten a clase presencial de hasta un $20 \%$.

2. Las tasas de rendimiento y éxito han mejorado hasta un $26 \%$ del promedio de asignaturas de $1^{\circ}$ y $2^{\circ} \mathrm{cursos}$, en la asignatura de Ingeniería de Materiales.

3. La eficiencia ha sido alta pues la plataforma Moodle funciona bien.

4. La opinión de los estudiantes ha sido muy positiva, pues los cuestionarios reconocen con la calificación obtenida sus logros y aprecian que el profesor está interesado en el progreso de su aprendizaje.

5. Todos los profesores quieren consolidar y mejorar la innovación. El proyecto está abierto a otros profesores interesados. 


\section{Aprender preguntando online. Realizar cuestionarios y actividades utilizando la plataforma Moodle}

José Antonio Rojo¹, José María Agudo, Ana Esteban, Elena Lanchares, Marta Sofía Valero, Jaume Tormo, Susana Bayarri, Consuelo Pérez, Regina Lázaro, Jesús Valero-Gil, Javier Sayago

1Departamento de Ciencia y Tecnología de Materiales y Fluidos, jarojo@unizar.es

Contexto: 11 profesores de siete departamentos y seis centros: EINA, Facultad de Veterinaria, Escuela Politécnica Superior de Huesca, Facultad de Ciencias de la Salud y el Deporte de Huesca, EUPLA, Facultad de Economía y Empresa

\section{Objetivos:}

1) Lograr mayor motivación y dedicación en el aprendizaje del estudiante

2) Crear comunidad de aprendizaje on line entre los miembros del equipo

3) Aprender a elaborar preguntas adaptadas al nivel de los alumnos

\section{Metodología:}

1) Curso en el ADD para gestionar el equipo y compartir resultados

2) Contestar cuestionarios on line, en casa y en clase presencial

3) Lectura previa de 10 minutos: mini flipped classroom

\section{Resultados y conclusiones:}

1) El estudiante está activo y contesta con su móvil (ver foto en clase)

2) El porcentaje de asistencia a clase aumenta y la tasa de rendimiento ha mejorado hasta un $26 \%$ sobre la media (ver gráfica con promedios)

3) Todos los profesores quieren consolidar y mejorar la innovación

4) La innovación se adapta a grados, másteres y áreas muy distintas

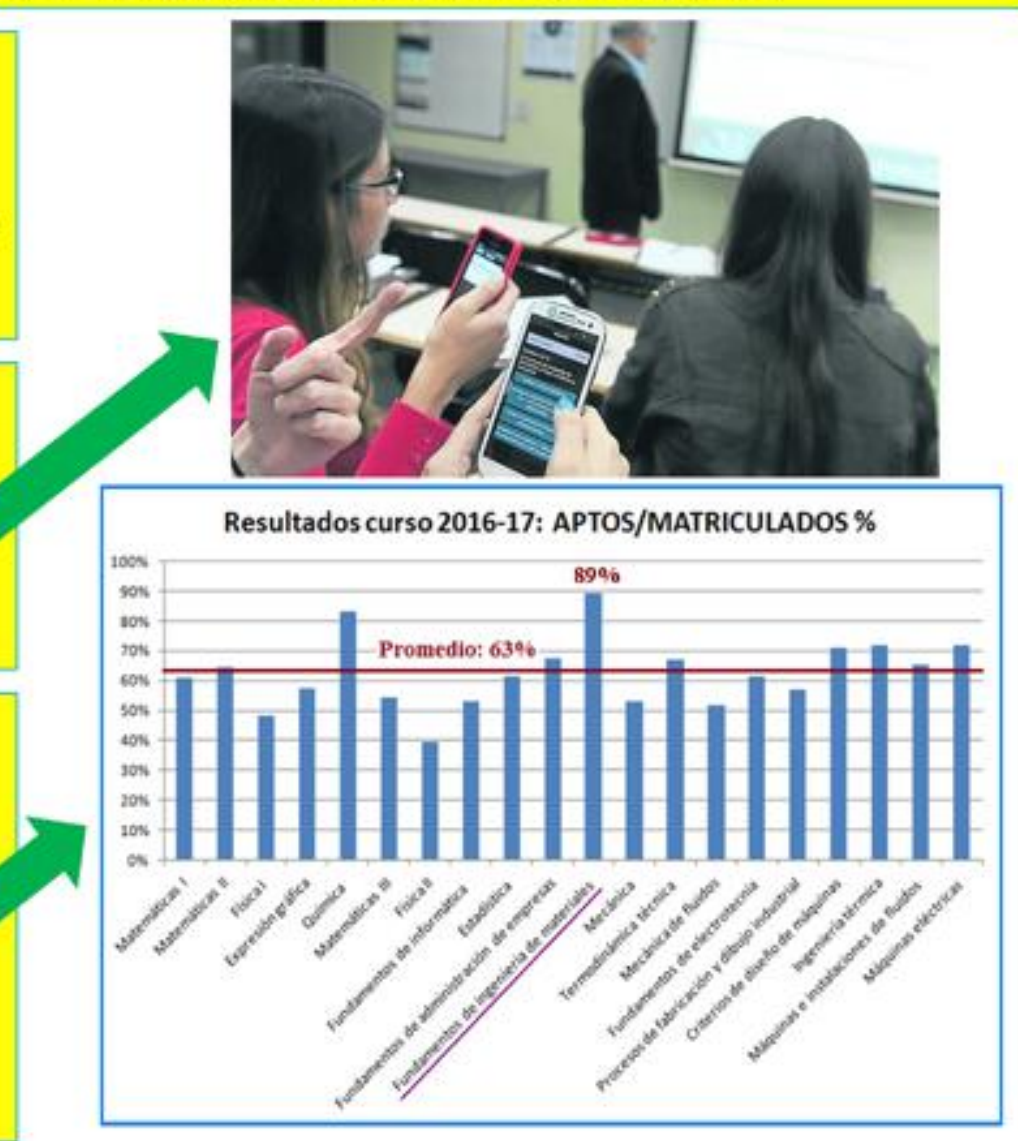

Fuente de datos de la gráfica: https://estudios.unizar.es/pdf/informes/2016/informe-es-144-v2.pdf 


\section{Aprendiendo Derecho de la competencia a través de la metodología de role playing}

Gállego Lanau, $M$

\section{Palabras clave}

Metodología activa, juegos de rol, simulación de juicios

\section{Resumen}

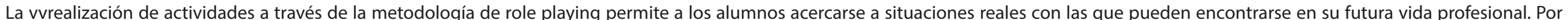

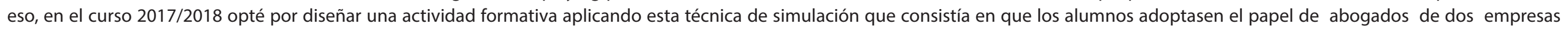
enfrentadas por una cuestión de competencia desleal.

El contexto académico en el que ha realizado esta actividad es la asignatura de Derecho Mercantil I que se imparte en el tercer curso del Grado en Derecho.

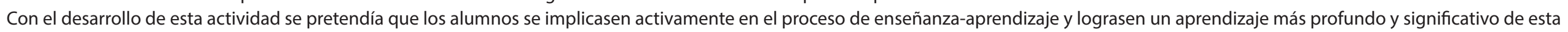

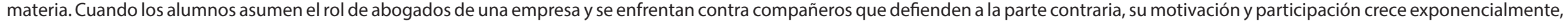
ya que ven como un reto personal alcanzar el objetivo de las actividades propuestas.

La actividad se ha articulado a través de varias fases:

1. explicación a los alumnos de la dinámica de la actividad, formación de grupos de 3 o 4 personas y entrega del supuesto de hecho;

2. cada grupo del subgrupo 1 de prácticas preparó un escrito de demanda. A continuación se trasladó cada demanda a un grupo del subgrupo 2 para que redactasen la contestación a la misma;

3. se realizó una especie de juicio simulado en el que cada pareja de grupos expuso de forma oral sus escritos.

Como resultado de esta actividad, los alumnos han mejorado sus destrezas comunicativas y argumentativas.

En conclusión, la metodología del role playing en el ámbito jurídico favorece que el alumno mejore en la adquisición de conocimiento y desarrollo de competencias propias de un jurista. 


\section{Aprendiendo Derecho de la competencia a través de la metodología de role}

\section{playing}

\section{Maria Gállego Lanau}

Departamento de Derecho de la empresa, mglanau@unizar.es

\section{Contexto académico:}

Titulación: Grado en Derecho

Curso: $3^{\circ}$

Asignatura: Derecho Mercantil I

Materia: Competencia desleal

\section{Objetivos:}

$\checkmark$ Implicar activamente al alumno en el proceso de enseñanza-aprendizaje $\checkmark$ Conseguir que el alumno mejore su expresión oral y escrita $\checkmark$ Facilitar que el alumno adquiera habilidades profesionales, como por ejemplo el asesoramiento jurídico a clientes

$\checkmark$ Fomentar el trabajo en equipo

\section{Metodología:}

(2) Traslado de la demanda

Grupo 1 (3/4 personas), abogados empresa $A$ -Reunión con su cliente (tutoría con la profesora) -Redacción del escrito de demanda

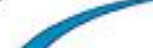

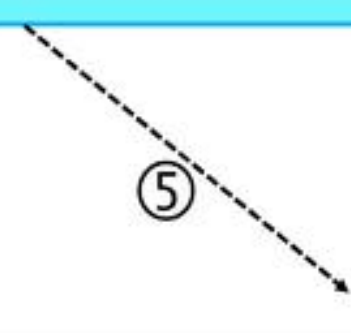

Desarrollo de un juicio simulado

Cada grupo expone de forma oral la postura de su cliente

\section{Resultados:}

Se comparan los dictámenes y exposiciones orales realizados durante el curso con los documentos jurídicos y las intervenciones que han resultado de esta actividad. Se observa:

$\checkmark$ Mejora en la redacción de escritos jurídicos y comunicación oral

$\checkmark$ Progreso en la búsqueda de fuentes legales, jurisprudenciales y doctrinales

$\checkmark$ Avance en la resolución de problemas en equipo
Grupo 2 (3/4 personas), abogados empresa $B$ -Reunión con su cliente (tutoría con la profesora) -Redacción del escrito de contestación a la demanda

\section{팸. Universidad

Conclusiones:

El role playing favorece la adquisición de conocimientos y el desarrollo de las competencias propias de un jurista 


\section{Control de la contaminación en un sistema industrial}

Alzueta Anía, M. U.; Abián Vicén, M.

\section{Palabras clave}

Ingeniería ambiental, medio ambiente, aprendizaje activo, juego educativo.

\section{Resumen}

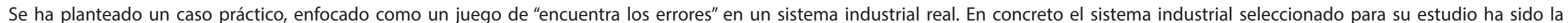

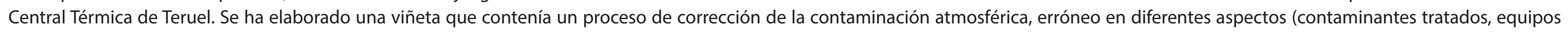

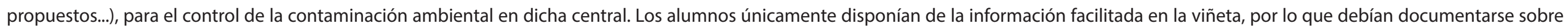
esta central y su entorno, identificar los errores presentes en la viñeta, y posteriormente elaborar ellos mismos el diagrama correcto de control de la contaminación ambiental del caso práctico.

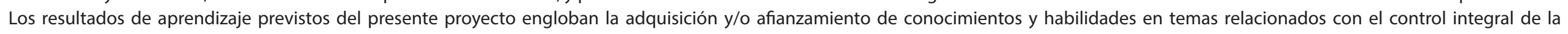

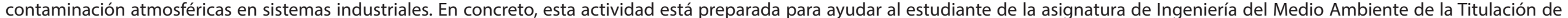

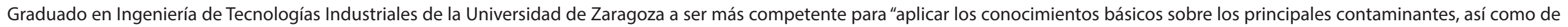
tecnologías medioambientales y criterios de sostenibilidad".

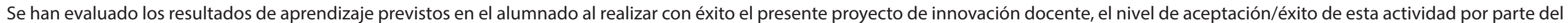

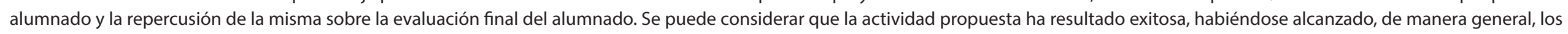
objetivos previstos en el proyecto.

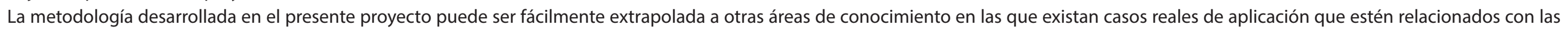
materias analizadas de clase. 


\title{
Control de la contaminación en un sistema industrial
}

\author{
Ma Ujué Alzueta, María Abián
}

Departamento de Ingeniería Química y Tecnologías del Medio Ambiente, uxue@unizar.es

Proyecto de innovación docente PIIDUZ_17_417, Curso académico 2017-2018

Contexto académico: Asignatura "Ingeniería del Medio Ambiente", asignatura obligatoria del Grado en Ingeniería de Tecnologías Industriales. La competencia específica que debe adquirirse al cursar dicha asignatura es: "Conocimientos básicos y aplicación de tecnologías medioambientales y sostenibilidad". Típicamente esta asignatura tiene unos 100 alumnos matriculados, distribuidos en distintos grupos.

Metodología ABP

(aprendizaje basado en problemas)

Caso práctico real enfocado como un juego de "descubre los errores"

1. Documentarse sobre la central y su entorno

2. Identificar los errores presentes en la viñeta

3. Proponer la solución de control de la contaminación atmosférica

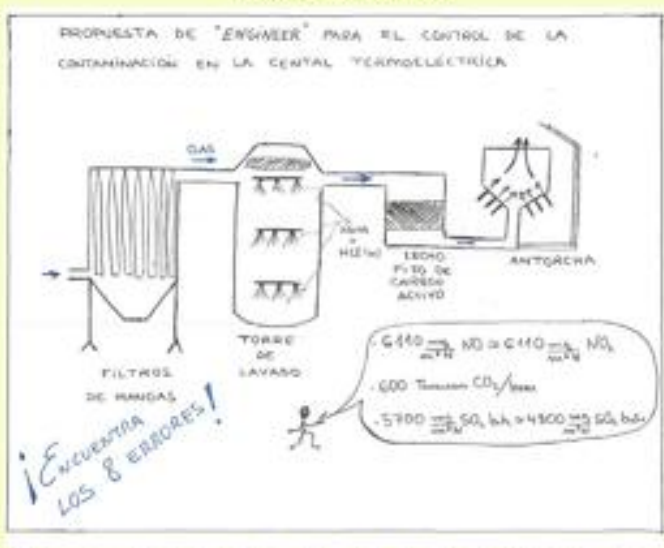

Viñeta con sistema "erróneo" de tratamiento de la contaminación ambiental de la Central Térmica de Teruel

\section{Objetivo}

Mejorar la capacidad de manejo y aplicación de especificaciones técnicas y de diseño de equipos y procesos, previsiblemente necesarios en la futura actividad profesional del estudiante, incluyendo y aplicando un enfoque ambiental.

\section{Resultados y conclusiones}

- Grado de implicación de los alumnos: El proyecto fue realizado por el $22 \%$ de los alumnos matriculados en la asignatura, que decidieron participar de manera voluntaria.

- Calidad del entregable presentado por los alumnos (coherencia, calidad de la presentación, grado de adecuación al contexto buscado y el dominio de la materia)

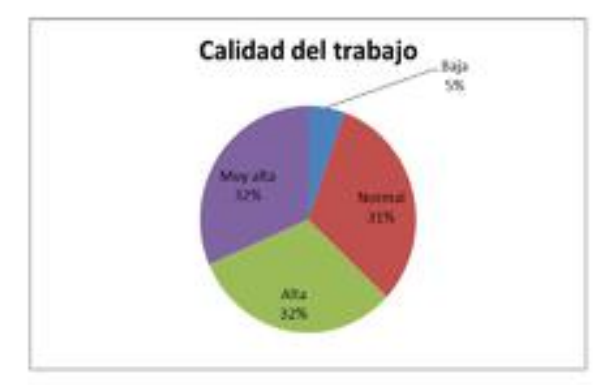

- Relación entre realización proyecto y calificación final en la asignatura. El $94.5 \%$ de los alumnos que realizaron el proyecto han superado con éxito la asignatura. Además, el $63 \%$ de los mismos ha obtenido una calificación de notable. 


\section{Creación de un curso ADD en abierto con material audiovisual de apoyo al estudio de la termodinámica y la ingeniería térmica}

Zabalza Bribián, l.; Peña Pellicer, B.; Llera Sastresa, E. M.; Usón Gil, S.; Martínez Gracia, A.; Romeo Giménez, L. M.

\section{Palabras clave}

Recursos multimedia, objetos de aprendizaje, vídeos docentes, OCW

\section{Resumen}

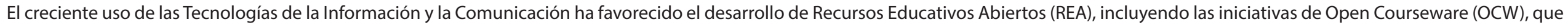
proporcionan un acceso libre y abierto al conocimiento producido por las universidades a cualquier persona interesada en cualquier lugar del mundo.

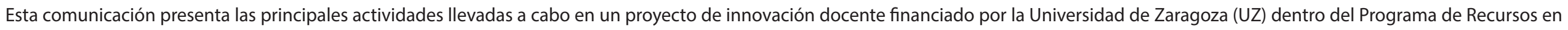

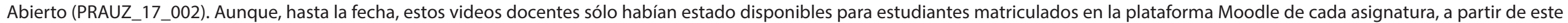
año se ha publicado el conjunto completo de videos dentro de un canal específico de YouTube, así como en la plataforma OCW de la UZ.

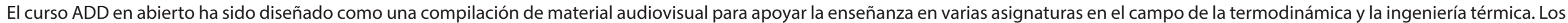

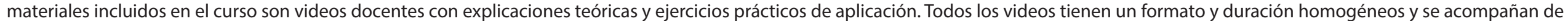

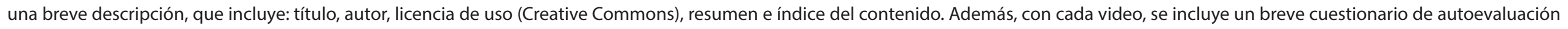

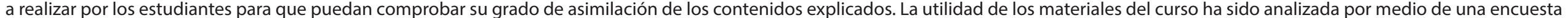

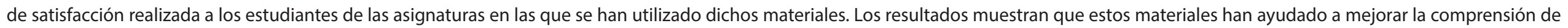
los conceptos más abstractos y complejos, contribuyendo al mismo tiempo a aumentar el nivel de motivación de los estudiantes. 


\section{Creación de un curso ADD en abierto con material audiovisual de apoyo al estudio de la termodinámica y la ingeniería térmica}

Ignacjo Zabalza, Begoña Peña, Eva Mª LJera, Sergjo Usón, Amaya Martínez, Luis Miguel Romeo

Departamento de Ingeniería Mecánica, \{izabal, bpp, ellera, suson, amayamg, luismi\}@unizar.es

\section{Contexto académico}

\begin{tabular}{|l|l|c|c|}
\hline \multicolumn{1}{|c|}{ Asignatura } & \multicolumn{1}{c|}{ Titulación } & Curso & $\begin{array}{c}\mathbf{N}^{\circ} \text { medio } \\
\text { estudiantes }\end{array}$ \\
\hline \multirow{4}{*}{$\begin{array}{l}\text { Termodinámica Técnica y } \\
\text { Fundamentos de Transmisión de Calor } \\
\text { (TT-FTC) }\end{array}$} & Ing. de Tecn. Industriales & $2^{\circ}$ & 205 \\
\cline { 2 - 5 } & Ing. Mecánica & $2^{\circ}$ & 201 \\
\cline { 2 - 5 } & Ing. Electrónica y Automática & $2^{\circ}$ & 81 \\
\hline & Ing. Química & $2^{\circ}$ & 62 \\
\cline { 2 - 5 } & Ing. Eléctrica & $2^{\circ}$ & 70 \\
\hline \multirow{3}{*}{ Ingeniería Térmica } & Ing. de Tecn. Industriales & $2^{\circ}$ & 187 \\
\hline & Ing. Mecánica & $3^{\circ}$ & 188 \\
\hline Máquinas y Motores Térmicos & Máster Ing. Industrial & $1^{\circ}$ & 9 \\
\hline & Ing. Mecánica & $3^{\circ}$ & 194 \\
\hline
\end{tabular}

\section{Objetivo}

Competencias especificas + Resultados aprendizaje

Termodinámica e Ingeniería térmica

\section{Metodología}

1. Definición objetivos

2. Definición competencias

+ resultados aprendizaje

3. Definición temario

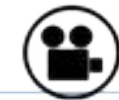

Compilación material audiovisual en abierto

4. Elaboración videos + cuestionarios autoevaluación

5. Creación canal YouTube + curso ADD abierto

6. Preparación encuesta satisfacción + análisis de resultados

\section{Principales resultados}

\%

https://moodle2.unizar.es/add/

course/view. .php?id=21154

YouTube

https://www.youtube.com

/channel/UCrnGX5EreK 10t06-XswAV3Q

\% IS Encuesta de satisfacción (TT-FTC Ing. Química)

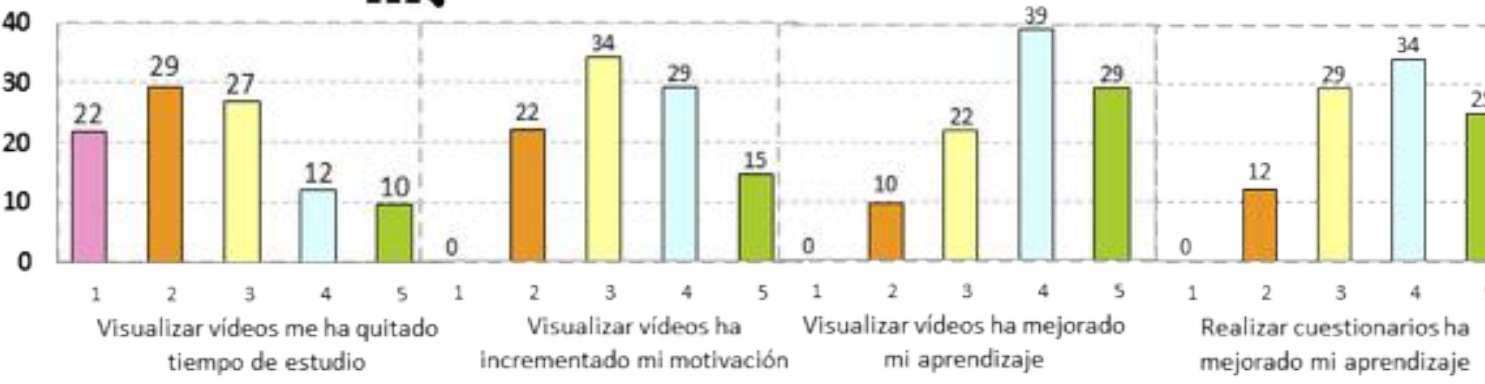

$\% 60$

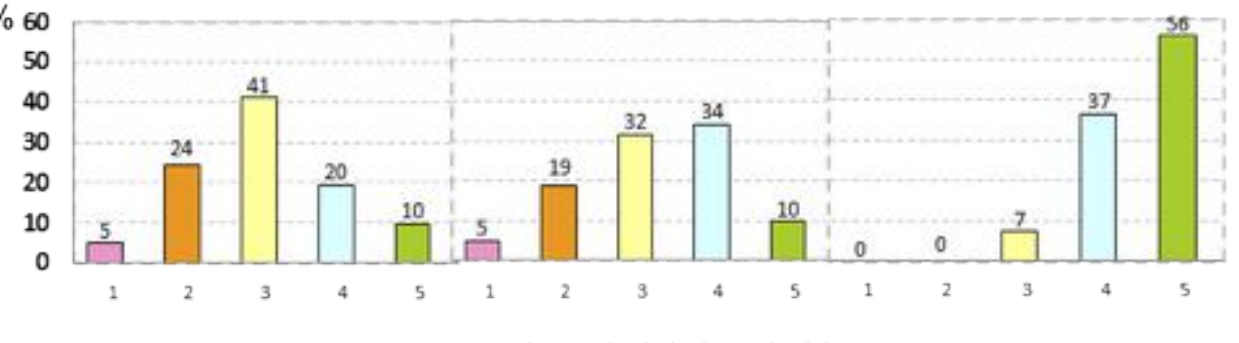

Conclusiones

$$
\text { vídeo }
$$

- Curso ADD abierto: apoyo al aprendizaje en asignaturas de grado, repositorio común de materiales, libre difusión del conocimiento

- Uso conjunto vídeos + cuestionarios: mejora del aprendizaje del estudiante

\section{퓨i Universidad} Im Zaragoza 


\section{Desafío para la sostenibilidad: aprendizaje cooperativo y colaborativo mediante el trabajo en grupo de tipo caja blanca}

Murillo Esteban, M. B.; Callejas Bermejo, A.; Gil Lalaguna, N.; Leris López, D.; Atienza Martínez, M.

\section{Palabras clave}

Problemática Ambiental, Equipo Multidisciplinar, Desarrollo Sostenible, Transversalidad, Congreso.

\section{Resumen}

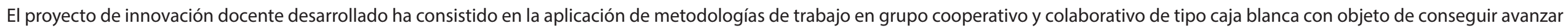

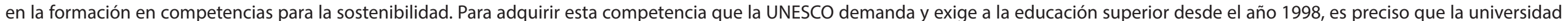

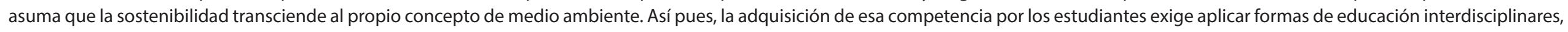

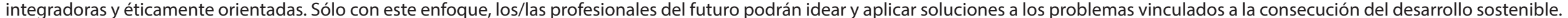

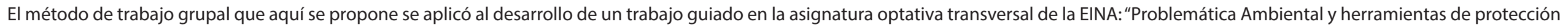

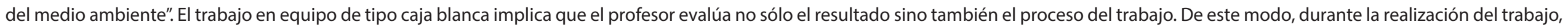

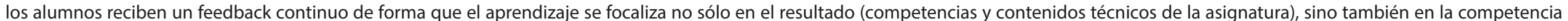

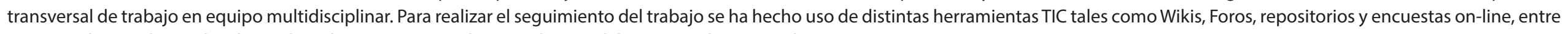
otras. También se han aplicado en clase diversas técnicas de aprendizaje colaborativo y dinámicas de grupo.

Agradecimientos al Vicerrectorado de Política Académica por la concesión del PIIDUZ_17_139. 


\section{Desafío para la sostenibilidad: aprendizaje cooperativo y colaborativo mediante el trabajo en grupo de tipo caja blanca. PIIDUZ_17_139}

María Benita Murillo, Alicia Callejas, Noemí Gil, Dolores Leris, María Atienza

Ingeniería Química y Tecnologías del Medio Ambiente, murillo@unizar.es

$\underline{\text { Objetivo }} \rightarrow$ mejorar competencias para:

Sostenibilidad y protección ambiental

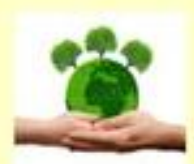

Trabajo en equipo multidisciplinar cooperativo.

Potenciar una visión holistica y sistémica de la protección ambiental.

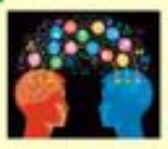

Optativa Transversal EINA ( $4^{\circ}$ curso): "Problemática Ambiental y Herramientas de Protección Ambiental'.

Estudiantes con diversos perfiles formativos y de diferentes paises.
METODOLOGÍA: Trabajo en Equipo de tipo Caja Blanca

$\Rightarrow$ Trabajo guiado en equipo en el cual 急

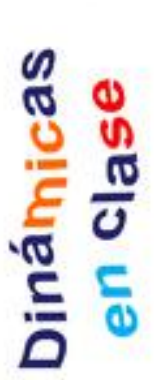

Interacción personal
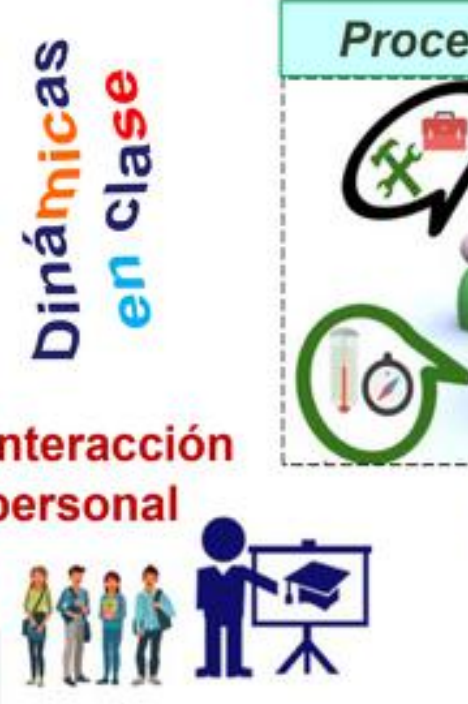

(1)
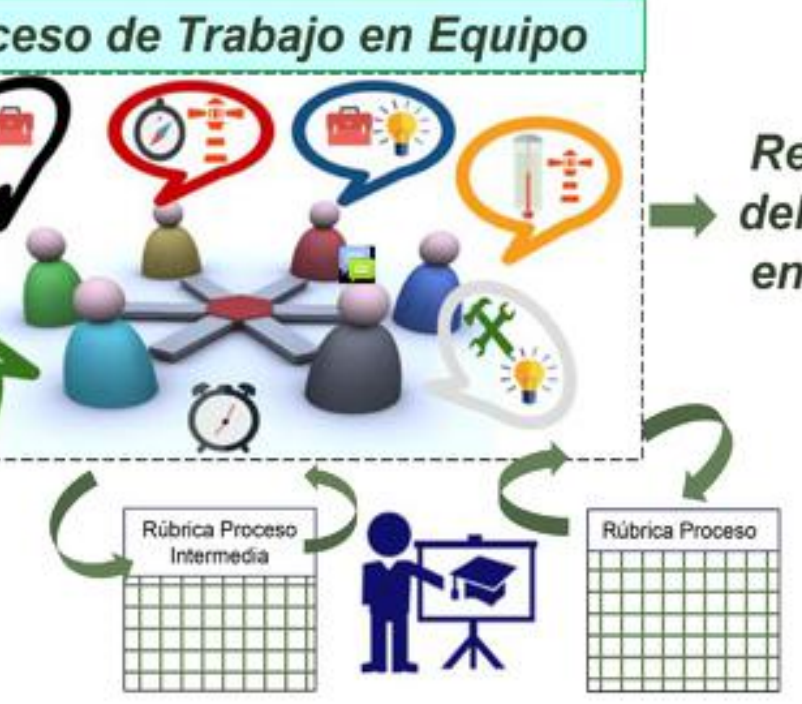

Resultado se evalúan el proceso y el resultado

CONCLUSIONES Y RESULTADOS: $100 \%$ de los alumnos recomiendan repetirlo

Lejora de habilidades para el trabajo en equipo

Coevaluación entre pares \&

Muy bien valorada la posibilidad de haber trabajado en equipo multicultural y multidisciplinar

L Los alumnos han mejorado su visión acerca de su aportación profesional a la sostenibilidad

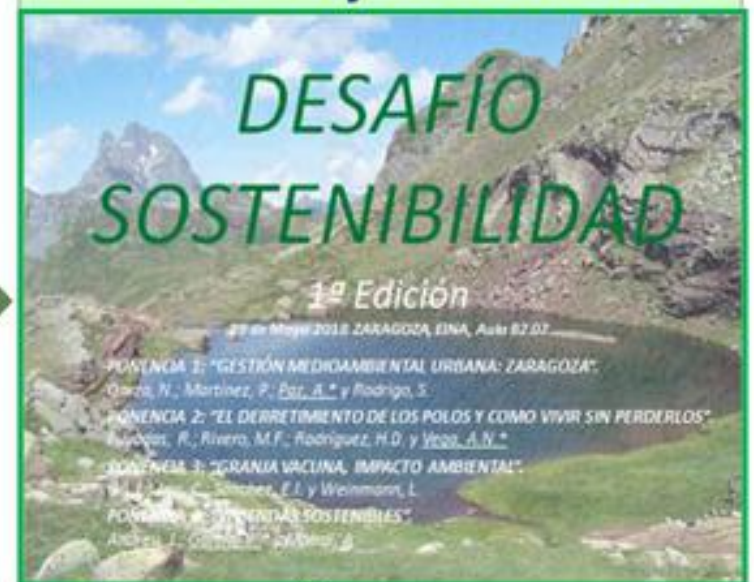

$30 \%$ de la

calificación final asignatura

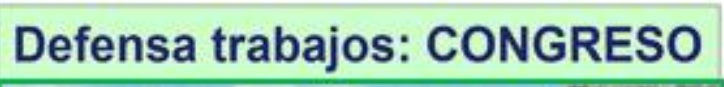

\section{퓨i Universidad \\ im Zaragoza}




\section{Elaboración de videotutoriales con ScreenCast-O-Matic para la clase invertida y el aprendizaje personalizado}

Allueva Pinilla, A. I.; Alejandre Marco, J. L.

\section{Palabras clave}

Aprendizaje activo, recursos docentes digitales, CTA

\section{Resumen}

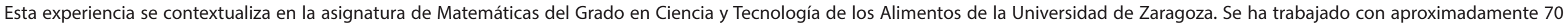

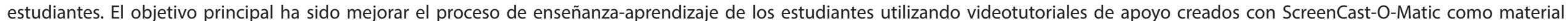
docente complementario en teoría y prácticas.

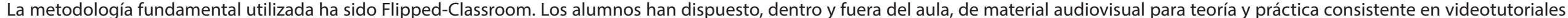

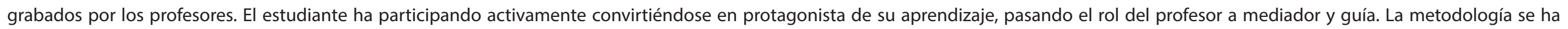

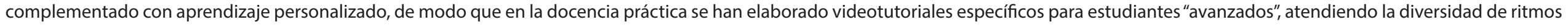
de aprendizaje.

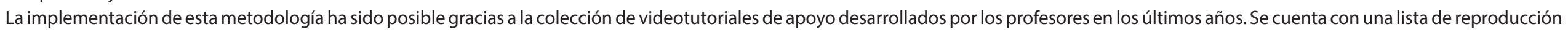

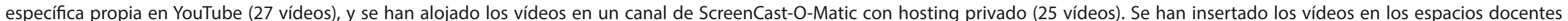

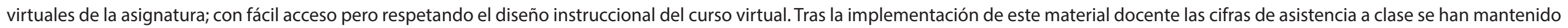
en niveles muy altos, así como la participación y se han mejorado las calificaciones respecto a cursos anteriores.

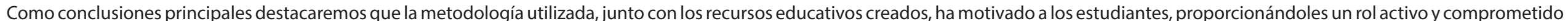

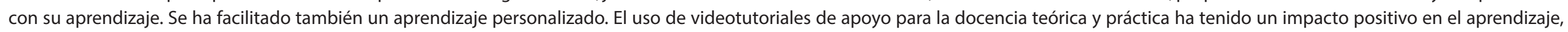

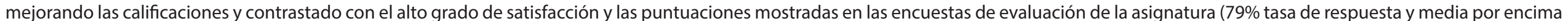
del Centro). Finalmente, la herramienta ScreenCast-O-Matic ha resultado muy versátil, flexible y con gran facilidad de uso. 


\section{Elaboración de videotutoriales con ScreenCast-O-Matic para la clase invertida y el aprendizaje personalizado}

\section{Ana lsabel Allueva Pinilla, José Luis Alejandre Mlarco}

Matemática Aplicada, allueva@unizar.es, jlalejan@unizar.es

Contexto: asignatura Matemáticas ubicada en el primer cuatrimestre del primer curso del Grado en Ciencia y Tecnología de los Alimentos de la Facultad de Veterinaria. 6 ECTS $(3 T+3 P)$; número de estudiantes entre 60-70.

Objetivo: mejorar el proceso de enseñanza-aprendizaje de los estudiantes utilizando videotutoriales de apoyo creados con ScreenCast-

O-Matic como material docente complementario en teoria y prácticas.

\section{Resultados:}

- Videotutoriales grabados por los profesores como apoyo docente en teoría y prácticas elaborados con ScreenCast-O-Matic.

- Videos alojados en ScreenCast-O-Matic (25 vídeos), YouTube (27 vídeos) y enlazados en aula virtual.

- El estudiante es protagonista de su aprendizaje.

- El profesor tiene también un rol de mediador y guía.

- Atención a la diversidad: videotutoriales especificos para distintos ritmos de aprendizaje.

\section{Conclusiones}

- Mayor motivación de los estudiantes.

- Experiencia de impacto positivo: mejora en calificaciones y alto grado de participación y satisfacción en las encuestas de evaluación de la asignatura.

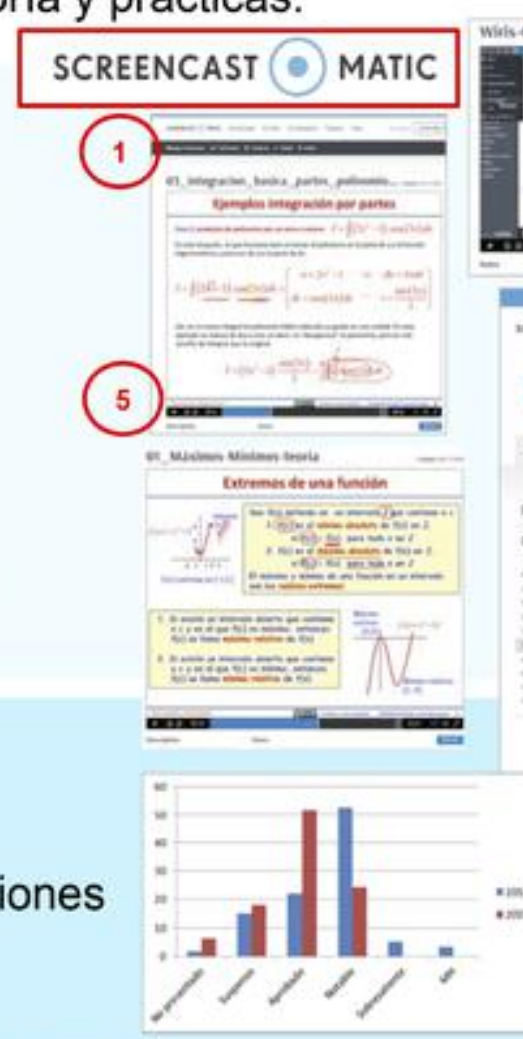

Metodología: Flipped-Classroom. Aprendizaje personalizado

- ScreenCast-O-Matic: una herramienta versátil, flexible y fácil.

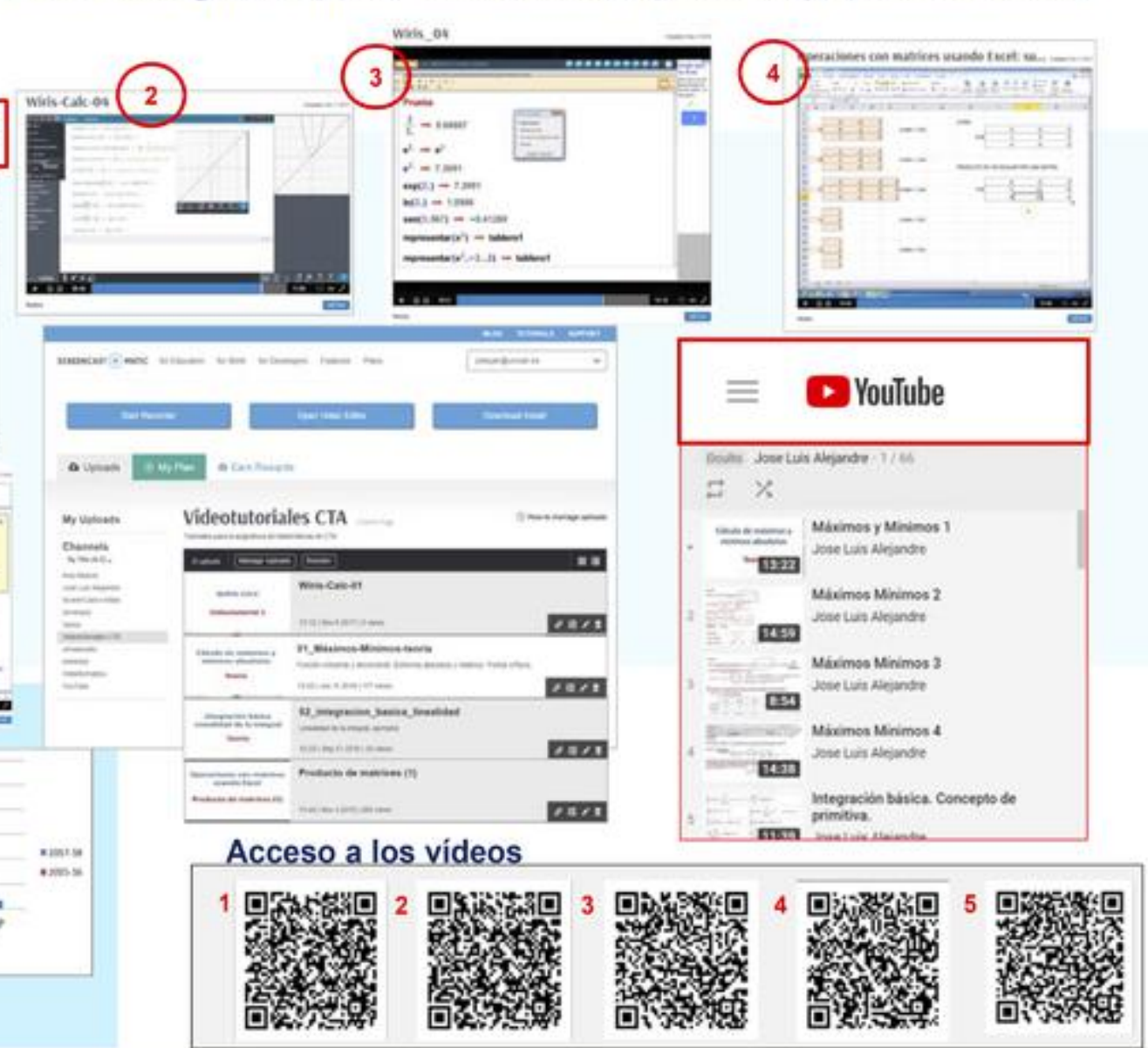

\section{ii․ Universidad III Zaragoza}




\section{Gamificación con Kahoot en el Grado en Gestión y Administración Pública}

Artero Escartín, l.; López Sánchez, C.; Villagrasa Rozas, M. M.; Rico Letosa, S.; Lobera Viñau, E.

\section{Palabras clave}

Aprendizaje activo, ludificación, retroalimentación, motivación, TIC.

\section{Resumen}

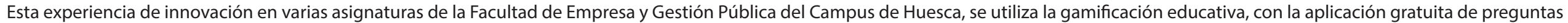
y respuestas, Kahoot, y los dispositivos móviles de los alumnos. El objetivo: comprobar si la ludificación educativa genera beneficios en la enseñanza universitaria.

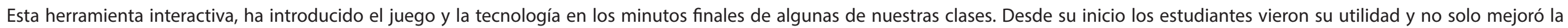

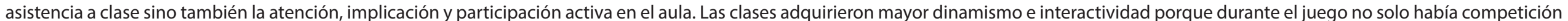
sino que se generaba un ambiente distendido y divertido que favorecía la comunicación e integración de los alumnos que comentaban y razonaban sobre cuál era la opción correcta.

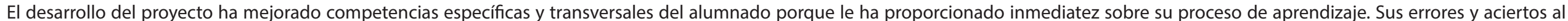

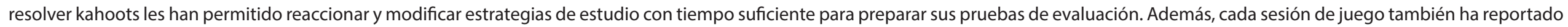

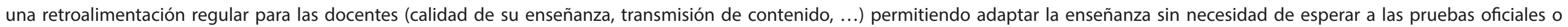
exámenes.

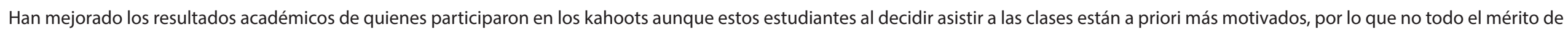

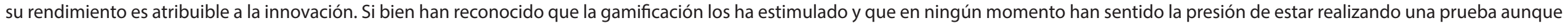
estaban autoevaluándose y ofreciendo información de su asimilación de conocimientos. 


\section{Gamificación con Kahoot en el Grado en Gestión y Administración Pública}

\section{Isabel Artero1, Caridad López², María Villagrasa ${ }^{3}$, Sara Rico², Emma Lobera ${ }^{4}$}

${ }^{1}$ Estr. y Economia Pública, ${ }^{2}$ Derecho de la Empresa, ${ }^{3}$ Derecho Público, ${ }^{4}$ Contabilidad y Finanzas, iartero@unizar.es

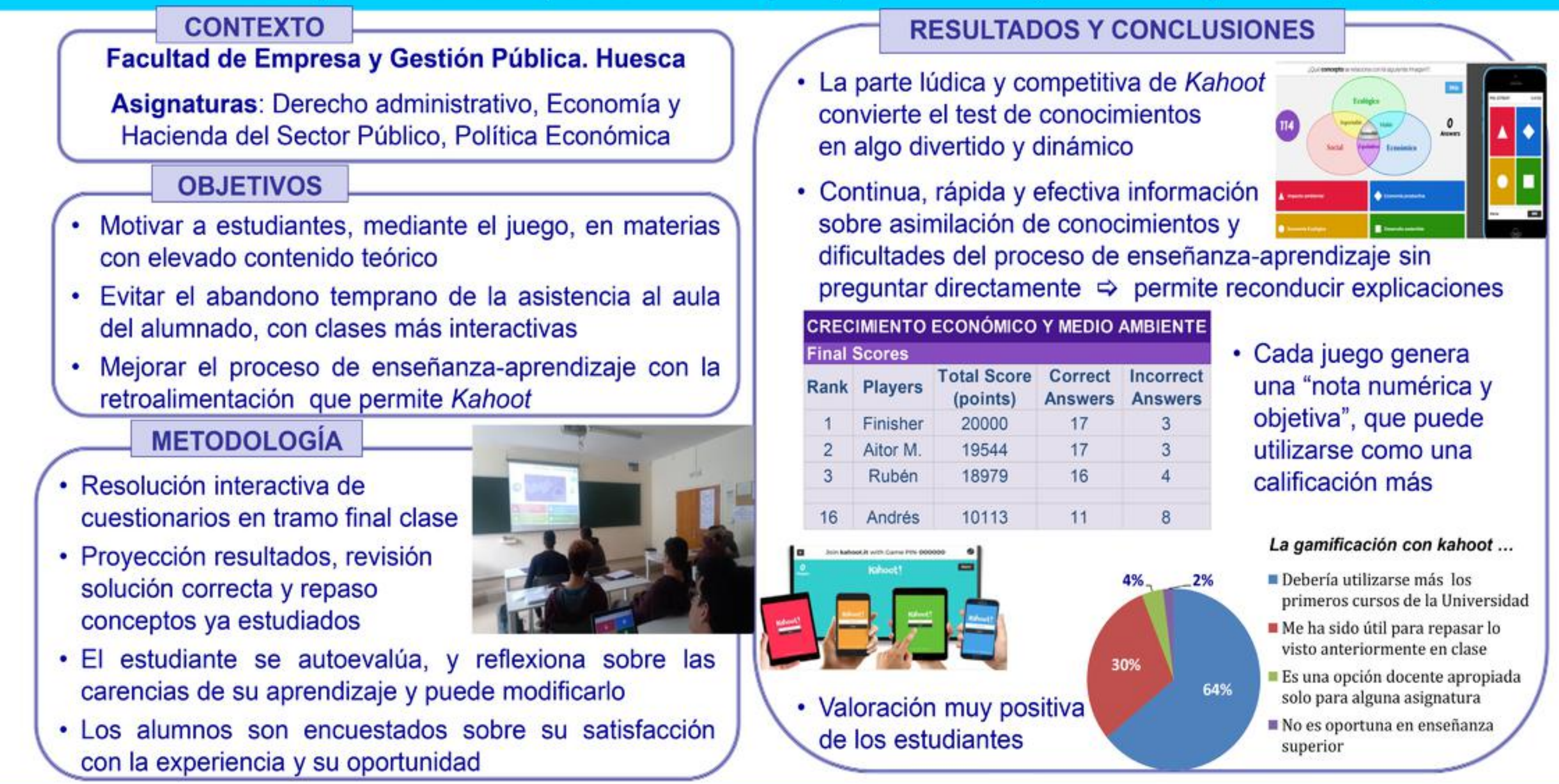




\section{Flipped Teaching como herramienta para la didáctica de Historia del Arte en el Grado de Turismo}

Íñiguez Berrozpe, L.; Melero Polo, I.

\section{Palabras clave}

Metodología, clase invertida, encuesta.

\section{Resumen}

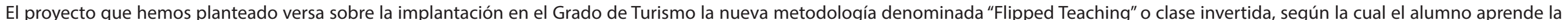

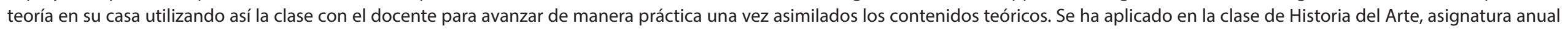

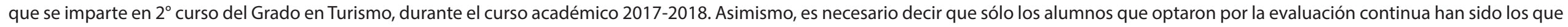
se han beneficiado de esta experiencia. En total contamos con 22 alumnos para el proyecto de los cuales 4 eran hombres y 18 mujeres.

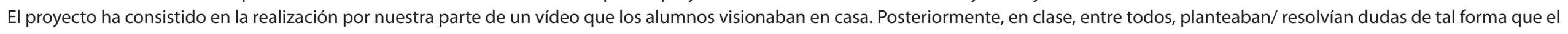

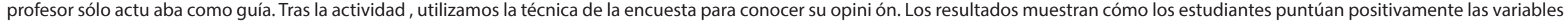

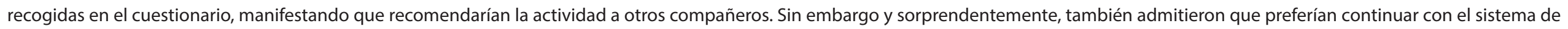

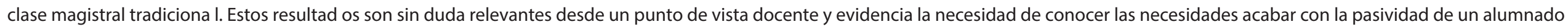
acostumbrado a escuchar sin participar en el aula.

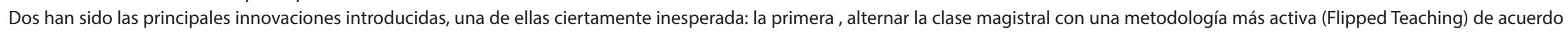

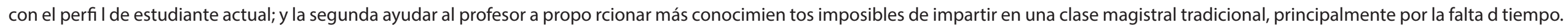




\title{
Flipped teaching como herramienta para la didáctica de Historia del Arte en
} el Grado de Turismo

\author{
Lara, Íñiguez, Iguácel Melero
}

Escuela de Turismo Universitaria de Zaragoza, laraib@unizar.es, Facultad de Economia y Empresa, imelero@unizar.es

\section{CONTEXTO}

Grado en Turismo $2^{\circ}$ Curso (2017-2018). Asignatura: Historia del Arte.

Participantes: 22 alumnos (18 mujeres +4 hombres).

\section{OBJETIVOS}

Acabar con la pasividad del alumnado.

Fomentar la actitud proactiva y reflexiva.

Adecuar la metodología docente al nuevo perfil de alumno (cultura visual). Ayudar al docente a la hora de profundizar en cuestiones inabordables con el uso exclusivo de la clase magistral.

\section{METODOLOGÍA DE LA ACTIVIDAD}

- El alumno visiona el material elaborado por el profesor: vídeo explicativo sobre el Arte Neoclásico con la herramienta "Eddpuzzle".

- El alumno apunta dudas surgidas

- El alumno elabora una "microtarea": resumen sobre el vídeo y entrega a través de Moodle.

\section{Tarea de reflexion}

Guiar tangencialmente: el estudiante "lidera", el profesor facilita:

- Pequeños debates reflexivos.

Concluir con una pequeña sesión magistral:

- Incidir en aquellos aspectos que han creado más controversia. aula (II)
Activadade - Resolver la dudas entre todos.
s en el
aula (I) - Corrección entre todos de las "microtareas".

Activdade - Resolver la dudas entre todos.
$s$ en el
aula (I)

- Breve recopilación de contenidos.

RESULTADOS y CONCLUSIONES

Metodología para conocer la opinión de los alumnos: encuesta auto-administrada acerca de las variables incluidas en el modelo conceptual propuesto y sobre algunas variables socio-demográficas, con escalas Likert de 7 puntos.

- Conclusiones (ver gráfico): el alumno recomendaría la actividad a sus compañeros pero prefiere la clase magistral (perfil de alumno pasivo).

Actividade
sen el

\section{Valores medios de las variables}

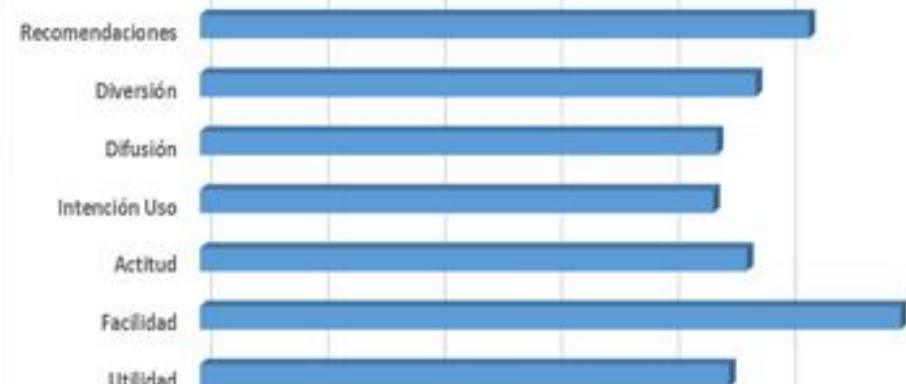




\section{La elaboración de conservas y dulces en la formación de maestros/as de Educación Infantil}

Carrasquer Álvarez, B.; Ponz Miranda, A

\section{Palabras clave}

Alimentación, ciencia cotidiana, sostenibilidad, indagación

\section{Resumen}

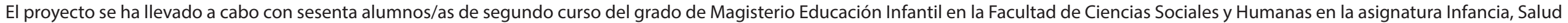
y Alimentación.

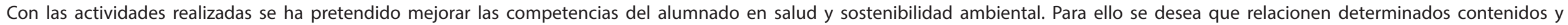

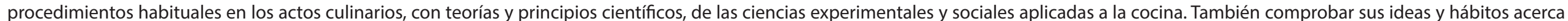
del consumo de agua y su implicación en la sostenibilidad en su comportamiento cotidiano.

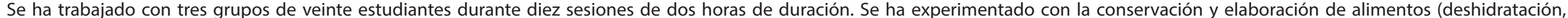

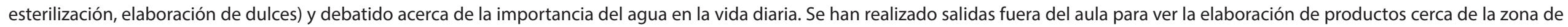

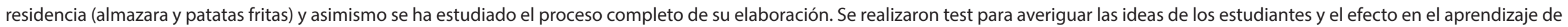
la realización de las actividades. Asimismo se ha intentado averiguar la satisfacción con las actividades realizadas.

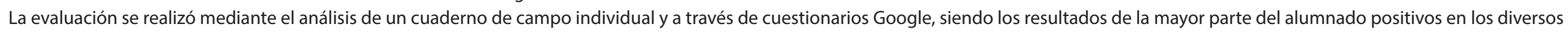
aspectos, en cuanto a adquisición de competencias tras la realización de las actividades.

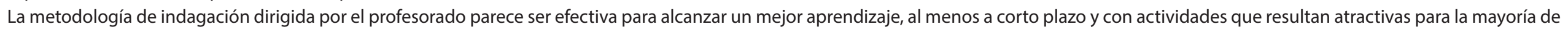
los/as estudiantes. La vinculación de los contenidos trabajados con las teorías científicas resultan más complejos debidos a falta de conocimientos previos. 
La elaboración de conservas y dulces en la formación de maestros/as de Educación Infantil

\section{Carrasquer Álvarez, B.;Ponz Miranda, A.*}

Dpto. de Didáctica de las Ciencias Experimentales.` Grupo Beagle (IUCA). E-mail contacto: becarras@unizar.es

\section{Contexto académico}

Alumnado del $2^{\circ}$ curso del Grado de Magisterio en Ed. Infantil (60 alumnos/as). Asignatura: Infancia, Salud y Alimentación.

\section{Objetivos}

Mejorar las competencias del alumnado (contenidos, ejecución de procesos, verbalización de fenómenos observados) relacionados con actividades cotidianas, en concreto de cocina, vinculando los acontecimientos con teorías y principios científicos.

\section{Metodología}

- Debates y consulta de textos.

- Prácticas y salidas fuera del aula.

\section{Evaluación}

- Cuadernos de laboratorio

- Pre y post-tests (cuestionarios Google Drive).

\section{Conclusiones}

- Importancia del método de indagación y experimentación con fenómenos cotidianos.

-Utilidad de las herramientas didácticas implementadas, y valoración muy positiva del alumnado.

\section{Resultados}

31,4

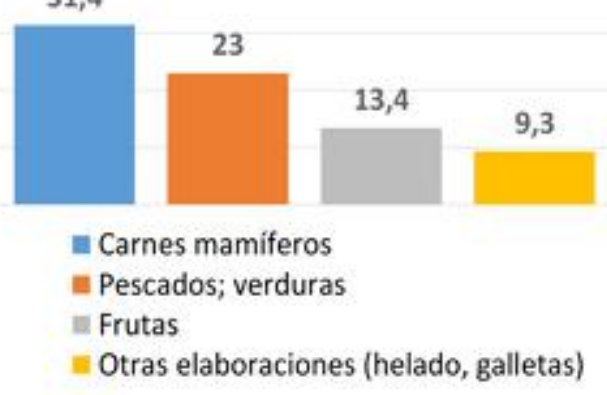

Evita la degradación del alimento

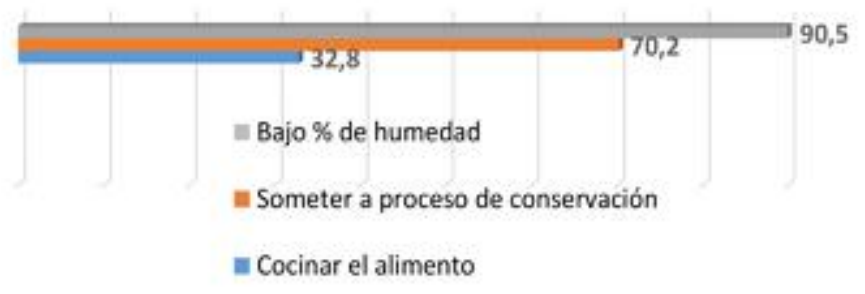

Hábitos poco sensibles en relación a consumo de agua (\% alumnado)

No sistemas de reducción

Ducha más de 10 minutos

Baño vs Ducha

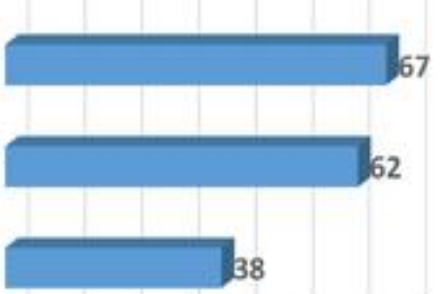

Tras las actividades, el alumnado:

- Ha reforzado conocimientos (conservación y procesado de alimentos).

- La mayoría se ha sensibilizado en relación al consumo de agua.

\section{풀. Universidad}




\section{La enseñanza de las artes visuales a través del taller para Educación Visual y Plástica; taller expositivo de luz y color}

Revilla Carrasco, A.; Cadena González, A.; Laliena Cantero, D.

\section{Palabras clave}

Educación Plástica, interdisciplinariedad, metodologías activas.

\section{Resumen}

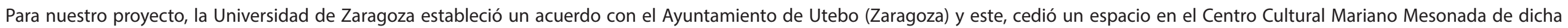

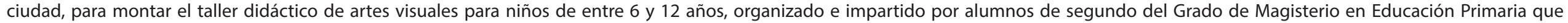

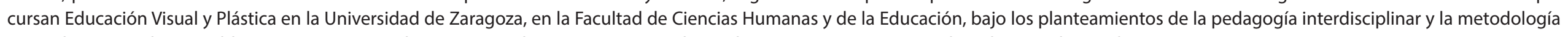
Aprendizaje Basado en Problemas. Este proyecto de innovación docente está inspirado en el proyecto expositivo-social Píxeles MIN de Honduras.

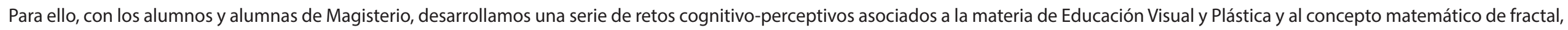

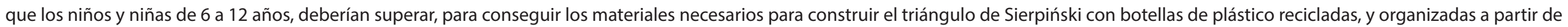
colores primarios, trabajados en tres paneles didácticos.

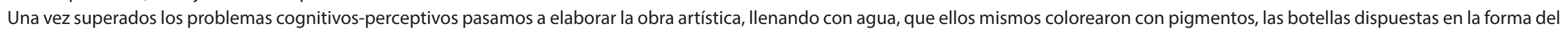
triángulo de Sierpiński, dando forma así, al proyecto expositivo común.

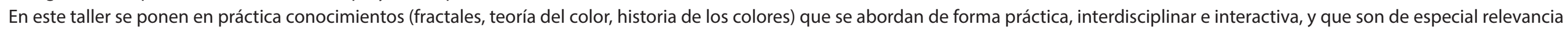

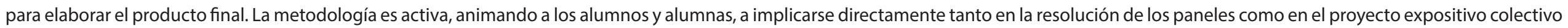
que se lleva a cabo. 


\section{La enseñanza de las artes visuales a través del taller para Educación Visual y Plástica; taller expositivo de luz y color}

\section{Relación de autores: Alfonso Revilla, Ana Cadena y Daniel Laliena}

Departamento de expresión musical, plástica y corporal, alfonsor@unizar.es, Facultad de CC HH y de la Educación de la Universidad de Zaragoza

Contexto académico: El proyecto se presenta para la asignatura de Educación Plástica y Visual, tanto para el grupo 3 y 4 , de la Facultad de Ciencias Humanas y de la Educación del Grado de Magisterio en Educación Primaria, que trabajaran dentro de la metodología de aprendizaje basado en problemas, en la realización de un taller sobre luz y color, basado en el triángulo de Sierpinky

Objetivos generales del proyecto:

Apertura de la Universidad a entidades culturales dotando al alumno de experiencias significativas. Desarrollo de la identidad profesional de los alumnos. Fomentar las metodologias activas y cooperativas centradas en el alumno, procurando desarrollar entornos cooperativos de aprendizaje y el trabajo en equipo, potenciando la comunicación y participación de los alumnos. Como objetivos específicos destacamos: desarrollo del trabajo colaborativo, desarrollo de la capacidad artística, realización conjunta de una obra artística, adopción de una actitud responsable y de iniciativa personal para conseguir un producto final satisfactorio, valoración de las posibilidades artisticas que nos ofrece el reciclaje y trabajo de habilidades relacionadas con la motricidad fina, la atención y la percepción.

Resultados y conclusiones: El proyecto muestra una mayor motivación y compromiso del alumnos en su aprendizaje, así como una mejor disposición a integrar conceptos de Educación Plástica en su práctica educativa. La valoración global de la aplicación del aprendizaje basado en problemas, desarrollado a partir de talleres, es positiva ya que los alumnos se implicaron activamente y aplicaron los conocimientos proporcionados para resolver los problemas propuestos.

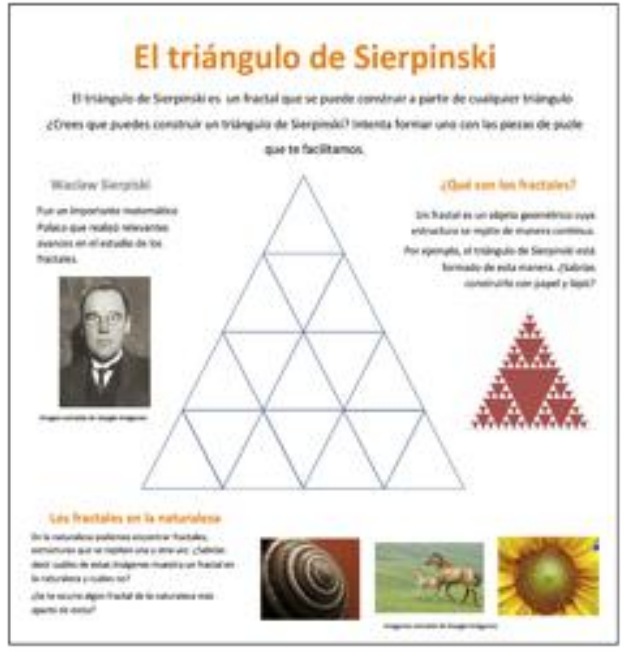

Panel didáctico sobre los fractales y el triángulo de Sierpiński
Metodología: La metodología básica es de taller donde se ponen en práctica conocimientos (fractales, teoria del color, historia de los colores) que se abordan de forma práctica e interactiva a través de determinados problemas (ABP) a implicarse directamente tanto en la resolución de los paneles como en el
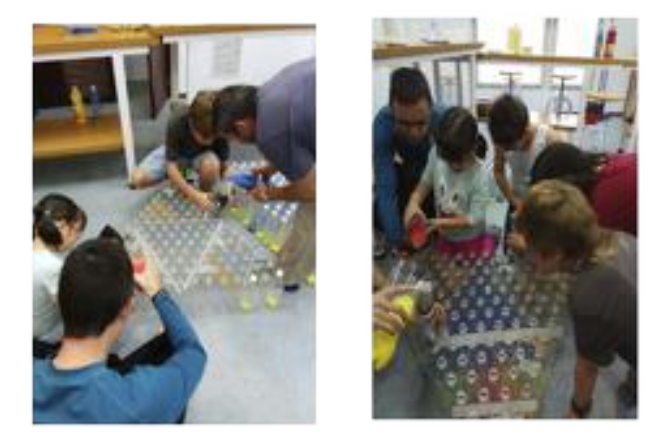

Rellenando el triángulo de Sierpinski 


\section{Los dioses en el arte. Adaptación del estudio de casos a la iconografía de las divinidades de la Antigüedad como instrumento para la comprensión de las culturas del pasado}

Carretero Calvo, R.; Criado Mainar, J.

\section{Palabras clave}

Arte, Mitología, Historia an0gua, Historia cultural, Aprendizaje activo.

\section{Resumen}

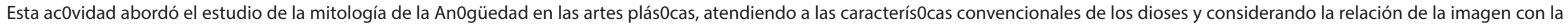

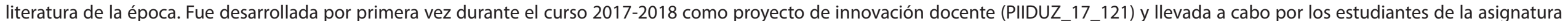
obligatoria "Arte de la An0güedad" de primero del Grado de Historia del Arte.

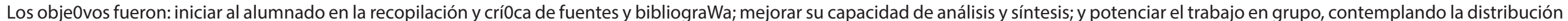
de tareas, la periodización y la coordinación como adelanto de la realidad académica y profesional.

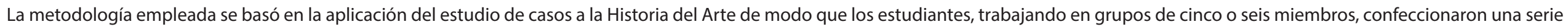

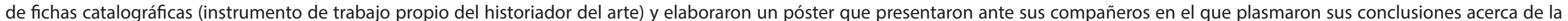
divinidad estudiada.

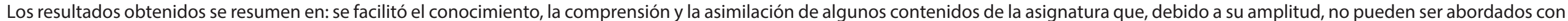

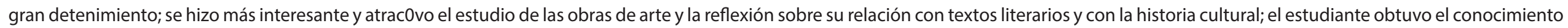

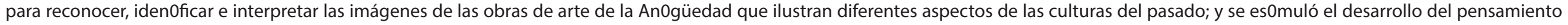
reflexivo y crí0co del alumnado que, además, profundizó en el conocimiento hasta donde su propio interés lo llevó. 


\section{Retos para la sostenibilidad: los estudiantes de primero de ingeniería tienen algo que contarte}

Abrego Garrués, J.; Callejas Bermejo, A.; Matute Najarro, R. P.; Mosteo Abad, R.; Murillo Esteban, M. B.; Sarasa Alonso, J.

\section{Palabras clave}

Ingeniería Ambiental, Sensibilización Ambiental, Cartel, Participación del público, Aprender enseñando.

\section{Resumen}

La actividad planteada se ha aplicado durante los cursos 2016-17 y 2017-18 en la asignatura Ingeniería del Medio Ambiente de primer curso de los Grados de Ingeniería Mecánica y Eléctrica.

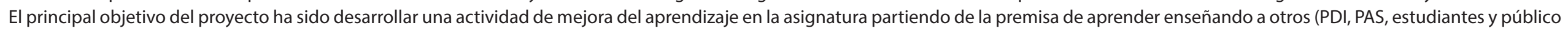

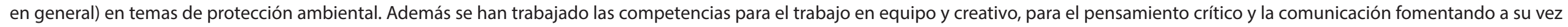
el uso de herramientas TIC.

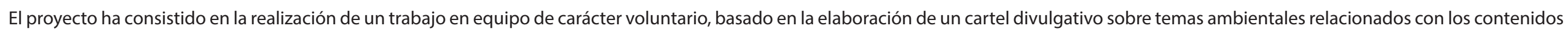
de la asignatura.

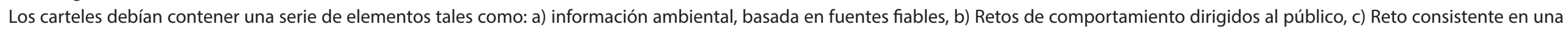
pregunta de temática ambiental relacionada con el temario de la asignatura, al cual se accede mediante un código QR, y d) cualquier otro tipo de mensaje de temática ambiental.

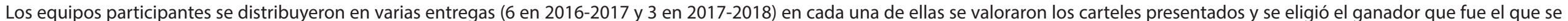
difundió públicamente.

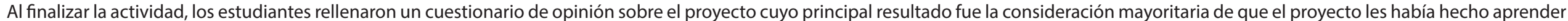

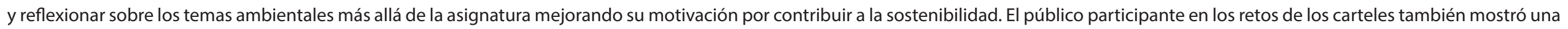
valoración muy positiva de la actividad a la que juzgaron motivante y aleccionadora.

Agradecimientos al Vicerrectorado de Política Académica por la concesión del PIIDUZ 16_348. 


\section{RETOS PARA LA SOSTENIBILIDAD: LOS ESTUDIANTES DE PRIMERO DE INGENIERÍA TIENEN ALGO QUE CONTARTE.}

Javier Ábrego, Alicia Callejas, Rosa P. Matute, Rosa Mosteo, Ma Benita Murillo, Judith Sarasa

Ingeniería Química y Tecnologias del Medio Ambiente, murillo@unizar.es 1. İ Implicar a los er curso en la vida de centro

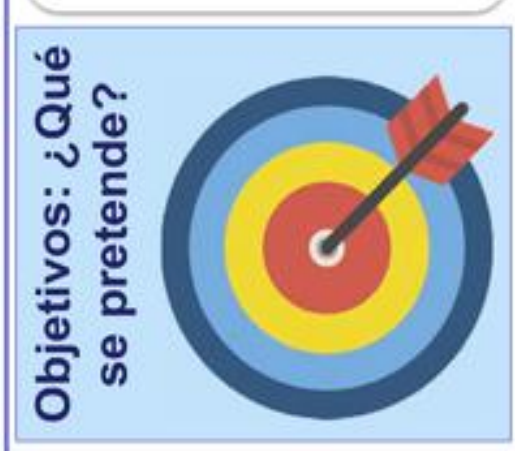

- Mejorar su aprender y su aportación a la sostenibilidad como futuros ingenier@s

Trabajar competencias transversales:

- Pensamiento crítico

- Creatividad y comunicación

- Trabajo en equipo

- Reforzar tutorías motivación por
(1) Aprender enseñando a otros

Contribuir a mejorar la conciencia ambiental de la comunidad universitaria

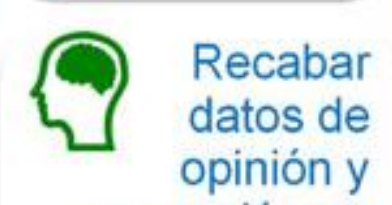
percepción en temas medio ambientales

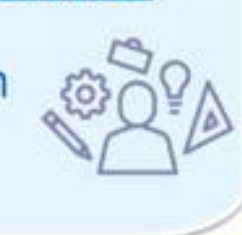

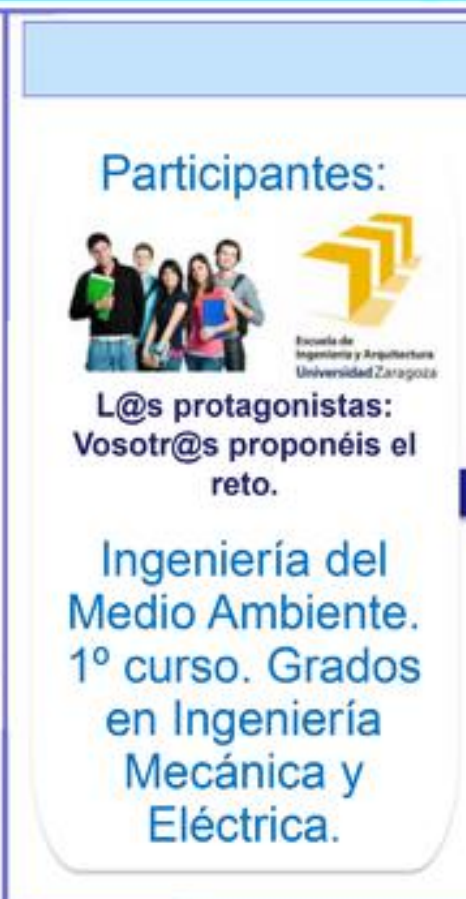

Metodología

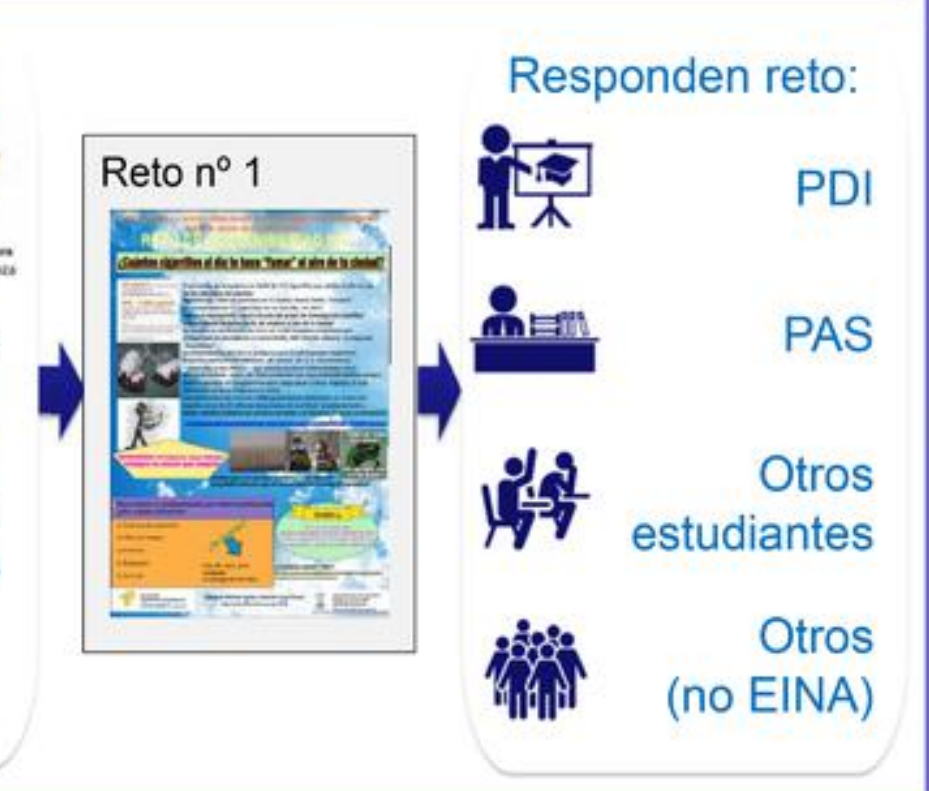

CONCLUSIONES Y RESULTADOS

200+ + Estudiantes

$\mathbf{8 7 \%}$ Consideran de trabajo / calificación

$96 \%$ Repetirian $100 \%$ Repetirian

$3,7 / 5$ (Estudiantes) 4,2/5 (Público) Ha hecho aprender, reflexionar, concienciar...

\section{Difusión}

Trabajos ganadores publicados en www.ima.unizar.es

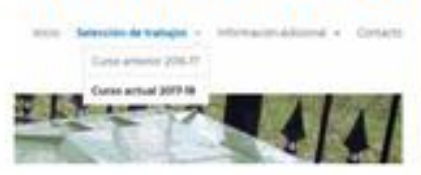

Y $f$ Difusión en redes sociales

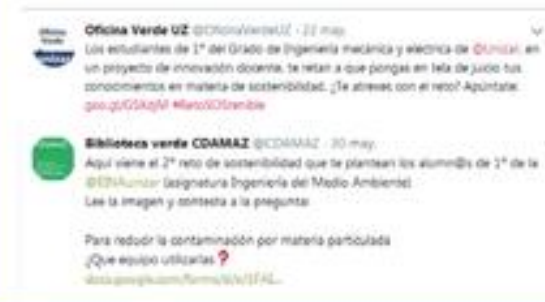

일 Universidad im Zaragoza

XII Jornadas de Innovación Docente e Investigación Educativa - 2018 


\section{Role playing en la práctica contencioso-administrativa del Máster Universitario en Abogacía}

Carreras Manero, O.; de Miguel Arias, S.; López Pérez, F.

\section{Palabras clave}

Metodologías activas, Aprendizaje basado en problemas, Derecho Público.

\section{Resumen}

Contexto académico:

Asignatura Práctica contencioso-administrativa (1er curso del Máster Universitario en Abogacía).

Objetivos:

Esta actividad pretende conseguir los siguientes objetivos:

- Facilitar un conocimiento práctico para el ejercicio de la profesión de abogado en el ámbito de las relaciones con la Administración pública.

- Fomentar que el alumnado adquiera habilidades y competencias necesarias para desarrollar la abogacía en esta esfera.

- Proporcionar al alumnado una mecánica de razonamiento jurídico y una base genérica de la práctica administrativa que le permita aspirar a la especialización.

Metodología:

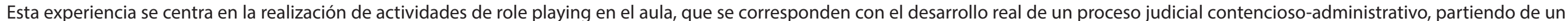

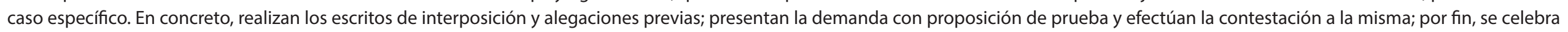

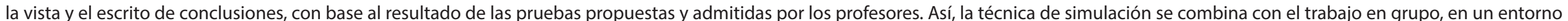
de aprendizaje cooperativo.

Principales resultados alcanzados:

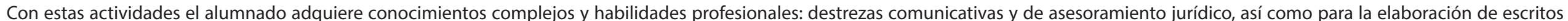
especializados.

Conclusiones:

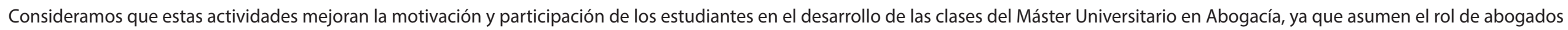
y ello les supone un reto personal. 
Role playing en la práctica contencioso-administrativa del Máster Universitario en Abogacía

\section{Olga Carreras, Sabina de Miliguel, Fernando López}

Departamento de Derecho de la Empresa / Centro Universitario de la Defensa (olgacarr@unizar.es, sabinade@unizar.es, lopezp@unizar.es)

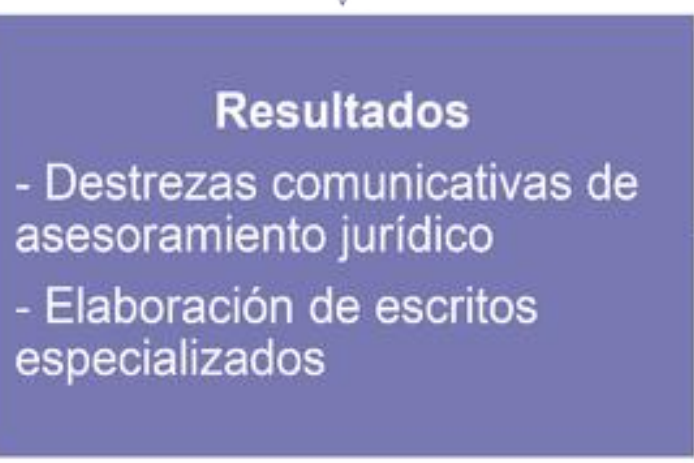

\begin{tabular}{l|l}
\multicolumn{1}{c|}{ Objetivos } & \multicolumn{1}{c}{ Metodología } \\
- Facilitar el conocimiento & - Role playing \\
práctico del ejercicio de la & \\
abogacia & - Desarrollo real de un proceso \\
- Dudicial contencioso- \\
- Dotar al alumnado de una \\
base genérica de la práctica \\
administrativa
\end{tabular}$\quad \begin{aligned} & \text { administrativo } \\
& \text { - Simulación y aprendizaje } \\
& \text { cooperativo }\end{aligned}$

Conclusiones

- Mayor motivación y participación de los estudiantes

\section{Contexto}

Práctica contenciosoadministrativa

1 er curso del Máster Universitario en Abogacia
- Destrezas comunicativas de asesoramiento juridico

- Elaboración de escritos especializados

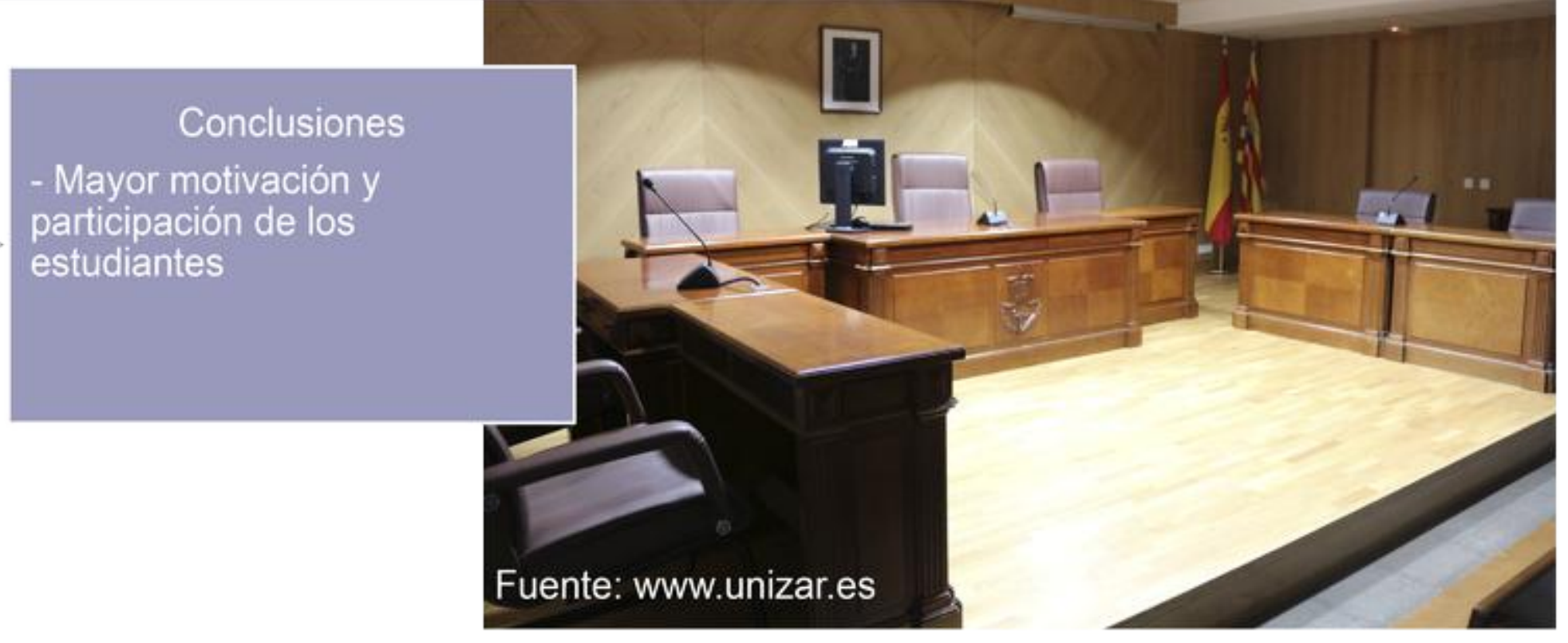




\section{Uso de vídeos disciplinares en inglés para el diseño de material docente en las asignaturas de Biología Humana en los grados de Medicina y Enfermería}

Luzón Marco, M. J.; Velilla Sánchez, M. A.; Albero Posac, S.

\section{Palabras clave}

AICLE, material audiovisual, colaboración.

\section{Resumen}

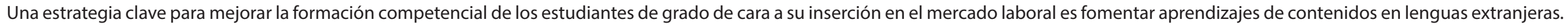

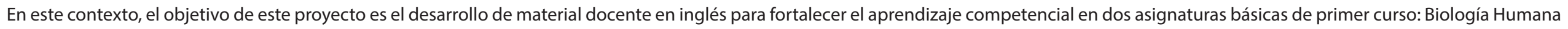

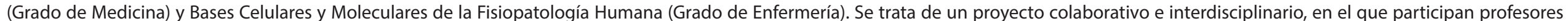

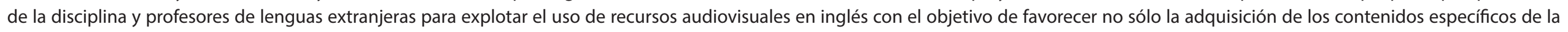

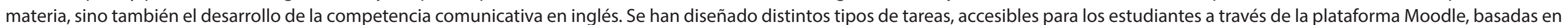

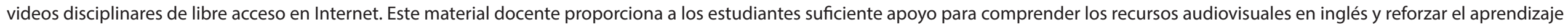
de contenidos de la asignatura, a la vez que fomenta el pensamiento crítico y la autonomía delaprendizaje.

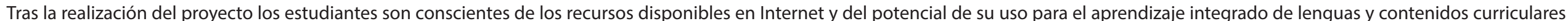

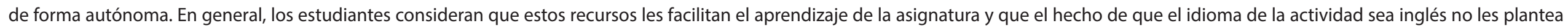

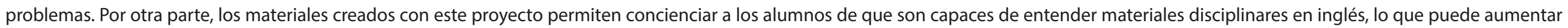
su motivación por usar textos accesibles en Internet en esta lengua. 


\section{Uso de vídeos disciplinares en inglés para el diseño de material docente en las asignaturas de Biología Humana en Medicina y Enfermería}

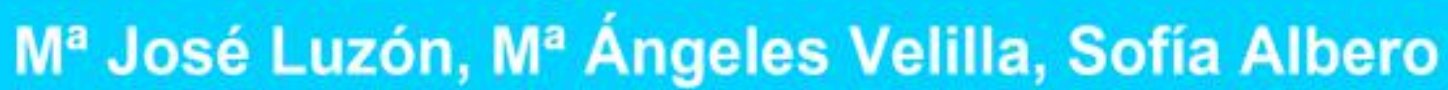

Departamento de Filología Inglesa y Alemana (mjluzon@unizar.es)

\section{CONTEXTO}

Bases celulares y moleculares de la fisiopatología humana $1^{\text {er }}$ curso Grado en Enfermería

Equipo de trabajo interdisciplinar: biomédica y humanistica

\section{OBJETIVOS}

Reforzar el aprendizaje de contenidos específicos

Mejorar la competencia comunicativa en inglés

Motivar a los estudiantes a usar recursos en inglés

Desarrollar la capacidad de aprendizaje autónomo

\section{METODOLOGÍA}

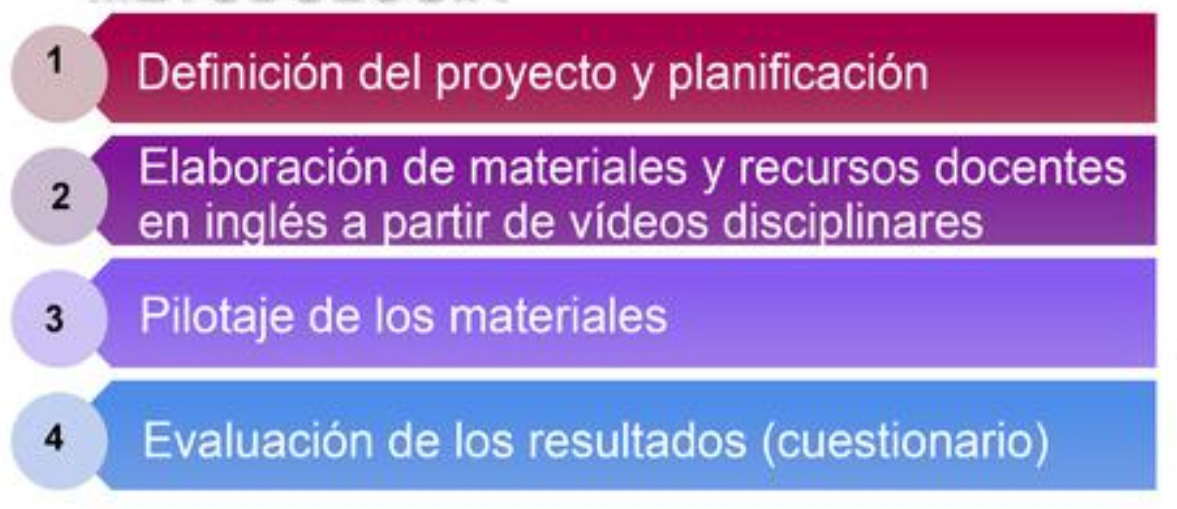

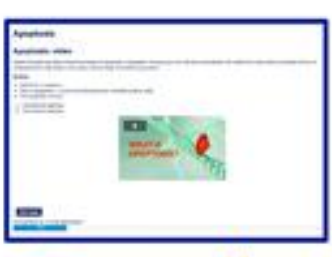

Thoodle

Hot Potatoes

\section{RESULTADOS}

$80 \%$ Utilidad para el aprendizaje de la asignatura

$70 \%$ El inglés no plantea problemas $\rightarrow$ posible aumento de motivación por usar textos en esta lengua

$80 \%$ Materiales útiles o muy útiles para comprender otros recursos en inglés

\section{CONCLUSIONES}
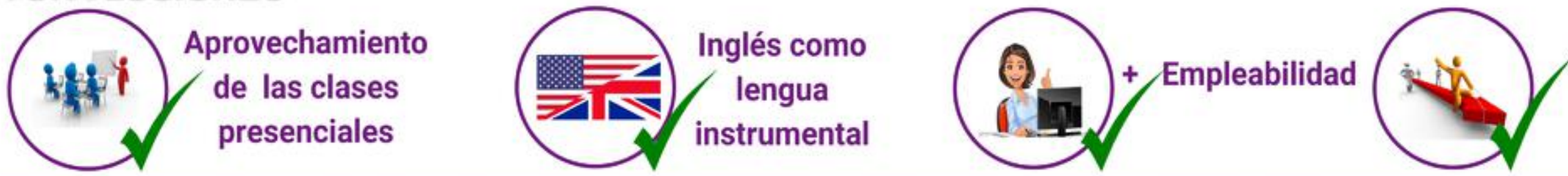

Continuidad del proyecto (2018-2019) 



\section{II \\ Evaluación del aprendizaje}




\section{Evaluación del aprendizaje}

1. Sanz del Pozo, M.; Romero Fernández, F.; Gil Sanz, M. J.; Subirá Ríos, J.; Borque Fernando, A.

Acogida del taller de Tacto Rectal con simuladores en grupos reducidos entre estudiantes del grado de Medicina de la Universidad de Zaragoza

2. Marcén Román, Y.; Sanz Rubio, M. C.; Franco Sierra, M. A.

Coevaluación como estrategia de evaluación

3. Sarasa Fernández, C.; Duarte Pac, R.; Sancho Anel, D.

Conocimientos, percepciones y actitudes medioambientales en el ámbito universitario: un estudio en la Universidad de Zaragoza

4. González Campo, F. de Asís

Docencia transversal de la violencia de género en la asignatura de Derecho Procesal Penal

5. Pardos Martínez, E.; Pessoa de Oliveira, A. K.

Evaluación de competencias transversales: comunicación académica en inglés en asignaturas de ADE

6. Garcés-Ayerbe, C.; Rivera-Torres, P.; Suárez-Perales, I.; Valero-Gil, J.

Introducción de la Experimentación como Metodología para la Formación en Gestión Medioambiental: Análisis de la Influencia en el Comportamiento Pro-Ambiental

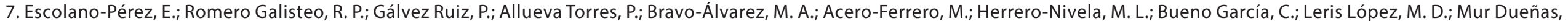
M. P.; Gil, V.

Instrumento para la evaluación inicial del aprendizaje autorregulado del alumnado universitario de nuevo ingreso

8. Alejandre Marco, J. L.; Allueva Pinilla, A. I.

Flipped Classroom y Gamificación al servicio de la evaluación continua

9. Rapún López, M.; Romero Martín, M. R.; Asún Dieste, S.

La evaluación formativa para mejorar la competencia de trabajo en equipo

10. Cantarero Carmona, I.; Luesma Bartolomé, M. J.

La Gamificación como estrategia en el proceso de enseñanza-aprendizaje en el Grado de Enfermería 
11. Carrasquer Álvarez, B.; Ponz Miranda, A.

La redacción de artículos sobre experiencias didácticas reales como medio para mejorar la expresión escrita académica y la compresión de los textos científicos

12. García Nieto, L.; Sebastián Cabeza, V.

Mejora de la competencia del estudiante para la resolución de problemas

13. Luño Lázaro, V., Martínez Asensio, F., González Ortí, N., Martí Jimenez, J. I., del Niño Jesús García, A., Gil Huerta, L. Participación activa del estudiante en el proceso de evaluación

14. Alda García, M.; Marco Sanjuán, I.; Muñoz Sánchez, F.; Vargas Magallón, M.; Vicente Reñé, R.

Percepción de los estudiantes del Grado en ADE acerca del trabajo en equipo

15. Cilla Hernández, M.; Pueo Arteta, M.; Guillén Lambea, S.; Sierra Pérez, J.

Seguimiento y mejora de la metodología de CoEvaluación (CE) en las actividades calificativas de la asignatura Expresión Gráfica y Diseño Asistido por Ordenador (EGDAO) 


\section{Acogida del taller de Tacto Rectal con simuladores en grupos reducidos entre estudiantes del grado de Medicina de la Universidad de Zaragoza}

Sanz del Pozo, M.; Romero Fernández, F.; Gil Sanz, M. J.; Subirá Ríos, J.; Borque Fernando, A.

\section{Palabras clave}

Tacto, rectal, taller, simuladores, urología.

\section{Resumen}

Contexto y objetivos:

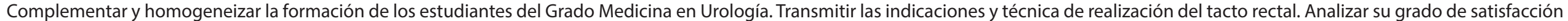
y habilidades adquiridas mediante el empleo de simuladores en grupos reducidos.

Metodología:

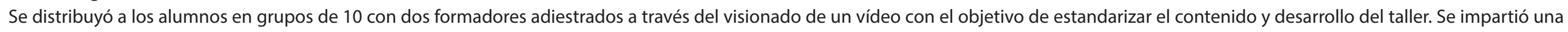

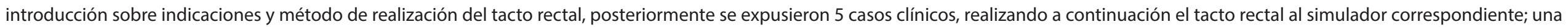
vez todos los alumnos hubieron completado cada exploración, los instructores explicaron la interpretación de cada caso.

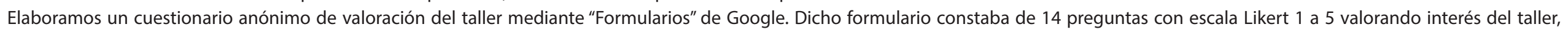
organización, adecuación de contenidos y recursos, satisfacción discente y continuidad del mismo.

Resultados:

Del total de 232 alumnos participantes, 53 (23\%) respondieron al formulario.

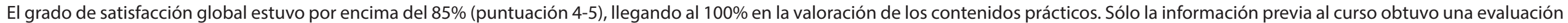
inferior, un 67\% de estimación 4-5. El 93\% de los alumnos recomendaría su continuidad dentro del contenido y estructura docentes del Grado.

Conclusiones:

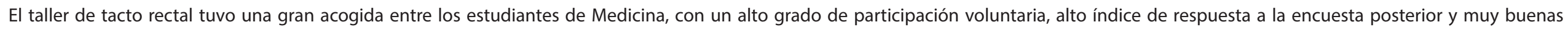

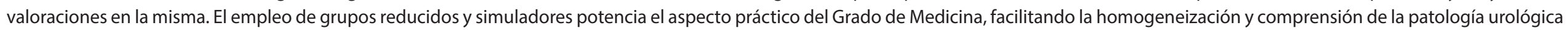
y logrando mayor confianza por parte del alumno de cara a su práctica clínica futura. 


\section{Acogida del taller de Tacto Rectal con simuladores en grupos reducidos entre estudiantes del grado de Medicina de la Universidad de Zaragoza.}

Sanz del Pozo, M.; Romero Fernández, F.; Gil Sanz, M.J.; Subirá Ríos, J., Borque Fernando, A.

Departamento de Urologia, Servicio de Urología del Hospital Universitario Miguel Servet, mosanzdelpozo@hotmail.com

CONTEXTO ACADÉMICO: Grado en Medicina: ECOE: Urología. OBJETIVOS:

- Complementar y homogeneizar la formación.

- Transmitir las indicaciones y técnica del tacto rectal.

- Analizar su grado de satisfacción y habilidades adquiridas.

METODOLOGÍA: 232 alumnos, 10 por grupo, dos formadores.
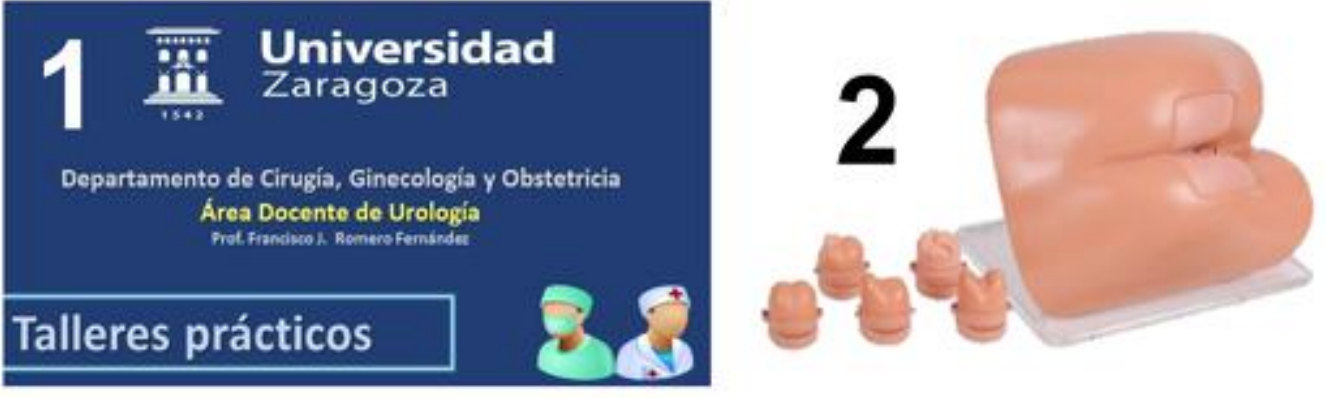

1. Introducción teórica.

2. 5 casos clínicos, tacto rectal individual, interpretación del caso.

3. Cuestionario anónimo de valoración.

RESULTADOS: $53(23 \%)$ respuestas al formulario.

Valoración global

Información previa

0(0\%)

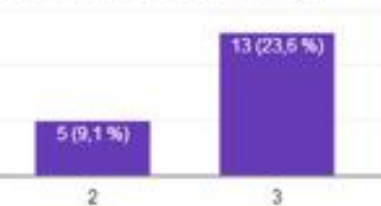

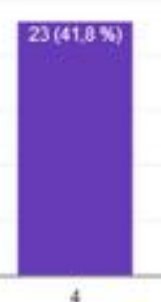

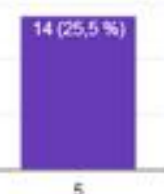

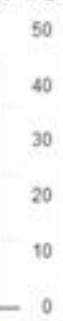

50
Contenidos prácticos

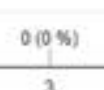

- $\mathrm{Si}$

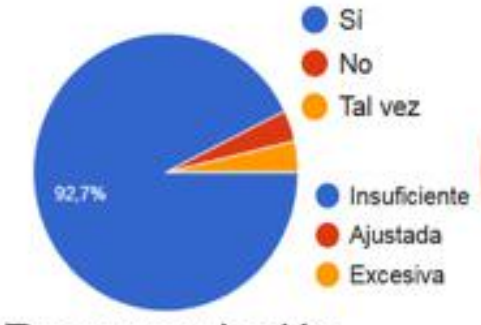

Recomendación

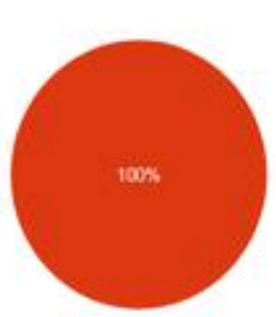

Duración

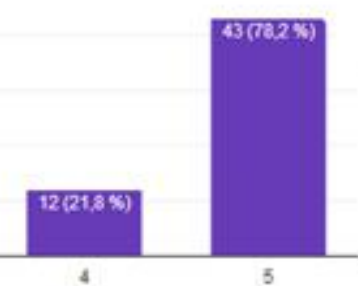

Contenidos teóricos 10
Materiales
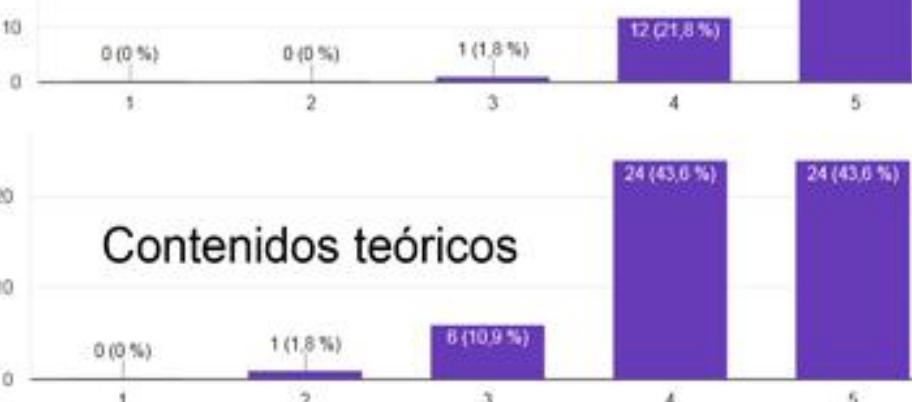

- Gran acogida entre los estudiantes.

- Alta participación y respuesta a la encuesta.

- Grupos reducidos y simuladores potencian el aspecto práctico: homogeneización de la enseñanza y aumento de la confianza en la práctica clínica futura. 


\section{Coevaluación como estrategia de evaluación}

Marcén Román, Y.; Sanz Rubio, M. C.; Franco Sierra, M. A.

\section{Palabras clave}

Innovación docente, aprendizaje, estrategias docentes

\section{Resumen}

Este proyecto piloto responde a la necesidad de llevar a cabo un proceso de mejora continua en la calidad de la docencia en el Grado de Fisioterapia.

El objetivo general es analizar si los cuestionarios de coevaluación constituyen estrategias válidas para incrementar la satisfacción del estudiante sobre su participación activa en la evaluación.

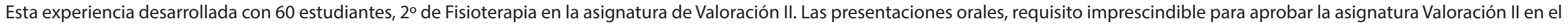
Grado de Fisioterapia, se presentan en pequeños grupos (3 o 4 estudiantes). Se caracterizan por ser casos clínicos que engloban los conocimientos teóricos/prácticos de la asignatura.

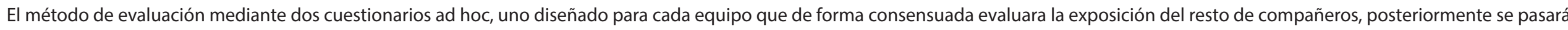
un cuestionario de satisfacción, permite conocer la percepción de cada estudiante sobre su participación activa en la evaluación de las presentaciones orales.

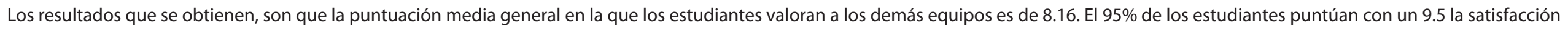
que sienten los estudiantes hacia esta experiencia.

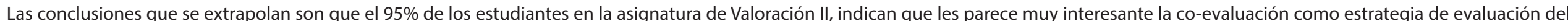

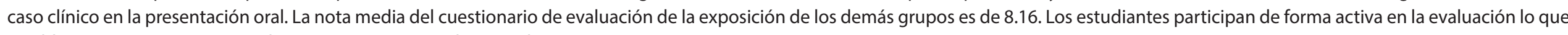
posiblemente aumentara su implicación en su proceso de aprendizaje. 


\section{COEVALUACIÓN COMO ESTRATEGIA DE EVALUACIÓN}

\section{Yolanda Marcén Román ${ }^{1}$, María Concepción Sanz Rubio ${ }^{1}$, María Ángeles Franco Sierra ${ }^{1}$}

Fisiatría y Enfermeria. Facultad de Ciencias de la Salud. Zaragoza. yomarcen@unizar.es

Proceso de mejora en la calidad de la docencia de grado en Fisioterapia

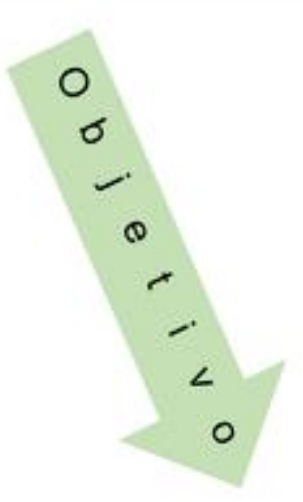

Analizar si los cuestionarios de coevaluación constituyen estrategias válidas para incrementar la satisfacción del estudiante.

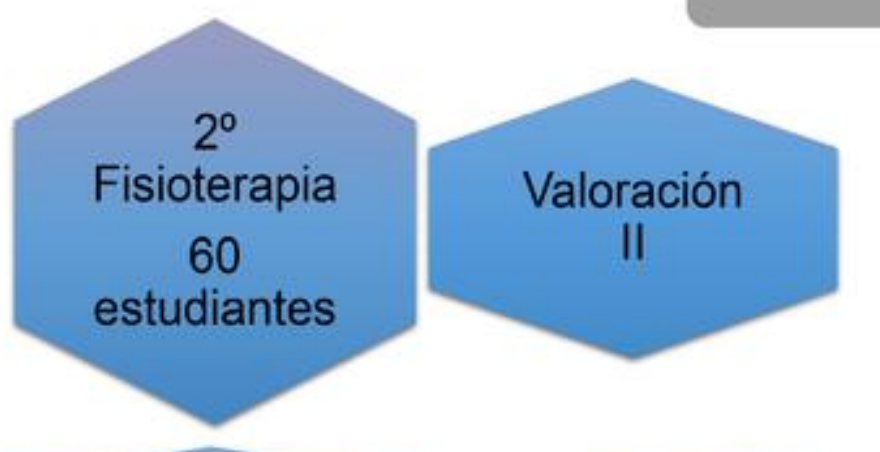

Participación activa

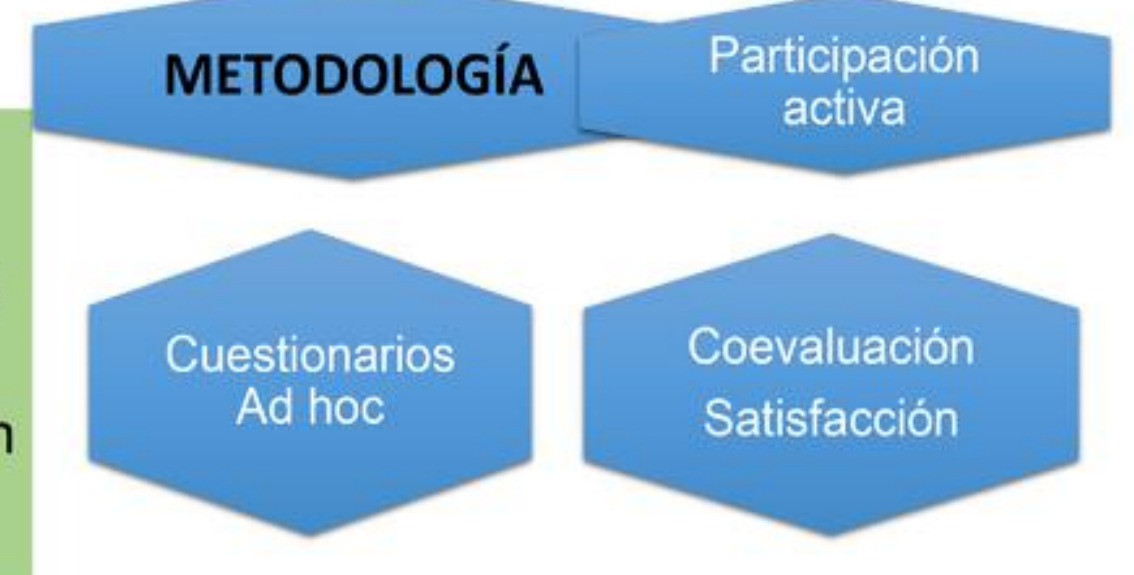

A la mayoría de los estudiantes les parece muy interesante la coevaluación como evaluación del caso clínico.

La nota media de la evaluación a los demás compañeros es alta. Los estudiantes participan de forma activa en el caso clínico y en la evaluación de la misma.

\section{제i: Universidad




\section{Conocimientos, percepciones y actitudes medioambientales en el ámbito universitario: un estudio en la Universidad de Zaragoza}

Sarasa Fernández, C., Duarte Pac, R., Sancho Anel, D.

\section{Palabras clave}

Educación ambiental, encuesta, patrones de consumo.

\section{Resumen}

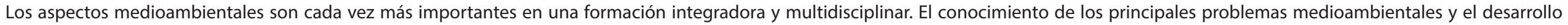

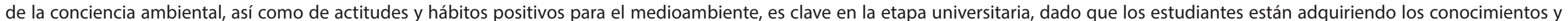

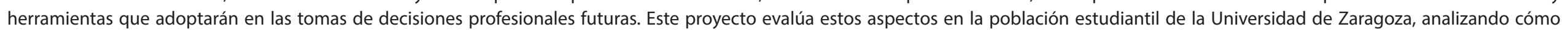

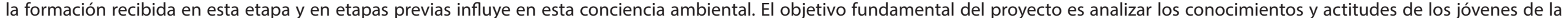

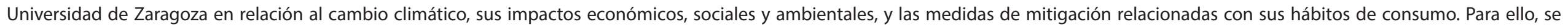

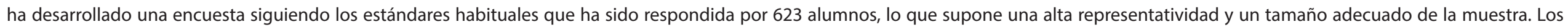

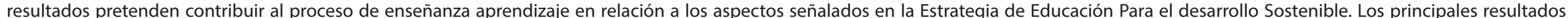

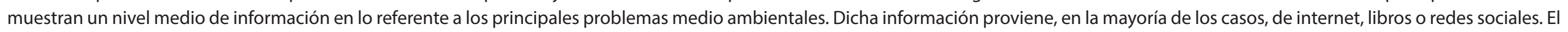

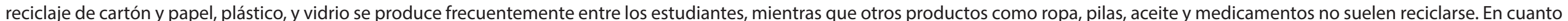

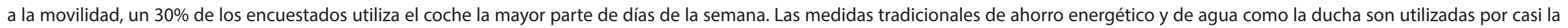
totalidad de estudiantes, mientras que otras más novedosas son menos frecuentes. 


\title{
Conocimientos, percepciones y actitudes medioambientales en el ámbito universitario: un estudio en la Universidad de Zaragoza
}

\author{
Cristina Sarasa, Rosa Duarte y Diego Sancho
}

Departamento de Análisis Económico, Facultad de Economía y Empresa. E-mail de contacto: csarasa@unizar.es

Contexto de aplicación: Todos los estudiantes de la Universidad de Zaragoza (muestra de 623 alumnos)

Objetivos: evaluar los conocimientos, percepciones y actitudes de los jóvenes de la Universidad de Zaragoza en relación al cambio climático, sus impactos económicos, sociales y ambientales, y las medidas de mitigación relacionadas con los hábitos de consumo.
Metodología: estudio estadístico en base a una encuesta sobre los conocimientos y actitudes medioambientales de los estudiantes de la Universidad de Zaragoza. La encuesta es diseñada según los estándares habituales, incluyendo preguntas de distinto formato que, de acuerdo a la literatura y a la práctica internacional, ofrecen una información significativa en relación a dichos aspectos.

\section{Principales resultados y Conclusiones:}

- Los resultados muestran un nivel medio de información en lo referente a los principales problemas medio ambientales.

- La Universidad no resulta fuente de información básica de la problemática medio ambiental.

- El reciclaje de papel, plástico y vidrio se produce frecuentemente. Otros productos (ropa, pilas, aceite y medicamentos) no suelen reciclarse (falta de información sobre dónde depositar, inexistencia de puntos de recogida).

- Más del $70 \%$ de los encuestados realiza algún desplazamiento a pie, un $30 \%$ utiliza el transporte público, otro $30 \%$ utiliza el coche, y se observa bajo uso de la bicicleta o moto. El uso de vehículo propio se realiza de forma compartida al $50 \%$.

- Más del $60 \%$ de los estudiantes ven positivas medidas de prohibición de vehículos privados por el centro de la ciudad.

- Casi la totalidad realiza medidas tradicionales de ahorro energético y de agua. Las nuevas medidas no son tan comunes.

- Bajo consumo de productos naturales (no supera el $30 \%$ ).

- El pago de vivienda es una categoría de gasto importante, pero el $43 \%$ no tiene pagos por vivienda.

- Respecto a las dietas, los resultados muestran que un 76,5\% de los estudiantes consume cereales diariamente o más de 4 días a la semana, y un $77,6 \%$ consume frutas y hortalizas con esta frecuencia. Por el contrario, la carne es consumida más de 4 dias a la semana por un $48,3 \%$ de los estudiantes y el pescado por sólo un $12,3 \%$. 


\section{Docencia transversal de la violencia de género en la asignatura de Derecho Procesal Penal}

González Campo, F. de Asís

\section{Palabras clave}

Enseñanza transversal, motivación, reflexión crítica, violencia de género.

\section{Resumen}

\section{Contexto:}

Asignatura: Derecho Procesal II ( $4^{\circ}$ curso Grado de Derecho).

Objetivos propuestos:

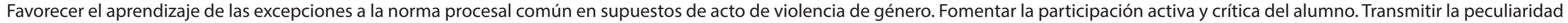
procesal de la cuestión mediante aspectos no meramente procesales para favorecer la comprensión de su problemática.

Metodología:

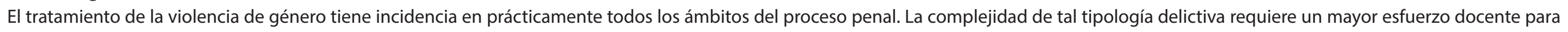

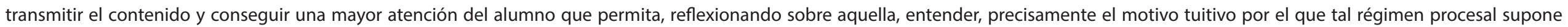
continuas excepciones a la norma común. Para ello:

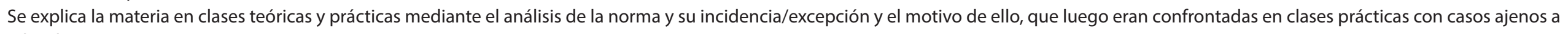
tal violencia.

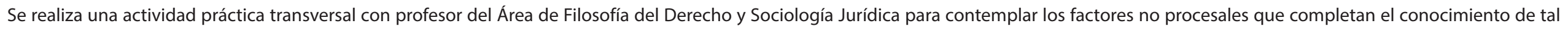

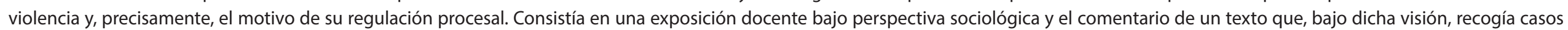
judiciales.

Resultados:

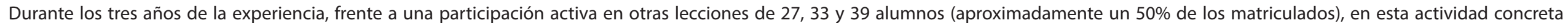
participaron activamente 32, 41 y 51 alumnos (aproximadamente un $25 \%$ más de alumnos).

Conclusiones:

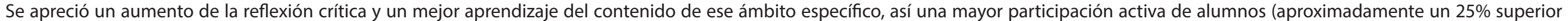
frente a otras lecciones). 
Tratamiento transversal de la violencia de género en la asignatura de Derecho Procesal Penal

\author{
Francisco de Asís González Campo
}

Área de Derecho Procesal, Departamento de Derecho Privado, Universidad de Zaragoza, fdagc@unizar.es

\title{
CONTEXTO ACADÉMICO
}

Alumnos de $4^{\circ}$ curso de Grado de Derecho. Asignatura: Derecho Procesal II (derecho procesal penal). Obligatoria. Créditos: 9 ECTS.

\section{OBJETIVOS}

$\checkmark$ Lograr conocimiento y reflexión transversal del fenómeno de la violencia de género y su complejidad.

$\checkmark$ Mejorar aprendizaje e interpretación del motivo tuitivo de la regulación procesal de la violencia de género,

\section{METODOLOGÍA}

1.- Explicación específica en cada lección de la especialidad procesal en violencia de género mediante análisis de la norma aplicable, su incidencia/excepción y el motivo de tal excepción 2.- Actividad práctica transversal con Área de Filosofía del Derecho y Sociología Jurídica sobre factores no procesales que permiten completar el conocimiento de tal cuestión.

\section{RESULTADOS Y CONCLUSIONES}

RESULTADOS: En las actividades no impartidas con esta metodología, participaron 27, 33 y 39 alumnos (aproximadamente un $50 \%$ de los matriculados). En esta actividad concreta participaron activamente 32, 41 y 49 alumnos con a su vez intervenciones más fundadas.

- CONCLUSIONES: Incremento del interés y participación activa del alumno. Mejora capacidad análisis e interpretación de la cuestión y comprensión jurídico procesal y transversal de la violencia de género

$\rightarrow$ Logro mejor aprendizaje concreto de la asignatura + conocimiento crítico y reflexivo global del fenómeno (aprox. 25\%)

Se comprueba que, mientras que se imparte la asignatura, al introducir la cuestión se alcanza, al finalizarla, un análisis y percepción de la globalidad de la cuestión y del mero aspecto jurídico procesal de la asignatura pues redunda en el mejor aprendizaje del modo en que el legislador procesal regula tal fenómeno en las normas vigentes.

\section{Universidad}




\section{Evaluación de competencias transversales: comunicación académica en inglés en asignaturas de ADE}

Pardos Martínez, E.; Pessoa de Oliveira, A. K.

\section{Palabras clave}

Colaboración interdisciplinar, segunda lengua, cuestionarios, comprensión lectora, comprensión oral.

\section{Resumen}

Objetivos y contexto académico

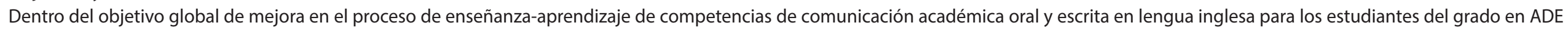

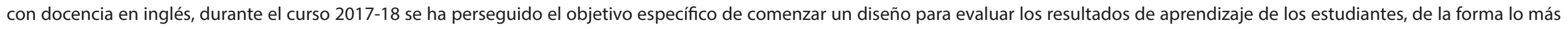
integrada posible con las actividades de cada asignatura.

\section{Metodología}

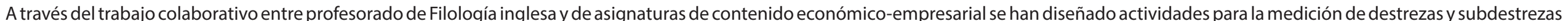

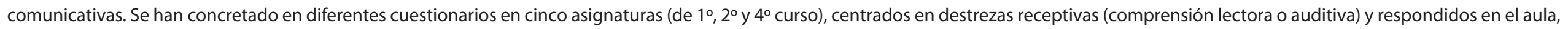
mediante plataformas como Socrative, Google forms o Kahoot. Se ha medido el número de respuestas correctas por subdestrezas y por niveles acreditados de inglés.

Resultados y conclusiones

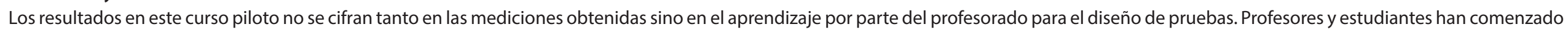

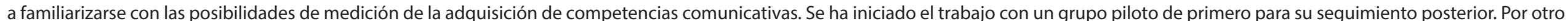

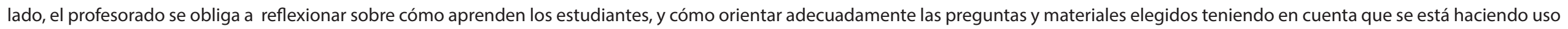

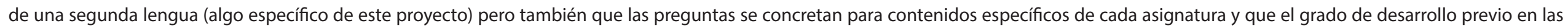
diferentes destrezas es diverso, relacionado en parte con los niveles acreditados de dominio de la lengua. 


\section{Evaluación de competencias transversales: comunicación académica en inglés en asignaturas de ADE}

\section{Pardos Martínez, E.*; Pessoa de Oliveira, A.K.^}

*Dpto. Estructura e Historia Económica y Economía Pública (epardos@unizar.es); ^Dpto. Contabilidad y Finanzas (apessoa@unizar.es)

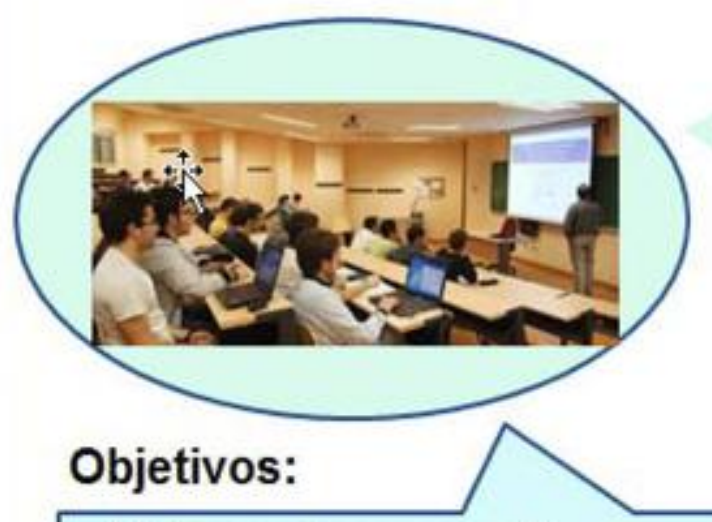

- Mejorar el proceso de enseñanza-aprendizaje - Diseñar una estrategia de medición de resultados en competencias comunicativas

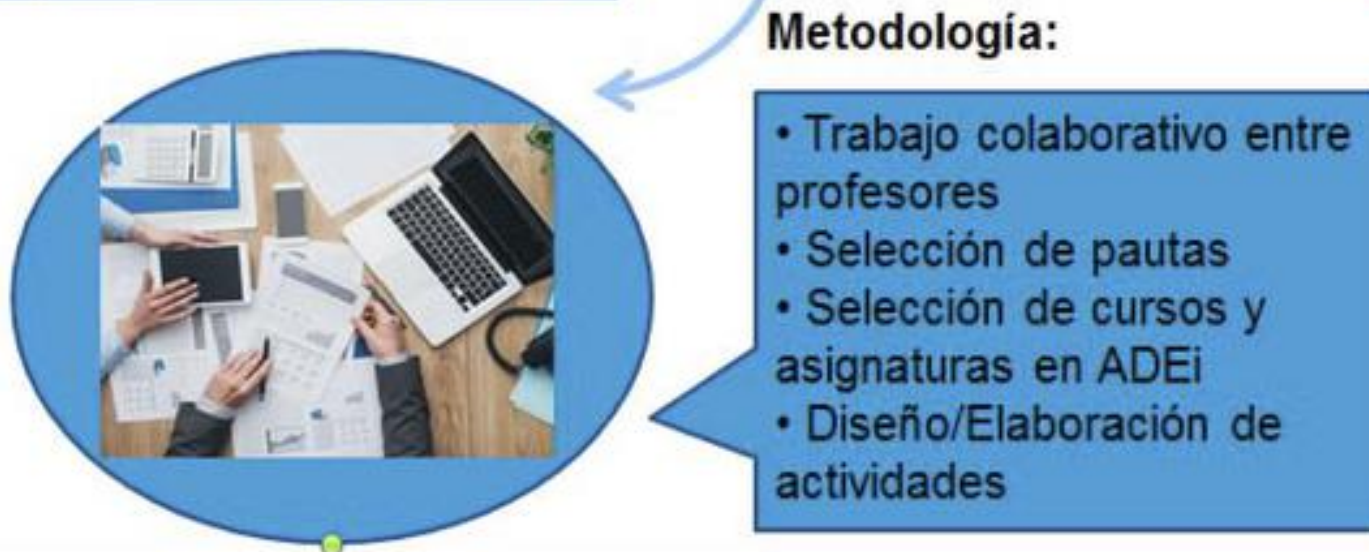

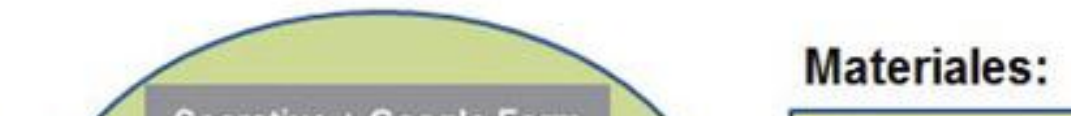

- Textos y vídeos en inglés por asignaturas - Ejercicios de medición de destrezas - Uso de Socrative y Google Forms

Actividades:

- Medición de resultados de las estrategias receptivas de reading y listening
감 Universidad iㅡ. Zaragoza
- Diferencias significativas del nivel de inglés al inicio del grado y evolución posterior

- Necesidad de un diseño detallado de la naturaleza de los elementos de medición adaptados al perfil del alumnado 


\section{Introducción de la Experimentación como Metodología para la Formación en Gestión Medioambiental: Análisis de la Influencia en el Comportamiento Pro-Ambiental}

Garcés-Ayerbe, C.; Rivera-Torres, P.; Suárez-Perales, I.; Valero-Gil, J.

\section{Palabras clave}

Aprendizaje; Investigación; Experimentación; Comportamiento Pro-Ambiental; Gestión Medioambiental.

\section{Resumen}

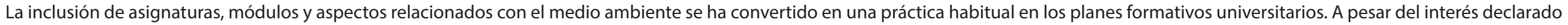

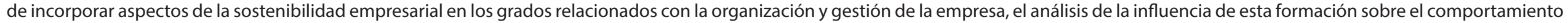
ambiental no ha contado con el suficiente detalle por parte de la academia.

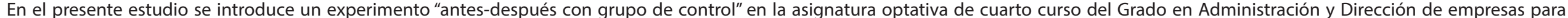

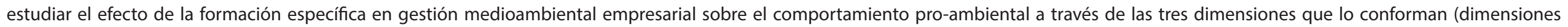
afectiva, cognitiva y disposicional).

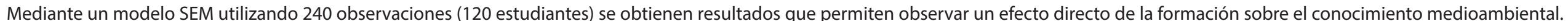

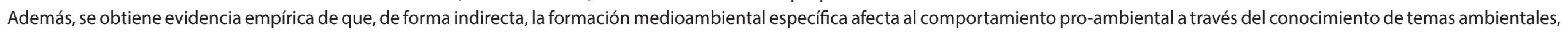

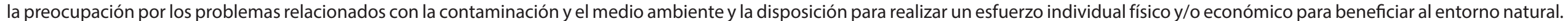

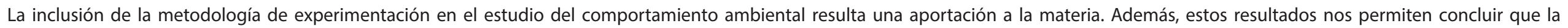

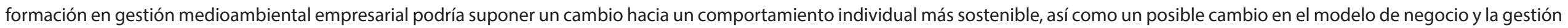
empresarial de los futuros managers. 


\section{CONTEXTO ACADÉMICO:}

El experimento se ha llevado a cabo en el Grado de Administración y Dirección de Empresas. Optativa $4^{\circ}$ Curso.

OBJETIVOS:

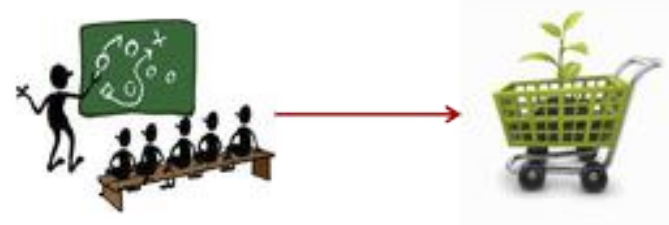

Estudiar el efecto de la formación específica en gestión medioambiental sobre el comportamiento proambiental

Analizar este efecto a través de las tres dimensiones del comportamiento pro-ambiental:

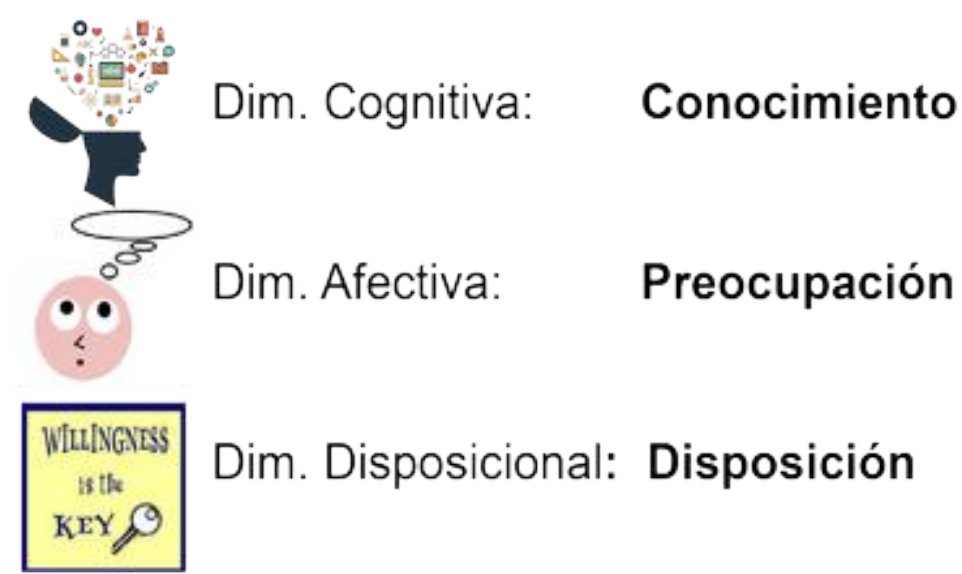

METODOLOGÍA:

Experimento "Antes y Después": Cuestionario Modelo Ecuaciones Estructurales

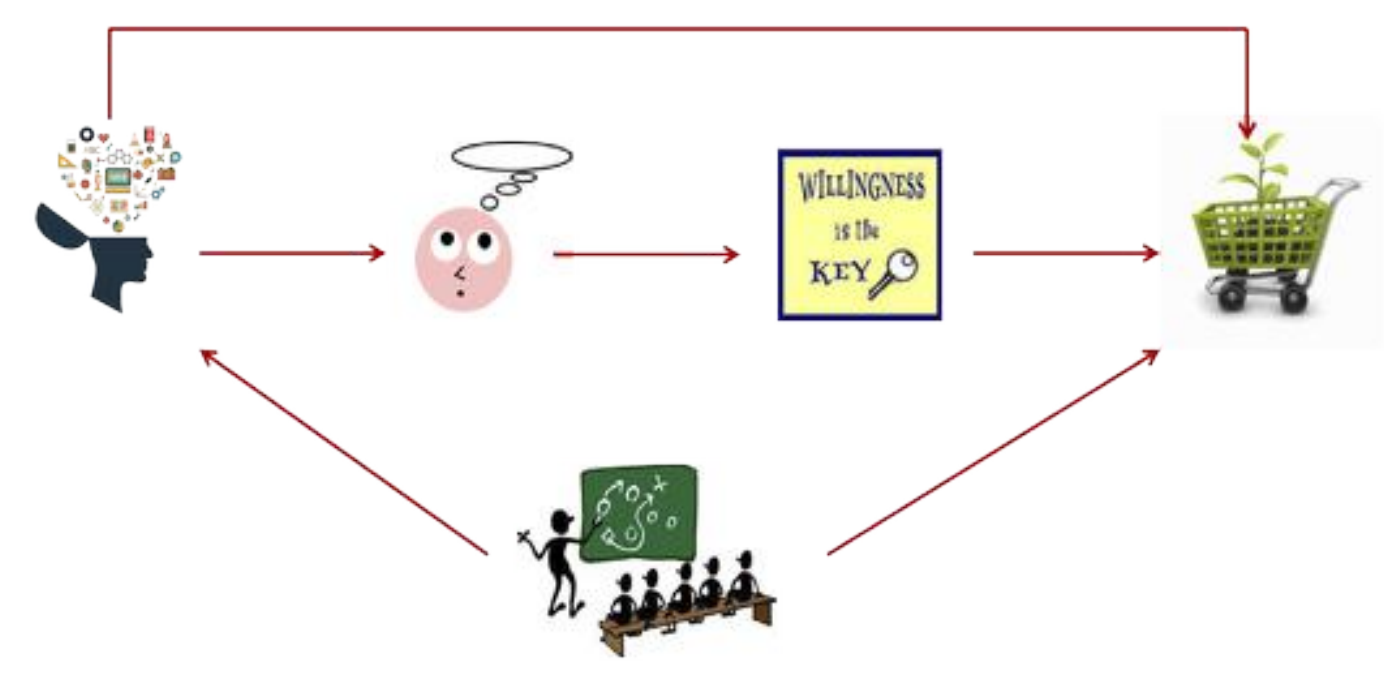

CONCLUSIONES:

La formación específica afecta al comportamiento pro-ambiental (indirecta). Aportación "Sustainability in Higher Education"

Se podría influir en el comportamiento corporativo a través del comportamiento individual.

Experimentación como novedad metodológica en la materia 


\section{Instrumento para la evaluación inicial del aprendizaje autorregulado del alumnado universitario de nuevo ingreso}

Escolano-Pérez, E.; Romero Galisteo, R. P.; Gálvez Ruiz, P.; Allueva Torres, P.; Bravo-Álvarez, M. A.; Acero-Ferrero, M.; Herrero-Nivela, M. L.; Bueno García, C.; Leris López, M. D.; Mur Dueñas, M. P.; Gil, V.

\section{Palabras clave}

Aprendizaje autónomo, funciones ejecutivas, Espacio Europeo de Educación Superior.

\section{Resumen}

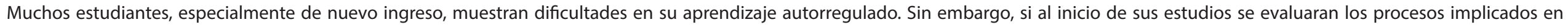

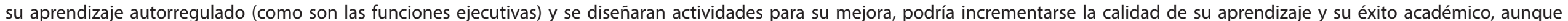

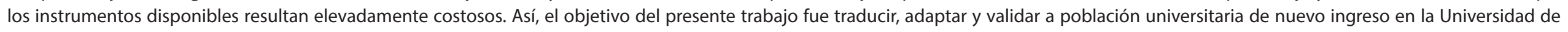
Zaragoza (UZ) el instrumento de evaluación AEFI (Baars, Bijvank, Tonnaer y Jolles, 2015), para evaluar las funciones ejecutivas con 10 items.

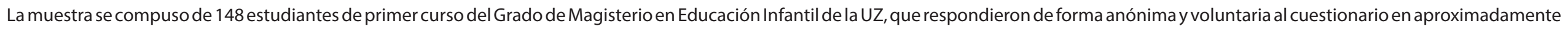
10 minutos al final de una clase habitual.

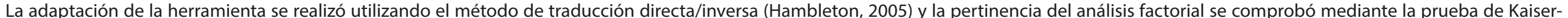

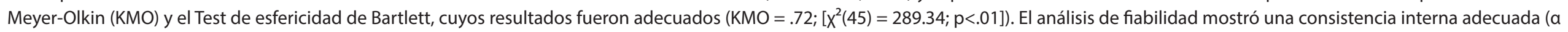

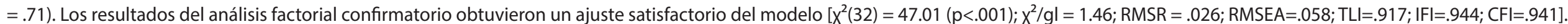

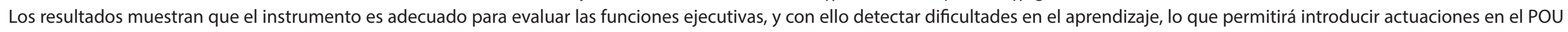
del centro orientadas a la mejora del aprendizaje y éxito académico, además de la prevención del abandono académico. 
Instrumento para la evaluación inicial del aprendizaje autorregulado del alumnado universitario de nuevo ingreso

Elena Escolano-Pérez*, Rita Pilar Romero, Pablo Gálvez, Pedro Allueva, Ma Ángeles BravoÁlvarez, Marian Acero-Ferrero, Ma Luisa Herrero-Nivela, Concepción Bueno, Ma Dolores Leris, Ma Pilar Mur, Victoria Gil

\section{1.- CONTEXTO}

Grado en Magisterio en Educación Infantil

1er curso

\section{2.- OBJETIVO}

Traducir, adaptar y validar para estudiantes universitarios de nuevo ingreso en la UZ el instrumento de evaluación AEFI (Baars, Bijvank, Tonnaer, \& Jolles, 2015), que permita identificar alumnado con probabilidad de presentar problemas en su aprendizaje autónomo.

\section{3.- METODOLOGÍA}

Traducción y adaptación del instrumento original

$\checkmark$ Método de traducción directa/inversa

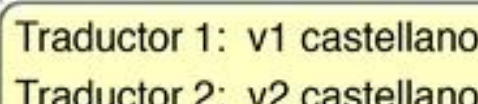

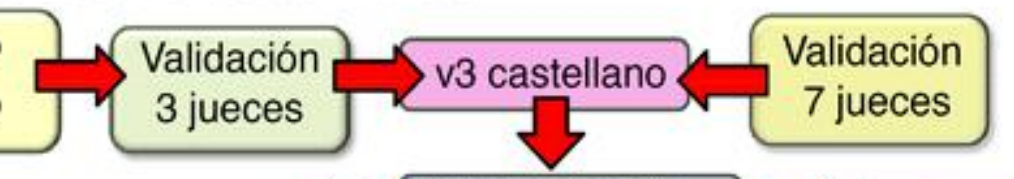

v1 inglés
Retrotraducción

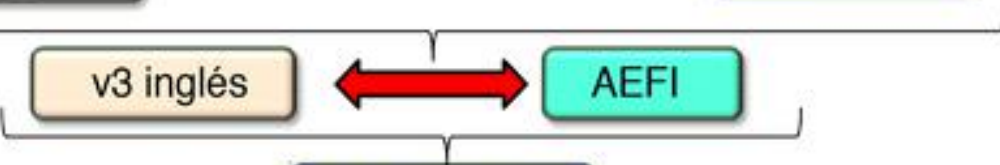

Validación del cuestionario

v4 castellano $\square$ Administración: 148 estudiantes

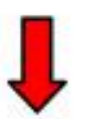

a) Análisis descriptivos

b) Análisis factorial exploratorio

c) Análisis factorial confirmatorio

v4 castellano

\section{4.- RESULTADOS}

Instrumento de evaluación válido en nuestro contexto

\section{5.- CONCLUSIONES}

Administración del instrumento
Detección alumnado de nuevo ingreso con dificultades en su aprendizaje autónomo
+ Aprendizaje

POU $\longrightarrow$ + Rendimiento académico

REFERENCIA: Baars, M. A. E., Bijvank, M. N., Tonnaer, G. H., \& Jolles, J. (2015). Self-report measures of executive functioning are a determinant of academic performance in first-year students at a university of applied sciences. Frontiers in Psychology, 6, 1131. 


\section{Flipped Classroom y Gamificación al servicio de la evaluación continua}

Alejandre Marco, J. L.; Allueva Pinilla, A. I.

\section{Palabras clave}

Aprendizaje activo, Kahoot, CTA, smartphone.

\section{Resumen}

Contexto académico

Grado en Ciencia y Tecnología de los Alimentos, asignatura Matemáticas, primer cuatrimestre, primer curso, 60-70 estudiantes.

Objetivo

Mejorarelprocesodeenseñanza-aprendizajedelosestudiantesatravésdelaevaluacióncontinua,tantoensesionesdeteoría(grupoúnico)comodeprácticas(gruposmásreducidos).

Metodología

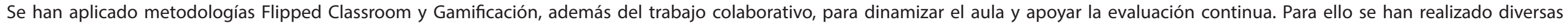
actividades evaluables.

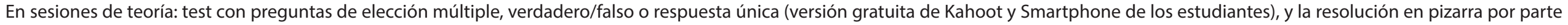
de los estudiantes de ejercicios propuestos que deben trabajar fuera del aula.

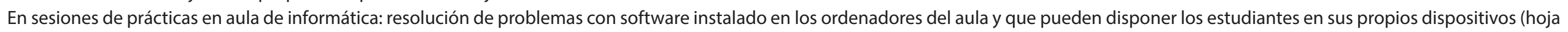

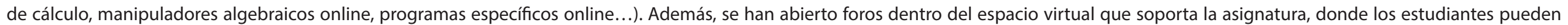
plantear dudas tanto de contenidos como de otros aspectos de la asignatura.

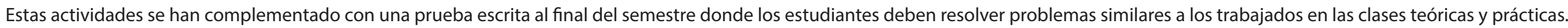

Resultados

Alta asistencia y participación en las clases, sobre todo en las teóricas. Mejoran las calificaciones con respecto a cursos anteriores.

Mejora la evolución de los estudiantes.

Conclusiones

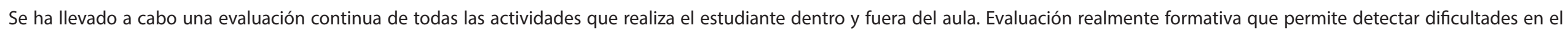
aprendizaje en estados tempranos.

Impacto positivo en el aprendizaje de los estudiantes.

Experiencia sostenible en el tiempo y transferible a cualquier asignatura, materia, disciplina, titulación y centro. 


\section{Flipped Classroom y Gamificación al servicio de la evaluación continua}

\section{José Lujs Alejandre Marco, Ana Isabel Allueva Pinilla}

Matemática Aplicada, jlalejan@unizar.es, allueva@unizar.es

Contexto: asignatura de Matemáticas de primer cuatrimestre en el primer curso del Grado en Ciencia y Tecnología de los Alimentos de la Facultad de Veterinaria, 6 ECTS $(3 T+3 P)$ y un número de estudiantes entre 60-70.

Objetivo: mejorar la evaluación continua tanto en la parte práctica como en las denominadas clases de teoria.

\section{Metodología}

- Actividades con Kahoot en sesiones de teoría

- Actividades en sesiones prácticas en aula tradicional

- Actividades en sesiones prácticas en aula de informática

- Participación en foros

- Apoyo en material audiovisual
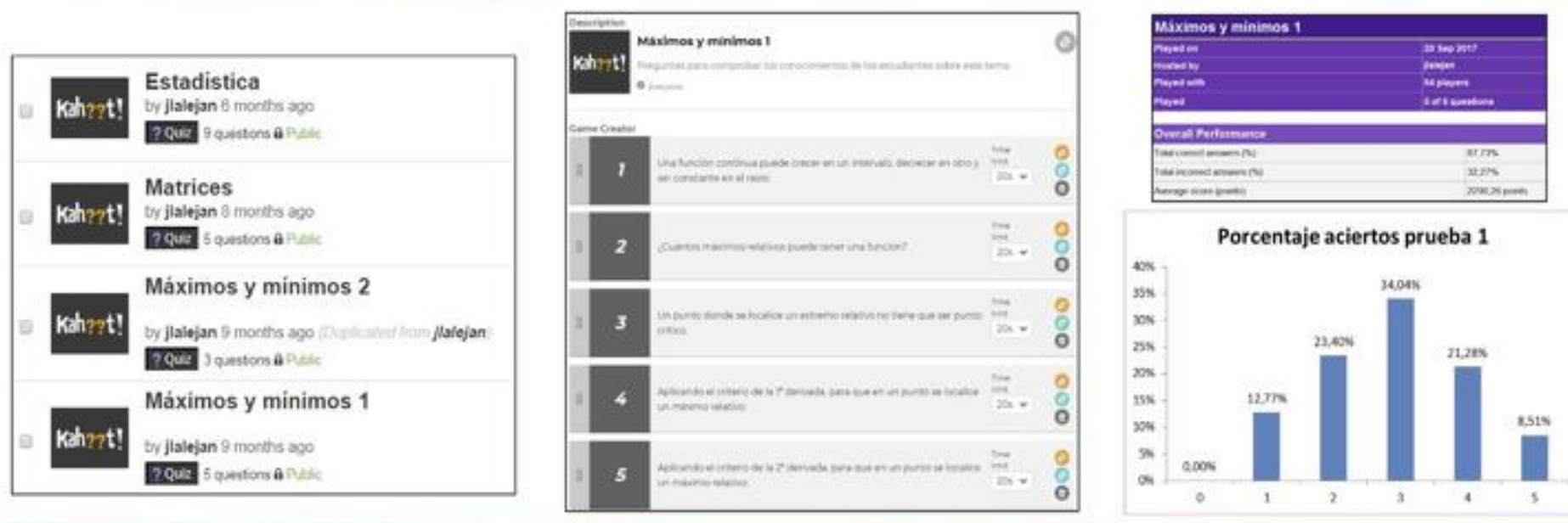

\section{Conclusiones}

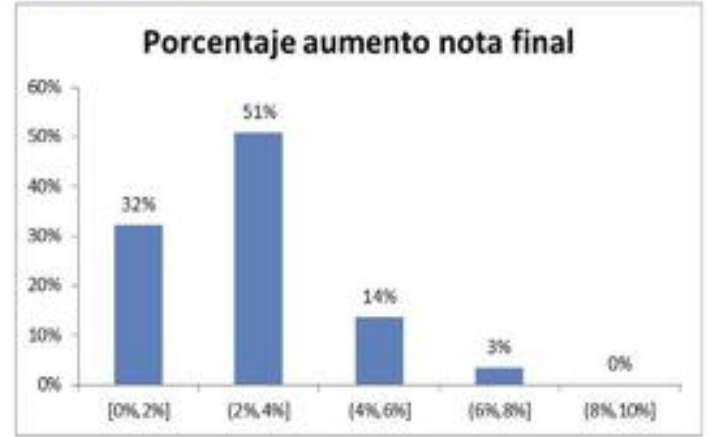

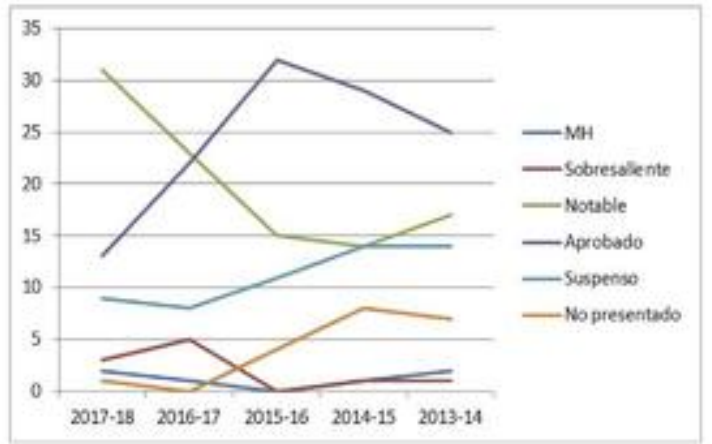

Aprendizaje activo

Material audiovisual como apoyo Ludificación como elemento motivante Evaluación formativa Desarrollo competencias transversales: colaboración, hablar en público, diferentes ritmos de aprendizaje... Foros no funcionan si no están dirigidos Mejora de calificaciones 


\section{La evaluación formativa para mejorar la competencia de trabajo en equipo}

Rapún López, M.; Romero Martín, M. R.; Asún Dieste, S.

\section{Palabras clave}

Educación Superior, autoevaluación, coevaluación, aprendizaje competencial.

\section{Resumen}

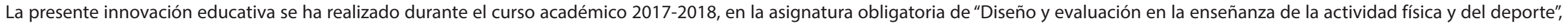
impartida en el tercer curso del Grado en Ciencias de la Actividad Física y del Deporte, de la Universidad de Zaragoza. Han participado 54 alumnos de los 63 matriculados en la asignatura.

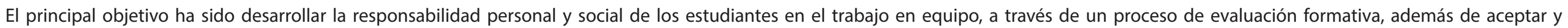
comprender su repercusión sobre la calificación individual en el trabajo grupal.

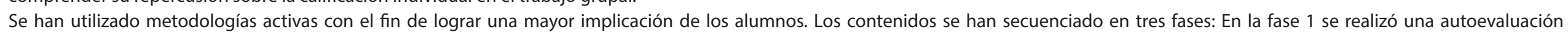

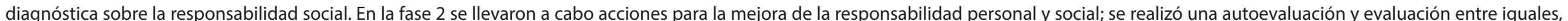

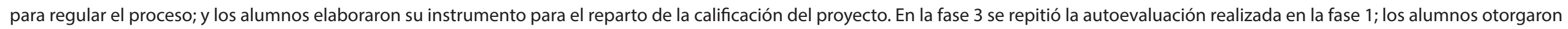

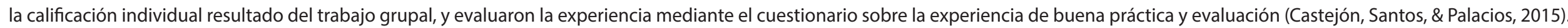

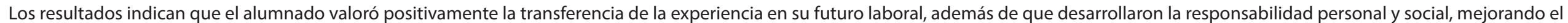
trabajo en equipo. También facilitó el reparto de la calificación individual en el trabajo grupal.

Por lo tanto, la experiencia ha resultado de utilidad para la mejora del trabajo en equipo a través del desarrollo de la responsabilidad personal y social. 


\section{La evaluación formativa para mejorar la competencia de trabajo en equipo.}

\section{Marta Rapún, Ma Rosario Romero, Sonia Asún.}

\section{Departamento de Expresión Musical, Plástica y Corporal. Universidad de Zaragoza. mrapun@unizar.es}

\section{CONTEXTO DE APLICACIÓN}

Asignatura Diseño y evaluación en la enseñanza de la actividad física y del deporte, Grado en Ciencias de la Actividad Física y del Deporte, Universidad de Zaragoza, Campus de Huesca.

\section{OBJETIVOS}

$>$ Desarrollar la responsabilidad personal y social de los estudiantes en el trabajo en equipo, a través de un proceso de evaluación formativa.

- Aceptar y comprender su repercusión sobre la calificación individual en el trabajo grupal.

\section{METODOLOGÍA}

\section{Fase 1}

Autoevaluación diagnóstica mediante una rúbrica.

\section{Fase 2}

Acciones para la mejora de la responsabilidad personal y social.

Autoevaluación y evaluación entre iguales.

Elaboración del sistema de reparto de la calificación.

\section{RESULTADOS}

- El desarrollo de la competencia genérica relacionada con el trabajo en equipo fue reconocido por los estudiantes como útil para su futuro laboral.

- Los estudiantes percibieron justicia en la calificación del trabajo en equipo mediante el sistema negociado y pactado por los propios miembros del equipo.

- Algunos estudiantes señalaron la dificultad de la evaluación entre iguales debido a las relaciones afectivas.

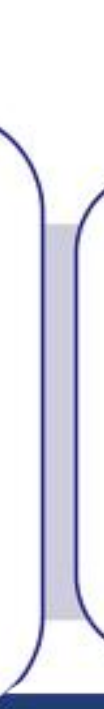

\section{CONCLUSIONES}

\section{Fase 3}

Autoevaluación realizada en la fase 1.

Utilización sistema de reparto de la calificación.
Eficacia de la buena práctica para mejorar los niveles de responsabilidad. docente ante los posibles conflictos de grupo.
$>$ Necesidad de un mayor apoyo 


\section{La Gamificación como estrategia en el proceso de enseñanza-aprendizaje en el Grado de Enfermería}

Cantarero Carmona, l.; Luesma Bartolomé, M. J.

\section{Palabras clave}

Innovación educativa, tecnología, aprendizaje basado en el juego.

\section{Resumen}

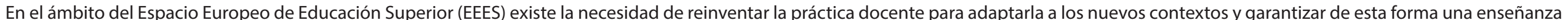

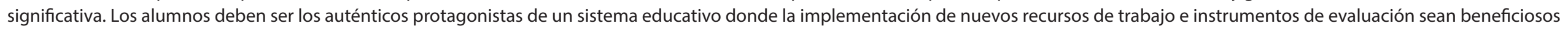

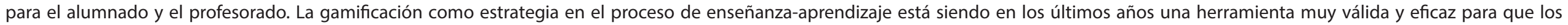
alumnos puedan afianzar conocimientos en determinadas materias, además de aumentar la motivación, fomentar el feed-back profesor-alumno y el aprendizaje cooperativo.

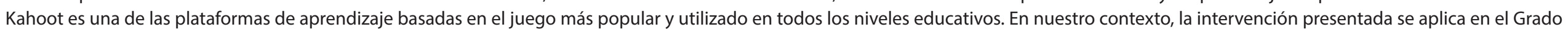

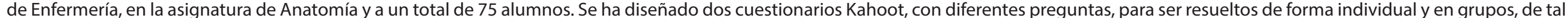

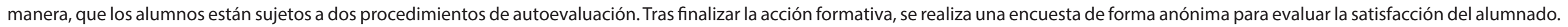

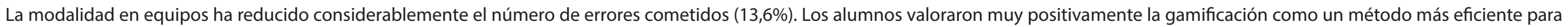
el aprendizaje (55\%), recomendando la experiencia y su ámbito de aplicación en otras asignaturas (96\%).

El profesor tiene la responsabilidad de innovar en metodologías emergentes y el compromiso de proporcionar todas las herramientas y recursos disponibles que favorezcan de calidad. 


\section{La Gamificación como estrategia en el proceso de enseñanza-aprendizaje en el Grado de Enfermería}

\section{Irene Cantarero ${ }^{1 *}$, María José Luesma²}

1•Dpto. Ciencias Morfológicas, Universidad de Córdoba. b12cacai@uco.es² Dpto. Anatomía Humana e Histologia, Universidad de Zaragoza. mjluesma@unizar.es

\section{Contexto académico}

Grado de Enfermería Asignatura Anatomía

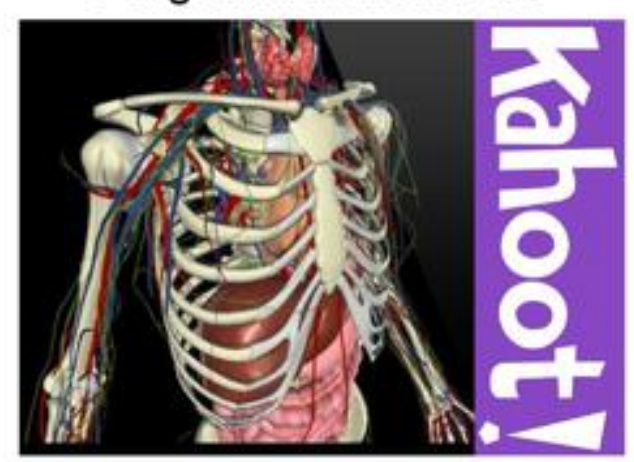

\section{Objetivos}

- Fomentar la interdependencia positiva.

- Promover las habilidades de equipo.

- Fortalecer el nivel académico de los integrantes del grupo.

- Favorecer la interacción estimuladora - Retroalimentación del alumno.

\section{Resultados}

Rendimiento global

= Respuestas correctas $=$ Respuestas incorrectas

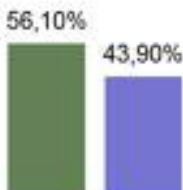

Individual

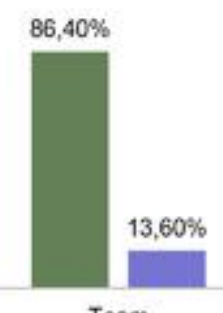

Recomendación de la experiencia en otras asignaturas

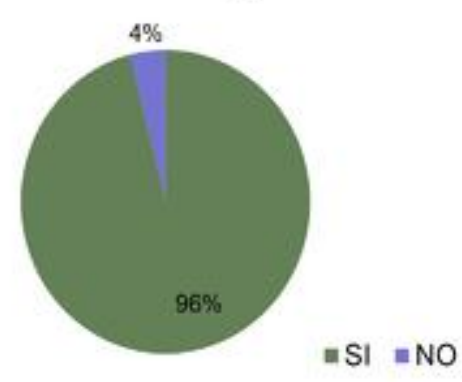

¿Consideras la gamificación un método mas eficiente para el aprendizaje?

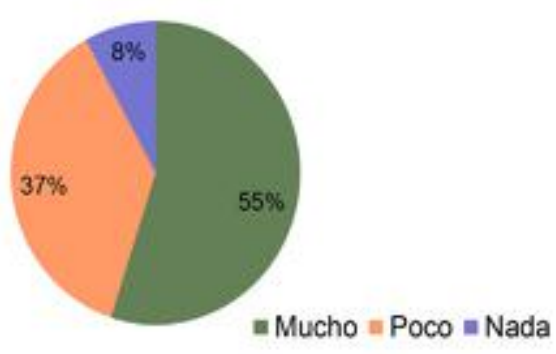

\section{Conclusiones}

Aumenta la motivación

Profundiza el impacto pedagógico

Compromiso y socialización a través de la interacción 


\section{La redacción de artículos sobre experiencias didácticas reales como medio para mejorar la expresión escrita académica y la compresión de los textos científicos}

Carrasquer Álvarez, B.; Ponz Miranda, A.

\section{Palabras clave}

Redacción de trabajos académicos, magisterio infantile, artíuclos de dicáctida de las ciencias exprimentales.

\section{Resumen}

Contexto académico:

El proyecto se ha llevado a cabo con alumnado del $2^{\circ}$ curso del Grado de Magisterio en Ed Infantil, en la Facultad de

Ciencias Sociales y Humanas (Teruel), en la asignatura "Las Ciencias de la Naturaleza en la Ed. Infantil".

Objetivos:

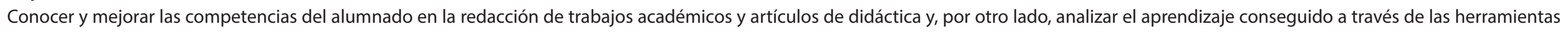
didácticas creadas para tal fin.

Metodología:

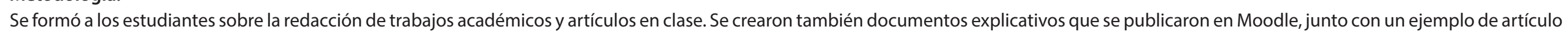

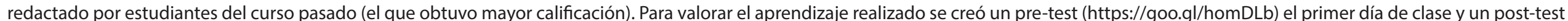

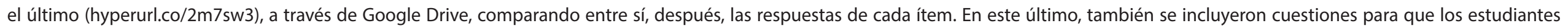

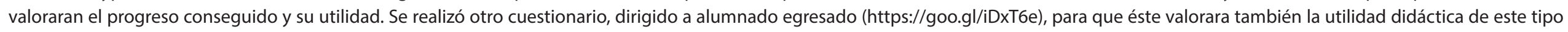
de actividad práctica.

\section{Resultados:}

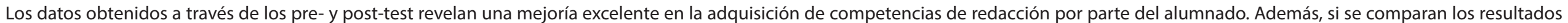
obtenidos respecto al curso anterior, también se ha obtenido una mayor calificación media global.

\section{Conclusiones:}

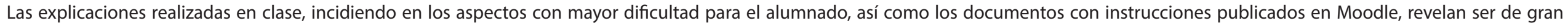
utilidad para el aprendizaje de los estudiantes. Confirmado también por el alumnado egresado consultado. 
La redacción de artículos sobre experiencias didácticas reales como medio para mejorar la expresión escrita

\section{académica y la comprensión de los textos científicos}

Carrasquer Álvarez, B. y Ponz, A.*

Dpto. Didáctica de las Ciencias Experimentales. *Grupo Beagle (IUCA). Email contacto: becarras@unizar.es

\section{Contexto académico}

Alumnado del $2^{\circ}$ curso del Grado de Magisterio en Ed. Infantil, asignatura: Las Ciencias de la Naturaleza en la Ed. Infantil.

\section{Objetivos}

Conocer y mejorar las competencias del alumnado necesarias para abordar la redacción de trabajos académicos sobre la Enseñanza de las Ciencias Experimentales en Ed. Infantil y estudiar-valorar el aprendizaje realizado a través de trabajos prácticos.

\section{Metodología}

- Refuerzo al aprendizaje en errores anteriores. - Mejora de documentos explicativos de Moodle. Ejemplo real de artículo redactado por estudiantes. Pre- y post-test (cuestionarios Google Drive).

\section{Conclusiones}

- Formación previa: una minoría (biblioteca). Sólo en una asignatura previa (APA, etc.). Aprendizaje excelente, a partir de las herramientas didácticas implementadas. Valoración muy positiva del alumnado. Utilidad didáctica del proceso verificada por el alumnado egresado de la titulación.

\section{Resultados}

Salvo en dos items, en todos las cuestiones tratadas, hubo una mejoria notable entre el pre- y post-test (Ej. Imagen inferior).

¿En qué apartado debes escribir los datos recogidos en tu estudio o trabajo (tablas, gráficas, etc.)?
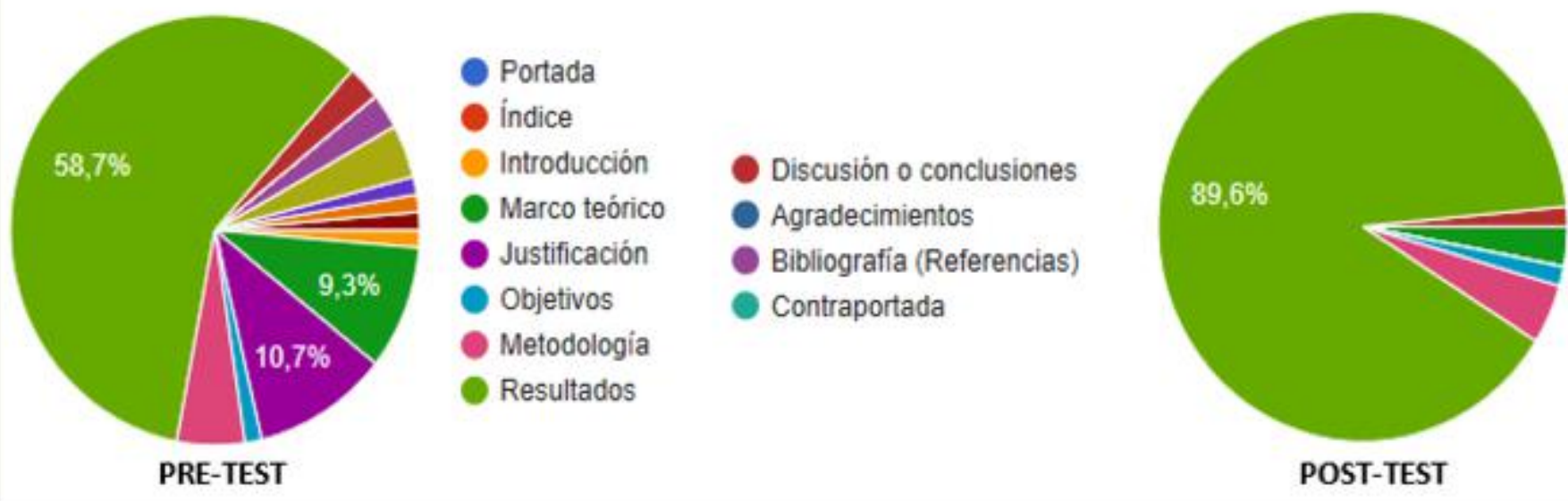

\section{풀. Universidad} III Zaragoza

- Discusión o conclusiones

- Agradecimientos

- Bibliografia (Referencias)

- Contraportada

POST-TEST 


\section{Mejora de la competencia del estudiante para la resolución de problemas}

García Nieto, L.; Sebastián Cabeza, V.

\section{Palabras clave}

Evaluación del aprendizaje, análisis de datos, Ingeniería química, diseño de reactores, estudios de Máster

\section{Resumen}

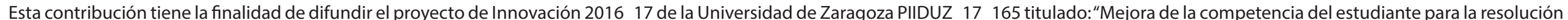

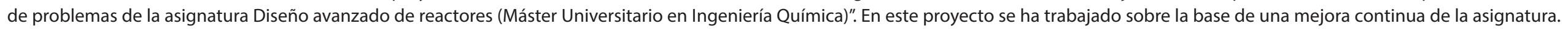

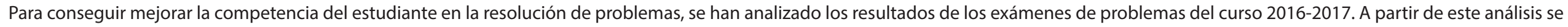

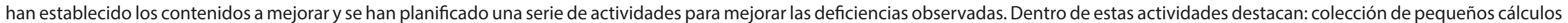

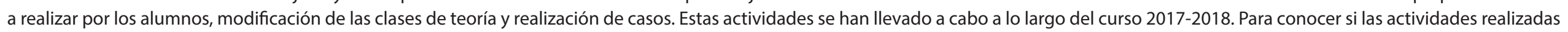

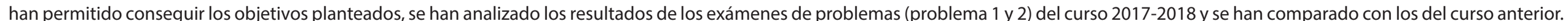

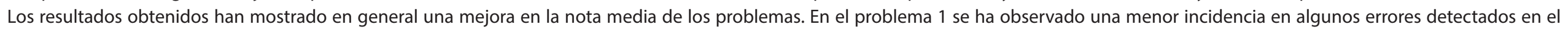

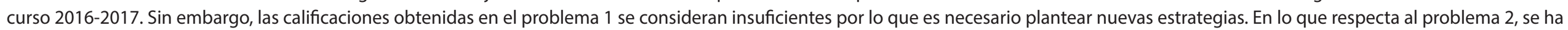

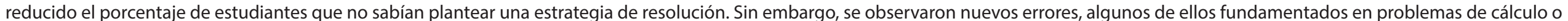

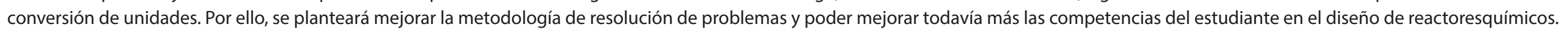




\section{Mejora de la competencia del estudiante para la resolución de problemas}

\section{Garcia Nieto, Lucia; Sebastián Cabeza, Victor}

Ingenieria Química y Tecnologias del Medio Ambiente, luciag@unizar.es

\section{Contexto académico:}

Titulación: Máster Universitario en Ingenieria Química

Curso: $1^{\circ}$

Asignatura: Diseño avanzado de reactores

Objetivos propuestos:

- Mejorar la competencia del estudiante en la resolución de problemas

- Obtener mejores calificaciones en los exámenes de problemas

- Facilitar la compresión de problemas técnicos y establecer metodologías de análisis para su correcta resolución

- Mejorar la satisfacción del estudiante con la asignatura y con la titulación.

Metodología: Mejora continua de la asignatura Análisis de resultados y de la metodología de trabajo

1. Análisis de resultados de los exámenes de problemas

2. Desarrollo de Contenidos a mejorar $\Rightarrow$ Propuesta de actividades (actuación sobre la metodología docente de la asignatura)

3. Análisis de los resultados de los exámenes de problemas del curso siguiente y valoración de las mejoras académicas adquiridas Herramientas: Estudio de Casos, Cálculos, Plataforma docente.

\section{Principales resultados:}

Problema 1

Problema 2
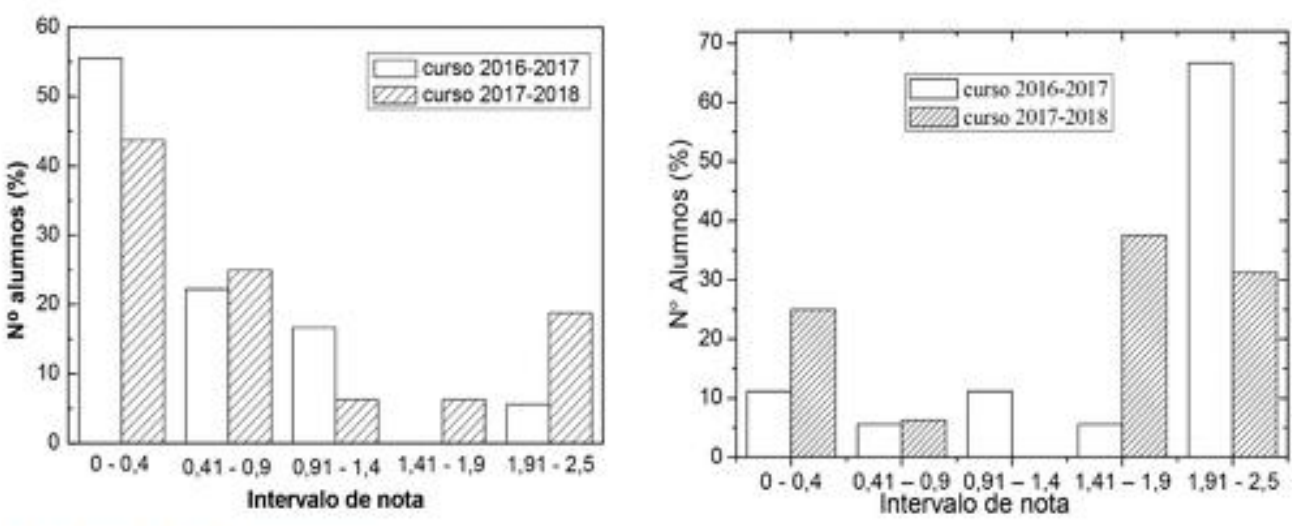

\section{Conclusiones:}

- Las actividades propuestas se consideran adecuadas, ya que se ha observado una mejora en la nota media del problema 1. Sin embargo, las calificaciones obtenidas se deben mejorar, ya que se observan nuevas carencias en el desarrollo del problema 2.

- Es necesario plantear nuevas estrategias de mejora. Se propone involucrar de manera más activa a los alumnos en su aprendizaje mediante la potenciación del trabajo continuado, así como fomentar la creatividad. 


\section{Participación activa del estudiante en el proceso de evaluación}

Luño Lázaro, V.; Martínez Asensio, F.; González Ortí, N.; Martí Jimenez, J. I.; del Niño Jesús García, A.; Gil Huerta, L.

\section{Palabras clave}

Coevaluación; Heteroevaluación; Rúbrica; Experiencia formativa

\section{Resumen}

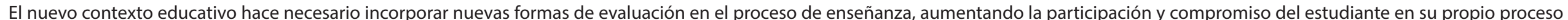

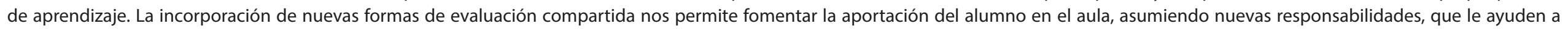

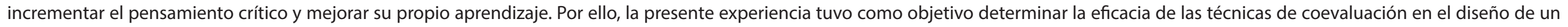
sistema de evaluación formativo y participativo.

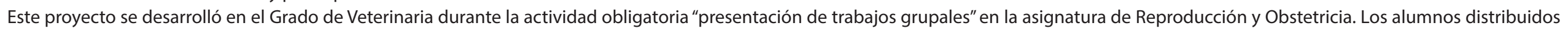

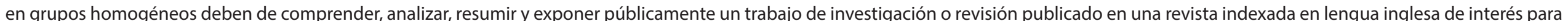

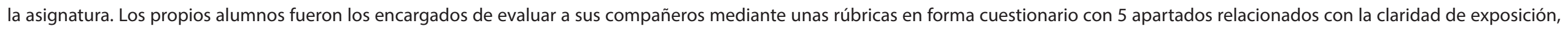

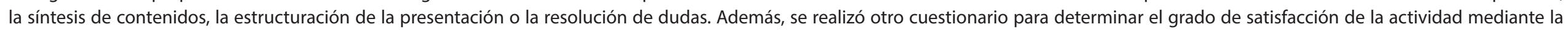
herramienta interactiva "Socrative".

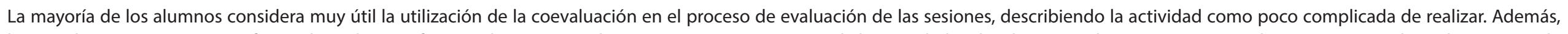

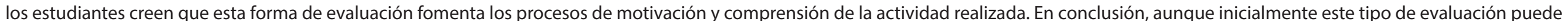

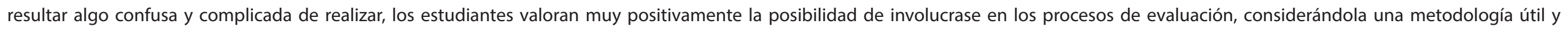
formativa que les ayuda en el proceso de aprendizaje. 


\section{Participación activa del estudiante en el proceso de evaluación}

\section{Victoria Luño, Felisa Martínez, Noelia Gonzálezz, José lgnacjo Mlarti, Antonjo del Niño, Lyolja GH}

Dpto Patologia Animal, Fac. Veterinaria, vicluno@unizar.es

\section{Contexto}

Asignatura de Reproducción y Obstetricia Grado de Veterinaria 2017/2018

\section{Objetivo}

Determinar la eficacia de la coevaluación

- ¿Más formativo y participativo?

¿ ¿Incrementa la calidad del aprendizaje?

\section{Metodología}

- Análisis, resumen y exposición de un trabajo indexado en lengua inglesa

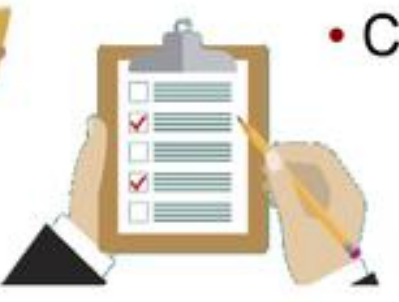

- Coevalución mediante rúbricas:

claridad de exposición síntesis de contenidos presentación resolución de dudas

\section{Resultados}

$96 \%$ de los alumnos participó en la experiencia Puntuaciones más bajas que la media de los profesores

A. ¿Te ha parecido útil la aplicación de la coevaluación?

B. ¿Ha sido complicada la evaluación de tus compañeros?

C. ¿Ha fomentado tu atención y compresión?

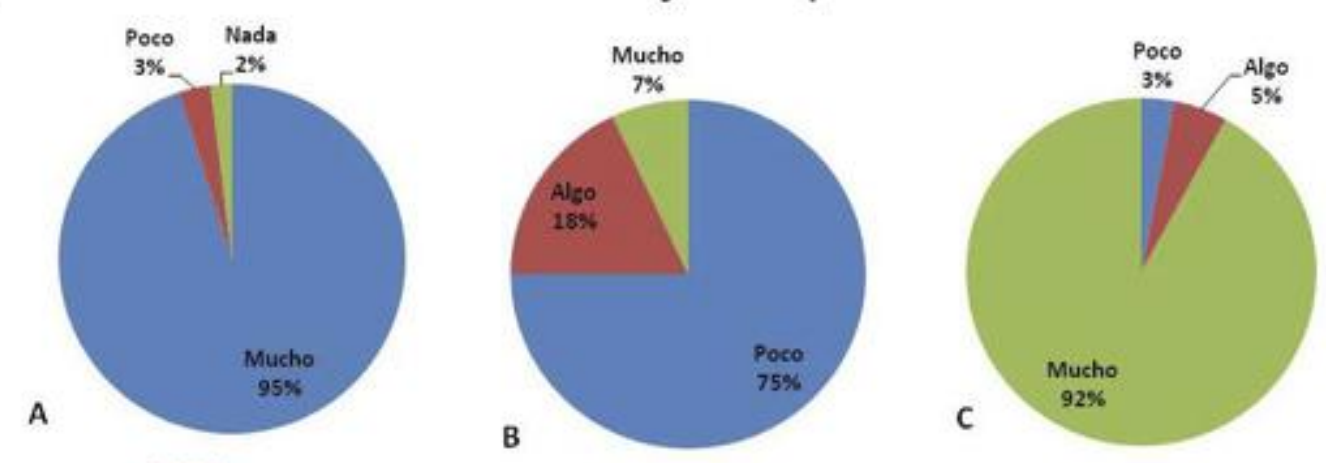

\section{Conclusiones}

- Es una metodología útil y formativa que mejora el proceso de aprendizaje

- Requiere mayor implicación por parte del estudiante y el profesorado 


\section{Percepción de los estudiantes del Grado en ADE acerca del trabajo en equipo}

Alda García, M.; Marco Sanjuán, I.; Muñoz Sánchez, F.; Vargas Magallón, M.; Vicente Reñé, R.

\section{Palabras clave}

Economía, empresa, encuestas, trabajo grupal.

\section{Resumen}

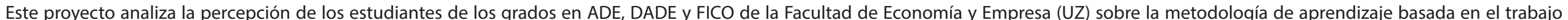

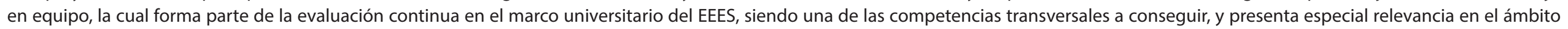
empresarial.

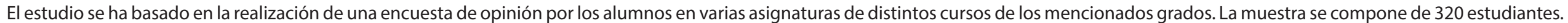

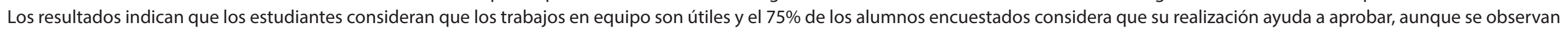
diferencias entre titulaciones (estudiantes de Derecho-ADE tienen la percepción de una menor utilidad que los estudiantes de ADE).

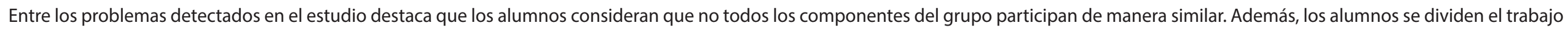

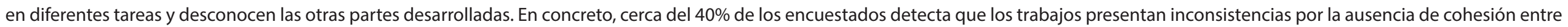

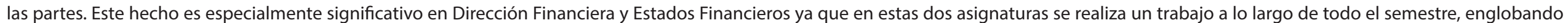
todos los contenidos de la materia.

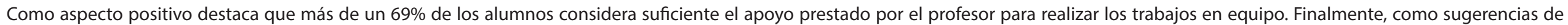
mejora se hace hincapié en la necesidad de evitar el solapamiento de fechas de entrega de trabajos de varias asignaturas o con otras pruebas de evaluación. 


\section{Percepción de los estudiantes del Grado en ADE acerca del trabajo en equipo}

\section{Mercedes Alda, Isabel Marco, Fernando Wuñoz, María Vargas, Ruth Vicente}

Departamento de Contabilidad y Finanzas, malda@unizar.es

- Contexto, objetivos y metodología:

- Estudio a través de encuestas de opinión sobre el trabajo en grupo como proceso de enseñanza-aprendizaje en la Facultad de Economía y Empresa, curso 17-18.

- Contexto y características de la muestra:

\begin{tabular}{|c|c|c|c|}
\hline Grados & Cursos & Asignaturas & $\mathbf{N}^{\circ}$ respuestas \\
\hline ADE & $4^{\circ}$ & Gestión de Tesorería & 26 \\
\hline ADE & $3^{\circ}$ & Dirección financiera & 70 \\
\hline ADE & $3^{\circ}$ & GRF & 121 \\
\hline ADE & $2^{\circ}$ & Estados Financieros & 23 \\
\hline ADE & $2^{\circ}$ & AVOF & 20 \\
\hline DADE & $3^{\circ}$ & AVOF & 43 \\
\hline FICO & $3^{\circ}$ & Gestión financiera & 17 \\
\hline \multirow{2}{*}{-Objetivos: } & & Total & 320 \\
\cline { 2 - 4 }
\end{tabular}

- Utilidad según los estudiantes de los trabajos en grupo.

-Analizar relaciones entre la labor y la calificación.

- Detectar problemas en el desarrollo de esta tarea.

- Metodología: encuestas de opinión

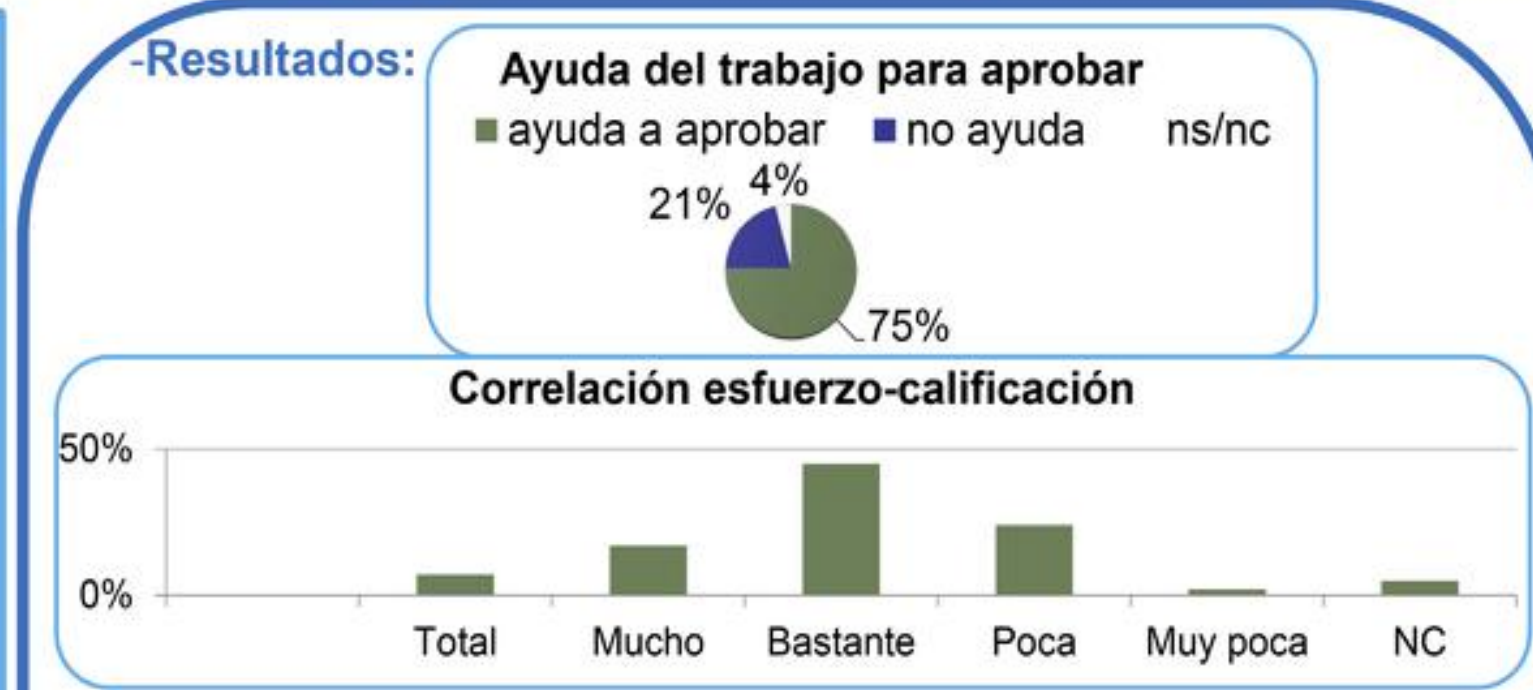

-Conclusiones:

- Los trabajos en grupo ayudan a aprobar ( $75 \%$ encuestados).

- Menor utilidad en: Derecho-ADE.

- $\mathrm{N}^{0}$ idóneo de participantes: 3-4 personas/grupo.

* Problemas:

* No todos los componentes participan de manera similar. $\star 40 \%$ de los encuestados detecta inconsistencias.

* Solo algunos alumnos revisan el trabajo por completo.

$>$ Positivo: Apoyo del profesor.

$\square$ Deficiencias a mejorar: Evitar solapamiento fechas entrega. 


\section{Seguimiento y mejora de la metodología de CoEvaluación (CE) en las actividades calificativas de la asignatura Expresión Gráfica y Diseño Asistido por Ordenador (EGDAO)}

Cilla Hernández, M.; Pueo Arteta, M.; Guillén Lambea, S.; Sierra Pérez, J.

\section{Palabras clave}

Engineering education, evaluation methods, student participation

\section{Resumen}

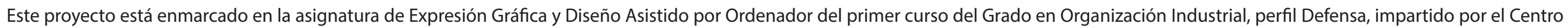

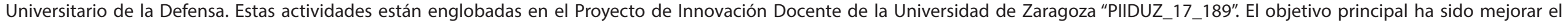
aprendizaje del estudiante mediante el uso de rúbricas, que le obliga a adoptar un roll más activo, facilitando la tarea del profesorado.

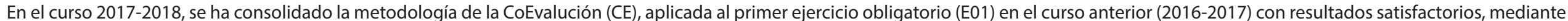

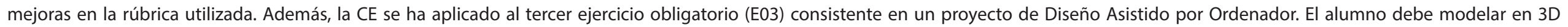

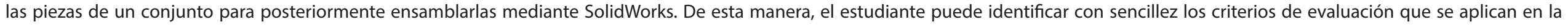
asignatura y por lo tanto tener más claros los puntos importantes del aprendizaje.

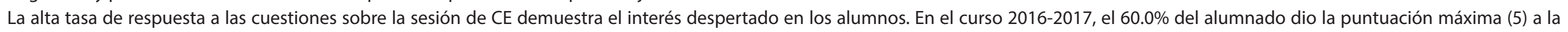

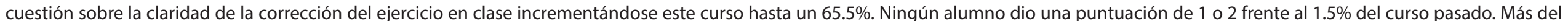
$90 \%$ del alumnado considera que el uso de la rúbrica ayudó mucho (5) o bastante (4) a identificar sus errores para poder mejorar en futuros ejercicios.

Estos resultados permiten concluir que se han alcanzado los objetivos, una mejora del aprendizaje de los aspectos más importantes en la realización de un dibujo técnico. 
Seguimiento y mejora de la metodología de CoEvaluación (CE) en las actividades calificativas de la asignatura Expresión Gráfica y Diseño Asistido por Ordenador (EGDAO)

\section{Myriam Cilla, Marcos Pueo, Silvia Guillén, Jorge Sierra}

\section{Contexto}

Centro Universitario de la Defensa de Zaragoza, mcilla@unizar.es

El presente trabajo es el resultado del proyecto de innovación docente llevado a cabo en la asignatura de Expresión Gráfica y Diseño Asistido por Ordenador (EGDAO), impartida en $1^{\circ}$ del Grado de Ingeniería de Organización Industrial en el Centro Universitario de la Defensa durante el curso 2017-2018.

\section{Objetivos}

- Mejorar el aprendizaje del alumno, desarrollando su madurez y responsabilidad.

- Implicarlo en su evaluación de manera activa.

- Facilitar la tarea del profesorado.

- Aumentar la motivación del alumnado en la asignatura.

\section{Metodología}

292 alumnos curso $2016-2017$

303 alumnos curso 2017-2018.
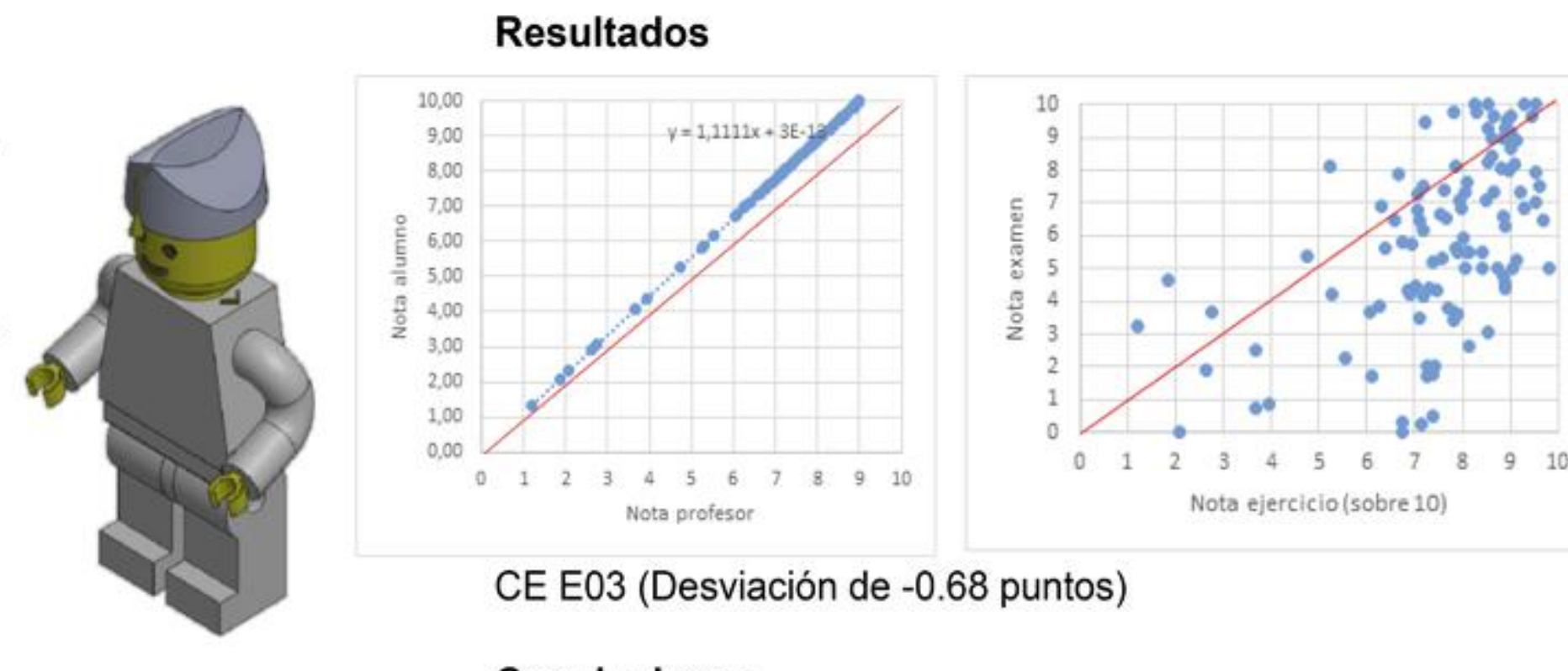

CE E03 (Desviación de -0.68 puntos)

\section{Conclusiones}
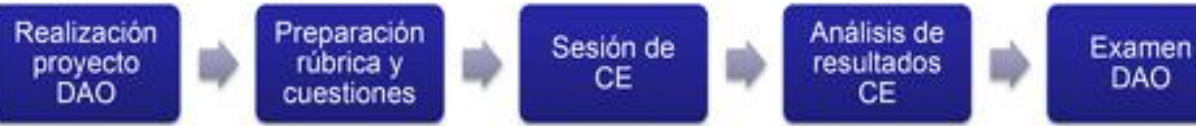

Análisis

El $90.3 \%$ del alumnado considera que el uso de la rúbrica ayudó mucho (5) o bastante (4) a identificar sus errores para poder mejorar en futuros ejercicios. 



\section{III \\ Experiencias de mejora de la calidad de las titulaciones}




\section{III.Experiencias de mejora de la calidad de las titulaciones}

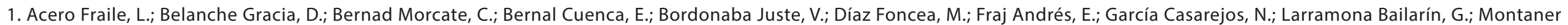
Guriérrez, T.; Pessoa de Oliveira, A.

Aprendizaje-Servicio en la Facultad de Economía y Empresa de Zaragoza: "Universitarios Unidos por la Formación Popular"

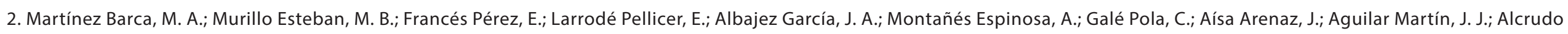

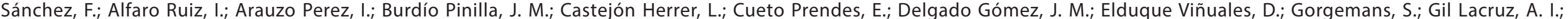

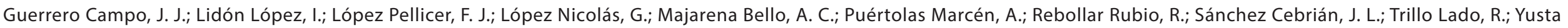
Loyo, J.M.

Análisis estratégico del master universitario de ingeniería industrial en la universidad de Zaragoza

3. Esteban Sánchez, A. L.; Embid López, M. S.; Remacha Andrés, M.

Autoevaluar para mejorar

4. Acero Fraile, I.; Hernández Ortega, B.; Melguizo Garde, M.

Desarrollo de actividades para la adquisición de competencias en la Facultad de Economía y Empresa durante el curso 2017-18

5. Vallés Brau J. A.; Remón Martín L.; Ares García J.; Collados Collados M. V.; Elia Guedea N.; López de la Fuente C.; Marcellán Vidosa M. C.; Perchés Barrena S.; Segura Calvo F. J. Encuesta online sobre la formación posterior, actividad profesional y adecuación del perfil de egreso de los titulados en Óptica y Optometría

6. Dejo-Oricain, N.; García-Cebrián, L.; Pastor-Agustín, G.

¿La participación activa en clase mejora el proceso de aprendizaje del estudiante?

7. Bustamate, J. C.; Fernández-Turrado, T.

Mejoras en los procesos de coordinación docente en Magisterio en Educación Infantil y Magisterio en Educación Primaria de la Facultad de Educación

8. Allueva Torres, P., Nuño Pérez, J., Escolano Pérez, E., Herrero Nivela, M. L.

Metodologías Docentes en los Grados en Magisterio en Educación Infantil y Primaria en la Facultad de Educación de la Universidad de Zaragoza

9. Abecia Martínez, B.; Casalod Lozano, Y.; Bernal Agudo, J. L.; Martínez Jarreta, B.

Módulo de e-learning "EMUTOM", plataformas de pacientes virtuales y blended learning: recursos de innovación docente que logran un cambio positivo y significativo en la actitud de los estudiantes de Medicina hacia la Medicina del Trabajo 


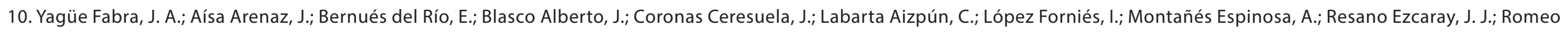
Giménez, L. M.; Romeo Tello, A.; Royo Vázquez, E.; Trillo Lado, R.

Sistematización para ayudar a la coordinación en la adquisición de competencias transversales

11. Pedraja Iglesias, M.; Marzo Navarro, M.

Valoración de los egresados del grado en Marketing e Investigación de Mercados 


\section{Aprendizaje-Servicio en la Facultad de Economía y Empresa de Zaragoza: "Universitarios Unidos por la Formación Popular"}

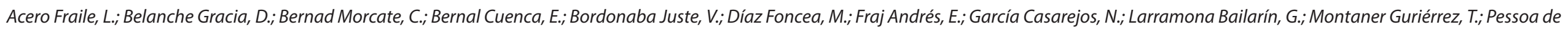
Oliveira, $A$.

\section{Palabras clave}

ApS, formación, entidad social, prácticas.

\section{Resumen}

Contexto:

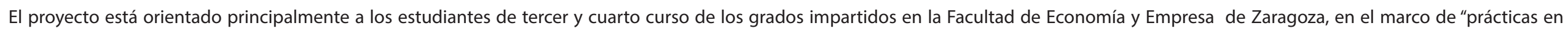
empresa'

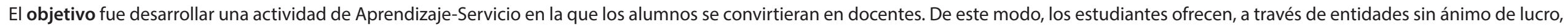
formación sobre materias estudiadas en sus grados a colectivos desfavorecidoso sin formación económico empresarial.

Metodología:

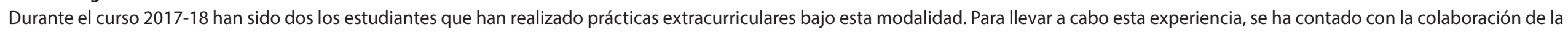

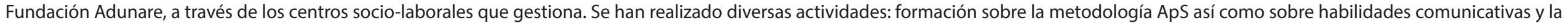
elaboración de entrevistas y encuestas; seminario sobre elección de temas; visitas a la entidad social; preparación de los temas y presentaciones; evaluación de la actividad.

Para evaluar la experiencia desarrollada se prepararon unos breves cuestionarios.

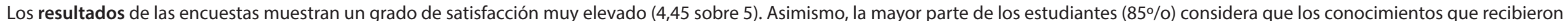
les serán muy útiles en un futuro y el $75 \%$ de los asistentes afirma que sí que recomendarían esta actividad (no hay ningún asistente que indique que no la recomendaría).

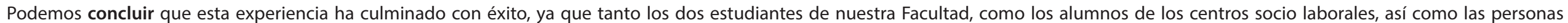
responsables de la Fundación Adunare han mostrado un elevado grado de satisfacción con esta experiencia pionera en la Facultad. 


\section{Aprendizaje-Servicio en la Facultad de Economía y Empresa de Zaragoza: "Universitarios Unidos por la Formación Popular" \\ Isabel Acero, Daniel Belanche, Cristina Bernad, Estrella Bernal, Victoria Bordonaba, Millán Díaz, Elena Fraj, Nieves García, Gemma Larramona, Teresa Montaner, Ana Pessoa \\ Facultad de Economía y Empresa de Zaragoza, iacero@unizar.es}

Contexto: Estudiantes $3^{\circ}$ y $4^{\circ}$ titulaciones Facultad Economía y Empresa Zaragoza. Modalidad "practicas en empresa".

Objetivo: Desarrollo de actividad ApS: estudiantes convertidos en docentes $\rightarrow$ centros socio-laborales Fundación Adunare.

Metodología:

Habilidades comunicativas cuestionarios

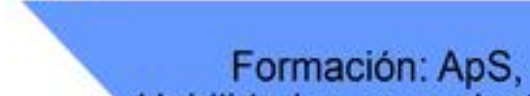

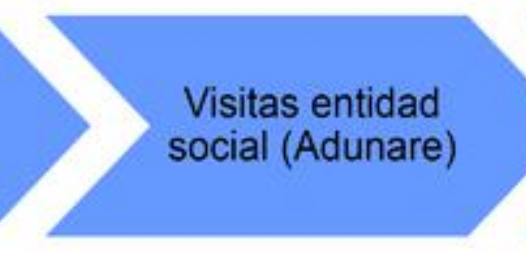

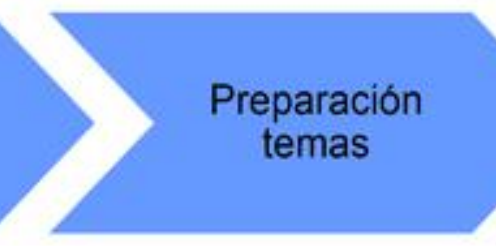

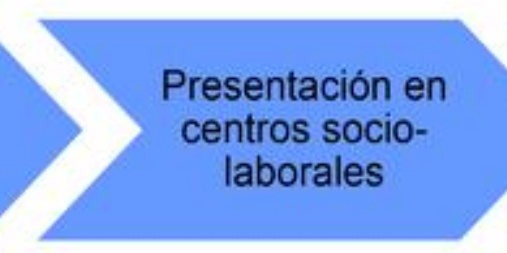
laborales

\section{Conclusiones:}

$\checkmark$ Alta satisfacción de todos los agentes implicados.

$\checkmark 75 \%$ asistentes recomendaría esta actividad (ninguno no la recomendaria)
Satisfacción

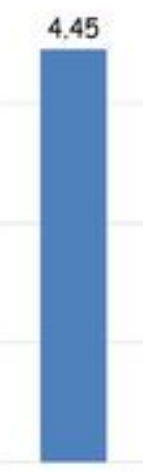

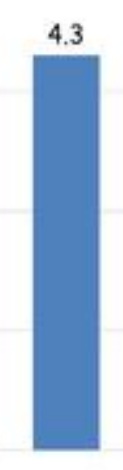

Interés Economia

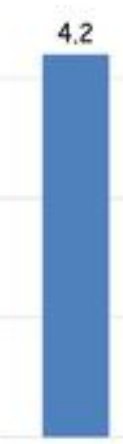

Amenidad Economía
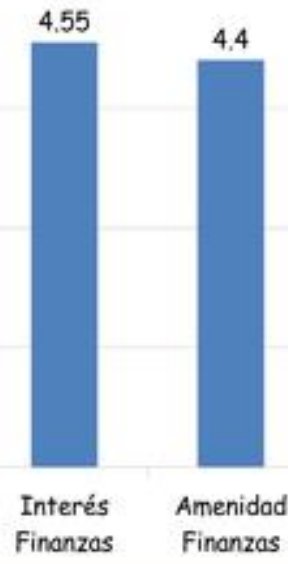

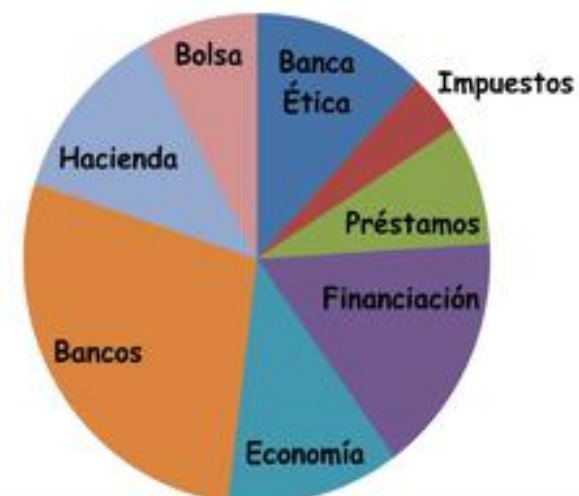

Evaluación de la experiencia

\section{…"in Universidad \\ Iin Zaragoza}

a

$\checkmark$ TFG

$\checkmark$ Consultoría Social Empresarial 


\section{Análisis estratégico del master universitario de ingeniería industrial en la universidad de Zaragoza}

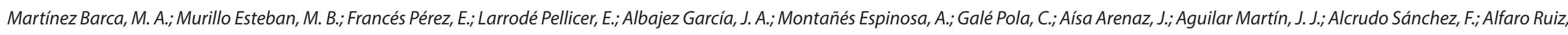

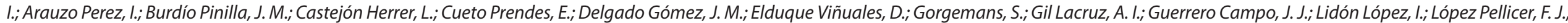
López Nicolás, G.; Majarena Bello, A. C.; Puértolas Marcén, A.; Rebollar Rubio, R.; Sánchez Cebrián, J. L.; Trillo Lado, R.; Yusta Loyo, J. M.

\section{Palabras clave}

Ingeniería Industrial, análisis estratégico titulaciones, profesión ingeniería industrial, mejora continua másteres universitarios.

\section{Resumen}

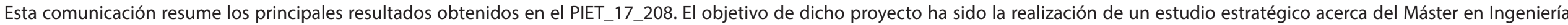

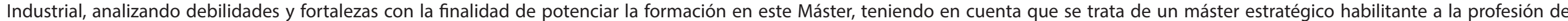
Ingeniero Industrial.

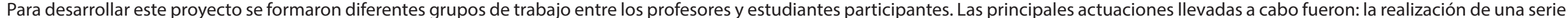

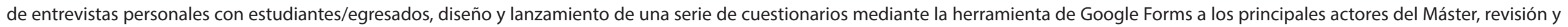

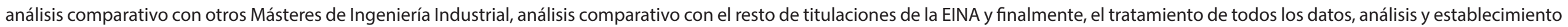
de líneas generales de mejora.

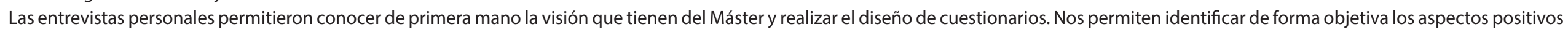

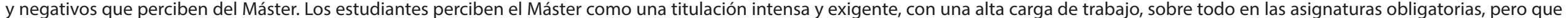

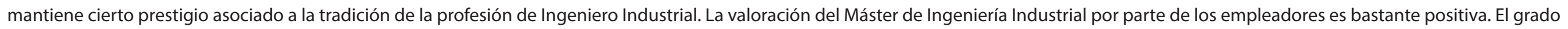
de satisfacción con los egresados del (96\% Alta o Muy Alta).

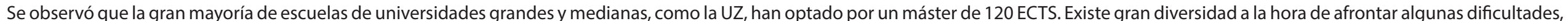
como es el acceso desde grados diferentes como GITI o los grados especialistas.

Agradecimientos al Vicerrectorado de Política Académica por la concesión del PIIDUZ_17_208. 


\section{ANALISIS ESTRATEGIO DEL MASTER UNIVERSITARIO DE INGENIERIA INDUSTRIAL EN LA UNIVERSIDAD DE ZARAGOZA}

M.A. Martínez, M. B. Murillo. E. Francés, E. Larrodé, J.A. Albajez, A. Milontañés, C. Galé, J. Aísa, J.J. Aguilar, F. Alcrudo, I Alfaro, I. Arauzo, J.M. Burdio, L. Castejón, E. Cueto, J.M. Delgado, D. Elduque, S. Georgemans, A. I. Gil, J.J. Guerrero, I. Lidón, F. J. López, G. López, A.C. Majarena, A. Puértolas, R. Rebollar, J.L Sánchez, R. Trillo, J.M. Yusta,

Escuela de Ingenieria y Arquitectura, miguelam@unizar.es

\section{SITUACION}

Master Ingenieria Industrial: Master 120 ECTS carácter profesionalizante

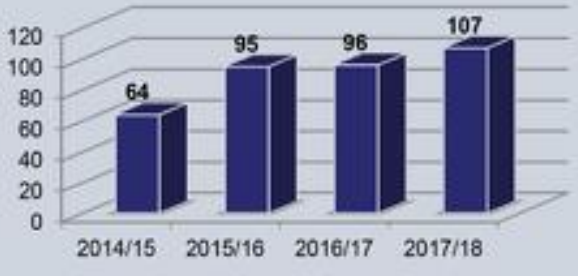

Evolución Matrícula

\section{OBJETIVOS}

- Análisis estratégico situación MUIIND después de 4 promociones

- Criterios selección Máster por parte estudiantes Grados

- Evaluación grado satisfacción estudiantes

- Establecimiento posibles Tineas mejora continua

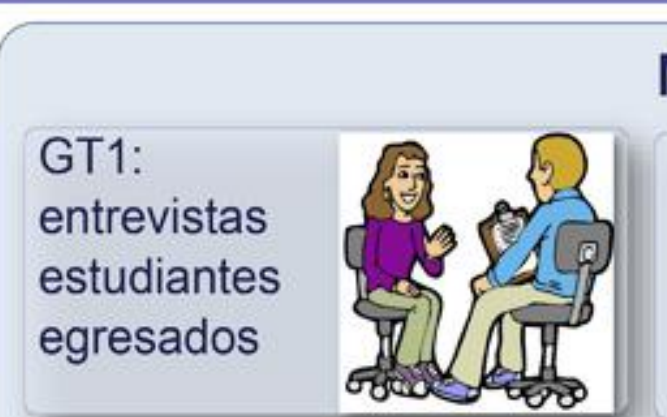

GT4: Revisión

planes

estudios otras

Univ.
METODOLOGÍA

GT2: Diseño cuestionarios Google Forms estudiantes

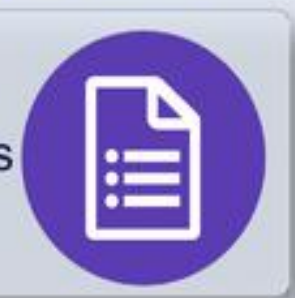

GT5: Análisis compara. otr másteres EINA

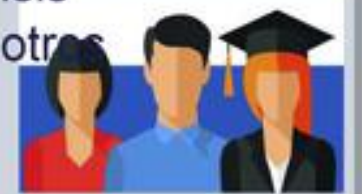

GT3: Diseño cuestionarios Google Forms empleadores

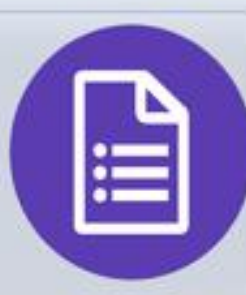

GT5: Tratamiento datos, conclusiones, líneas futuras

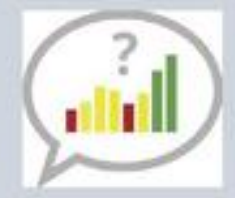

\section{RESULTADOS Y CONCLUSIONES}

Estudiantes

Master intenso

Alto prestigio

Alta flexibilidad

$2^{\circ}$ año Erasmus

× Carácter muy generalista

x Repetición contenidos

x Gran salto de $4^{\circ}$ Grado a $1^{\circ}$ Máster

\section{Empleadores}

$96 \%$ Satisfacción Alta/Muy

Alta egresados MUIIND

$92 \%$ diferencian titulación Grado/Master

MUIIND: Muy Alta empleabilidad

Interés en colaborar con la Universidad
Otras Universidades Grandes escuelas: 120 ECTS

Situación Máster similar en mayoría escuelas Diversidad soluciones grados especialistas/GITI UZ-EINA alto nivel optatividad 


\section{Autoevaluar para mejorar}

Esteban Sánchez, A. L.; Embid López, M. S.; Remacha Andrés, M.

\section{Palabras clave}

Competencia digital, autoevaluación, DigComp, docente, rúbricas.

\section{Resumen}

\section{Contexto académico:}

La experiencia se desarrolla con el profesorado de todos los Grados y cursos de la Escuela Universitaria Politécnica de La Almunia (EUPLA)

Objetivos:

La difusión del instrumento de evaluación de la Competencia Digital Docente, creado por el Instituto Nacional de Tecnologías Educativas y de

Formación del Profesorado (INTEF), y su implantación en la EUPLA como un servicio de autoevaluación.

\section{Metodología:}

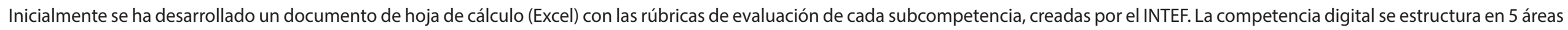

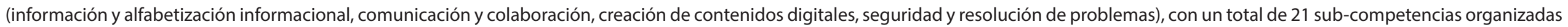

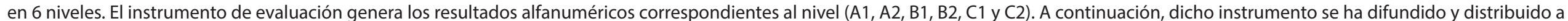

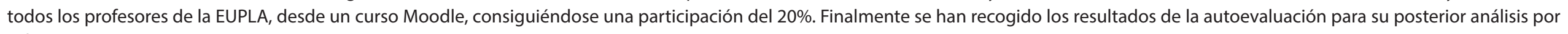
subcompetencia y por área.

Resultados:

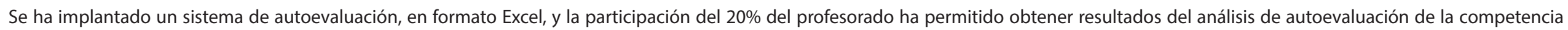
digital docente, generalizada a nivel de áreas y puntualizada a nivel de subcompetencias.

\section{Conclusiones:}

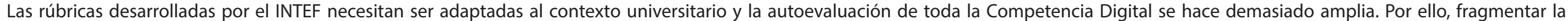

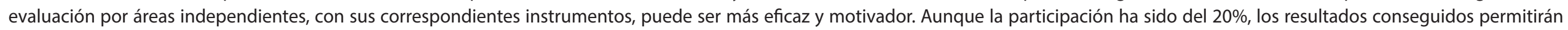
iniciar el diseño de planes de mejora en las Competencias Digitales. 


\section{Autoevaluar para mejorar}

\section{Ana Lucía Esteban, Sagrario Embid, Mónica Remacha}

EUPLA, anaeste@unizar.es, msembid@unizar.es, monicare@unizar.es

\section{Objetivos:}

1. Difundir el "Marco Común de Competencia Digital Docente"

2. Crear y utilizar una herramienta de autoevaluación

3. Analizar el nivel de Competencia Digital de los participantes

Contexto: EUPLA, profesores voluntarios de Arquitectura Técnica e Ingenierías Civil, Mecatrónica y Organización Industrial.

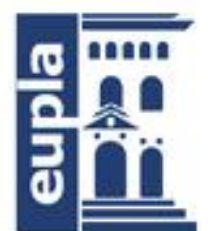

\section{Metodología:}

Marco Común Competencia Digital Docente INTEF-2017

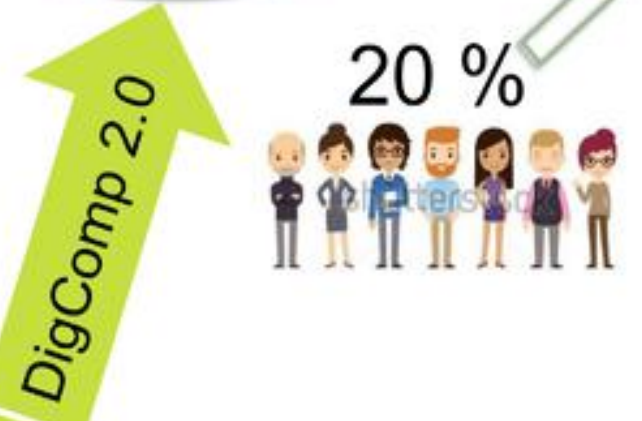

Rúbricas autoevaluación

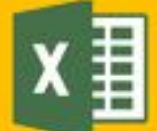

MICROSOFT EXCE

\section{Conclusiones:}

- Adaptación contexto universitario

- Evaluación áreas independientes

- Buena aceptación (20\%)

- Base para diseñar planes de mejora en Competencias Digitales

\section{Resultados:}
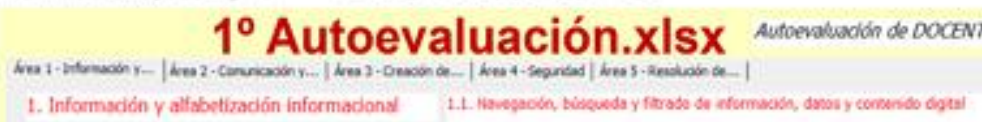
$4|22| x \mid$

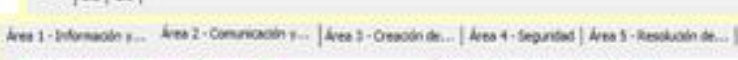

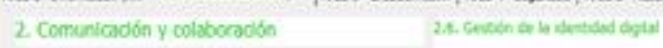

$2 t|22| 22|24| 25 \quad 26 \mid$

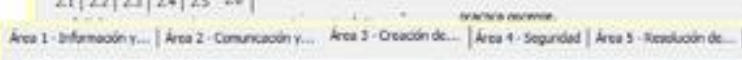

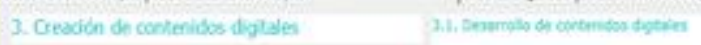

$2 \pi|2 x| 23|14|$

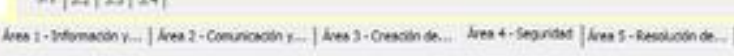

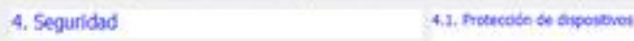

4 4. $|42|<3|44|$

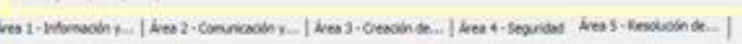

5. Resabiodin de Jecoleman

$21 \mid 12]=3150 \mid$
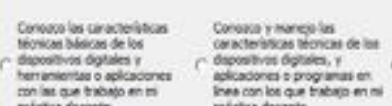

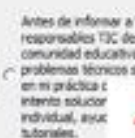

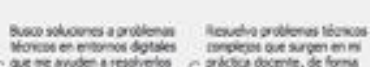

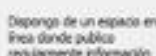
on $2^{\circ}$ Resultados de nivel por áreas
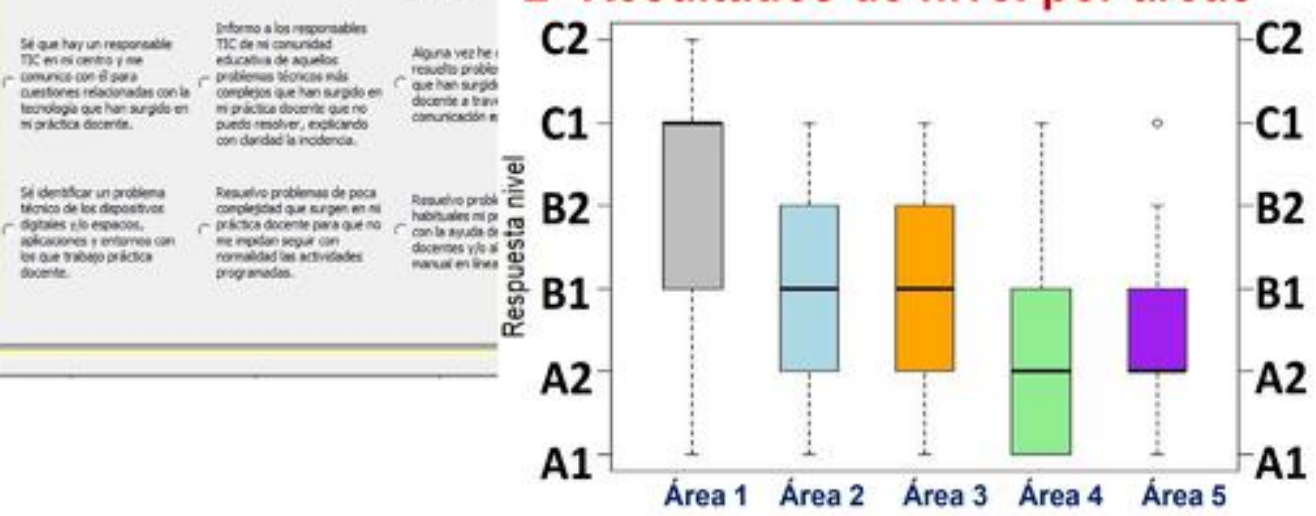

\section{풀 Universidad} III Zaragoza 


\section{Desarrollo de actividades para la adquisición de competencias en la Facultad de Economía y Empresa durante el curso 2017-18}

Acero Fraile, I.; Hernández Ortega, B.; Melguizo Garde, M.

\section{Palabras clave}

Comunicación efectiva, habilidades en las relaciones interpersonales, jornada de salidas profesionales, oratoria.

\section{Resumen}

Contexto:

El proyecto analiza la adquisición de competencias transversales en actividades complementadas desarrolladas en la Facultad de Economía y Empresa de Zaragoza.

El objetivo fue fomentar la formación en competencias transversales en los estudiantes de nuestra Facultad.

Metodología:

Durante el curso 2017-18 se desarrollaron dos actividades:

1. Curso "La Articulación de la Palabra. Curso avanzado en la formación de la palabra verbalizada;

2. Jornada de Salidas Profesionales para el Economista.

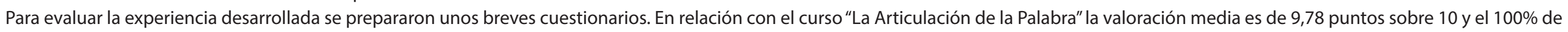

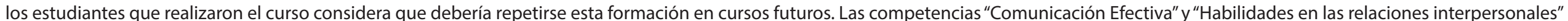

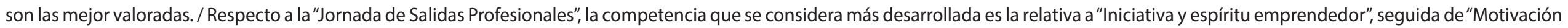

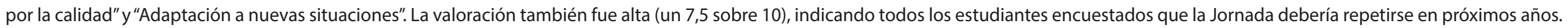

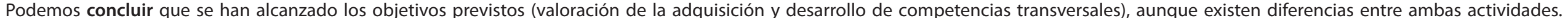

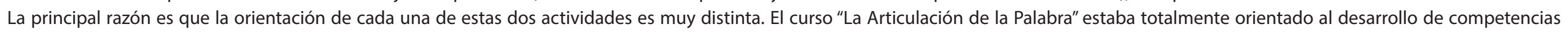
transversales relacionadas con la comunicación, mientras que el objetivo de la Jornada de Salidas Profesionales es principalmente acercar el mundo empresarial a nuestros estudiantes. 
Desarrollo de actividades para la adquisición de competencias en la Facultad de Economía y Empresa durante el curso 2017-2018

\author{
Isabel Acero, Blanca Hernández, Marta Melguizo
}

Facultad de Economia y Empresa, iacero@unizar.es)

CONTEXTO: FEE: desarrollo de actividades complementarias para el desarrollo de competencias transversales (Grados: ADE-ADEi, ECO, FICO, MIM, DADE).

OBJETIVO: Fomentar formación en competencias transversales en los estudiantes de la Facultad de Economía y Empresa.

METODOLOgÍA: Actividades organizadas: 1) Curso "La Articulación de la Palabra. Curso avanzado en la formación de la palabra verbalizada; 2) Jornada de Salidas Profesionales para el Economista.

RESULLTADOS: Curso "Articulación de la Palabra"

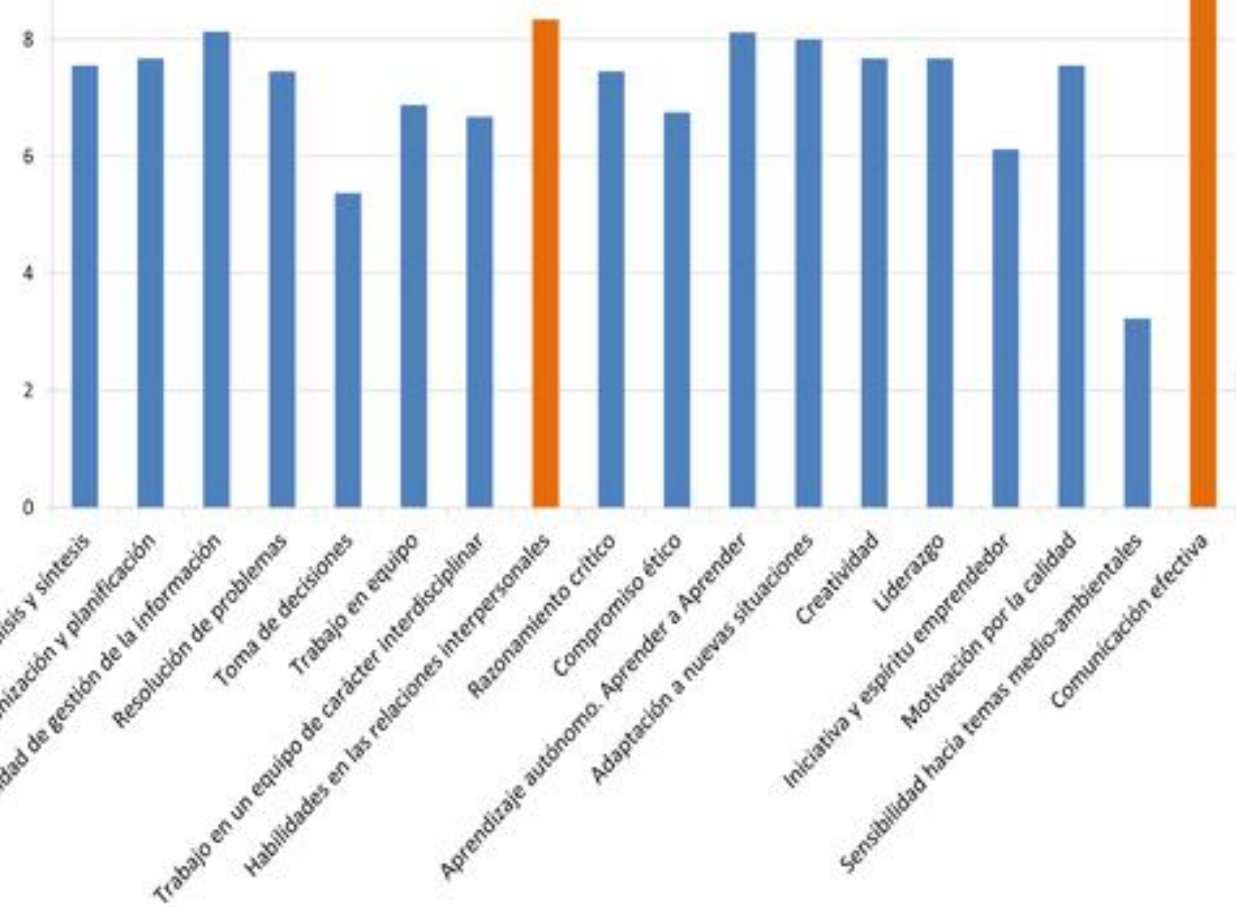

Jornada Salidas Profesionales

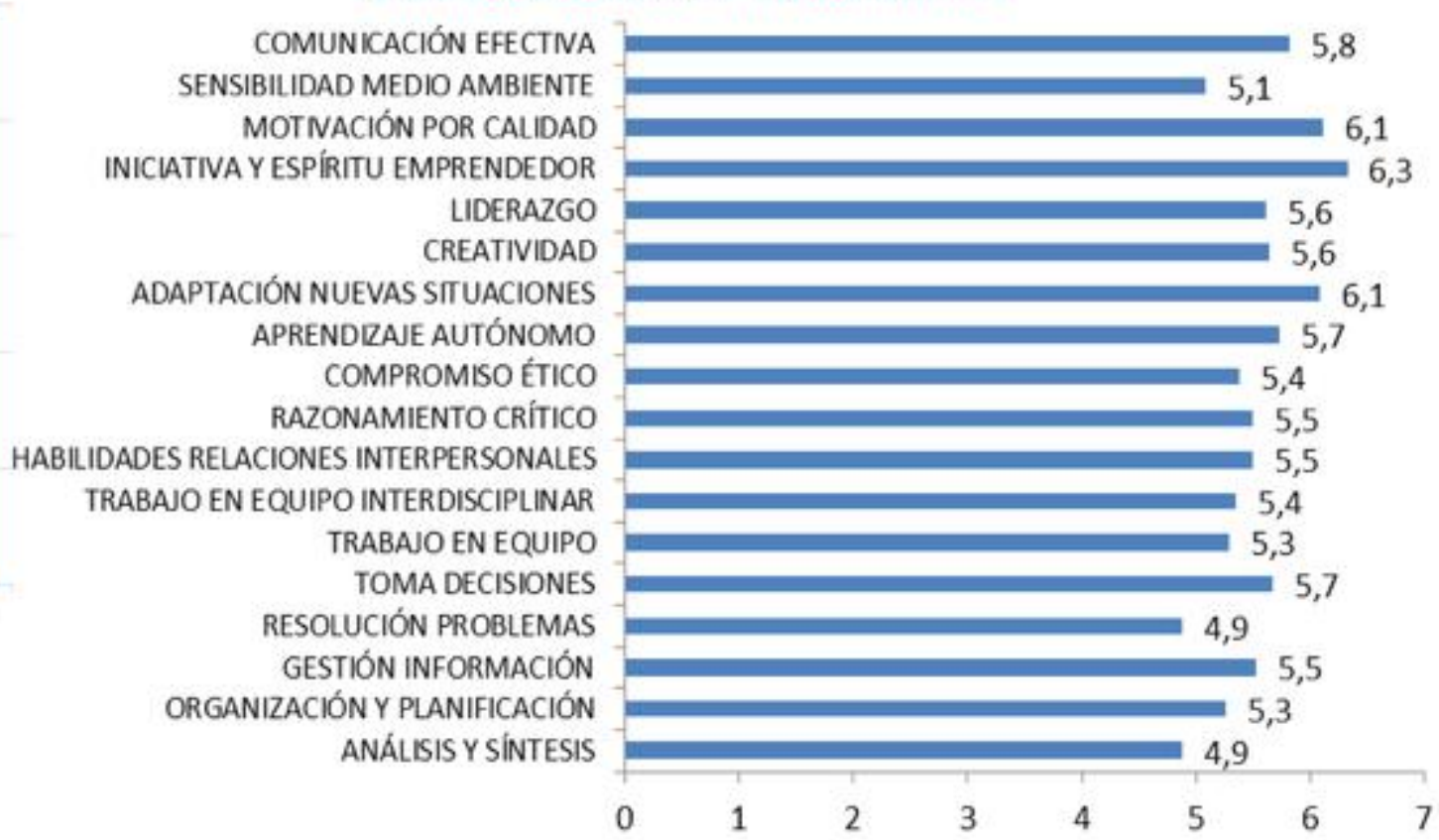

CONCLUSIONES: Objetivos alcanzados: evaluación adquisición competencias transversales. 


\section{Encuesta online sobre la formación posterior, actividad profesional y adecuación del perfil de egreso de los titulados en Óptica y Optometría}

Vallés Brau, J. A.; Remón Martín, L.; Ares García, J.; Collados Collados, M. V.; Elia Guedea, N.; López de la Fuente, C.; Marcellán Vidosa, M. C.; Perchés Barrena, S.; Segura Calvo, F. J.

\section{Palabras clave}

Calidad de la Educación, evaluación del currículo, empleo del estudiante.

\section{Resumen}

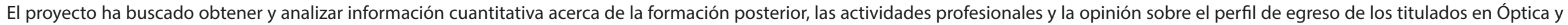

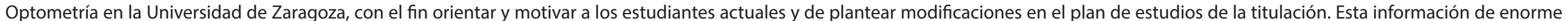
interés no se encuentra a disposición de las titulaciones en la actualidad.

Se elaboró una encuesta en Google Formularios (una aplicación de Google Drive) subdividida en 4 bloques:

- Información General,

- Formación Complementaria,

- Inserción Laboral y

- Satisfacción con la formación recibida en la Universidad de Zaragoza. Google Formularios ofrece una gran versatilidad en la configuración de la encuesta y además realiza un primer análisis estadístico de las respuestas. La encuesta se mantuvo abierta durante 4 meses y su existencia se difundió a través de las redes sociales.

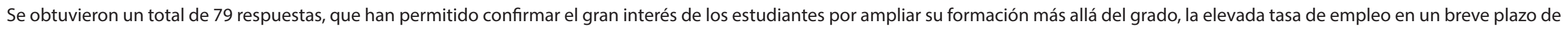
tiempo desde la finalización de sus estudios, el elevado grado de satisfacción con la formación recibida. También ha permitido identificar puntos débiles u omisiones en el plan de estudios.

Las preguntas de respuesta abierta proporcionan una información asimismo muy útil, aunque con mayor dificultad de sistematización

El proyecto es sostenible, fácilmente transferible a otras titulaciones y su verdadero impacto se medirá al utilizar sus resultados para plantear mejoras en el plan de estudios de la titulación. 


\section{Encuesta online sobre la formación posterior, actividad profesional y}

adecuación del perfil de egreso de los titulados en Óptica y Optometría

Juan A. Vallés, Laura Remón, Jorge Ares, María V. Collados, Noemi Elia, Carmen López, Maria C. Marcellán, Sara Perchés, Francisco J. Segura

Departamento de Física Aplicada, juanval@unizar.es

Objetivo: obtención y análisis de información cuantitativa acerca de la formación posterior y las actividades profesionales desarrolladas por los titulados en Óptica y Optometría y su opinión sobre la adecuación del perfil de egreso.

Metodología: se elaboró una encuesta en Google Formularios, aplicación de Google Drive que ofrece una gran versatilidad y realiza un primer análisis estadístico de las respuestas.
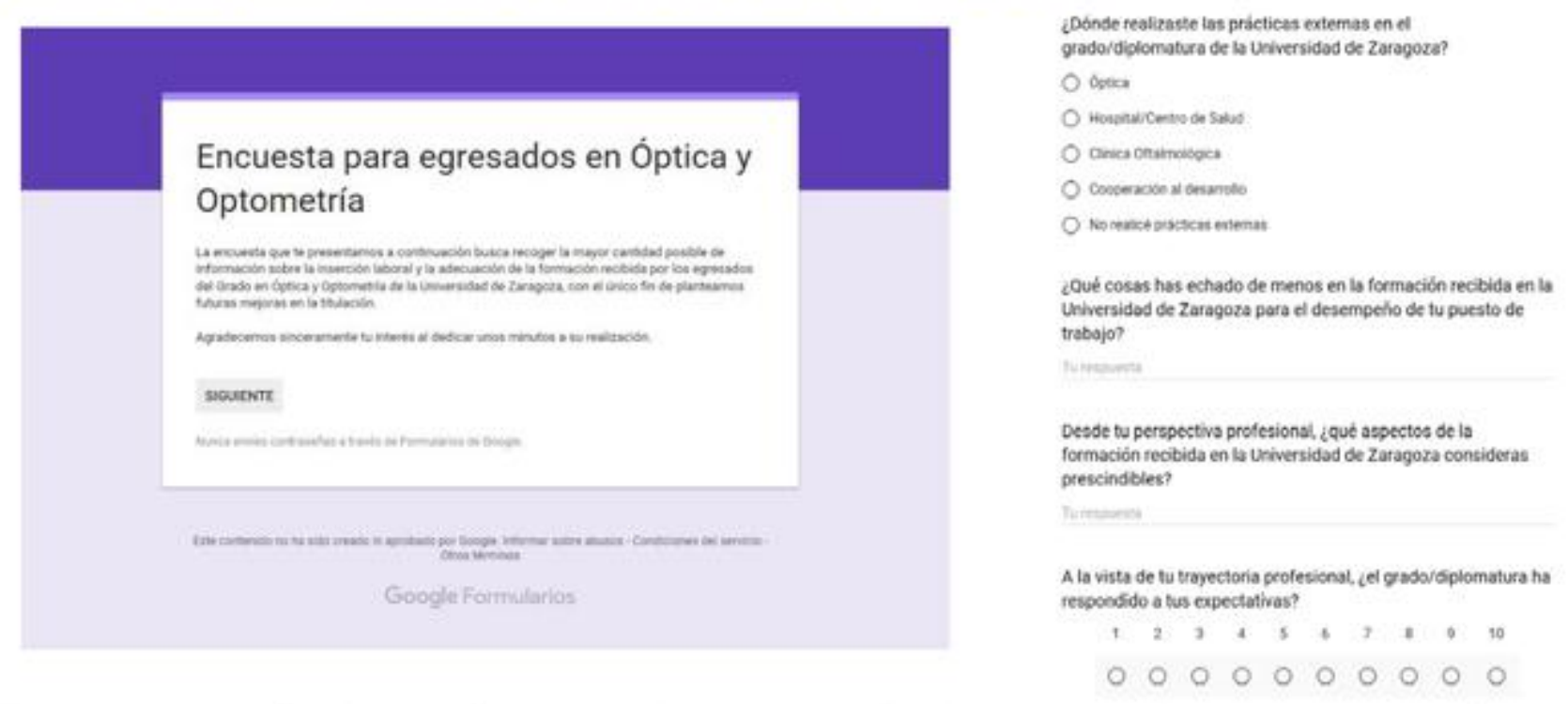
Puntos débiles de la formación recibida

Resultados: Se ha confirmado el gran interés de los estudiantes por ampliar su formación, la elevada tasa de empleo en un breve plazo de tiempo, el elevado grado de satisfacción con la formación recibida. También ha permitido identificar puntos débiles u omisiones en el plan de estudios

Conclusiones: Se ha obtenido una gran cantidad de información. El proyecto es sostenible, fácilmente transferible a otras titulaciones y su verdadero impacto se medirá al plantear mejoras en el plan de estudios de la titulación. 


\section{¿ La participación activa en clase mejora el proceso de aprendizaje del estudiante ?}

Dejo-Oricain, N.; García-Cebrián, L.; Pastor-Agustín, G.

\section{Palabras clave}

Actividades, calificaciones, examen, voluntarias.

\section{Resumen}

El proyecto surge de la percepción por parte de los profesores de la baja participación de los alumnos en actividades de clase.

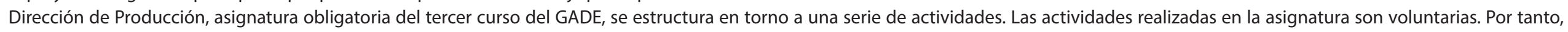

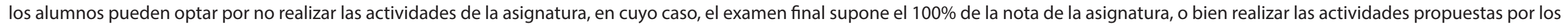
profesores, en cuyo caso el examen supone el $50 \%$ de la nota final de la asignatura y el resto de la calificación corresponde a las actividades.

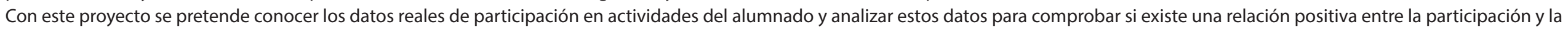
nota en el examen. En caso de que haya relación positiva se comunicará a los alumnos con objeto de motivarles para que participen más en clase.

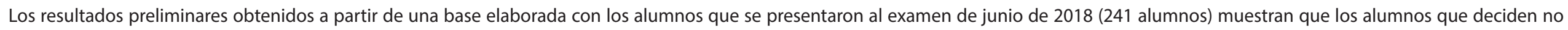

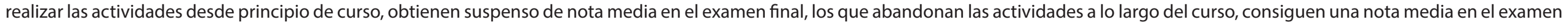
de casi aprobado (4,8). Los alumnos que completan las actividades tienen un aprobado de nota media en el examen.

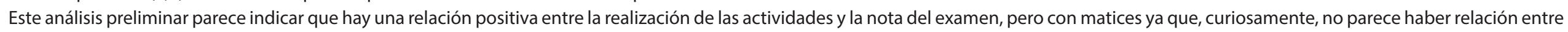
una buena calificación en actividades y buena calificación en el examen. El trabajo se completará con las notas de los estudiantes que se presenten a la convocatoria de septiembre 2018. 
¿La participación activa en clase mejora el proceso de aprendizaje del estudiante?

\section{Natalia Dejo-Oricain, Lucía García-Cebrián, Gema Pastor-Agustín}

Departamento de Dirección y Organización de Empresas, ndejo@unizar.es

\begin{tabular}{|c|c|c|c|c|}
\hline $\begin{array}{l}\text { Motivación: incentivar } \\
\text { que los alumnos } \\
\text { participen en las }\end{array}$ & \multirow{2}{*}{\multicolumn{2}{|c|}{$\begin{array}{l}\text { CONTEXTO: DIRECCIÓN DE LA PRODUCCIÓN } \\
\text { (Asignatura Obligatoria } 3^{\circ} \text { GADE). } \\
\text { Estudio realizado en el marco del PIIDUZ 17_010 } \\
\text { OBJETIVO: ¿Relación positiva entre la participación } \\
\text { en actividades de clase y la nota del examen? }\end{array}$}} & \multirow{2}{*}{\multicolumn{2}{|c|}{$\begin{array}{l}\text { METODOLOGÍA: Base de datos con } \\
\text { muestra de } 241 \text { alumnos presentados } \\
\text { al examen de la asignatura en junio } \\
\text { 2018. Análisis Excel preliminar. }\end{array}$}} \\
\hline $\begin{array}{l}\text { actividades voluntarias } \\
\text { de clase }\end{array}$ & & & & \\
\hline \multicolumn{2}{|c|}{ Resultados } & \multicolumn{2}{|c|}{$\begin{array}{l}\text { Nota media del examen } \\
\text { final }\end{array}$} & $\begin{array}{l}\text { Los alumnos que } \\
\text { realizan actividades }\end{array}$ \\
\hline \multicolumn{2}{|c|}{ Una minoria (12\%) decide no realizar las actividades desde un principio } & SUSPENSO 4,3 & & suelen aprobar el \\
\hline \multicolumn{2}{|c|}{ Una minoría algo mayor (14\%) abandona las actividades durante el curso } & $\begin{array}{l}\text { CASI APROBADO } \\
4,8\end{array}$ & & $\begin{array}{l}\text { Pero curiosamente los } \\
\text { que mejores notas }\end{array}$ \\
\hline \multicolumn{2}{|c|}{ El resto de los estudiantes $(74 \%)$ completa las actividades } & APROBADO 5,3 & & $\begin{array}{l}\text { actividades, no obtienen } \\
\text { mejor nota media en el }\end{array}$ \\
\hline \multicolumn{2}{|c|}{$\begin{array}{l}\text { Los estudiantes con SUSPENSO de nota media en las tres entregas } \\
\text { parciales del informe }\end{array}$} & SUSPENSO 4,7 & & $\begin{array}{l}\text { examen. Este análisis } \\
\text { preliminar se } \\
\text { combletará con los }\end{array}$ \\
\hline \multicolumn{2}{|c|}{$\begin{array}{l}\text { Los estudiantes con NOTABLE de nota media en las tres entregas parciales } \\
\qquad \text { del informe }\end{array}$} & APROBADO 5,5 & & $\begin{array}{l}\text { datos de las notas de } \\
\text { septiembre de } 2018 \text {. }\end{array}$ \\
\hline \multicolumn{2}{|c|}{$\begin{array}{l}\text { Curiosamente, los de nota media SOBRESALIENTE en las tres entregas } \\
\text { parciales consiguen menos nota media en el examen que los de Notable }\end{array}$} & APROBADO 5,2 & & $\begin{array}{l}\text { agradece el apoyo del grupo de } \\
\text { tigación COMPETE S52_17R-DGA }\end{array}$ \\
\hline
\end{tabular}




\section{Mejoras en los procesos de coordinación docente en Magisterio en Educación Infantil y Magisterio en Educación Primaria de la Facultad de Educación}

Bustamate, J. C.; Fernández-Turrado, T.

\section{Palabras clave}

Calidad, organización docente, plan de actuación.

\section{Resumen}

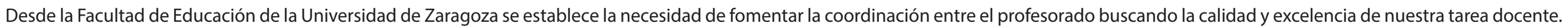
Para ello es necesario concretar las funciones que tiene el "coordinador de asignatura". Así, la eficacia de esta figura pasa por la clarificación de sus funciones y por dar mayor entidad a dicho rol.

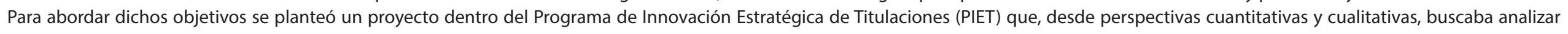

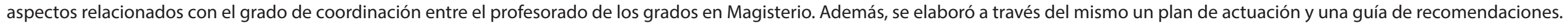

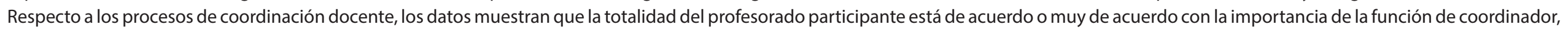

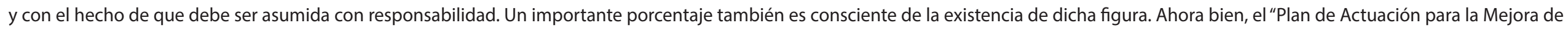

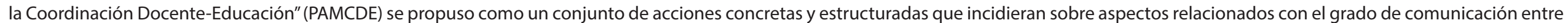

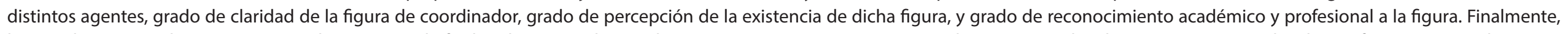

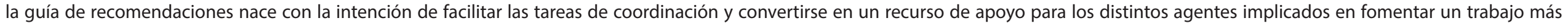
coordinado.

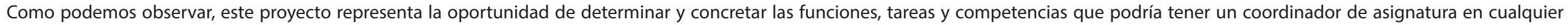
titulación y centro. 


\section{Metodologías Docentes en los Grados en Magisterio en Educación Infantil y Primaria en la Facultad de Educación de la Universidad de Zaragoza}

Allueva Torres, P.; Nuño Pérez, J.; Escolano Pérez, E.; Herrero Nivela, M. L.

\section{Palabras clave}

Educación Infantil, educación primaria, metodología, proceso de enseñanza-aprendizaje, formación docente.

\section{Resumen}

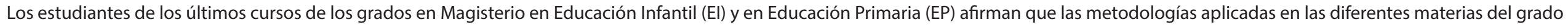
no son, en general, las más adecuadas para el proceso de enseñanza-aprendizaje ni para su formación como futurosdocentes.

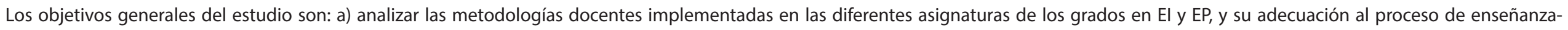

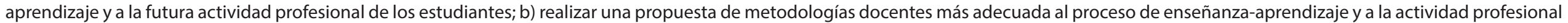
que deberán desarrollar los futuros graduados en El y EP.

La muestra estuvo compuesta por 200 participantes de un total de 416 estudiantes de $4^{\circ}$ curso de los grados en El y EP.

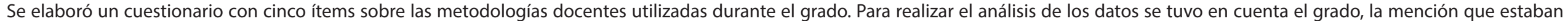

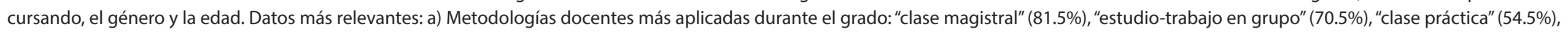

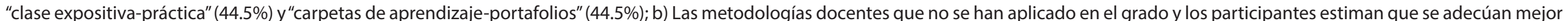

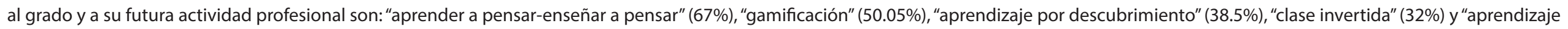
basado en proyectos"(29.5\%).

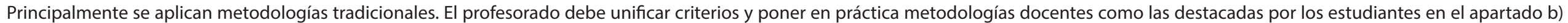
del párrafo anterior, adaptándolas a la materia, a las características personales y necesidades competenciales de los estudiantes. 


\section{Metodologías Docentes en los Grados en Magisterio en Educación Infantil y Primaria en la Facultad de Educación de la Universidad de Zaragoza Pedro Allueva, Javier Nuño, Elena Escolano, Maria Luisa Herrero \\ Departamento de Psicología y Sociologia, Universidad de Zaragoza, pallueva@unizar.es}

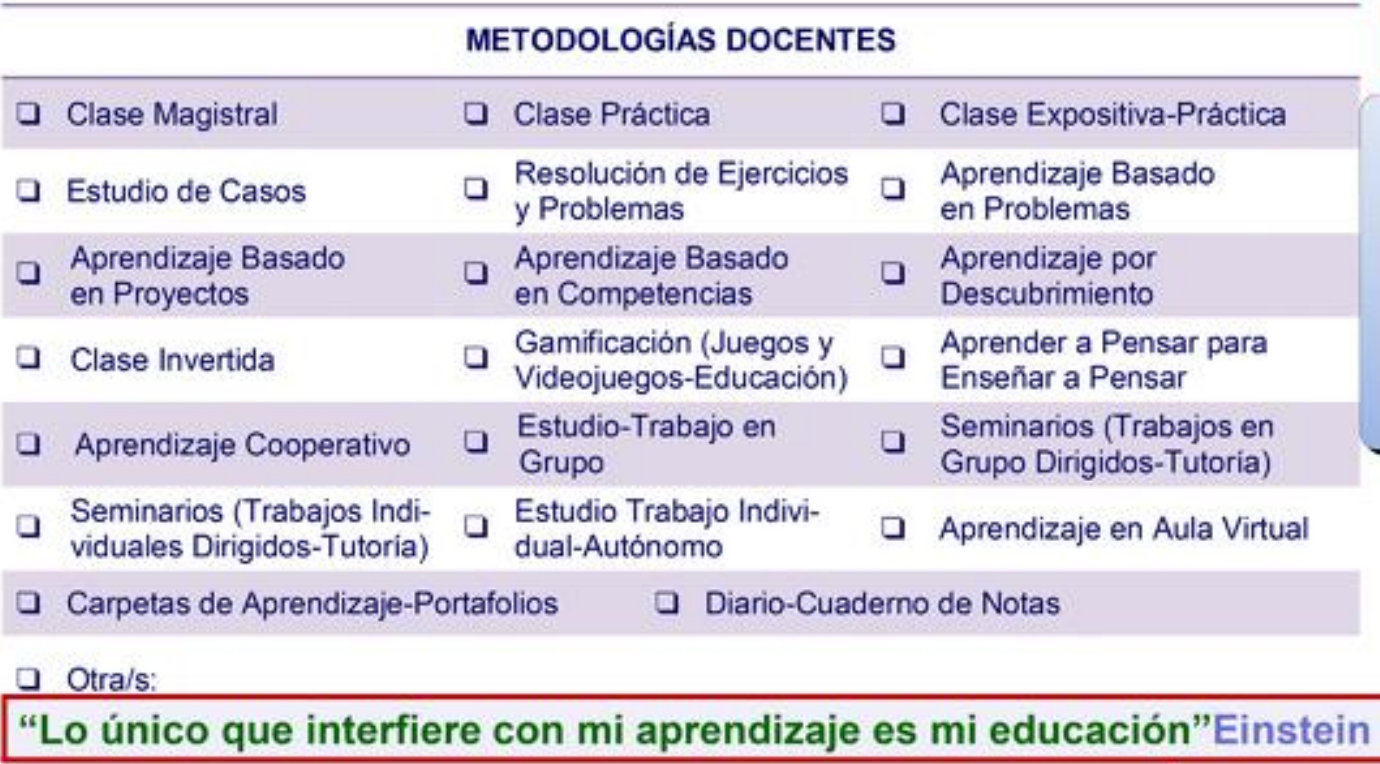

\section{Conclusiones}

1- En general, se aplican metodologías tradicionales.

2- No son las más adecuadas para el proceso de enseñanza-aprendizaje de los estudiantes, ni para desarrollar las competencias profesionales.

3- El profesorado debemos unificar criterios y poner en práctica metodologías docentes adaptadas a la Materia, a los Estudiantes y a su aplicación futura como Educadores.

Muestra: $4^{\circ}$ Curso, Grados en El y EP $\mathrm{N}=416 ; n=200$

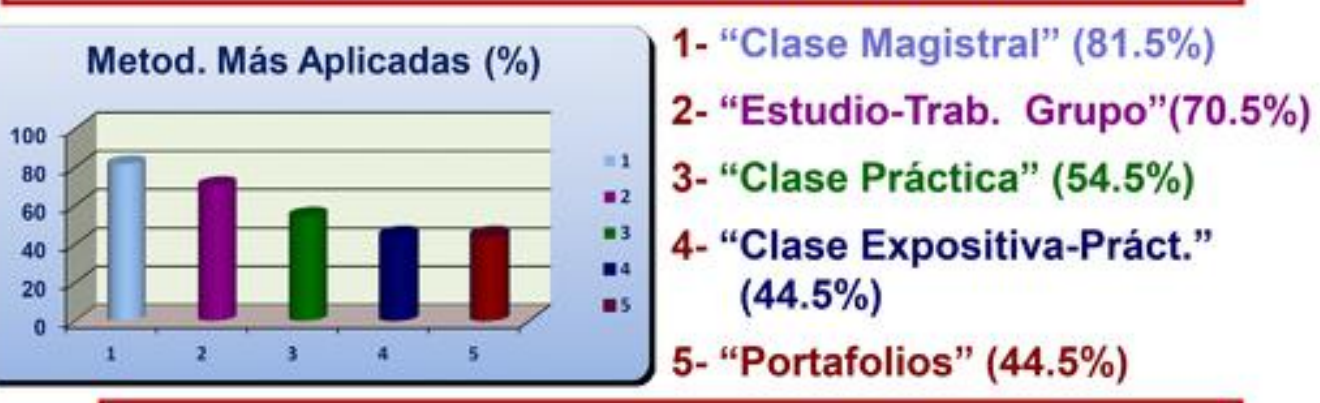

5- "Portafolios" (44.5\%)
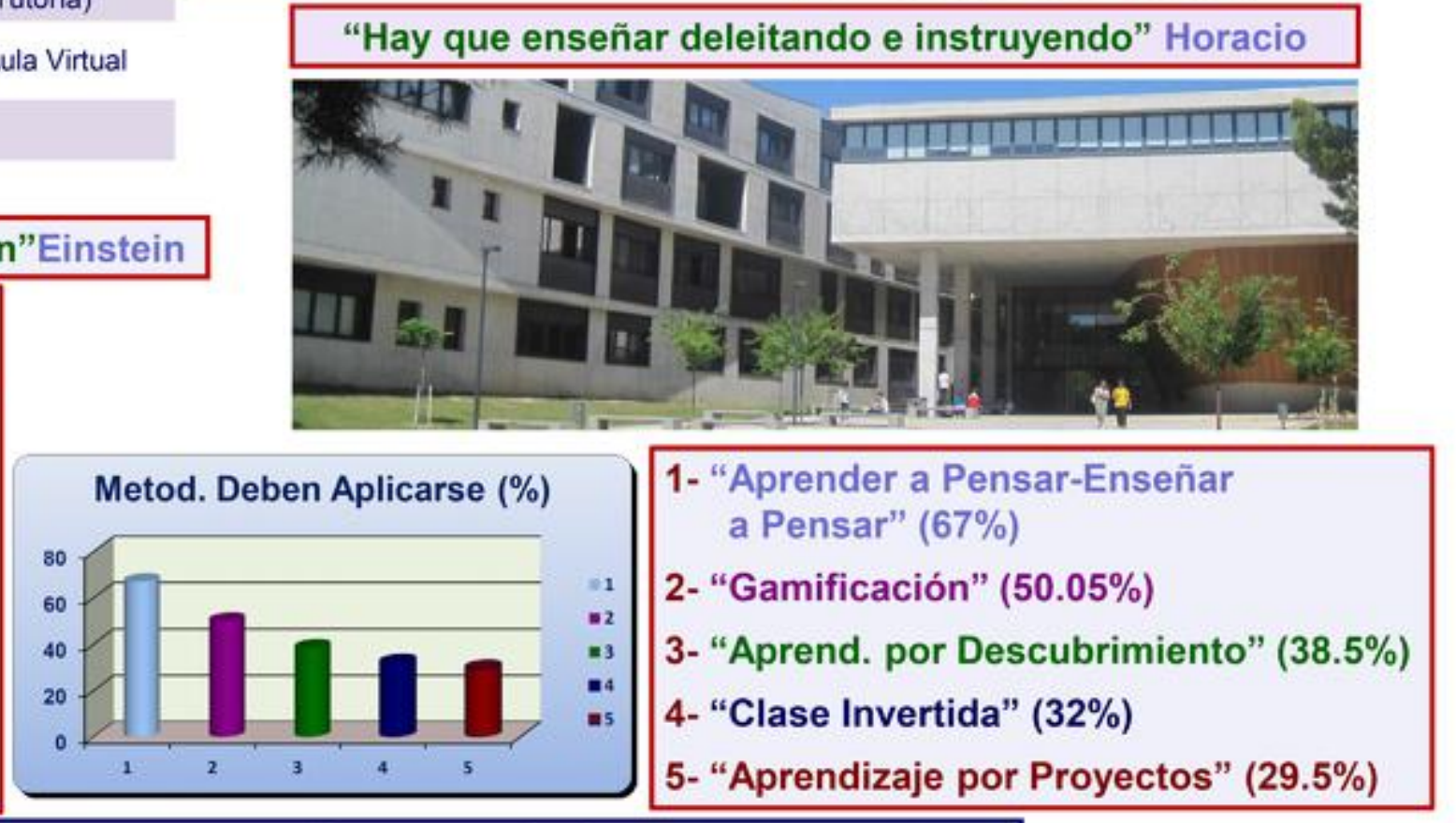

5- "Aprendizaje por Proyectos" (29.5\%)

"Es más importante saber pensar, que tener muchos conocimientos" (Allueva, 2011)

Univiversidad Im Zaragoza
XII Jornadas de Innovación Docente e Investigación Educativa - 2018 


\section{Módulo de e-learning "EMUTOM", plataformas de pacientes virtuales y blended learning: recursos de innovación docente que logran un cambio positivo y significativo en la actitud de los estudiantes de Medicina hacia la Medicina del Trabajo}

Abecia Martínez, B.; Casalod Lozano, Y.; Bernal Agudo, J. L.; Martínez Jarreta, B.

\section{Palabras clave}

Blended learning, medicina del trabajo, innovación docente, satisfacción, evaluación.

\section{Resumen}

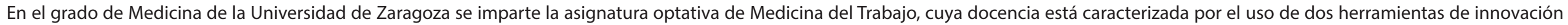
docente (el módulo e-learning EMUTOM y la plataforma de pacientes virtuales o Casus, generada por tres distintos Proyectos Europeos) y seguir un formato blended learning.

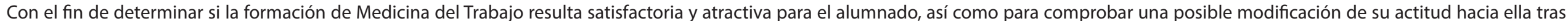

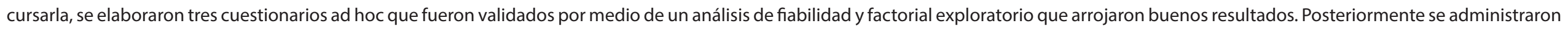
a los estudiantes durante cuatro cursos académicos (2014-2015,2015-2016, 2016- 2017 y 2017-2018) ( $\mathrm{n}=627)$.

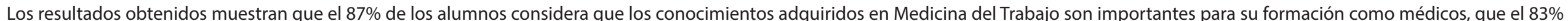

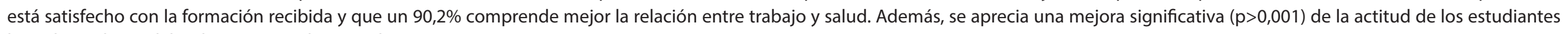
hacia la Medicina del Trabajo antes y después de cursar esta materia.

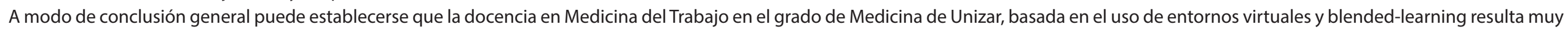
satisfactoria para los futuros médicos y contribuye a cambiar positivamente su actitud hacia esta especialidad. 
Módulo de e-learning "EMUTOM", plataformas de pacientes virtuales y blended learning. Recursos de innovación docente que logran un cambio positivo y significativo en la actitud de los estudiantes de Medicina hacia la Medicina del Trabajo Begoña Abecia, Yolanda Casalod, José Luis Bernal, Begoña Martínez-Jarreta Dept AP, Medicina Legal y Forense y Toxicologia y Grupo GIIS-063 del IIS de Aragón. 682454@unizar.es

Contexto Académico: Grado de Medicina (cursos: 2014-2015,2015-2016, 2016-2017 y 2017-2018). Medicina del Trabajo.

Objetivo: Determinar si la formación en Medicina del Trabajo basada en el uso de recursos de innovación docente (módulo de elearning EMUTOM, sistema Casus o plataforma online de pacientes virtuales para aprendizaje basado en la resolución de problemas y blended-learning) resulta satisfactoria y atractiva para los estudiantes de Medicina y puede ayudar a mejorar su actitud hacia esta especialidad.

Metodología: La docencia de la materia Medicina del Trabajo en la Facultad de Medicina de Zaragoza se llevó a cabo por medio de blended learning y utilizando una plataforma de pacientes virtuales generada por dos Proyectos Europeos, así como un módulo elearning fruto asimismo de otro Proyecto Europeo. Para valorar la satisfacción de los alumnos con la formación recibida y con el uso de estas herramientas se elaboraron tres cuestionarios ad hoc, uno de ellos destinado a evaluar un posible cambio de actitud hacia la Medicina del Trabajo tras la impartición de la docencia. Los cuestionarios se validaron por medio de análisis de fiabilidad y factorial exploratorio, previamente a su administración a los alumnos durante cuatro cursos académicos consecutivos (2014-2018) ( $n=627)$.

Principales resultados:

- El $87 \%$ del alumnado consideró que los conocimientos adquiridos en Medicina del Trabajo son importantes para su formación como médicos.

- El 83\% manifestó estar satisfecho con la formación recibida.

- El $90,2 \%$ comprendió mejor la relación trabajo y salud.

- Se aprecií una mejora significativa $(p>0,001)$ de la actitud hacia la Medicina del Trabajo entre los estudiantes, antes y después de cursar la materia.

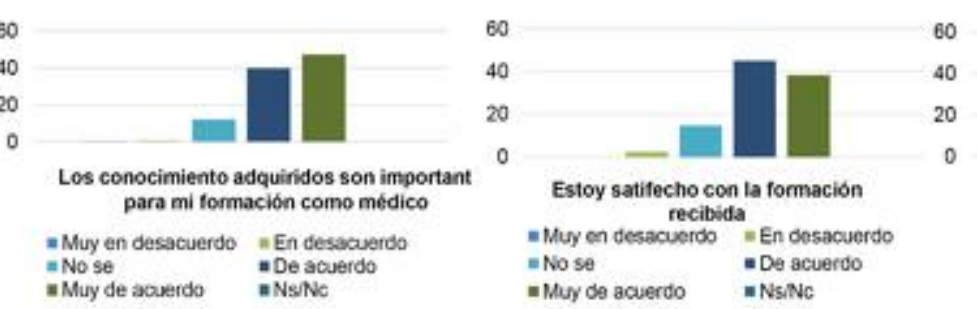

Conclusiones: La docencia en Medicina del Trabajo en el grado de Medicina de Unizar, basada en el uso de entornos virtuales y blendedlearning resulta muy satisfactoria para los futuros médicos $y$ contribuye a cambiar positivamente su actitud hacia esta especialidad. 


\section{Sistematización para ayudar a la coordinación en la adquisición de competencias transversales}

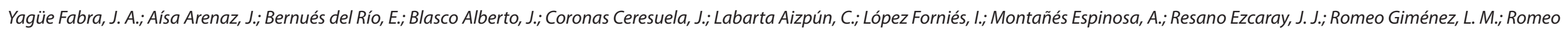
Tello, A.; Royo Vázquez, E.; Trillo Lado, $R$.

\section{Palabras clave}

Planificación, niveles, elementos, evaluación.

\section{Resumen}

Contexto:

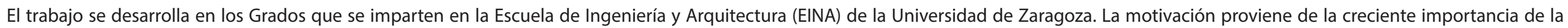

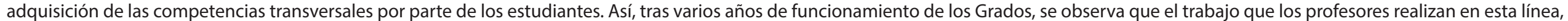
en general, puede completarse con una mayor planificación global.

Objetivos:

El presente trabajo persigue la planificación de la adquisición de las competencias transversales en las titulaciones de Grado en la EINA.

\section{Método:}

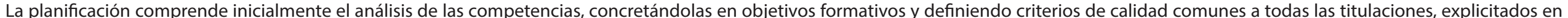

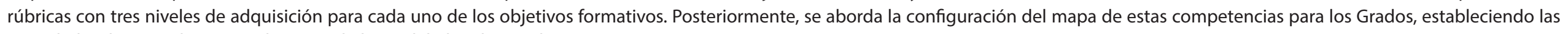
actividades de aprendizaje y evaluación a lo largo del plan de estudios.

Resultados:

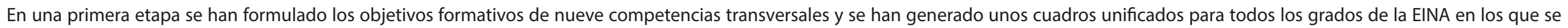
indican los aspectos que han de cumplir dichas competencias para asegurar su adquisición por parte del estudiante en tres niveles distintos de creciente competencia.

\section{Conclusiones:}

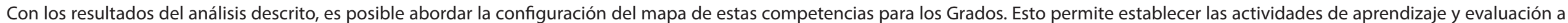

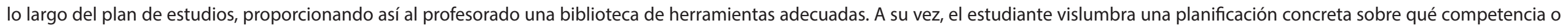
competencias adquirirá, a qué nivel y en qué asignatura o asignaturas. 
Sistematización para ayudar a la coordinación en la adquisición de competencias transversales

Yagïe, J.A.; Alsa, J.; Bernués, E; Blasco, J; Coronas, J.; Labarta, C.; Lópezz, L.; Montañés, A.; Resano, J.J.; Romeo, L.M.; Romeo, A.; Royo, E,; Trillo, R.

Escuela de Ingenieria y Arquitectura. Universidad de Zaragoza. jyague@unizar.es

Contexto: Grados de la Escuela de Ingeniería y Arquitectura (EINA) de la Universidad de Zaragoza.

- Creciente importancia de las competencias transversales.

- Conveniente una mayor planificación global.

Objetivo: Planificación de la adquisición de las competencias transversales.

Método: Análisis de las competencias $\rightarrow$ Objetivos formativos y criterios de calidad comunes $\rightarrow 3$ niveles de adquisición para cada objetivo formativo $\rightarrow$ Mapa real de competencias $\rightarrow$ Actividades de aprendizaje y evaluación.

Resultados: Se han formulado los objetivos formativos de 9 competencias transversales $\rightarrow$ cuadros unificados para todos los grados de la EINA $\rightarrow 3$ niveles de creciente competencia.

Conclusiones: Planificar la adquisición de estas competencias a lo largo del plan de estudios $\rightarrow$ Profesorado: biblioteca de herramientas adecuadas $\rightarrow$ Estudiante: foto global.
Nivel 1: indica el aprendizaje del alumno adquirido por las explicaciones, prácticas, lecturas, apuntes, ejemplos, etc. En este nivel el alumno debe demostrar que recuerda y comprende el nivel elemental de lo explicado.

Nivel 2: indica el aprendizaje del alumno por la puesta en práctica de los conocimientos adquiridos en el nivel 1. En este nivel el alumno debe demostrar que es capaz de aplicar procedimientos y conocimientos teóricos

C8: Capacidad para trabajar en un grupo multidisciplinar y en un entorno multilingüe.

\begin{tabular}{|c|c|c|c|}
\hline Elementos & Nivel 1 & Nivel 2 & Nivel 3 \\
\hline $\begin{array}{l}\text { Conformar un } \\
\text { grupo de trabajo } \\
\text { y establecer sus } \\
\text { reglas de } \\
\text { funcionamiento } \\
\text { y } \\
\text { procedimientos } \\
\text { operativos }\end{array}$ & $\begin{array}{l}\text { Conoce las } \\
\text { caracteristicas que } \\
\text { debe reunir un grupo } \\
\text { de trabajo para poder } \\
\text { cumplir una misión } \\
\text { encomendada. } \\
\text { Sabe los tipos de } \\
\text { roles en un grupo de } \\
\text { trabajo y sus } \\
\text { funciones } \\
\text { Conoce las reglas de } \\
\text { funcionamiento más } \\
\text { adecuadas en función } \\
\text { del tamaño y la } \\
\text { heterogencidad del } \\
\text { grupo de trabajo. } \\
\text { Conoce los tipos de } \\
\text { herramientas TIC } \\
\text { involucradas en el } \\
\text { funcionamiento de un } \\
\text { grupo de trabajo }\end{array}$ & $\begin{array}{l}\text { Constituye un grupo de } \\
\text { trabajo siguiendo un } \\
\text { procedimiento establecido } \\
\text { por el profesor, } \\
\text { distribuyendo los roles } \\
\text { entre los miembros. } \\
\text { Asigna y asume las } \\
\text { responsabilidades de los } \\
\text { roles y establece los } \\
\text { mecanismos de } \\
\text { verificación de su } \\
\text { cumplimiento. } \\
\text { Pone en común con los } \\
\text { compañeros aspectos } \\
\text { relacionados con la } \\
\text { afinidad, intereses } \\
\text { personales, disponibilidad } \\
\text { de horarios y acuerda los } \\
\text { procedimientos operativos } \\
\text { para el trabajo } \\
\text { colaborativo. } \\
\text { Elige las reglas de } \\
\text { funcionamiento más } \\
\text { adecuadas para el tipo de } \\
\text { grupo y sus objetivos } \\
\text { concretos. }\end{array}$ & $\begin{array}{l}\text { Constituye de forma autónoma } \\
\text { un grupo de trabajo, } \\
\text { comprobando que el grupo } \\
\text { formado cumple con las } \\
\text { características marcadas } \\
\text { inicialmente y puede realizar la } \\
\text { misión encomendada. } \\
\text { Establece reglas de } \\
\text { comportamiento y chequea en } \\
\text { las reuniones su conveniencia o } \\
\text { modificación, así como la } \\
\text { posible reestructuración del } \\
\text { grupo o la reasignación de } \\
\text { roles. }\end{array}$ \\
\hline
\end{tabular}

Nivel 3: indica la autonomía del problemas y cuestiones lumno debe demestar que plapaz de desurostrar que es capaz de desarrollar procedimientos y aplicarlos.

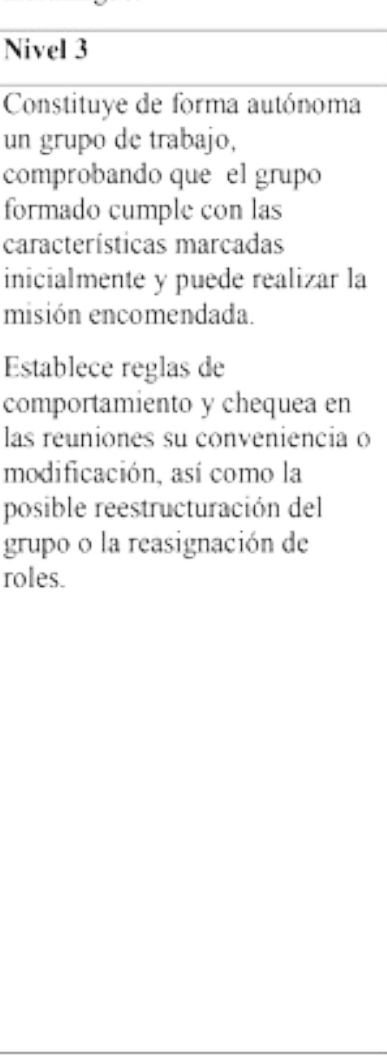
alumno en la resolución de los 


\section{Valoración de los egresados del grado en Marketing e Investigación de Mercados}

Pedraja Iglesias, M.; Marzo Navarro, $M$.

\section{Palabras clave}

Inserción Laboral, Egresados en Marketing e Investigación de Mercados, satisfacción con la formación, utilidad de la formación.

\section{Resumen}

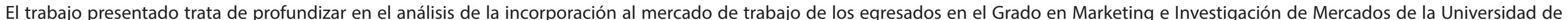

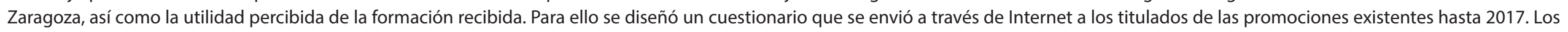

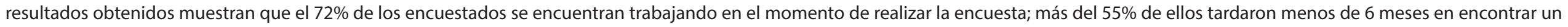

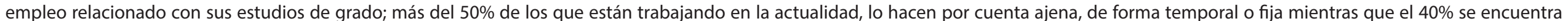

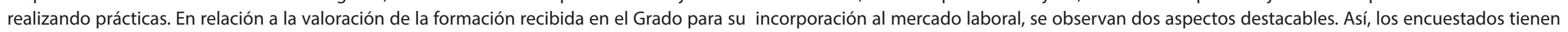

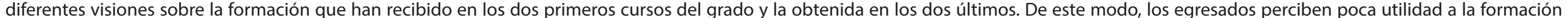

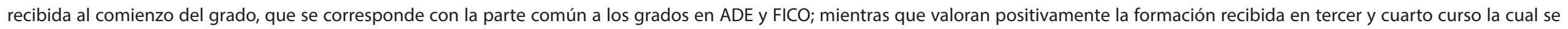

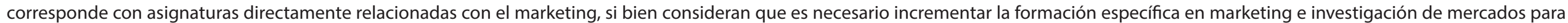

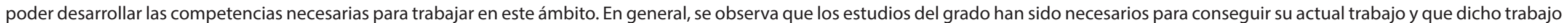
se encuentra relacionado con el grado. 


\title{
Valoración de los egresados del grado en Marketing e Investigación de Mercados
}

\author{
Marta Pedraja Iglesias, Mercedes Marzo Navarro \\ Departamento de Dirección de Marketing e Investigación de Mercados, \\ mmarzo@unizar.es
}

OBJETIVO: Analizar la inserción laboral de los egresados en Marketing e Investigación de Mercados (MIM) de la Universidad de Zaragoza y conocer su opinión sobre la utilidad de la formación recibida.

99 encuestados, diversas promociones

72 trabajan actualmente

Encuesta auto-administrada

Fecha: 2017

Tiempo hasta encontrar trabajo relacionado con el grado

\begin{tabular}{lc}
\hline Aun no he encontrado & $44,3 \%$ \\
\hline $0-3$ meses & $49,5 \%$ \\
\hline $3-6$ meses & $6,2 \%$ \\
\hline
\end{tabular}

Tipo contrato

\begin{tabular}{lc}
\hline Prácticas & $40,3 \%$ \\
\hline Asalariado fijo & $29,2 \%$ \\
\hline Asalariado temporal & $25,0 \%$ \\
\hline Autónomo & $2,8 \%$ \\
\hline Empresa familiar & $2,8 \%$ \\
\hline
\end{tabular}

\begin{tabular}{lc}
\cline { 2 - 2 } & Media* \\
\hline Mis estudios del grado han sido necesarios para conseguir mi actual trabajo & 6,26 \\
\hline Mi trabajo actual se relaciona con mis estudios de grado & 6,13 \\
\hline Estoy satisfecho con mi trabajo actual & 5,45 \\
\hline $\begin{array}{l}\text { Teniendo en cuenta mi experiencia en el mundo laboral, los conocimientos } \\
\text { adquiridos en el grado han sido muy útiles para mi inserción laboral }\end{array}$ & 5,44 \\
\hline En general, estoy contento con la formación que recibi en el Grado & 5,99 \\
\hline La formación que recibi en los dos primeros años me ha sido útil & 3,94 \\
\hline La formación de $3^{\circ}$ y $4^{\circ}$ me ha sido útil & 7,52 \\
\hline $\begin{array}{l}\text { Las asignaturas de marketing proporcionan las competencias necesarias } \\
\text { para trabajar en Marketing }\end{array}$ & 5,86
\end{tabular}

*Escalas de acuerdo desde 0 "Totalmente en Desacuerdo" hasta 10 "Totalmente De acuerdo" CONCLUSIONES:

- Los estudios de MIM han sido necesarios para conseguir su trabajo

- Su trabajo se encuentra relacionado con el grado en MIM 



\section{IV Aplicación de metodologías activas II}




\section{Aplicación de metodologías activas II}

1. Usón Gil, S.; Peña Pellicer, B.; Llera Sastresa, E. M.; Zabalza Bribián, I.; Romeo Giménez, L. M.

Combinando el modelo de aula inversa con el uso de TIC y metodologías activas

2. Laborda Soriano, A. A.; Cambra Aliaga, A.; Vidal Sánchez, M. I.; Gonzalo Ciria, L.; Sanz Valer, P. Construyendo la identidad profesional a través de las narrativas

3. Delgado Crespo, V.; Mur Dueñas, P.; Pellicer Ortín, S.

Desarrollo de destrezas de pensamiento y comunicación en la clase de inglés como lengua extranjera en el Grado de Maestro en Educación Primaria

4. Márquez Marzal, A.; Pérez Bailón, J.; Medrano Marqués, N.; Calvo López, B.

Desarrollo de un proceso de medida de ruido en sistemas electrónicos como actividad formativa integradora de conocimientos

5. Alegret Badiola, L.

Educación a través de la exploración: excursión virtual a los afloramientos geológicos de Zumaia (Guipúzcoa)

6. Resano López, J. C.; Murillo Ligorred, V.

El arte chino contemporáneo como recurso didáctico en el Grado de Maestro de Primaria: transversalidad, multiculturalidad y narrativas migratorias. Arte y sociedad en el contexto global

7. Latorre Cosculluela, C.; Vázquez Toledo, S.; Rodríguez Martínez, A.; Arbués Salazar, J.; Liesa Orús, M.

El pensamiento creativo y cooperativo a través de Design Thinking: una metodología auténtica para trabajar la innovación en el aula universitaria

8. Oliván Blázquez, B.; Gómez Poyato, M. J.; Masluk, B.; Asensio Martínez , A.; Magallón Botaya, R.

Flip Teaching en el rendimiento académico y la satisfacción de los estudiantes del grado de trabajo social

9. Mur Sangrá. M.; Domeque Claver, N.; Artero Escartín, I.

Flippeando Economía con Active Presenter

10. Cuevas Salvador, J.; Huertas Talón, J. L.; Ayensa Vázquez, J. A

La experiencia del design thinking en el desarrollo de la co mpetencia iniciativa y espíritu emprendedor 
11. Mitjana Nerin, O.; Boira Sarto, S.; Laborda, A.; Bonastre Rafales, C.; Falceto Recio, M. V.; Serrano, C .; Rodriguez, J.; Olivan, B.; García Campayo, J.;López del Hoyo, Y. Píldoras audiovisuales para mejorar las habilidades de comunicación en los postgraduados del Grado de Veterinaria: un proyecto interdisciplinar

12. Cabanés Cacho, B.; García-Casarejos, N.; Romera Rodríguez, I.

¿Qué le aporta al estudiante crear contenido en YouTube a través de la metodología ApS?

13. Cristóbal Hornillos, R.; Sanjuán Alvarez, M.; Villanueva Roa, J. D.

Unidades didácticas para la educación literaria basada en canciones 


\section{Combinando el modelo de aula inversa con el uso de TIC y metodologías activas}

Usón Gil, S.; Peña Pellicer, B.; Llera Sastresa, E. M.; Zabalza Bribián, I.; Romeo Giménez, L. M.

\section{Palabras clave}

Moodle, vídeos didácticos, clase invertida, innovación universitaria, educación en Ingeniería.

\section{Resumen}

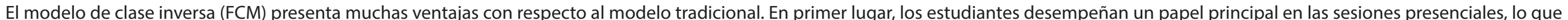

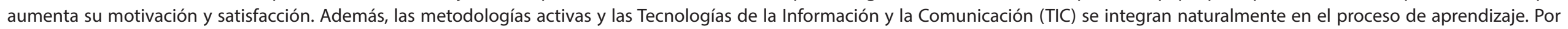
último, ciertas competencias transversales pueden ser desarrolladas y evaluadas en el aula.

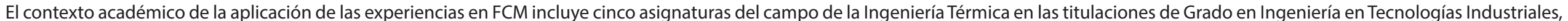

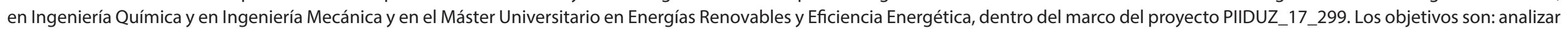
y comparar las experiencias, recopilar resultados positivos y proponer estrategias de mejora.

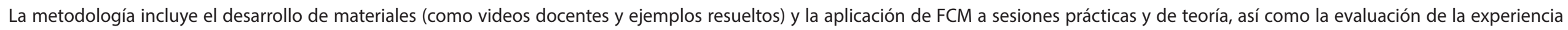

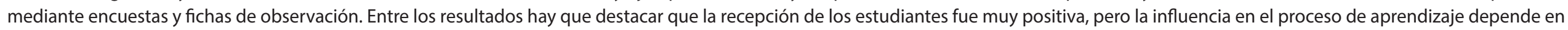

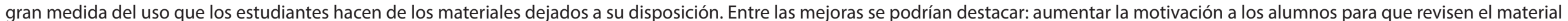
y poder contar con un profesor adicional en determinadas sesiones.

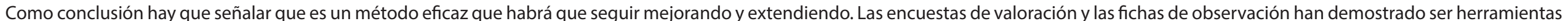
necesarias para la evaluación del modelo pedagógico y para mejorar curso a curso. 


\section{Combinando el modelo de aula inversa con el uso de TIC y metodologías activas}

\section{Sergjo Usón, Begoña Peña, Eva lja Llera, Ignacjo Zabalza, Lujs Mijguel Romeo}

Departamento de Ingeniería Mecánica, \{suson, bpp, ellera, izabal, luismi\}@unizar.es

\begin{tabular}{|c|c|c|c|c|}
\hline Asignatura & Matriculados & Horas & $\begin{array}{l}\text { Titulación } \\
\text { / Semestre }\end{array}$ & Curso \\
\hline $\begin{array}{l}\text { Termodinámica Técnica y Fund. } \\
\text { Transmisión de Calor }\end{array}$ & $\begin{array}{l}70 \\
52\end{array}$ & 6 & GITI. S3 & $\begin{array}{l}2016-2017 \\
2017-2018\end{array}$ \\
\hline Ingenieria Térmica & 51 & 5 & GITI. S4 & 2016-2017 \\
\hline Termotecnia & 32 & 3 & GIQ. S6 & 2016-2017 \\
\hline Máquinas y Motores Térmicos & 106 & 3 & GIM. S6 & 2016-2017 \\
\hline $\begin{array}{l}\text { Eficiencia Energética en la } \\
\text { Edificación }\end{array}$ & 8 & 2 & MU, ERyEE & 2016-2017 \\
\hline
\end{tabular}

Experiencia englobada en el proyecto PIIDUZ_17_299

\section{Objetivo}

Recopilar y analizar datos sobre las diversas experiencias, compararlas según tipo de clase, nivel de estudios y perfil profesional de la titulación, recopilar las buenas prácticas y los problemas encontrados y proponer estrategias de mejora.

\section{Metodología}

\begin{tabular}{|l|c|c|c|c|c|}
\hline Metodologia & TD & IT & T & MMT & EEE \\
\hline Textos/ Bibliografia & $\mathrm{X}$ & $\mathrm{X}$ & $\mathrm{X}$ & $\mathrm{X}$ & $\mathrm{X}$ \\
\hline Videos docentes & $\mathrm{X}$ & $\mathrm{X}$ & & $\mathrm{X}$ & \\
\hline Ejemplos resueltos & & & $\mathrm{X}$ & $\mathrm{X}$ & \\
\hline LEs materia conocida? (repaso) & & & $\mathrm{X}$ & $\mathrm{X}$ & \\
\hline Práctica & $\mathrm{X}$ & & & $\mathrm{X}$ & \\
\hline ABP & $\mathrm{X}$ & $\mathrm{X}$ & $\mathrm{X}$ & & \\
\hline Cuestionario + debate & & & & & $\mathrm{X}$ \\
\hline
\end{tabular}

\section{Principales resultados}

Aplicación en clases prácticas: solventar el problema de la desincronización temporal entre las clases magistrales y las prácticas de laboratorio. Acciones futuras:

- Realizar cuestionario previo al comienzo de la sesión $\Rightarrow$ evitar copias.

- Alcanzar nota mínima para poder realizar la práctica $\Rightarrow$ todos la preparen.

Experiencias en clases magistrales: Aumentar la motivación y el compromiso de los alumnos en la asignatura para mejorar el aprovechamiento de las clases presenciales. Acciones futuras:

- Apoyo de un segundo profesor en el aula.

- Seleccionar y priorizar las tareas a realizar $\Rightarrow$ terminar lo mínimo en clase.

Diferencias entre grados de diferente perfil profesional. Observaciones:

- En GITI sin preparar la primera sesión. La actitud mejora en las siguientes sesiones, trabajan en grupos pequeños.

- En GIQ, mejor actitud inicial, muestran mayor interés. Trabajan de forma individual.

Diferencias entre niveles educativos (grado-master): Grupos más reducidos y mejor base académica. Comparativa de encuestas:

- Tiempo dedicado previamente a los materiales igualmente bajo.

- Mayor grado de aprovechamiento de las clases tradicionales en el máster.

- Mayor grado de satisfacción sobre FCM en máster, pero menor aprovechamiento.

\section{Conclusiones}

- Los materiales para preparar las clases deben ser muy específicos y concisos.

- Conviene contar con dos profesores en el aula para resolver dudas.

- Conviene incluir una tarea práctica antes de la sesión magistral. 


\section{Construyendo la identidad profesional a través de las narrativas}

Laborda Soriano, A. A.; Cambra Aliaga, A.; Vidal Sánchez, M. I.; Gonzalo Ciria, L.; Sanz Valer, P.

\section{Palabras clave}

Terapia ocupacional, historias de vida, aprendizaje.

\section{Resumen}

\section{Introducción:}

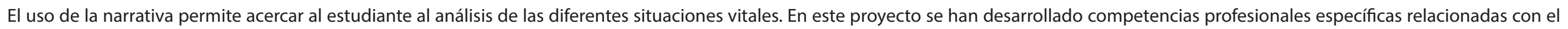
uso de la narrativa en el proceso terapéutico de personas que utilizan los servicios de Terapia Ocupacional en Zaragoza.

Objetivos:

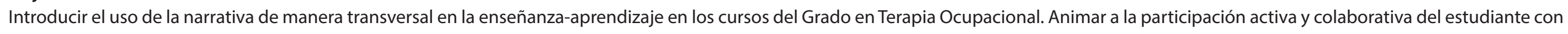
el fin de fortalecer su identidad profesional. Crear grupos de aprendizaje.

\section{Resultados:}

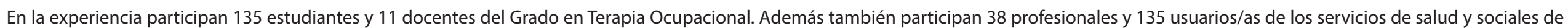

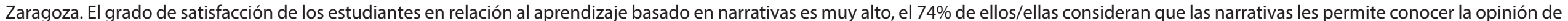

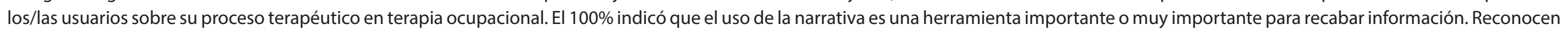

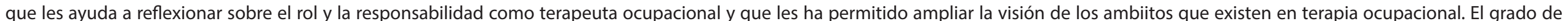
satisfacción de los/las docentes y participantes con el proyecto es muy alto (92\%). Y el grado de satisfacción de los/las profesionales externos con el proyecto es alto (80\%).

\section{Conclusiones:}

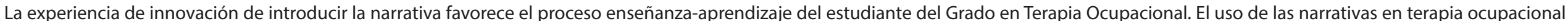
se identifica como una herramienta útil en el manejo de la información desde la perspectiva del estudiante. 


\title{
Construyendo la identidad profesional a través de las narrativas
}

\author{
Ana Alejandra Laborda, Alba Cambra, María Isabel Vidal, Laura Gonzalo, Patricia Sanz.
}

Departamento de Fisiatría y Enfermería, analabor@unizar,es

La narración es el relato de una serie de acontecimientos, delimitados en

tiempo y contexto que reflejan la forma en la que las personas

aprendemos y construimos todo aquello que nos rodea.

\section{OBJETIVOS}

- Introducir el uso de la narrativa de manera transversal en el Grado en

Terapia Ocupacional.

-Animar a la participación activa y colaborativa del estudiante con el fin de fortalecer su identidad profesional.

- Crear grupos de aprendizaje.

\section{METODOLOGÍA}

\section{RESULTADOS}

\section{Participación activa de}

135 estudiantes y 11 docentes

del Grado en TO.

38 profesionales y 135

usuarios y usuarias de los

servicios de salud y sociales

de Zaragoza.

\section{Actividades}

transversales

Se recogen y analizan

135 narrativas.

Se desarrollan 6

seminarios prácticos en asignaturas de $3^{\circ}$ y $4^{\circ}$

curso.
Los estudiantes opinan

Que las narrativas les permite conocer la opinión de las personas con la TO.

Que el uso de la narrativa es una herramienta importante para recabar información.

Que les ayuda a reflexionar sobre su rol y su responsabilidad.

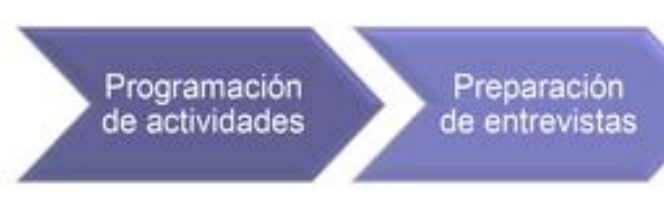

\section{CONCLUSIONES}

La experiencia de innovación de introducir la narrativa favorece el proceso enseñanzaaprendizaje del estudiante del Grado en TO. El uso de las narrativas en se identifica como una herramienta útil en el manejo de la información desde la perspectiva del estudiante.

\section{inif Universidad \\ iㅡ. Zaragoza}




\section{Desarrollo de destrezas de pensamiento y comunicación en la clase de inglés como lengua extranjera en el Grado de Maestro en Educación Primaria}

Delgado Crespo, V.; Mur Dueñas, P.; Pellicer Ortín, S.

\section{Palabras clave}

Metodologías activas, aprendizaje visible, enfoque comunicativo, estrategias metacognitivas, rutinas de pensamiento.

\section{Resumen}

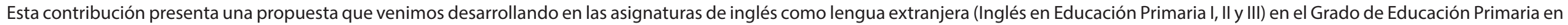

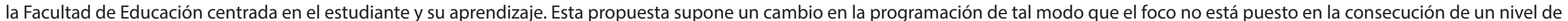

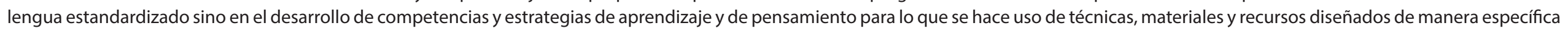
teniendo en cuenta el contexto de instrucción, las necesidades de los alumnos, así como sus intereses formativos y profesionales.

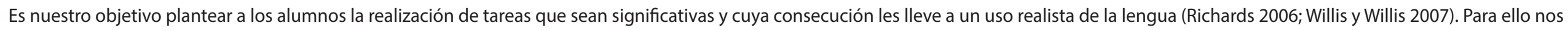

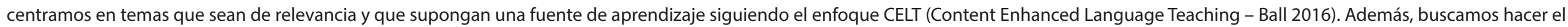

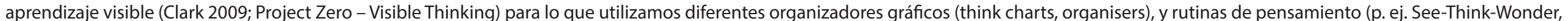

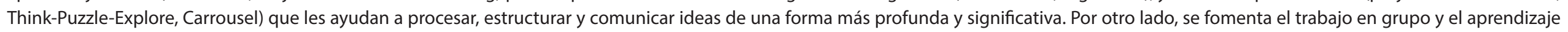

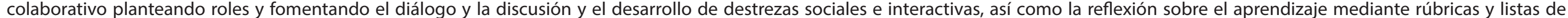

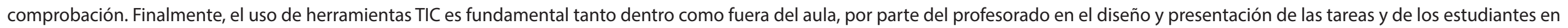
su consecución y presentación. 
Desarrollo de destrezas de pensamiento y comunicación en la clase de inglés como lengua extranjera en el Grado de Maestro en Educación Violeta Delgado Crespo, Pilar Mur Dueñas, Silvia Pellicer Ortín

Primaria

Departamento de Filología Inglesa y Alemana, violedel@unizar.es, pmur@unizar.es, spellice@unizar.es

\section{CONTEXTO}

Inglés en Educación Primaria I, II y III

Grado Maestro en Ed. Primaria

\section{OBJETIVOS}

- Planificar asignaturas específicas para el futuro maestro, respondiendo a sus intereses y necesidades

- Desarrollar competencias y estrategias de aprendizaje

- Fomentar el trabajo en grupo y el aprendizaje cooperativo

- Hacer y promocionar un uso efectivo de las TIC

\section{METODOLOGÍA}

- Enfoque comunicativo y basado en tareas

- CELT (Content Enhanced Language Teaching - Ball 2016)

- Aprendizaje y pensamiento visible (Clark 2009; Project Zero)

\section{CONCLUSIONES}

\section{RESULTADOS}

Tasks and task cards

Se plantean tareas significativas para el futuro maestro y que fomenten el uso realista de la lengua..

\section{Think charts, organisers}

El uso de organizadores gráficos permite el desarrollo de destrezas de pensamiento de diferente orden, favorece la generación de contenidos e ideas y su procesamiento.

\section{Thinking routines (rutinas de pensamiento)}

See- Think-Wonder

Think-Puzzle-Explore

Carrousel

\section{Reflective learning: checklists, rubrics, exit tickets}

Guían el proceso de aprendizaje; ayudan al estudiante a desarrollar la tarea. Fomentan la autoevaluación y la evaluación por pares.

\section{TIC}

Trabajo colaborativo

Creación de materiales y dinamización Game-based learning
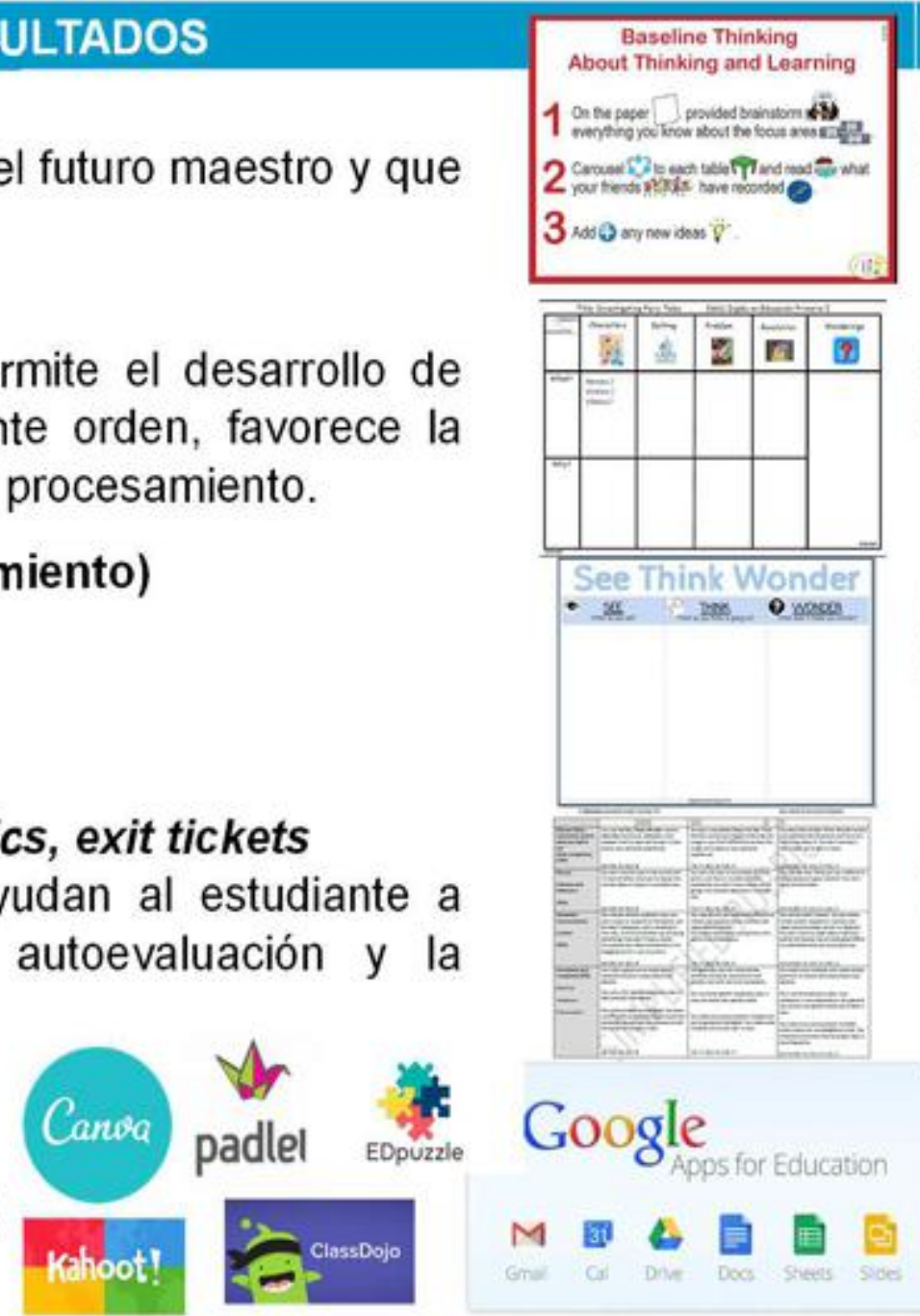
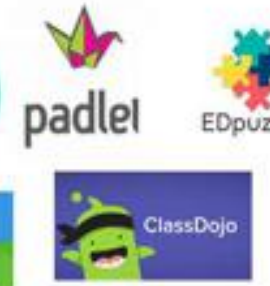

http://bit.ly/2 PabKOo

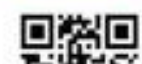
新霹 回经

http://bit.ly/thi nkcharts

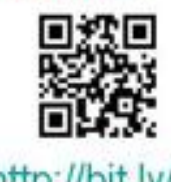

http://bit.ly/2 wiMVs!

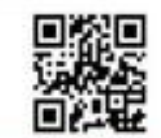

http://bit.ly/2 LwSqsD

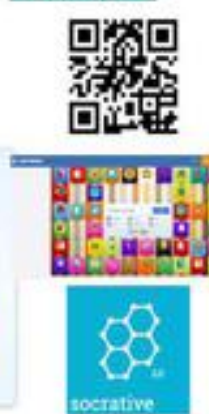

Los alumnos se implican en su proceso de aprendizaje y desarrollan su competencia comunicativa y otras competencias transversales. 


\section{Desarrollo de un proceso de medida de ruido en sistemas electrónicos como actividad formativa integradora de conocimientos}

Márquez Marzal, A.; Pérez Bailón, J.; Medrano Marqués, N.; Calvo López, B.

\section{Palabras clave}

Instrumentación electrónica, técnicas de medida, aprendizaje basado en proyectos, integración de conocimientos.

\section{Resumen}

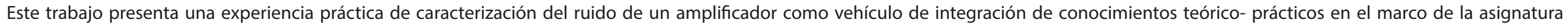

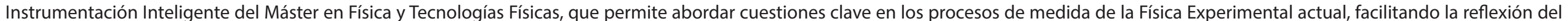
estudiante sobre las consideraciones prácticas de un proceso de medida real.

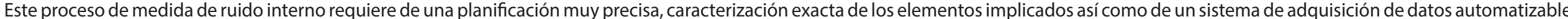

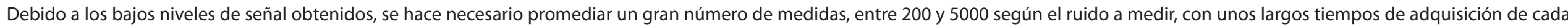

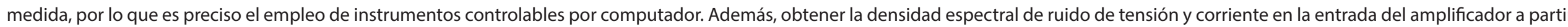

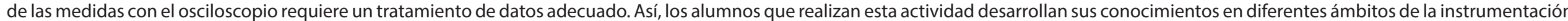
y medida, diseño del experimento, programación del sistema de automatización de medida y tratamiento de datos y obtención de conclusiones.

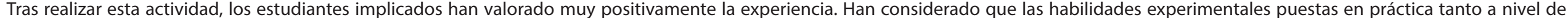

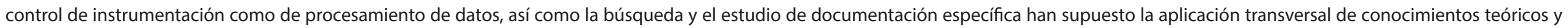

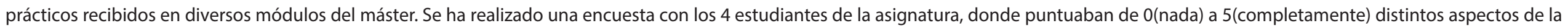
experiencia. Los resultados medios obtenidos han sido:

1. Interés general de la experiencia: 4,7 ;

2. Grado de satisfacción con la metodología: 5;

3. Grado de satisfacción con el proyecto: 4,7 ;

4. Seguimiento y apoyo docente: 4,5;

5. Nivel de adecuación del tiempo previsto frente al empleado: 3 ;

6. Satisfacción con los resultados obtenidos: 4,8.

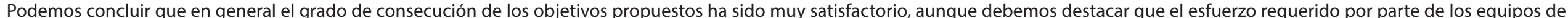

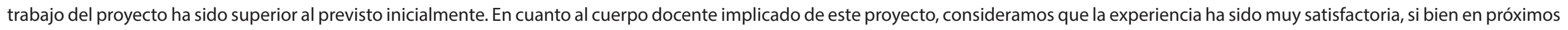
cursos se intentará ajustar con mayor precisión la carga de trabajo. 


\section{Desarrollo de un proceso de medida de ruido en sistemas electrónicos como actividad formativa integradora de conocimientos}

\section{Alejandro Márquez, Jorge Pérez-Bailón, Nicolás Medrano, Belén Calvo}

Departamento de Ingenieria Electrónica y Comunicaciones, Área de Electrónica, \{amarquez, jorgepb, nmedrano, becalvo\}@unizar.es

\section{Objetivo}

Desarrollo de una experiencia realista desde el punto de vista industrial o científico, que integre conocimientos teóricos y habilidades experimentales de la asignatura Instrumentación Inteligente del Máster en Física y Tecnologías Físicas de la Universidad de Zaragoza

\section{Metodología}

\section{Aprendizaje basado en proyectos}

$\checkmark$ Trabajo colaborativo: Grupos de 2-4 estudiantes

\section{Problema propuesto}

$\checkmark$ Diseño y caracterización de un sistema completo de adquisición de medida y control de la instrumentación: desarrollo integral de un sistema de medida del ruido de un amplificador

$\checkmark$ Evaluación: Portfolio, Exposición

\section{Resultados}

Dispositivo-bajo-test (DUT): amplificador operacional ISL28148

Diseño del sistema de medida

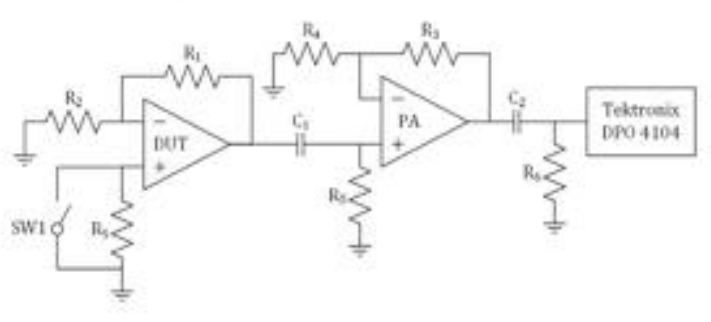

\section{Conclusiones}

\section{Estudiantes}

$\checkmark$ Grado de consecución de objetivos: muy satisfactorio

$\checkmark$ Esfuerzo requerido: mayor al previsto inicialmente

\section{Equipo docente}

Caracterización experimental automatizada
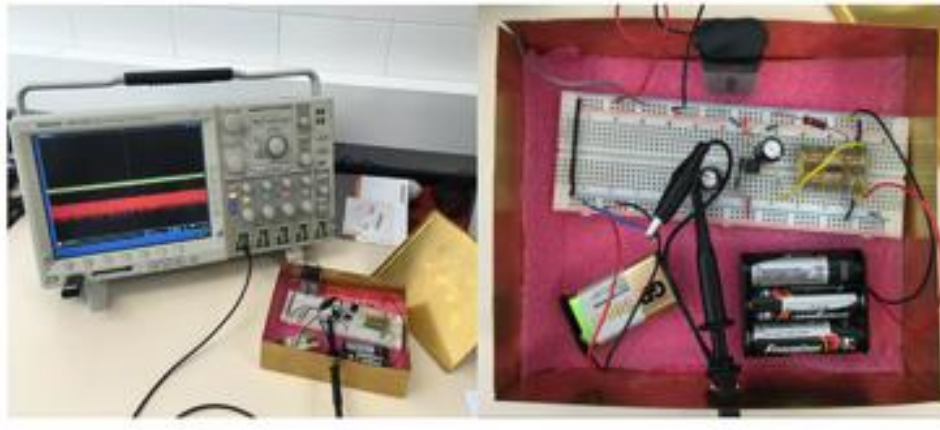

$\checkmark$ Experiencia satisfactoria

$\checkmark$ En el futuro: ajustar mejor la carga de trabajo 


\section{Educación a través de la exploración: excursión virtual a los afloramientos geológicos de Zumaia (Guipúzcoa)}

Alegret Badiola, L.

\section{Palabras clave}

Realidad virtual, geología, extinción, eventos.

\section{Resumen}

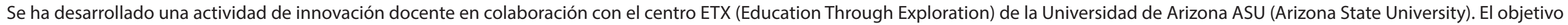

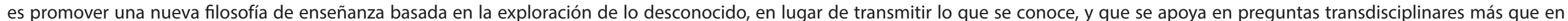

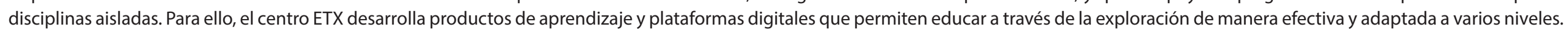

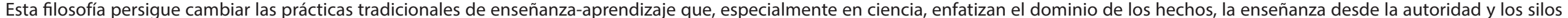

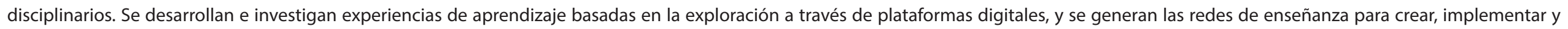
adaptar contenidos.

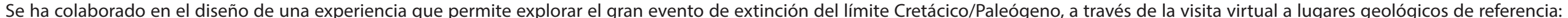

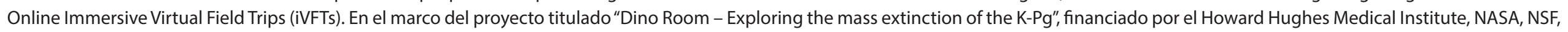

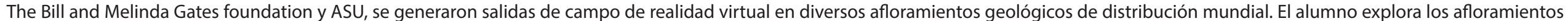

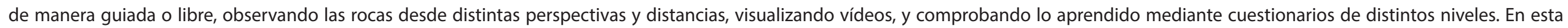

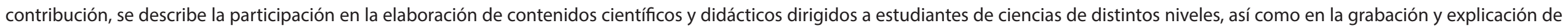
los mismos en los afloramientos vascos de Zumaia. 


\title{
Educación a través de la exploración: excursión virtual a los afloramientos geológicos de Zumaia (Guipúzcoa).
}

\author{
Laia Alegret
}

Departamento Ciencias de la Tierra, laia@unizar.es

\section{Contexto y objetivos}

Con el objetivo de promover una nueva filosofía de enseñanza de las ciencias basada en la exploración de lo desconocido, se ha diseñado una experiencia que permite explorar uno de los mayores eventos de la historia de la Tierra: la extinción del limite Cretácico/Paleógeno (K/Pg, 66 millones de años).

En colaboración con el centro ETX (Education Through Exploration; Arizona State University) se generó un producto de aprendizaje para estudiantes de titulaciones universitarias en ciencias (geología, biología, química, etc.), en una plataforma digital atractiva y adaptada a varios niveles, para educar explorando, con intervenciones de científicos en afloramientos internacionales: http://vft.asu.edu/iVFTLocations/KPG/KPGoptions.html

3 Modos de realizar la experiencia Explorando la extinción en masa del $\mathrm{K} / \mathrm{Pg}$

Actividad interactiva completamente guiada

Exploración de la experiencia completa $60-90$ mins

Actividad guiada en secciones

6 secciones que pueden ser exploradas individualmente, 10-15 mins/sección

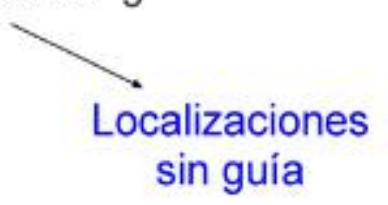

7 localidades que pueden ser exploradas individualmente, tiempo flexible

Auto-exploración del contenido

\section{Metodología y resultados}

Se capturaron imágenes esféricas y fijas de alta resolución-gigapan, videos e imágenes aéreas con dron y se elaboraron contenidos científicos y didácticos: https://vft.asu.edu/VFTKPG/panos/KPGZumaia/.

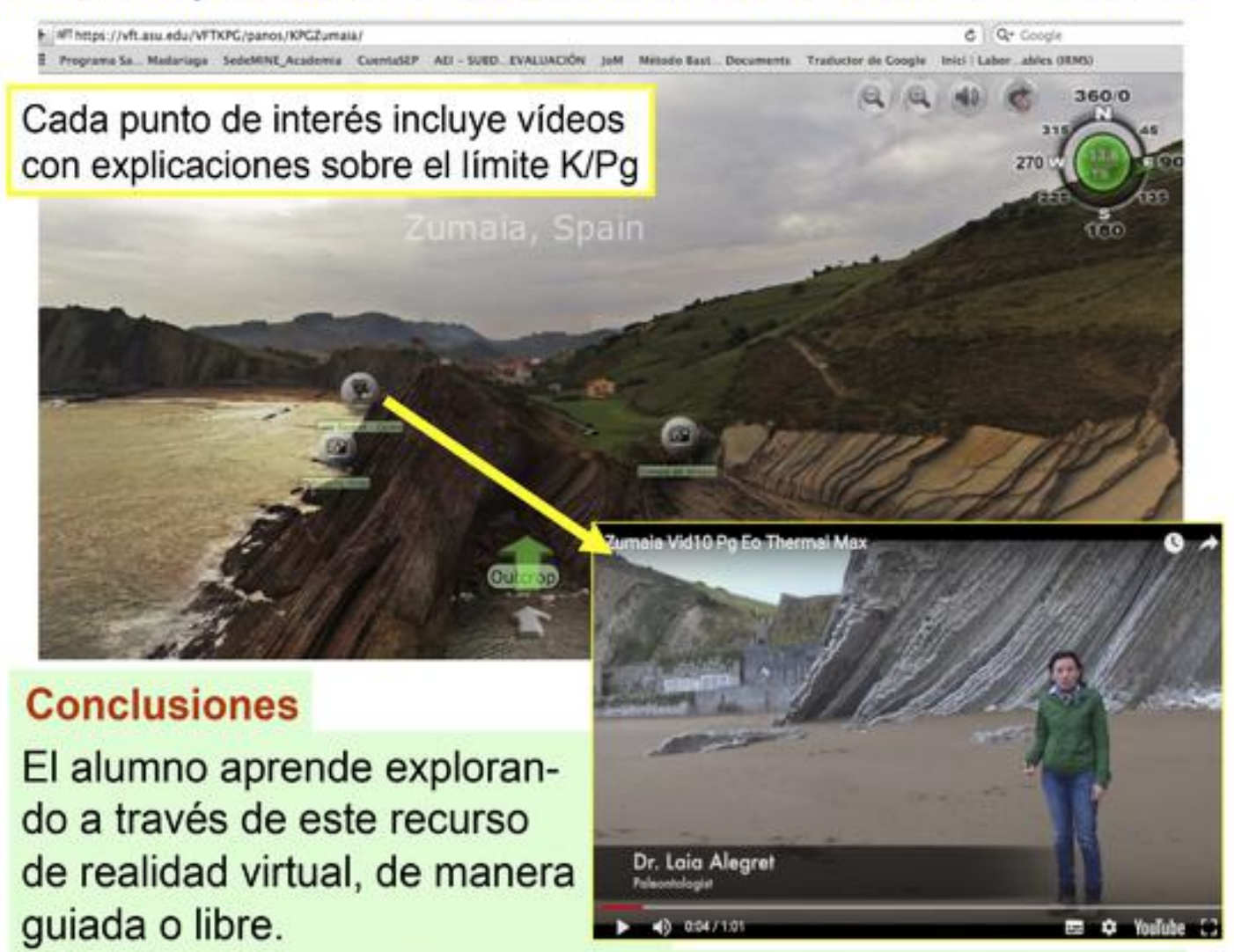

Comprueba lo aprendido con cuestionarios de varios niveles. 


\section{El arte chino contemporáneo como recurso didáctico en el Grado de Maestro de Primaria: transversalidad, multiculturalidad y narrativas migratorias. Arte y sociedad en el contexto global}

Resano López, J. C.; Murillo Ligorred, V.

\section{Palabras clave}

Educación primaria, educación artística, cultura visual, arte contemporáneo.

\section{Resumen}

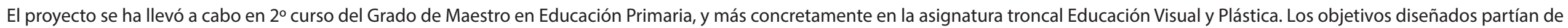

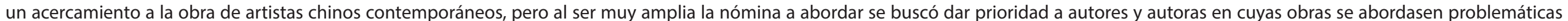

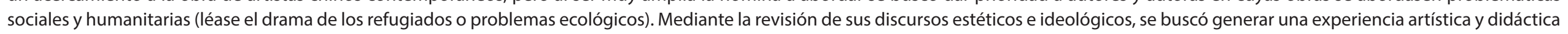

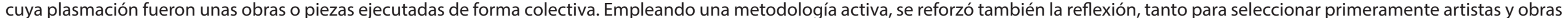

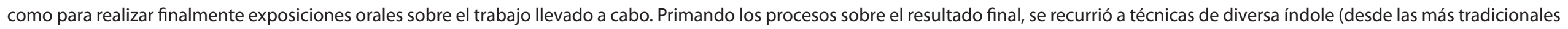
a las más innovadoras), lo cual favoreció la experimentación y la hibridación de lenguajes.

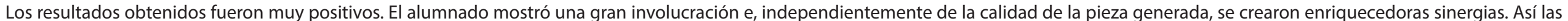

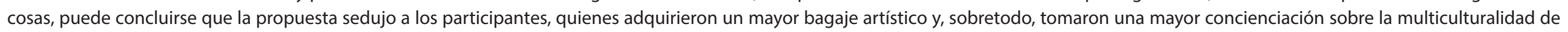

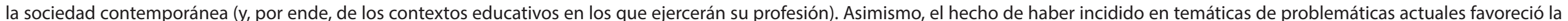

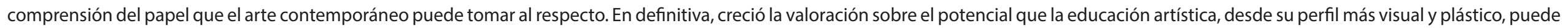
ofrecer como recurso didáctico específico pero también de forma transversal. 


\section{El arte chino contemporáneo como recurso didáctico en el Grado de Maestro de Primaria: transversalidad, multiculturalidad y narrativas migratorias. Arte y sociedad en el contexto global. Juan Cruz Resano, Víctor Murillo \\ Departamento de Expresión Musical, Plástica y Corporal,}

Contexto académico: Grado de Maestro en E. Primaria, $2^{\circ}$ curso, Educación Visual y Plástica.

Objetivos propuestos. Apreciar el arte en su función social y crítica. Dar a conocer el arte chino contemporáneo como un generador de conocimiento activo, social y comprometido con la actualidad de los tiempos, potenciando el sentido crítico y ampliando el bagaje cultural de los futuros maestros. A ello se añade aprender a trabajar en equipo y la toma de una mayor concienciación ante el reto de la multiculturalidad en la sociedad.

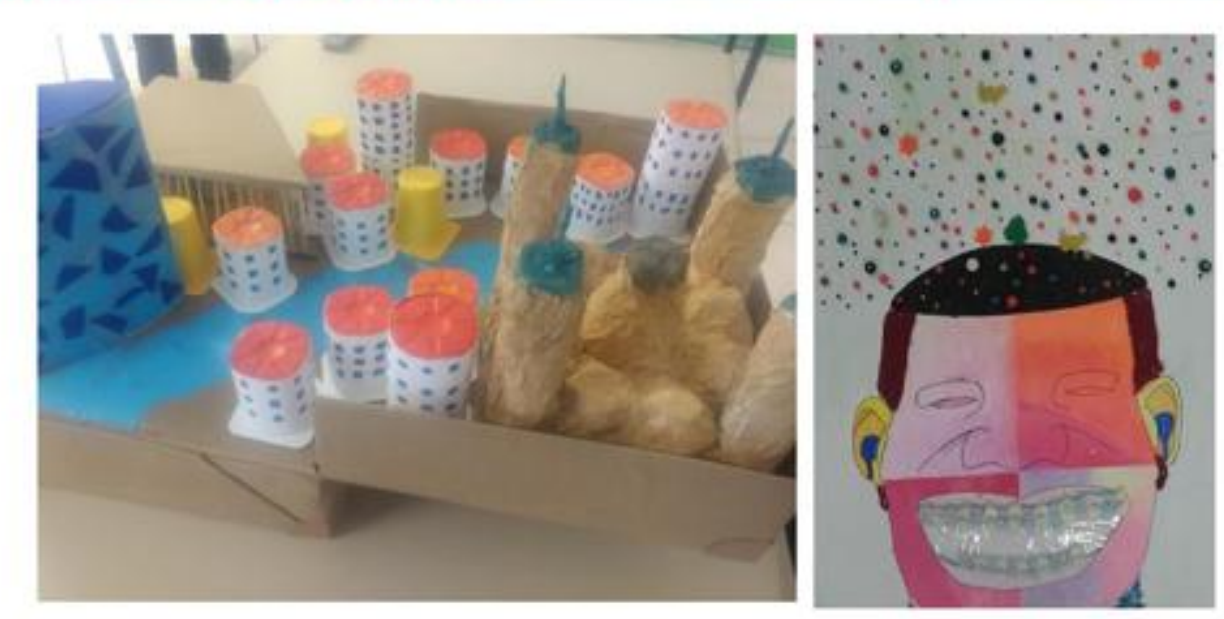

Metodología. Partiendo de la revisión y análisis de obras de artistas chinos, se recurrió a estrategias artísticas activas para realizar obras colectivas empleando técnicas variadas (témperas, collage, medios informáticos, etc.), concluyendo el proyecto con exposiciones orales sobre las propuestas realizadas.

Resultados. El proyecto ha tenido unos resultados muy satisfactorios. Los trabajos generados dieron prueba de ello y se logró afianzar en el alumnado el sentido crítico y reflexivo que el arte puede tener.

Figs. 1 y 2 (parte superior), trabajos creados a partir de obras de Yin Xiuzhen y Yue Minjun. Fig. 3, fase de trabajo colaborativo a partir de una obra de Zeng Fanzhi.

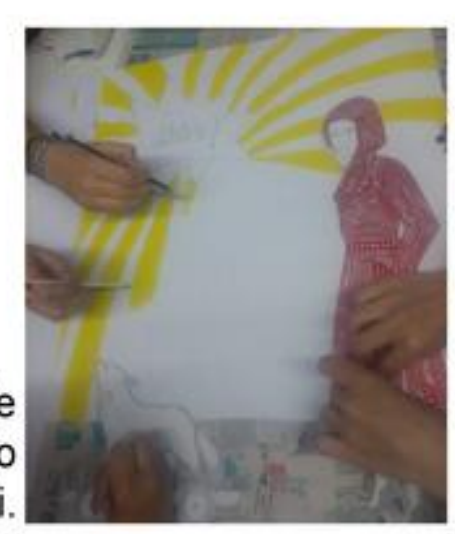

Conclusiones obtenidas. El alumnado descubrió una serie de artistas que desconocia por completo y ha mejorado su percepción tanto del arte contemporáneo como de la multiculturalidad, redundando ello además en su valoración sobre el papel que la educación artística puede jugar en la futura dedicación docente que aguarda al alumnado de magisterio . 


\section{El pensamiento creativo y cooperativo a través de Design Thinking: una metodología auténtica para trabajar la innovación en el aula universitaria}

Latorre Cosculluela, C.; Vázquez Toledo, S.; Rodríguez Martínez, A.; Arbués Salazar, J.; Liesa Orús, M.

\section{Palabras clave}

Empatía, creatividad, proyecto de innovación educativa; metodología auténtica.

\section{Resumen}

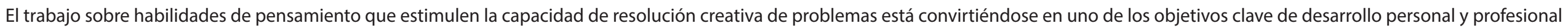

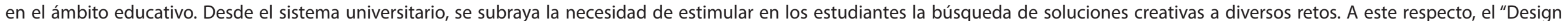

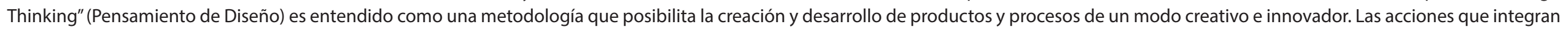
dicho método tienen, como eje conductor, la práctica y entreno del pensamiento lógico, la colaboración, la creatividad, la empatía y el aprendizaje a través de procesos de ensayo-error.

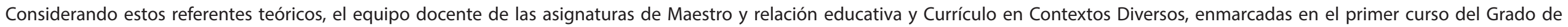

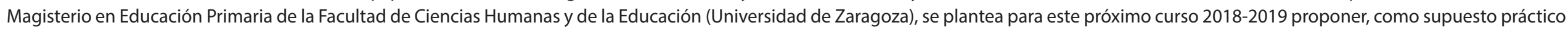

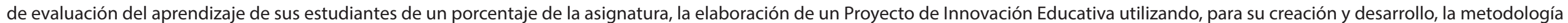

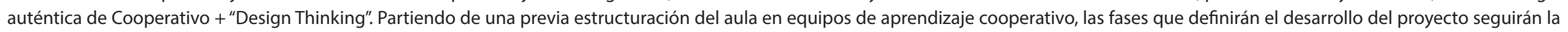

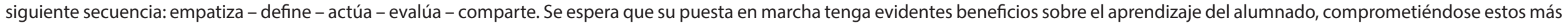
activamente en las tareas, buscando las mejores formas de aprender y desarrollando una mentalidad de análisis de diferentes opciones para alcanzar la mejores soluciones. 
El pensamiento creativo y cooperativo a través del Design Thinking: una metodología auténtica para trabajar la innovación en el aula universitaria Cecilia Latorre, Sandra Vázzquez, Ana Rodríguez, Jorge Arbués y Marta Liesa

Departamento de Ciencias de la Educación, clatorre@unizar.es

\section{CONTEXTUALIZACIÓN}

$1^{\circ} \mathrm{Grado}$ de Magisterio en Educación Primaria.

Facultad de Ciencias Humanas y de la Educación (Universidad de Zaragoza)

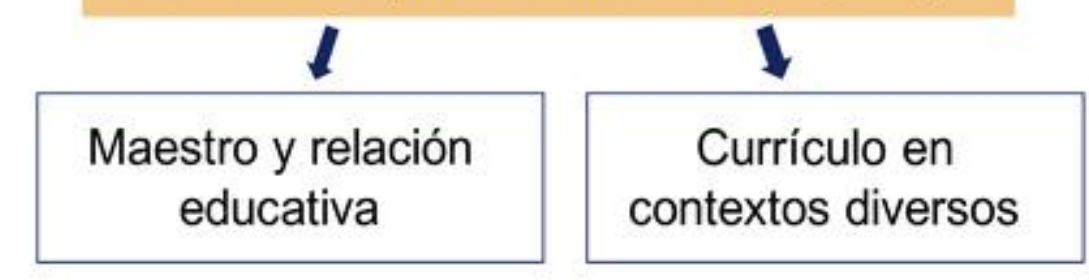

\section{OBJETIVOS}

Proponer, como supuesto práctico de ambas asignaturas (para el curso 2018-19), el diseño de un Proyecto de Innovación Educativa fundamentado en un trabajo interdisciplinar

Ruta de diseño del proyecto

Metodología Auténtica:

Cooperativa + Design Thinking

\section{METODOLOGIA (Design Thinking)} EMPATIZA
(y entorno) involucradas en el proyecto a desarrollar.

DEFINE-IDEA Selección de información única que conduce a perspectivas interesantes. Pensamiento expansivo.

ACTÚA-PROTOTIPA Las ideas se vuelven realidad. Los prototipos permiten visualizar las posibles soluciones para mejorarlas.

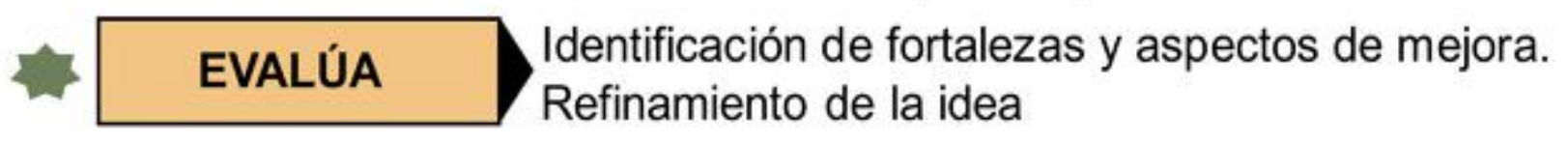

COMPARTE Ampliar el conocimiento y facilitar la proyección

\section{RESULTADOS ESPERADOS}

\section{Procesos de aprendizaje}

Generación de respuestas innovadoras y creativas para necesidades reales.
Actitudes positivas

Empatía y trabajo en equipo 


\section{Flip Teaching en el rendimiento académico y la satisfacción de los estudiantes del grado de trabajo social}

Oliván Blázquez, B.; Gómez Poyato, M. J.; Masluk, B.; Asensio Martínez, A.; Magallón Botaya, R.

\section{Palabras clave}

Flip Teaching, rendimiento académico, satisfacción, Grado de Trabajo Social.

\section{Resumen}

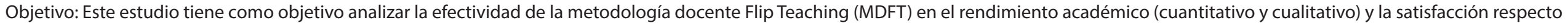
al aprendiza en la asignatura de"Trabajo Social con Grupos" en el Grado de Trabajo Social.

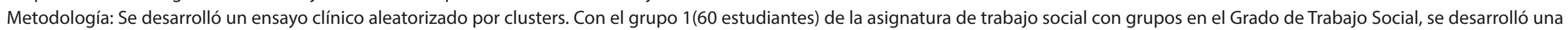

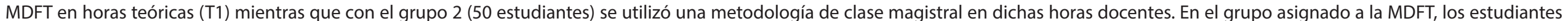

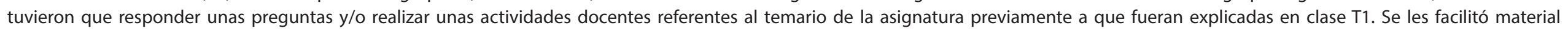
previamente: vídeos docentes elaborados mediante el programa Active Presenter y contenidos teóricos elaborado por el profesorado de la asignatura.

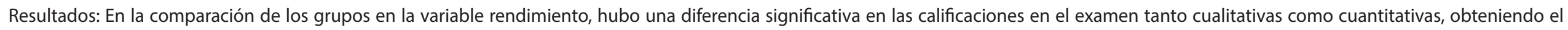

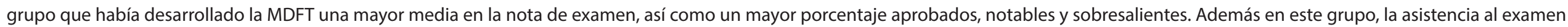

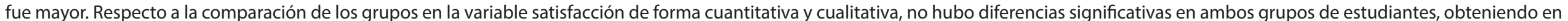

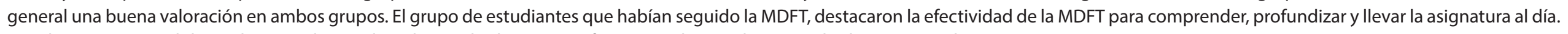
Conclusión: La metodología docente Flip Teaching ha resultado ser más efectiva en el aprendizaje que la clase magistral. 


\section{FLIP TEACHING EN EL RENDIMIENTO ACADÉMICO Y LA SATISFACCIÓN DE LOS ESTUDIANTES DEL GRADO DE TRABAJO SOCIAL.}

Oliván Blázquez, B*; Gómez Poyato, Mª J*; Masluk, B*; Asensío, A*; Magallón Botaya, $\mathrm{R}^{\star *}$. *Depart. de Psicología y Sociología, ${ }^{* \star}$ Depart. de Medicina, Psiquiatría y Dermatología. E-mail contacto: bolivan@unizar.es.)

CONTEXTO ACADÉMICO: Proyecto de innovación docente desarrollado en el grado de Trabajo Social, con los estudiantes del grupo 1 y 2 de la asignatura de Trabajo Social con Grupos, en la Facultad de Ciencias Sociales y del Trabajo de la Universidad de Zaragoza.

OBJETIVO: Analizar la efectividad de la metodología docente Flip Teaching (MDFT) en el rendimiento académico y la satisfacción respecto al aprendizaje.

METODOLOGÍA: Ensayo clínico aleatorizado por clusters $(n=110$ estudiantes). Con el grupo 1(60 estudiantes) se desarrolló una MDFT en horas teóricas (T1) mientras que con el grupo 2 (50 estudiantes) se utilizó una metodología de clase magistral.

Intervención: Preguntas y/o realizar unas actividades docentes referentes al temario de la asignatura previamente a que fueran explicadas en clase $\mathrm{T} 1$.

Material facilitado para su realización: Vídeos docentes y contenidos teóricos elaborados por el profesorado.
RESULTADOS: La muestra está formada en un $90,1 \%$ por mujeres, con una edad media de 20,5 años (DT: 3,27 ). No hay diferencias significativas iniciales entre ambos grupos.

Los resultados respecto al rendimiento académico se muestra en la siguiente tabla.

\begin{tabular}{|c|c|c|c|}
\hline VARIABLES & $\begin{array}{c}\text { GRUPO FLIPPED } \\
\text { TEACHING } \\
\mathrm{N}=58\end{array}$ & $\begin{array}{c}\text { GRUPO } \\
\text { CONTROL } \\
\mathrm{N}=43\end{array}$ & Pvalor \\
\hline $\begin{array}{l}\text { Calificaciones } \\
\text { cuantitativas }\end{array}$ & $6,56$ (DT: 1,58$)$ & $5,42$ (DT: 1,97$)$ & 0,002 \\
\hline $\begin{array}{l}\text { Sobresaliente } \\
\text { Notable }\end{array}$ & $\begin{array}{l}6,9 \% \\
34,5 \%\end{array}$ & $\begin{array}{r}2,3 \% \\
20,9 \%\end{array}$ & \\
\hline $\begin{array}{l}\text { Aprobado } \\
\text { suspenso }\end{array}$ & $\begin{array}{c}39,7 \% \\
19 \% \\
\end{array}$ & $\begin{array}{l}30,2 \% \\
46,5 \% \\
\end{array}$ & 0,025 \\
\hline Horas de estudio & 14,87 (DT; 10,26 ) & 15,11 (DT: 11,56 ) & 0,922 \\
\hline
\end{tabular}

Respecto a la satisfacción, no hubo diferencias significativas, obteniendo una buena valoración en ambos grupos, aunque el grupo de MDFT destacaron su efectividad para comprender, profundizar y llevar la asignatura al día.

CONCLUSIÓN: La metodología docente Flip Teaching ha resultado ser más efectiva en el rendimiento académico que la clase magistral. 


\section{Flippeando Economía con Active Presenter}

Mur Sangrá. M.; Domeque Claver, N.; Artero Escartín, I.

\section{Palabras clave}

Aprendizaje activo, motivación, flipped classroom, Active Presenter, TIC.

\section{Resumen}

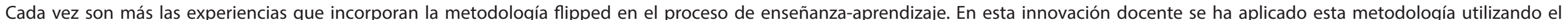

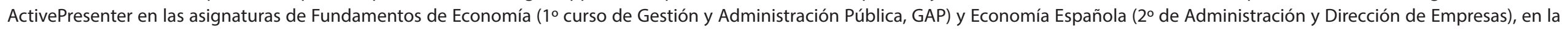
Facultad de Empresa y Gestión Pública; y en Economía Aplicada ( $2^{\circ}$ de Ciencias Ambientales), en la Escuela Politécnica Superior.

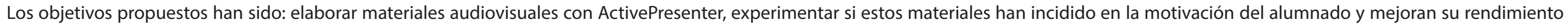
académico y analizar las posibilidades que esta aplicación ofrece en la enseñanza a distancia del Grado en GAP.

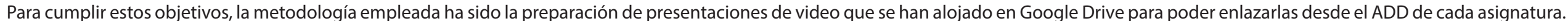

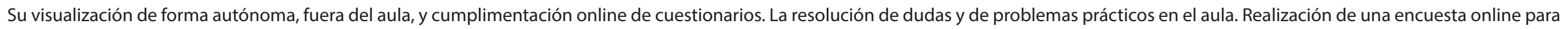
la evaluación de la nueva metodología. Y análisis de los resultados académicos.

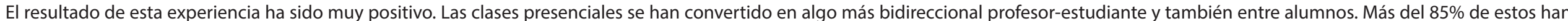

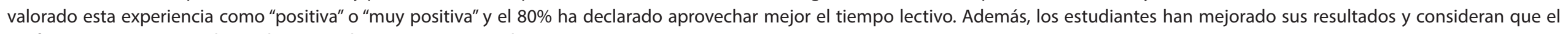
profesor está más motivado en el proceso de enseñanza aprendizaje.

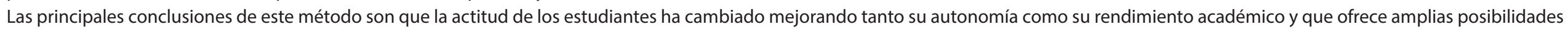
para la enseñanza a distancia en el Grado en GAP. 


\section{Flippeando Economía con ActivePresenter}

\section{Melania Mur, Nuria Domeque, Isabel Artero}

Estructura e H. Económica y Economia Pública, mmur@unizar.es

\section{CONTEXTO}

\section{Facultad de Empresa y Gestión Pública/ Escuela Politécnica Superior. Campus de Huesca}

Asignaturas: Fundamentos de Economía y Estructura Económica, Economía Española y Economía Aplicada

\section{OBJETIVOS}

- Preparar audiovisuales de apoyo a la "clase invertida" con ActivePresenter.

- Conseguir una clase presencial más bidireccional profesor-alumno y mayor cooperación entre estudiantes.

- Experimentar si materiales audiovisuales elaborados "ad hoc" favorecen una mayor implicación/ Motivación.

\section{METODOLOGÍA}

- Elaboración de "píldoras de aprendizaje".

- Vídeos alojados en carpetas de Google Drive (vinculadas a Unizar).

- Trabajo autónomo del alumno fuera del aula. Discusión y resolución de prácticas en clase.

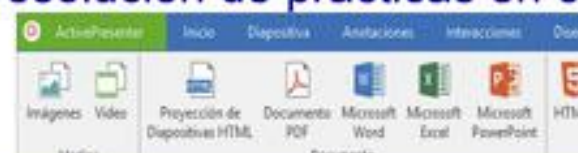

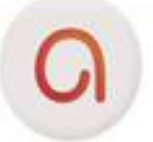

Active Presenter

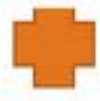

\section{The flipped woosssej $^{\circ}$}

\section{RESULTADOS Y CONCLUSIONES}

- La motivación del alumnado es mayor y su aprendizaje más participativo y dinámico.

- Los estudiantes llevan los temas "flippeados" más al día.

- Los vídeos creados por el profesorado permiten entender mejor las explicaciones al poderse visualizar varias veces.

- El alumnado considera que el profesorado está más implicado en el proceso de enseñanza-aprendizaje.

Valoración global de la experiencia de FlipTeaching a partir de presentaciones utilizando el ActivePresenter (siendo 1 muy negativo y 5 muy positivo).

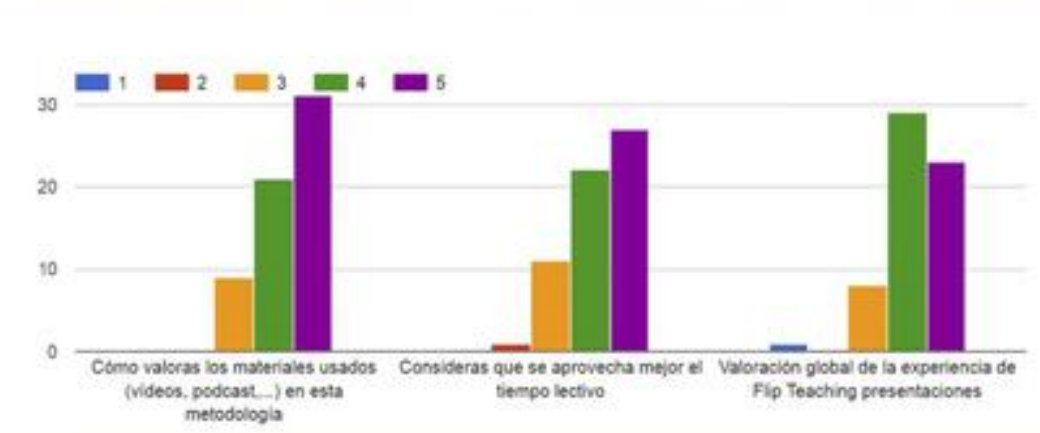




\section{La experiencia del design thinking en el desarrollo de la competencia iniciativa y espíritu emprendedor}

Cuevas Salvador, J.; Huertas Talón, J. L.; Ayensa Vázquez J. A.

\section{Palabras clave}

Educación, mentalidad, competencia, indicadores didácticos.

\section{Resumen}

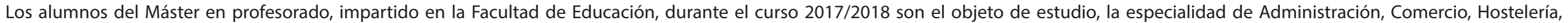
Informática y Formación y Orientación Laboral forman la muestra.

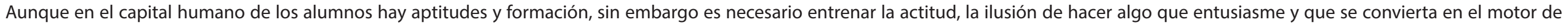
búsqueda del sentido de la competencia emprendedora. Para conseguirlo se ha implementado el proceso del design thinking siguiendo tres objetivos:

1. Implementar la metodología design thinking para estimular la creatividad en los alumnos y la adquisición de la competencia "sentido de iniciativa y espíritu emprendedor".

2. Establecer puentes entre el proceso design thinking en su dimensión educativa y la dimensión social, personal y laboral, como experiencia de aprendizaje cercanas a la realidad profesional del alumno.

3. Desarrollar indicadores didácticos en el procedimiento estandarizado de la metodología design thinking para la mejora del proceso de enseñanza-aprendizaje.

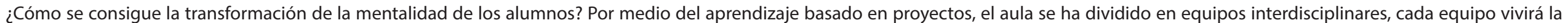
experiencia de implementar el proceso design thinking en la creación de una startup.

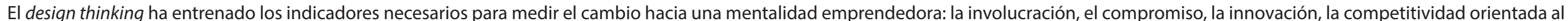
mercado liberal y el management o gestión de las organizaciones.

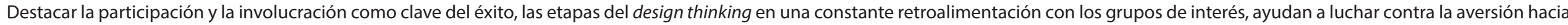
el trabajo y la desmotivación, ayuda a comprender la necesidad de humanizar el trabajo, las relaciones laborales, los modelos de gestión y los procesos productivos. 


\section{La experiencia del design thinking en el desarrollo de la competencia iniciativa y espíritu emprendedor}

Jesús Cuevas, José Luis Huertas, José Ángel Ayensa

Didáctica de las Lenguas y de las Ciencias Humanas y Sociales, jesuscs@unizar.es

- Máster Universitario en Profesorado E.S.O. Bachillerato, F.P. Y Enseñanzas de Idiomas, Artísticas y Deportivas

- Especialidad: Administración, Comercio, Hostelería, Informática y FOL

- Asignatura: El entorno productivo

- Muestra: 25 alumnos/as

\section{OBJETIVOS}

1. Implementar la metodologia design thinking para estimular la creatividad en los alumnos y la adquisición de la competencia "sentido de iniciativa y espiritu emprendedor".

2. Establecer puentes entre el proceso design thinking en su dimensión educativa y la

dimensión social, personal y laboral, como experiencia de aprendizaje cercanas a la realidad profesional del alumno.

3. Desarrollar indicadores didácticos en el procedimiento estandarizado de la metodología design thinking para la mejora del proceso de enseñanza-aprendizaje.

\section{RESULTADOS}

- Involucración

- Compromiso

- Innovación

- Competitividad

- Administración y gestión
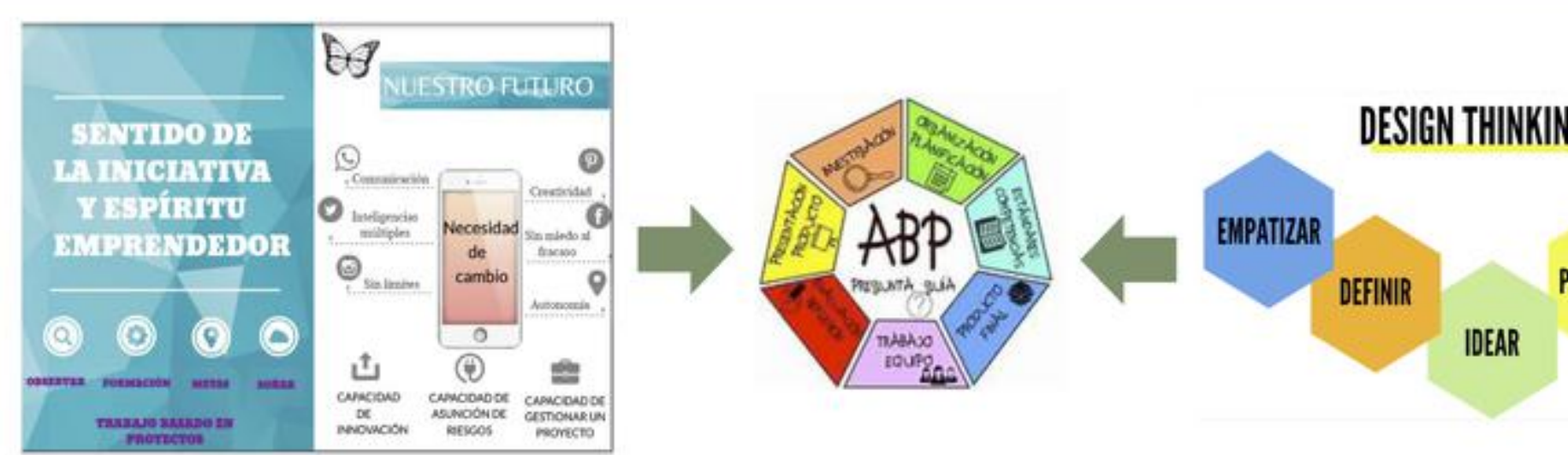

PROTOTIPAR

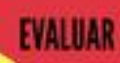

AR

CONCLUSIONES

- El design thinking significa humanizar el trabajo y un medio para la realización por el trabajo.

- El retrato de los indicadores que permiten encontrar sentido al estilo de vida emprendedor: escuchar, opinar, negociar, participar, generar conocimiento, sentido de responsabilidad, creatividad, innovación, iniciativa y toma de decisiones, asunción de riesgos, planificar y gestionar. 


\section{Píldoras audiovisuales para mejorar las habilidades de comunicación en los postgraduados del Grado de Veterinaria: un proyecto interdisciplinar}

Mitjana Nerin, O.; Boira Sarto, S.; Laborda, A.; Bonastre Rafales, C.; Falceto Recio, M. V.; Serrano,C.; Rodriguez, J.; Olivan, B.; García Campayo, J.; López del Hoyo, Y.

\section{Palabras clave}

Competencias, relación interpersonal, audiovisuales.

\section{Resumen}

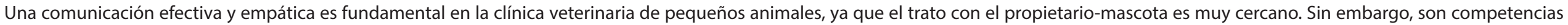

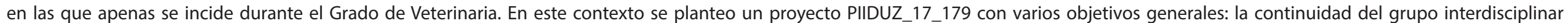

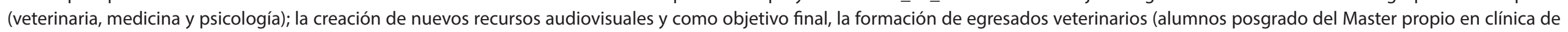

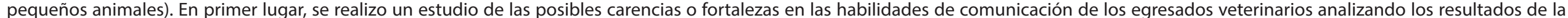

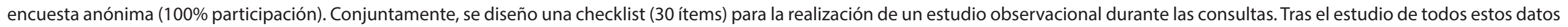

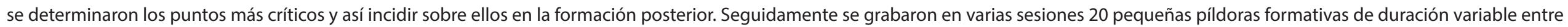

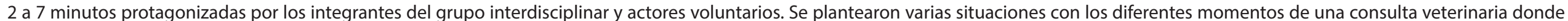

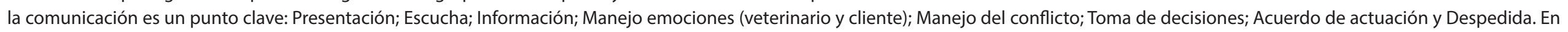

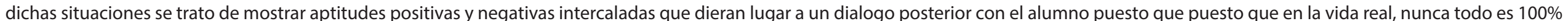

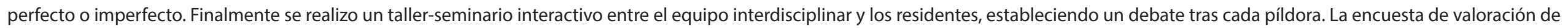
la actividad (97\% participación) lo considero muy positivo para su formación tanto profesional como personal. 
Píldoras audiovisuales para mejorar las habilidades de comunicación en los postgraduados del grado de veterinaria: un proyecto interdisciplinar Olga Mitjana', Santiago Boira², Alicia Laborda', Cristina Bonastre', Victoria Falceto', Carolina Serrano , Jose Rodriguez', Bárbara Olivan ${ }^{3}$, Javier García Campayo ${ }^{3}$,Yolanda López del Hoyo

${ }^{1}$ Dpto. Patologia Animal-Hospital Veterinario. Facultad de Veterinaria ${ }^{2}$ Dpto. de Psicología y Sociología. Facultad de Ciencias Sociales y del Trabajo. ${ }^{3}$ Dpto. de Medicina, Psiquiatría y Dermatología. Facultad de Medicina omitjana@unizar.es

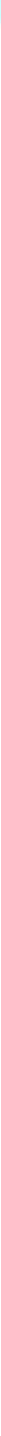




\section{¿Qué le aporta al estudiante crear contenido en YouTube a través de la metodología ApS?}

Cabanés Cacho, B.; García-Casarejos, N.; Romera Rodríguez, I.

\section{Palabras clave}

Creación de contenidos, competencia digital, aprendizaje servicio, habilidades comunicativas, educación financiera.

\section{Resumen}

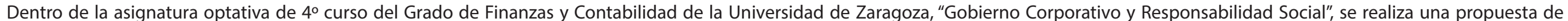

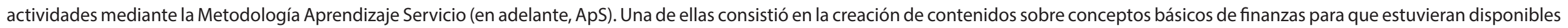
en YouTube. Esta ApS perseguía un triple objetivo:

1. Trabajar aspectos financieros a partir de la reflexión y el pensamiento crítico;

2. Prestar un servicio a la comunidad en materia de educación financiera, con un lenguaje claro y comprensible;

3. Incorporar las nuevas tecnologías a la formación creando un contenido digital de acceso ilimitado, inmediato y ubicuo.

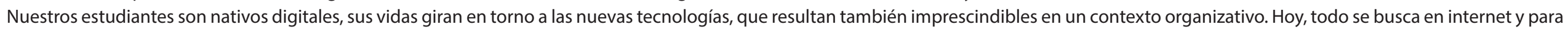

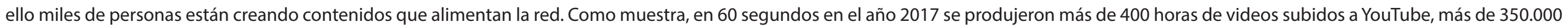

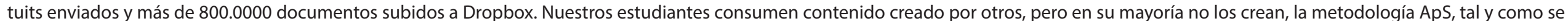
ha aplicado en este caso, les ha permitido convertirse en creadores de contenido.

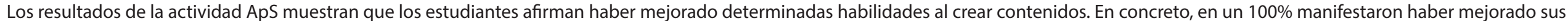

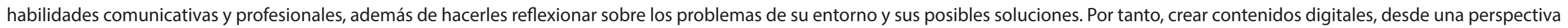
de ApS, permite mejorar las competencias transversales de nuestros estudiantes, lo cual mejora su empleabilidad más allá de los conocimientos técnicos. 


\title{
¿Qué le aporta al estudiante crear contenido en YouTube a través de la metodología Aps?
}

\author{
Begoña Cabanés, Nieves García-Casarejos, Israel Romera
}

Facultad de Economia y Empresa, bcabanes@unizar.es

La ApS consiste en el diseño, elaboración y creación de un video explicativo de conceptos básicos de finanzas para colaborar en la educación financiera de la sociedad, donde se utilicen términos habituales en las relaciones con las entidades bancarias con un lenguaje claro y comprensible.

Nuestros estudiantes están acostumbrados a consumir a diario contenido digital creado por otros. Con este trabajo se pretende ayudarles a crear contenido digital desde una perspectiva de servicio a la sociedad, al tiempo que se aproxima la universidad al mundo real. Cada vez es mayor la información que los estudiantes consumen en formato video respecto al formato texto. El desarrollo de estas competencias ayudará a su futura empleabilidad.

\section{OBJETIVOS :}

1. Favorecer la reflexión, el pensamiento crítico y las habilidades comunicativas

2. Prestar un servicio a la comunidad en materia de educación financiera

3. Incorporar las nuevas tecnologias creando un contenido digital relacionado con sus conocimientos adquiridos en la universidad

METODOLOGÍA:

Learning by doing y Aprendizaje Servicio (ApS)

Contextualización de la ApS

\begin{tabular}{|c|c|}
\hline \multicolumn{2}{|c|}{ Ficha Técnica } \\
\hline Facultad & Economía y Empresa \\
\hline Grado & Finanzas y Contabilidad \\
\hline & Gobierno Corporativo y \\
\hline Asignatura & Responsabilidad Social \\
\hline Curso & 49 \\
\hline Tipo de asignatura & Optativa \\
\hline ECTS & 6 \\
\hline Naturaleza de la ApS & $\begin{array}{l}\text { Obligatoria dentro de la } \\
\text { evaluación continua }\end{array}$ \\
\hline Modalidad de trabajo & Grupal \\
\hline Curso académico & 2017-2018 \\
\hline
\end{tabular}

\section{RESULTADOS Y CONCLUSIONES}

El 100\% de los estudiantes de esta ApS manifestaron, a través de un cuestionario que cumplimentaron, que habían mejorado sus habilidades comunicativas y profesionales al crear contenido digital. También les ayudó a reflexionar sobre los problemas de su entorno y posibles soluciones.

Trabajo financiado por la Universidad de Zaragoza Proyecto: PIIDUZ_17_164 


\section{Unidades didácticas para la educación literaria basada en canciones}

Cristóbal Hornillos, R.; Sanjuán Alvarez, M.; Villanueva Roa, J. D.

\section{Palabras clave}

Literatura, música, intertexto, interactividad.

\section{Resumen}

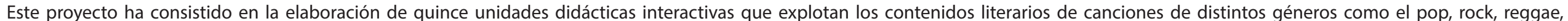

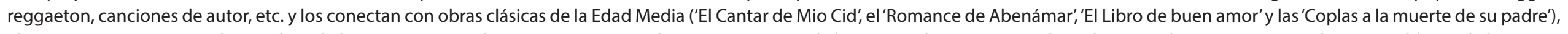

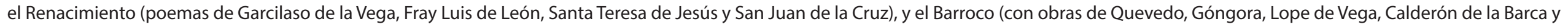
Sor Juana Inés de la Cruz).

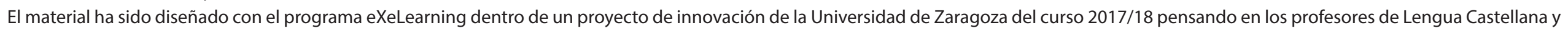

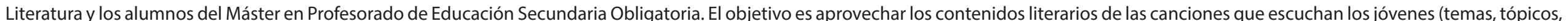

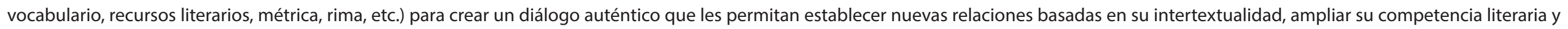

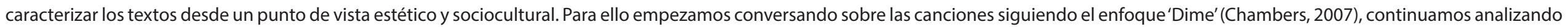
los contenidos literarios presentes en estas y concluimos ahondando en aspectos literarios del texto clásico.

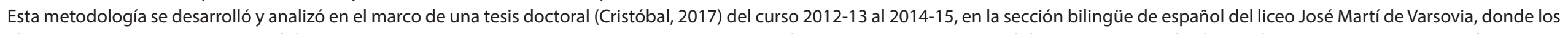

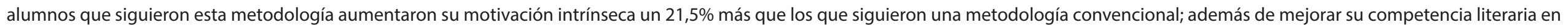
un $15,4 \%$ más que estos. 


\section{Unidades didácticas para la educación literaria basada en canciones}

Relación de autores: Cristóbal Hornillos, R; Sanjuán Álvarez, M; Villanueva Roa, J. D.

Universidad de Zaragoza, Universidad de Granada, IES Ramón Pignatelli / rcristobalh@educa.aragon.es

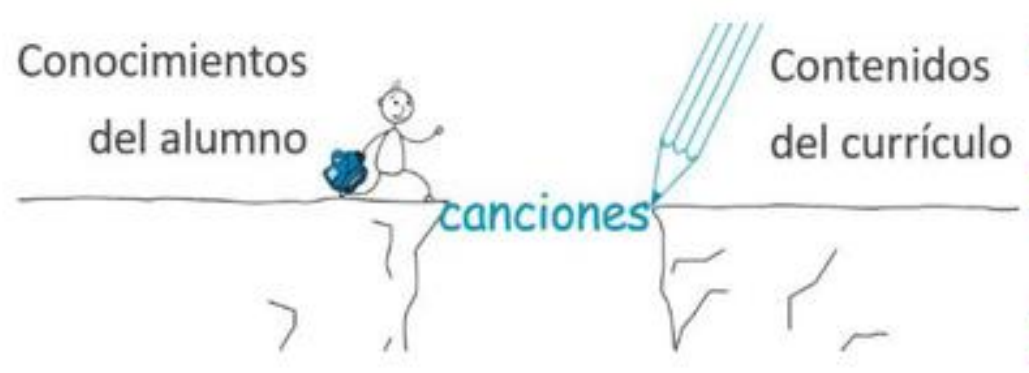

2 Proyecto de innovación de la Universidad de Zaragoza del curso 2017/18 para profesores de Literatura de $3^{\circ}$ de ESO y del Máster en Profesorado. $\gg$ El objetivo es aprovechar las canciones que escuchan los jóvenes para conectar con la tradición literaria y crear un diálogo intertextual auténtico.

$\gtrsim$ Los alumnos que siguieron esta propuesta dentro de una investigación

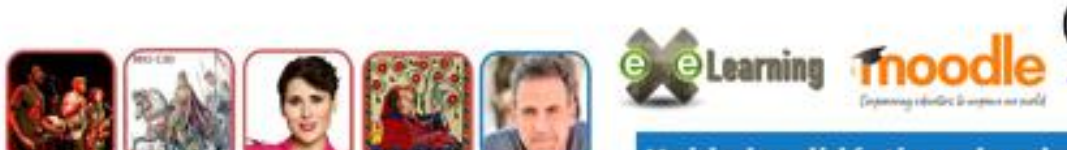
(Cristóbal, 2017) aumentaron su motivación y su competencia literaria.
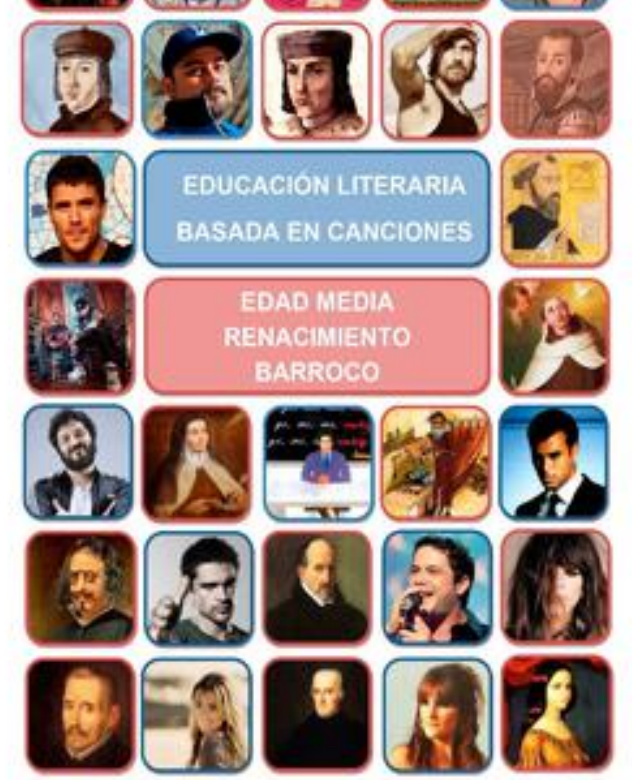

Unidades didácticas de educación literaria basada en canciones

Unidad 1. El motivo del destierro. Del rock alternativo al Cantar del Cid

Unidad 2. La descripción de Granada. De Rosa López al romance de Abenámar

Unidad 3. La búsqueda del buen amor. De Carlos Ponce al Arcipreste de Hita

Unidad 4. La vida y la muerte, De Nach a jorge Manrique

Unidad 5. El 'tempus fugit'. De Macaco y Fito a Garcilaso de la Vega

1. Introducción de contenidos a partir de la canción

2. Conexión de canción y el texto literario

3. Profundización y contextualización

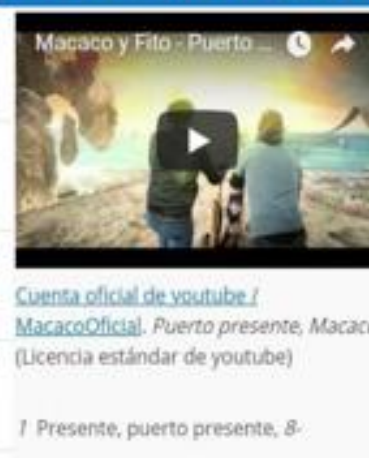

2 presente y aqui a tu lao $(\times 2)$ 8a

4 Traigo mis sorpresas enlacadas 10 .

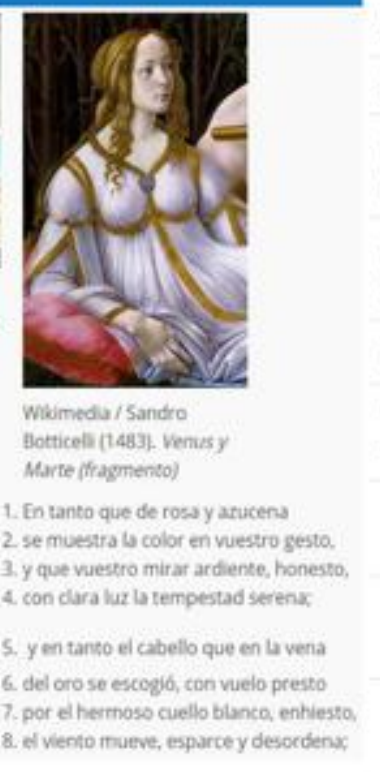

Unidad 6. El 'beatus ille'. Del Canto del Loco a Fray Luis Unidad 7. El lamento vital. Del Kanka a Santa Teresa Unidad 8. El amor carnal. Del reggraeton a la poesia mistica Unidad 9. Los vicios humanos. De 'No sopor, no sopor' de Sabina a la picaresca

Unidad 10. El amor eterno. De Enrique Iglesias a Francisco de Quevedo

Unidad 11. El Carpe Diem. De Juanes a Luis de Góngora Unidad 12. La descripción del amor. De Alejandro Sanz a Lope de Vega.

Unidad 13. La violencia de género. De 'Ella', de Bebé, a 'Fuenteovejunta', de Lope

Unidad 14. La vida como sueño. De 'Soñaré', de la Oreja de Van Gogh, a Calderón

6 Taptmonos la vida, 7

7 wenid hasta el congelador, 98 8 aquil ahora, la celebracón. 108 a Sor Juana Inés de la Cruz 



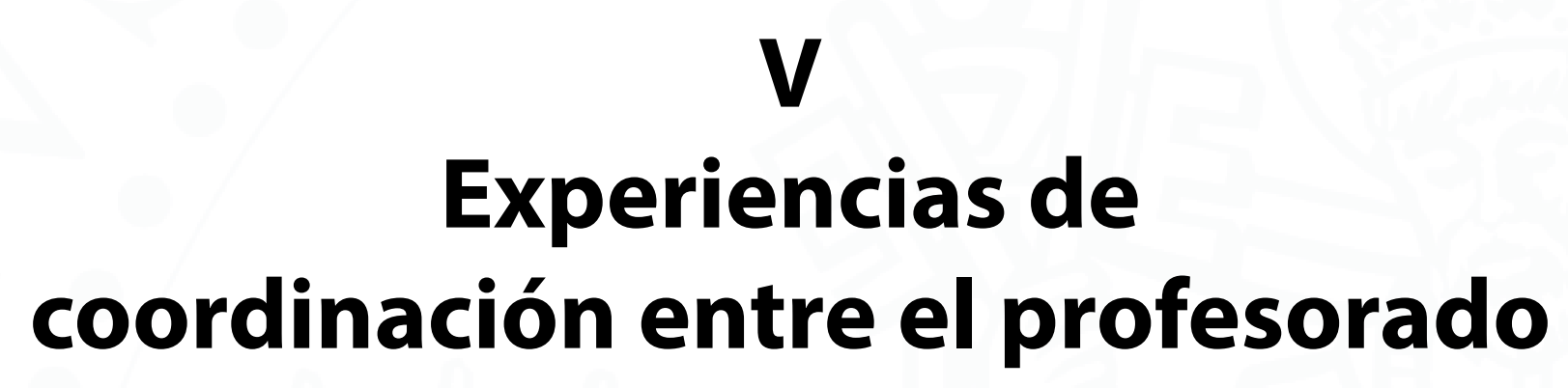




\section{Experiencias de coordinación entre el profesorado}

1. Gea Galindo, G.; Millera Peralta, Á.; Aznar Villacampa, M. P.; Francés Pérez, E.; Atienza Martínez, M.; Gil Lalaguna, N.

Aprendizaje mediante coordinación de asignaturas de tercer curso del Grado en Ingeniería Química

2. Guillén Navarro, N. A.

El alumnado chino ante las asignaturas jurídicas del Grado de Turismo de la Universidad de Zaragoza

3. Del Barrio Aranda, L.; López Casanova , M. B.; Nadal García, I.

El desarrollo de proyectos de colaboración interinstitucional como contribución a la formación educativa musical del estudiante de magisterio

4. Echeverría Domingo, J.; Royo Grasa, P.

Experiencia fuera del aula: Diseño y aplicación de métodos de aprendizaje activos por los alumnos de "Inglés en Educación Primaria II"

5. Vicente Romero, J.; Molinos Rubio, L. M.; Vélez Jiménez, M. P.; Pasamar Alzuria, G. V.; y el resto de miembros de AprenRED

Evaluación de la adquisición de competencias transversales entre profesores anfitriones y visitantes miembros de AprenRED

6. Bretos Fernández, I.; Díaz Foncea, M.; Marcuello Servós, C.; Sarasa Aznar, C.

Experiencias de co-creación de conocimiento crítico y colaborativo en el ámbito de la organización y gestión empresarial: El caso del Laboratorio de Economía Social (LAB_ES)

7. Aibar Solana, A.; Sevil Serrano, J.; Generelo Lanaspa, E.; Julián Clemente, J. A.; Murillo Pardo, B. Journal Club: transferencia de conocimiento y formación permanente entre iguales

8. Lucha López, P.; Sáez Bondía, M. J.; Claver Giménez, A. M.

Implicaciones de un proyecto de Aprendizaje y Servicio (ApS): redes de colaboración escuela-universidad para actualizar un plano del parque Miguel Servet de Huesca

9. Fernández Amat, C.; Nadal García, l.; Maestro Guerrero, F.; Balsera Gómez, F. J.; Contreras Sequeira, P.; López Casanova, B.; Alonso Blesa, J. F.

I Muestra de Juegos Tradicionales en la Facultad de Educación de Zaragoza

10. García Marco, F. J.; Pedraza Gracia, M. J.; Salvador Oliván, J. A.; Martínez Pestaña, M. J.; Ruberte Andreu, S.; Gracia Lafaja, C.

Plan de visibilización del Grado de Información y Documentación: Análisis de factores que inciden en la matrícula de nuevo ingreso, propuesta de estrategias y diseño de un plan de visibilidad 
11. Sánchez Sansegundo, F. J.; Gozalo Mandrión, A.

Reinvent The Classroom: Hacia la transformación del aula 


\section{Aprendizaje mediante coordinación de asignaturas de tercer curso del Grado en Ingeniería Química}

Gea Galindo, G.; Millera Peralta, Á.; Aznar Villacampa, M. P.; Francés Pérez, E.; Atienza Martínez, M.; Gil Lalaguna, N.

\section{Palabras clave}

Colaboración interdisciplinar, aprendizaje basado en problemas, integración de conocimientos.

\section{Resumen}

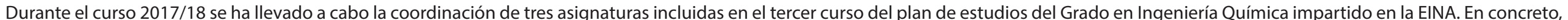

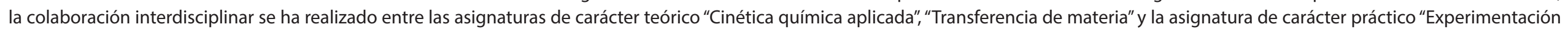

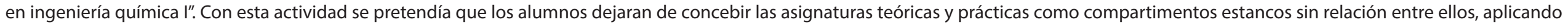

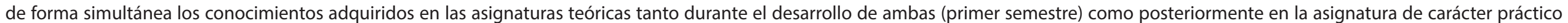
(segundo semestre).

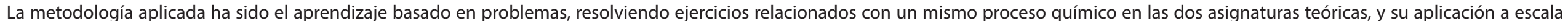

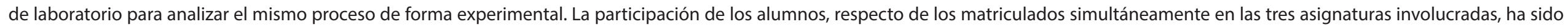

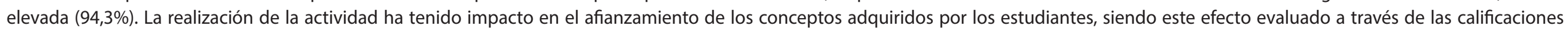

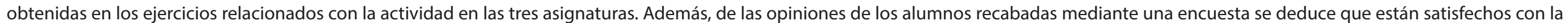
actividad y que ésta les ha servido para aprender a interrelacionar los conocimientos adquiridos.

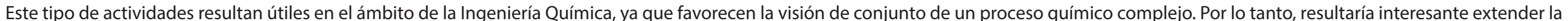
coordinación a otras asignaturas del mismo curso, e incluso de cursos diferentes.

Agradecimientos al Vicerrectorado de Política Académica por la concesión del PIIDUZ_17_351. 


\section{Aprendizaje mediante coordinación de asignaturas de tercer curso del Grado en Ingeniería Química}

Gloria Gea, Ángela Millera, Maria Pilar Aznar, Eva Francés, María Atienza, Noemí Gil

Ingenieria Química y Tecnologias del Medio Ambiente, glogea@unizar.es

Colaboración interdisciplinar entre asignaturas de $\underline{3 \text { er curso }}$ del Grado en Ingeniería Química:

- Cinética química aplicada (CQA)

- Transferencia de materia (TM)

- Experimentación en Ingeniería Química I (EIQI)

METODOLOGÍA: Aprendizaje mediante problemas y aplicación en el laboratorio.

Selección del problema: Proceso de absorción de $\mathrm{CO}_{2}$ sin/con reacción química

OBJETIVO: Integrar y aplicar
conocimientos adquiridos en distintas
asignaturas para favorecer la visión de
conjunto de un proceso químico.

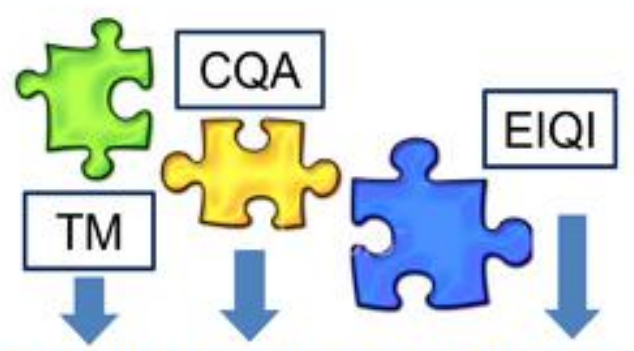

Carácter teórico $\longleftrightarrow$ Carácter práctico $1^{\mathrm{er}}$ semestre

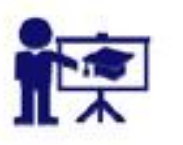

1. Ejercicio CQA

3. Práctica de laboratorio (EIQI)
Resolución simultánea para la obtención teórica de parámetros complementarios Comparación de resultados experimentales y teóricos

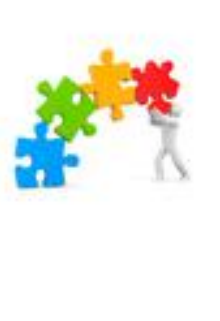

$2^{\circ}$ semestre

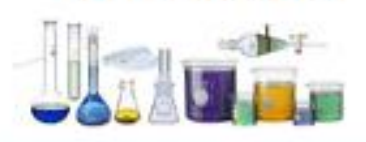

Encuesta realizada

Valoración muy positiva de la actividad por parte de los alumnos.

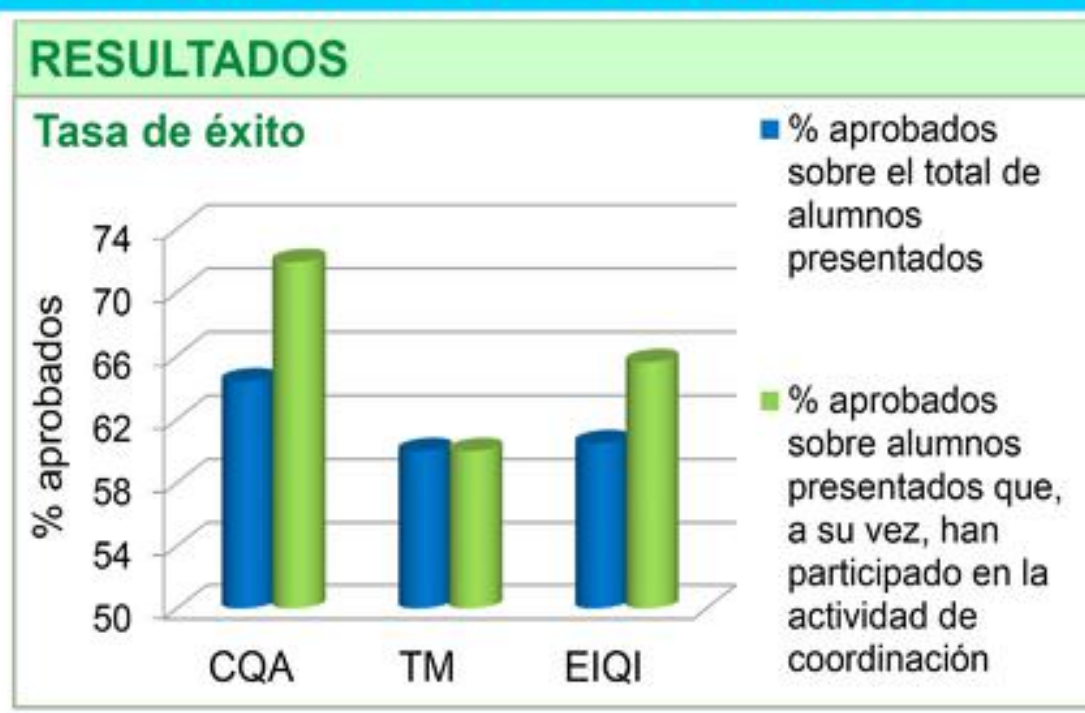

Calificaciones de la pregunta del examen de EIQI relacionada con la actividad

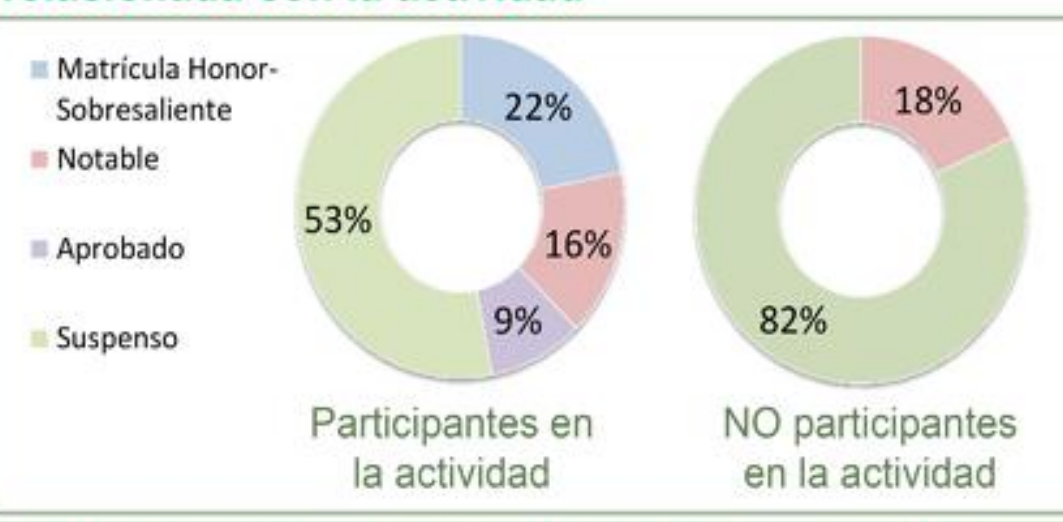

CONCLUSIONES: impacto positivo en el afianzamiento de los conceptos 


\section{El alumnado chino ante las asignaturas jurídicas del Grado de Turismo de la Universidad de Zaragoza}

Guillén Navarro, N. A.

\section{Palabras clave}

Derecho, China, integración, cultura.

\section{Resumen}

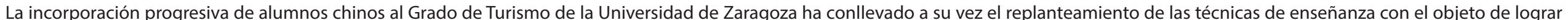

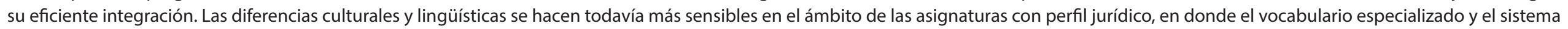

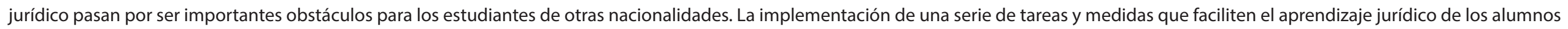
chinos, pasa por ser un elemento interesante que a su vez ayude a superar con éxito la correspondiente asignatura.

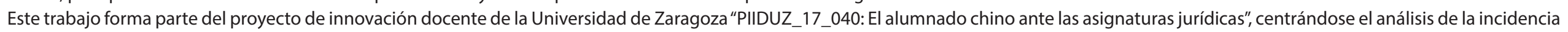

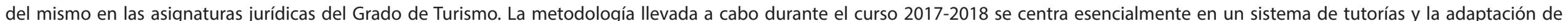

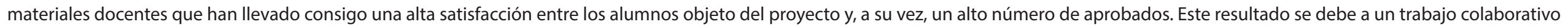

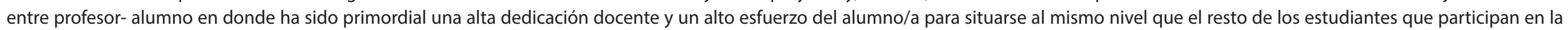

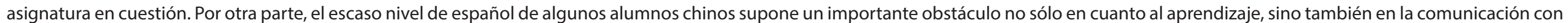
el profesor y el resto de compañeros de clase. 


\section{Universidad de Zaragoza}

\section{Nicolás Guillén}

Escuela de Turismo Universitaria de Zaragoza. nicolasg@unizar.es
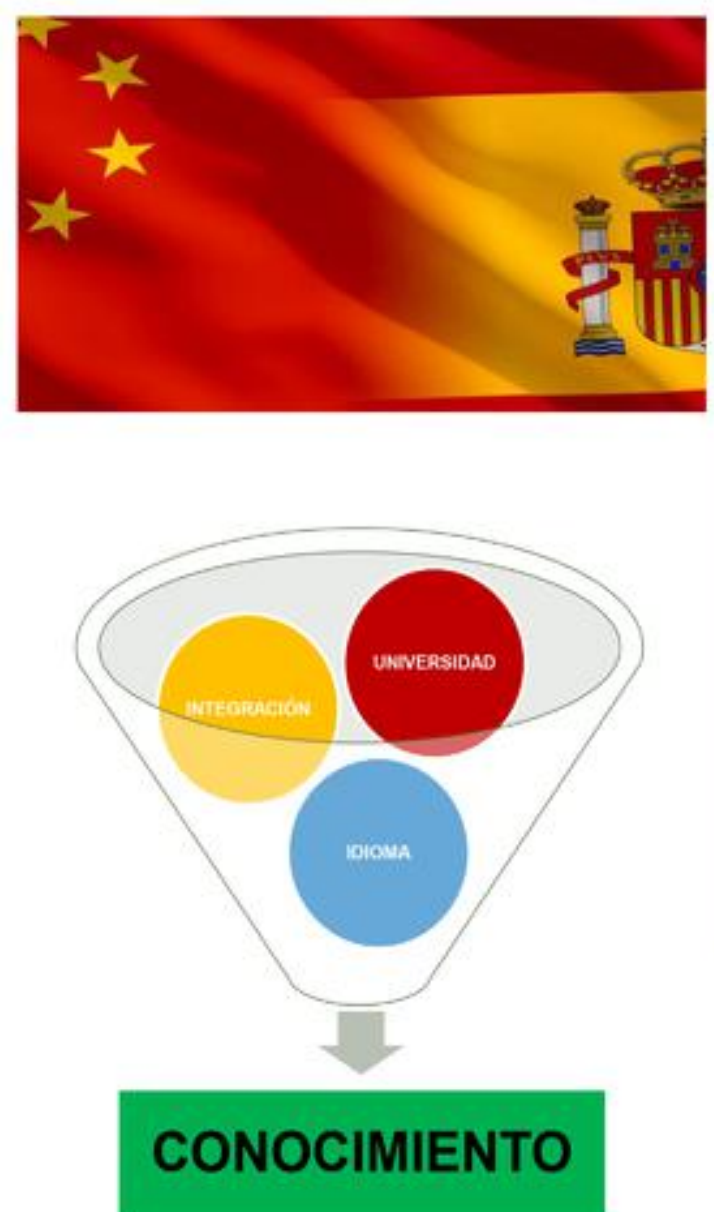

ESCUELA DE TURISMO DE ZARAGOZA GRADO DE TURISMO / ASIGNATURAS JURÍDICAS 27 ALUMNOS CHINOS EN EL CURSO 2017-2018

\section{OBJETIVOS}

- Realización de acciones que favorezcan el seguimiento por parte del alumnado chino en las asignaturas del Grado de Turismo de la Universidad de Zaragoza.

- Favorecer la permanencia y desarrollo provechoso de los estudios de turismo por parte de los alumnos chinos.

\section{ACCIONES}

- Tutorías / materiales adaptados / acciones de integración con los estudiantes españoles.

\section{CONCLUSIONES}

- Alto número de aprobados

- Integración total 


\section{El desarrollo de proyectos de colaboración interinstitucional como contribución a la formación educativa musical del estudiante de magisterio}

Del Barrio Aranda, L.; López Casanova, M. B.; Nadal García, l.

\section{Palabras clave}

Educación musical, educación infantil, praxis docente.

\section{Resumen}

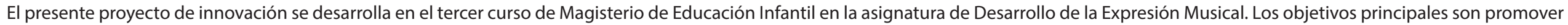

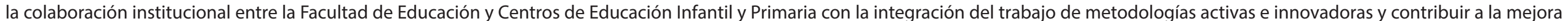

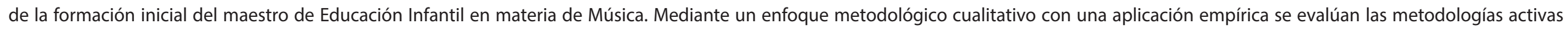

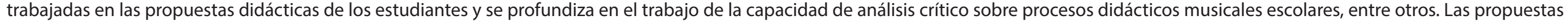

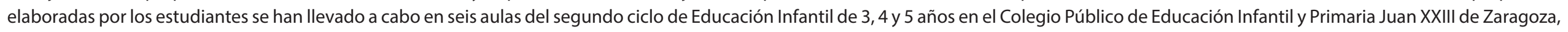

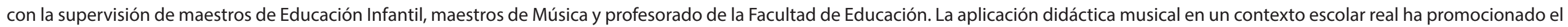

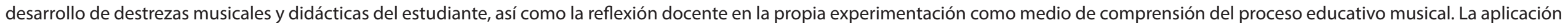

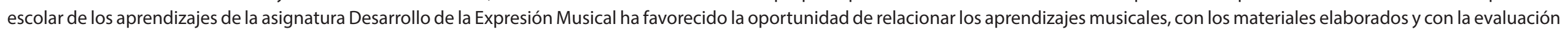

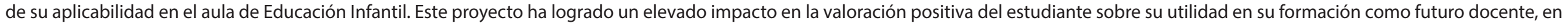
la promoción del trabajo cooperativo entre estudiantes y profesorado y en el establecimiento de redes colaborativas de actuación entre instituciones. 


\title{
El desarrollo de proyectos de colaboración interinstitucional como contribución a la formación educativa musical del estudiante de magisterio
}

\author{
Luis del Barrio, M. Belén López, Icíar Nadal \\ Departamento de Expresión Musical, Plástica y Corporal \\ delbarri@unizar.es, belocasa@unizar.es, iciarnad@unizar.es
}

Contexto: La coordinación entre el profesorado universitario y el de un Centro de Educación Infantil y Primaria con los estudiantes de tercer curso de magisterio en Educación Infantil que cursan la asignatura Desarrollo de la Expresión Musical.

Objetivos: a) Promover la colaboración entre la Facultad de Educación y centros de Educación Infantil y Primaria hacia la mejora de la formación musical del maestro de Educación Infantil. b) Potenciar el trabajo cooperativo. c) Implementar y evaluar las metodologías activas. d) Estimular la reflexión del estudiante en entornos colaborativos. e) Educar la capacidad de análisis crítico sobre los proyectos musicales escolares.

Metodología: Investigación-acción. Observación participante, pauta de evaluación (coevaluación), cuestionarios pretest y postest. Aplicación de las propuestas. Recogida de datos y análisis.

\section{Principales resultados:}

Implicación en el trabajo cooperativo

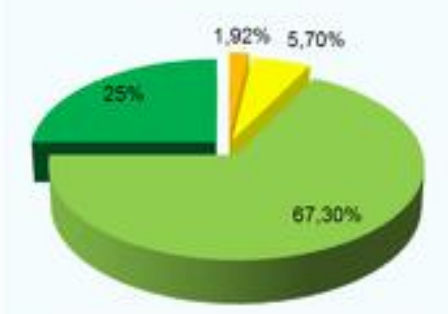

- Nada $=$ Poco Aceptable $=$ Bastante $=$ Mucho
Metodologias didácticas

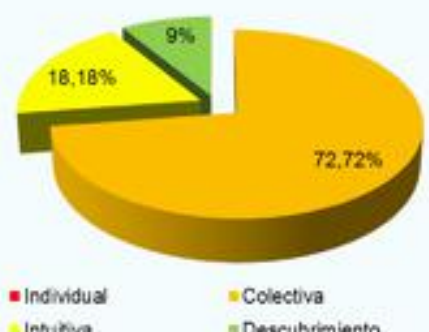

Análisis critico

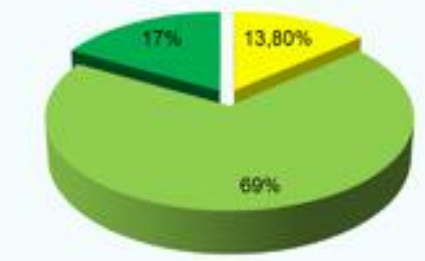

- Nada uPoco Aceptable = Bastante = Mucho

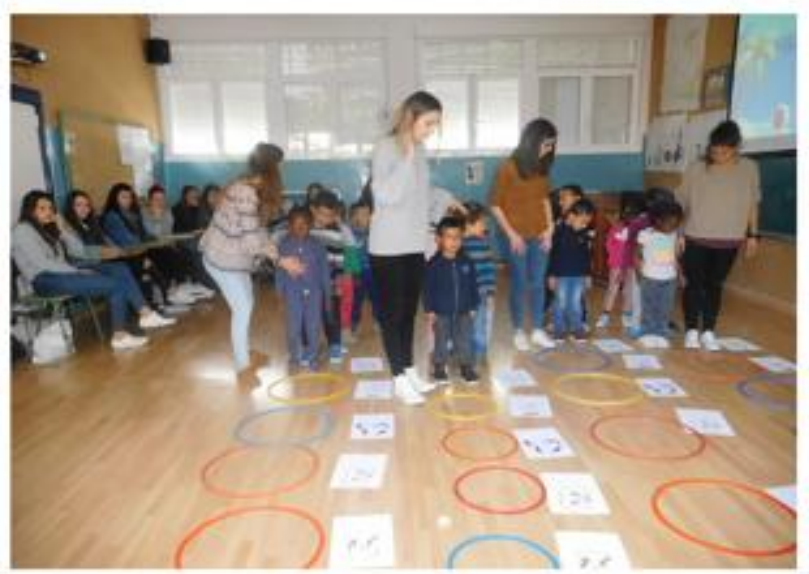

Conclusiones: La aplicación de proyectos cooperativos en un entorno escolar ha motivado la praxis docente, la reflexión y el análisis del conocimiento musical y didáctico en la propia experimentación. Su evaluación ha entrenado la capacidad didáctica y crítica del estudiante. 


\section{Experiencia fuera del aula: Diseño y aplicación de métodos de aprendizaje activos por los alumnos de "Inglés en Educación Primaria II"}

Echeverría Domingo, J.; Royo Grasa, P.

\section{Palabras clave}

Aprendizaje por proyectos, integración, coordinación profesor-alumno, bilingüismo, inteligencia emocional.

\section{Resumen}

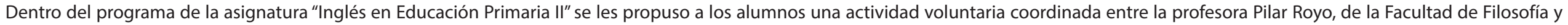

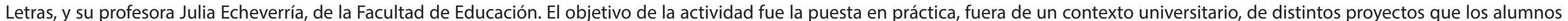

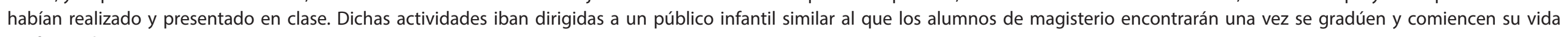
profesional.

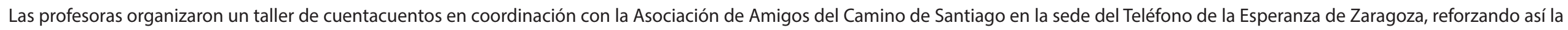

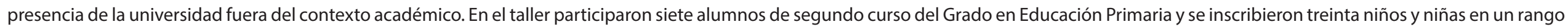

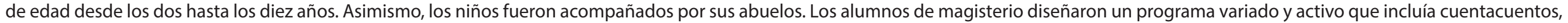
canciones, experimentos y juegos en inglés con los que consiguieron motivar e integrar tanto a los niños como a sus abuelos.

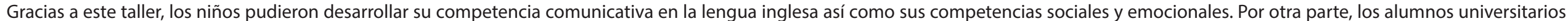

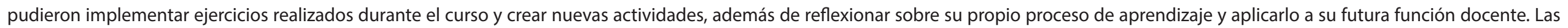

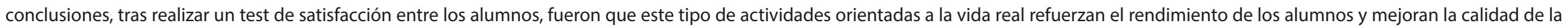
experiencia universitaria. 
Experiencia fuera del aula: Diseño y aplicación de métodos de aprendizaje activos por los alumnos de "Inglés en Educación Primaria II"

\section{Jullia Echeverría, Pilar Royo}

Departamento Filologia Inglesa y Alemana,prg@unizar.es, juliaed@unizar.es

1. CONTEXTO ACADÉMICO

- Titulación: Grado en Magisterio de Educación Primaria

- Curso: Segundo

- Asignatura: Inglés en Educación Primaria II

- Actividad: "Let's Play: Taller de cuentacuentos y juegos en inglés" realizado por alumnos y dirigido a un público infantil

- Colaboradores: Asociación Amigos del Camino de Santiago y Sede del Teléfono de la Esperanza (Zaragoza)

\section{METODOLOGÍA}

- Método comunicativo: Preparación de taller en inglés dirigido a niños entre $2 \mathrm{y}$ 10 años.

- Aprendizaje basado en proyectos:

-Experimento científico

-Actividades para el desarrollo de la inteligencia emocional de los niños

-Cuentos
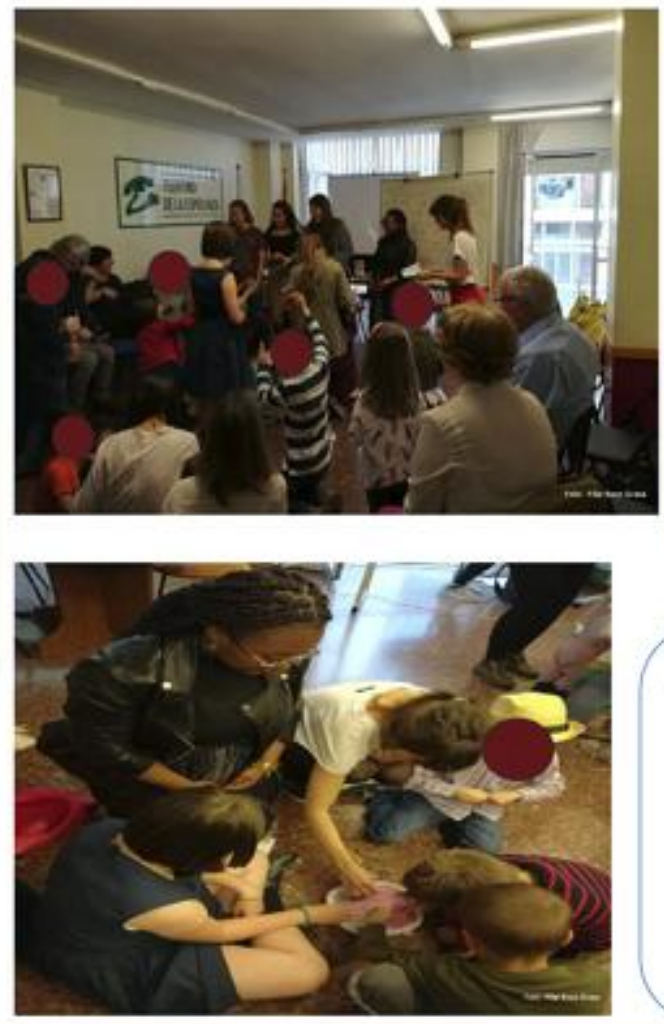

2. OBJETIVOS PROPUESTOS

* Aplicación de proyectos realizados en clase en el mundo real

* Reflexión del alumno sobre su propio aprendizaje

* Desarrollo de competencias comunicativas y sociales

* Práctica docente en lengua inglesa

* Resolución de problemas

\section{RESULTADOS}

$\checkmark$ Toma de contacto con su futura labor docente

$\checkmark$ Aumento de la motivación de los alumnos

$\checkmark$ Mejora de sus habilidades sociales y lingüísticas

$\checkmark$ Mayor habilidad para manejar una clase con distintos niveles y edades

\section{CONCLUSIONES}

El taller permitió que los alumnos fueran profesores por un día, mejorando su motivación, autoestima y satisfacción con la asignatura. Además, les ayudó a tomar conciencia sobre la importancia de diseñar actividades teniendo en cuenta la diversidad existente en las aulas. 


\section{Evaluación de la adquisición de competencias transversales entre profesores anfitriones y visitantes miembros de AprenRED}

Vicente Romero, J.; Molinos Rubio, L. M.; Vélez Jiménez, M. P.; Pasamar Alzuria, G. V.; y el resto de miembros de AprenRED

\section{Palabras clave}

Cooperación intelectual, mejora de la educación, desarrollo de las habilidades.

\section{Resumen}

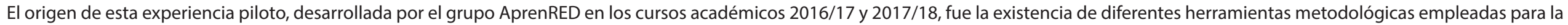
adquisición de competencias transversales. AprenRED está integrada actualmente por 45 profesores de 11 centros de la Universidad de Zaragoza de diversas áreas y especialidades.

Objetivos

- Determinar nivel de adquisición de las competencias transversales planteadas, según profesorado y alumnos.

- Valorar nivel de evaluación de las competencias transversales planteadas, según profesorado y alumnos.

Metodología

- Analizar viabilidad de posibles intervenciones de mejora.

Se propusieron los siguientes grupos y se distribuyó a los miembros en los mismos:

- Instrumental: Capacidad de análisis, síntesis, resolución de problemas y toma de decisiones

- Personal: Trabajo en equipo

- Sistémica: Creatividad, liderazgo, iniciativa y espíritu emprendedor

Varios profesores 'visitantes' asistieron a las clases prácticas de profesores 'anfitriones' de los distintos grupos. Mediante una encuesta, adaptada para

cada competencia y rol del profesor, se valoró la adquisición y evaluación de las competencias. Los alumnos cumplimentaron una encuesta anónima para conocer su percepción.

Resultados y conclusiones

En general, la percepción de los visitantes es de mayor nivel de adquisición que el previsto por el anfitrión. Esto muestra la necesidad de objetivar la evaluación de estas competencias.

- Los alumnos tienen una percepción, normalmente, intermedia entre anfitrión y visitante, lo queindica que las actividades están planteadas adecuadamente.

- Se trabajan de forma adicional a un nivel medio/avanzado diversas competencias transversales en una misma práctica.

- En las experiencias presentadas, no suele establecerse un sistema de evaluación específico para las competencias transversales. Esto muestra la necesidad de sistematizar el proceso de evaluación de competencias transversales. 
Evaluación de la adquisición de competencias transversales entre profesores anfitriones y visitantes miembros de AprenRED

Jorge Vicente*, Lucia Ma Molinos, Mi: Palmira Vélez, Gonzalo Vicente Pasamar, y el resto de miembros de AprenRED

AprenRED-unizar(http://aprenred.unizar.es), "jorgevr@unizar.es

\section{$\square$ CONTEXTO}

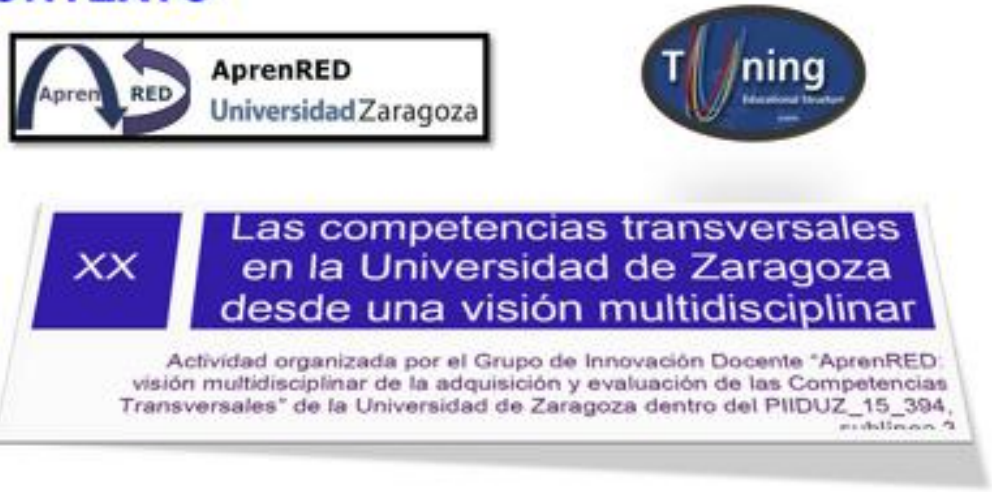

\section{口 OBJETIVOS}

- Determinar nivel de adquisición de competencias transversales planteadas.

- Valorar su nivel de evaluación.

- Analizar viabilidad de posibles intervenciones de mejora.

\section{a METODOLOGÍA}

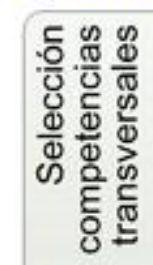

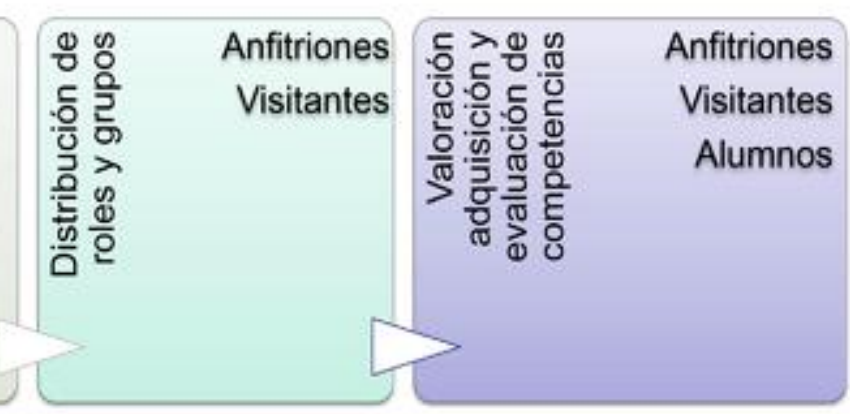

\section{口 RESULTADOS}

¿A qué nivel crees que los alumnos han podido adquirir competencias personales?

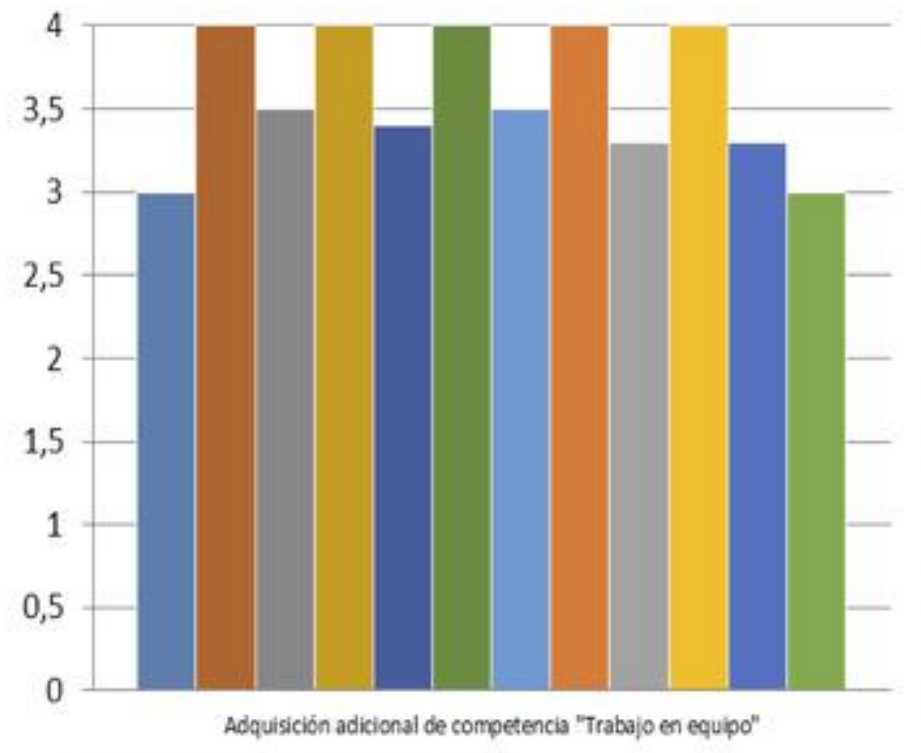

= Visitantes - Robótica

- Anfitrión- Robótica

- Visitartes - Análisis de plezas y ensamblajes

asstido por ordenador

Anfitrion-Analiss de plezas y ensamblajes

asistido por ordenador
- Visitartes - Mundo actual

- Anfitrión-Mundo actual

- Visitantes - Amér ica contemporánea

= Anfitrión - Amerika contemporánea

= Visitartes - Introducción al márketing

= Anfitrión - Introducción al märketing

- Visitartes - Disetio Gráfico Aplicado a Producto

" Anfitrión - Diseìo Gráfico Aplicado a Producto $\square$ CONCLUSIONES

- Necesidad de objetivar evaluación de competencias.

- Las actividades trabajan adecuadamente las competencias principales, así como las secundarias.

- Sistematizar evaluación de competencias transversales.

- Se debe buscar la coordinación de los títulos. 


\section{Experiencias de co-creación de conocimiento crítico y colaborativo en el ámbito de la organización y gestión empresarial: El caso del Laboratorio de Economía Social (LAB_ES)}

Bretos Fernández, I.; Díaz Foncea, M.; Marcuello Servós, C.; Sarasa Aznar, C.

\section{Palabras clave}

Economías alternativas, educación empresarial, Innovación docente, organizaciones de economía social, universidad.

\section{Resumen}

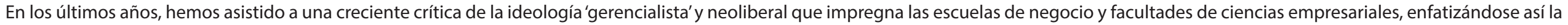
marginalización del pensamiento crítico sobre la organización y gestión que se produce diariamente en dichos espacios educativos.

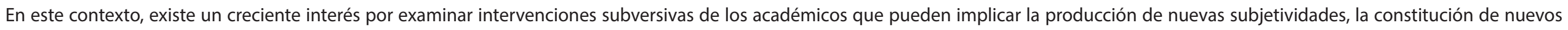
modelos organizacionales y/o la vinculación de estos modelos con los movimientos sociales actuales.

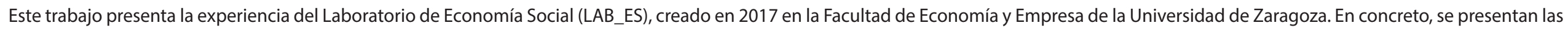
principales experiencias e intervenciones realizadas desde el LAB_ES en torno a tres ejes:

(1) Espacio de trabajo colectivo; (2) Espacio de participación de la comunidad universitaria; (3) Espacio de Investigación colectiva.

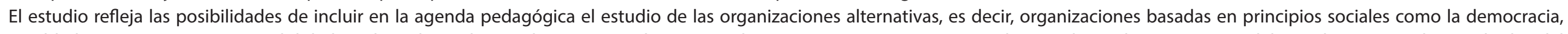

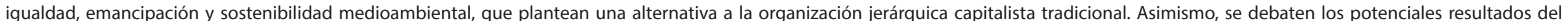

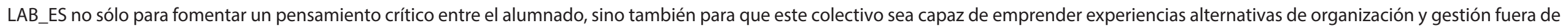

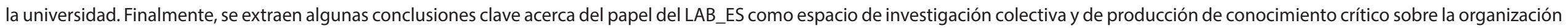

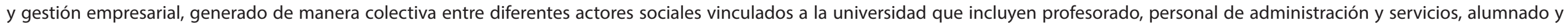
profesionales del sector. 
Experiencias de co-creación de conocimiento crítico y colaborativo en el ámbito de la organización y gestión empresarial: El caso del Laboratorio de Economía Social (LAB_ES)

\author{
Ignacio Bretos, Millán Díaz Foncea, Carmen Marcuello, Clara Sarasa
}

Dpto.de Dirección y Organización de Empresas; ibretos@unizar.es; millan@unizar.es; cmarcue@unizar.es; clarasarasa@gmail.com

\begin{abstract}
Contexto académico
Alumnado, PDI y PAS de

la Facultad de Economía

y Empresa (Universidad de Zaragoza)
\end{abstract}

¿Por qué el LAB_ES?

- Marginalización de modelos alternativos de organización y gestión en la docencia en economía y empresa

- EI LAB_ES nace en 2017 como un espacio para experimentar con la Economía Social (ES) por parte de la comunidad universitaria $\rightarrow$ alumnado, PDI y PAS practican con proyectos basados en los principios de la ES
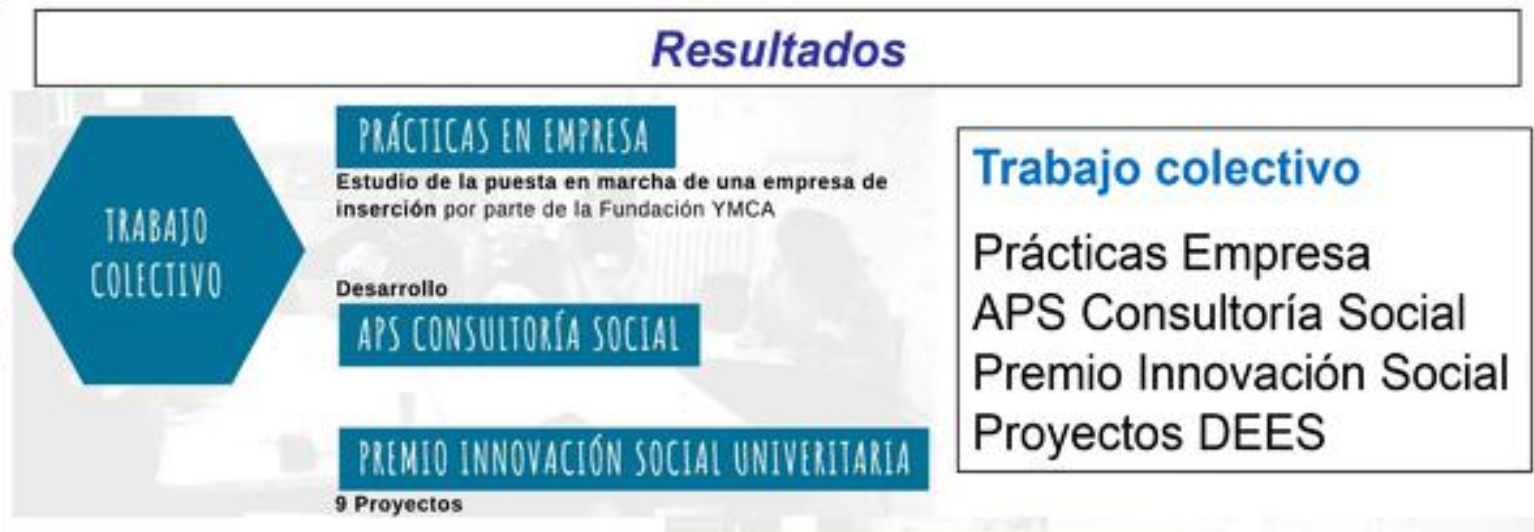

Participación Comunidad

Presentación LAB_ES

Semillero de Ideas

Encuentro Universidad-ESS

Miércoles Comercio Justo

Del Laboratorio al Aula CLAUSULLS SOCIALIS
53 entidades analizadas I TFG I
Guía para la contratación pública

EMPRENDEDORES COOPERAIIVOS 65 casos analizados I TFG

DiRECTORIO DE ECONOMIA SOCIAL

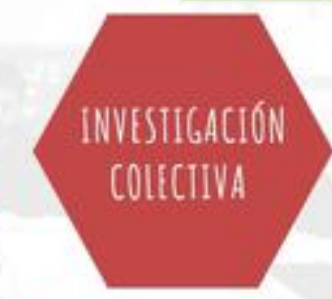

502 entidades / Herramienta / Ayuntamiento de Zaragoza / Caja Laboral / Universidad de Zaragoza (créditos)

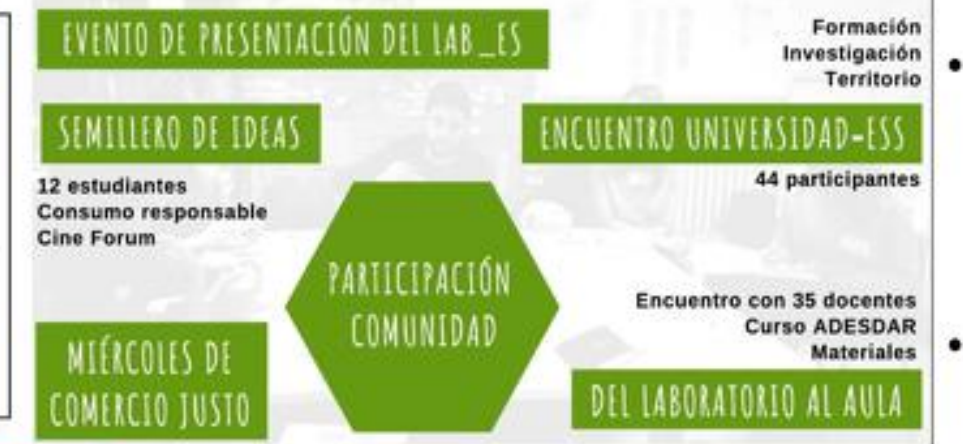

Investigación colectiva

Cláusulas Sociales

Emprendedores Cooperativos

y Contratación Pública

Directorio de Economía Social
Conclusiones

- Difusión entre la comunidad universitaria de experiencias de organización y gestión basadas en los principios de democracia, solidaridad, ayuda mutua, compromiso con el entorno, etc.

- Potenciación entre los participantes de una visión crítica de la economía y la gestión empresarial

- Generación de conocimiento de manera colectiva entre diferentes agentes (profesores, alumnos, PAS, profesionales y trabajadores de la Administración Pública)

- Espacio transformador con un largo recorrido de futuro 


\section{Journal Club: transferencia de conocimiento y formación permanente entre iguales.}

Aibar Solana, A.; Sevil Serrano, J.; Generelo Lanaspa, E.; Julián Clemente, J. A.; Murillo Pardo, B.

\section{Palabras clave}

Traducción integrada del conocimiento, formación permanente, investigación cuantitativa y cualitativa, competencias transversales.

\section{Resumen}

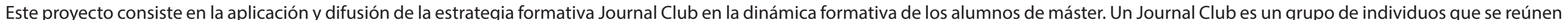

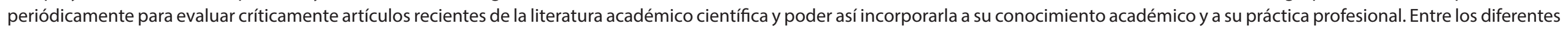
objetivos planteados, esta experiencia pretendía:

1. fomentar las competencias transversales y específicas de la difusión científica;

2. comprender la importancia de la transferencia integrada del conocimiento entre la sociedad.

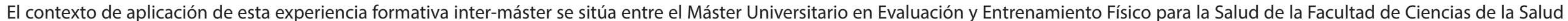

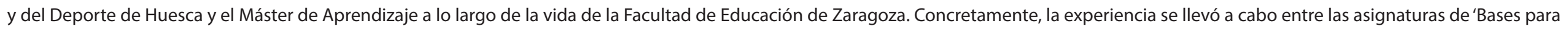

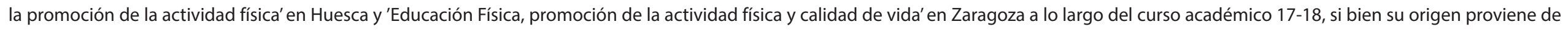
una experiencia piloto del curso 16-17.

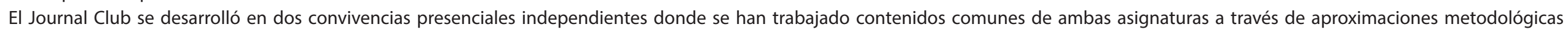

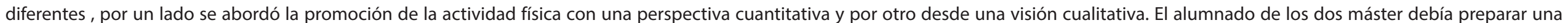

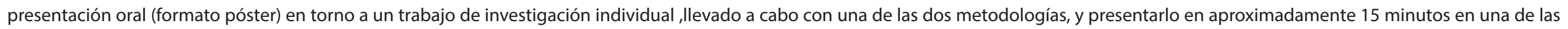

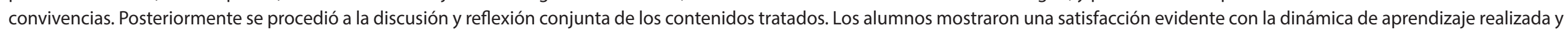
el conocimiento de la estrategia de formación continua para su futuro profesional. 


\title{
Journal Club: transferencia de conocimiento y formación permanente entre
} iguales

\author{
Alberto Aibar, Javier Sevil, Eduardo Generelo, José Antonio Julián \& Berta Murillo
}

Departamento de Expresión Musical, Plástica y Corporal, aibar@unizar.es

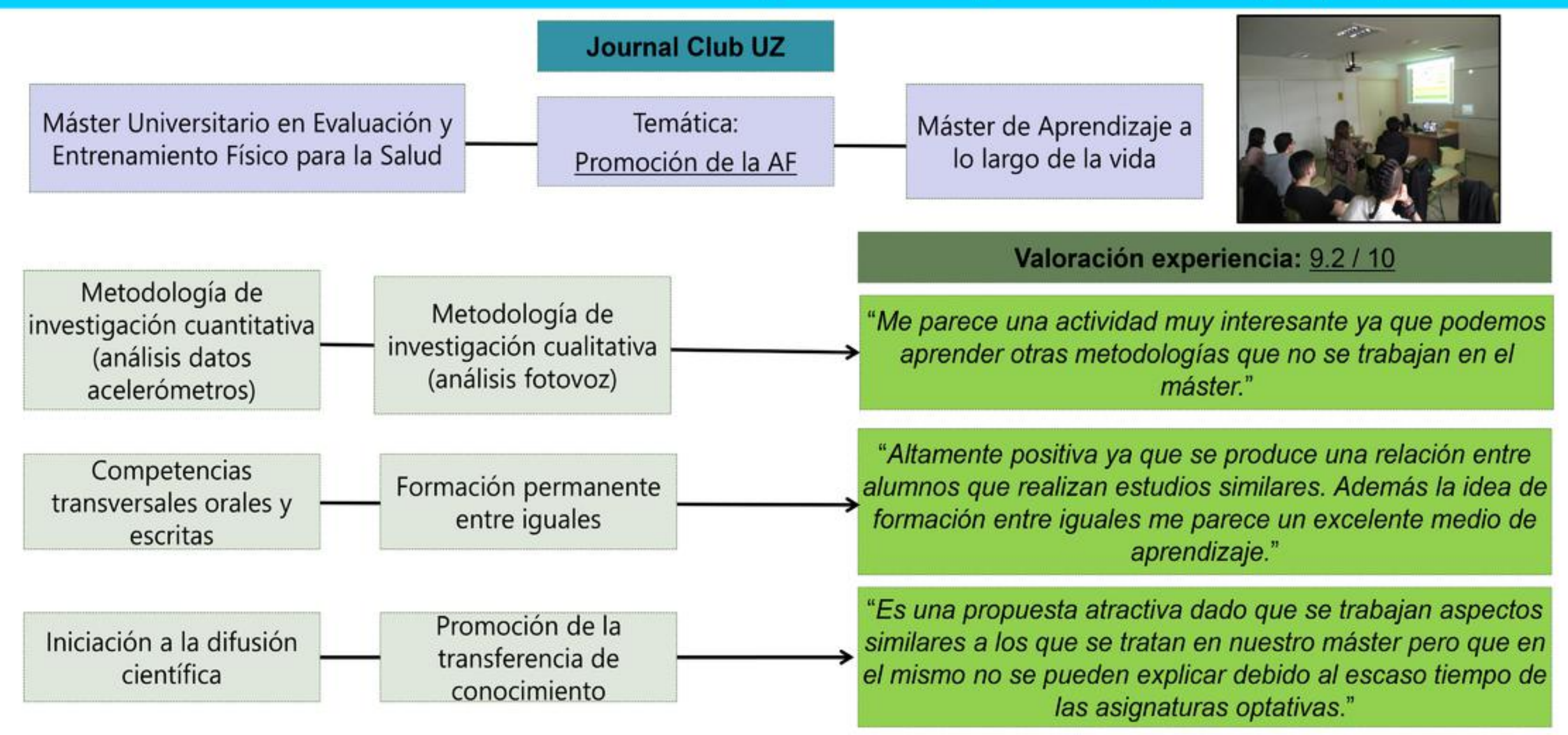

Conclusión: Dinámica positiva de aprendizaje y formación continua 


\section{Implicaciones de un proyecto de Aprendizaje y Servicio (ApS): redes de colaboración escuela-universidad para actualizar un plano del parque Miguel Servet de Huesca}

Lucha López, P.; Sáez Bondía, M. J.; Claver Giménez, A. M.

\section{Palabras clave}

Coordinación inter-nivel, formación docente, educaciónprimaria.

\section{Resumen}

Contexto:

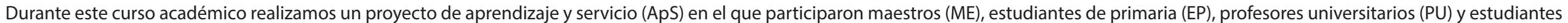
del Grado de Maestro en Educación Primaria(EGM).

Objetivo. Evaluar las implicaciones de la puesta en marcha de un proyecto de ApS desde las tres entidades participantes en el mismo: la escuela, la universidad y la ciudad de Huesca.

Metodología:

El desarrollo del proyecto de ApS constó de las siguientesfases:

- Diseño, acordado entre ME y PU, de una secuencia para conocer los árboles del parque Miguel Servet deHuesca.

- Puesta en marcha de la secuencia. Durante su desarrollo los EP detectaron que el plano de los árboles del parque estaba desactualizado. Se decidió actualizarlo. También colaboraron EGM, ME yPU.

- Presentación del nuevo plano alayuntamiento.

Resultados:

- Evaluación de los aprendizajes eimplicaciones.

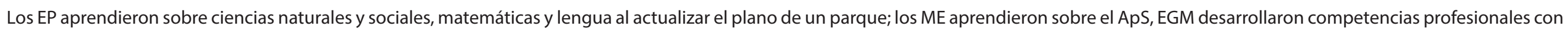

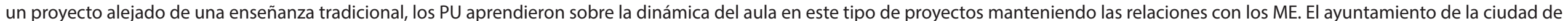
Huesca fue informado de la desactualización y recibió un plano actualizado.

\section{Conclusiones:}

Desde la formación de maestros y profesores el ApS aporta aprendizajes sobre el tema tratado, incrementa la eficacia de la acción docente y el compromiso en la transformación de la sociedad. 
Implicaciones de un proyecto de Aprendizaje y Servicio (ApS): redes de colaboración escuela-universidad para actualizar un plano del parque Miguel Servet de Huesca.

\section{Pedro Lucha, Ma José Sáezz, Ana Claver}

Departamento Didáctica de las Ciencias Experimentales, plucha@unizar.es

\begin{tabular}{|l} 
Contexto \\
Profesores de la asignatura Didáctica \\
del Medio Biológico y Geológico \\
(DMBG) de la Facultad de Ciencias \\
Humanas y de la Educación
\end{tabular}

Estudiantes del grado de maestro en educación Primaria realizando prácticas escolares y TFG

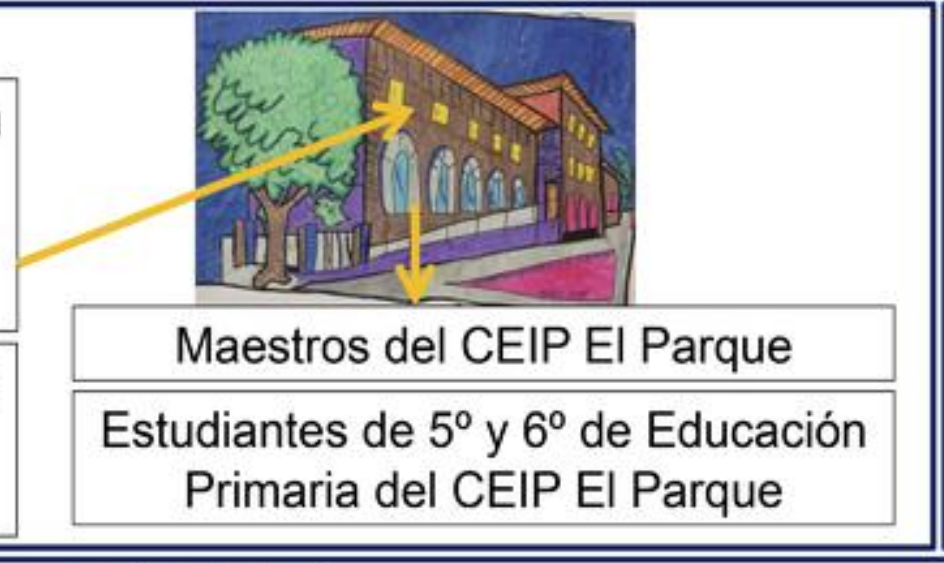

\section{Objetivo}

Evaluar las implicaciones de la puesta en marcha de un proyecto de ApS desde las tres entidades participantes en el mismo: la escuela, la universidad y la ciudad de Huesca

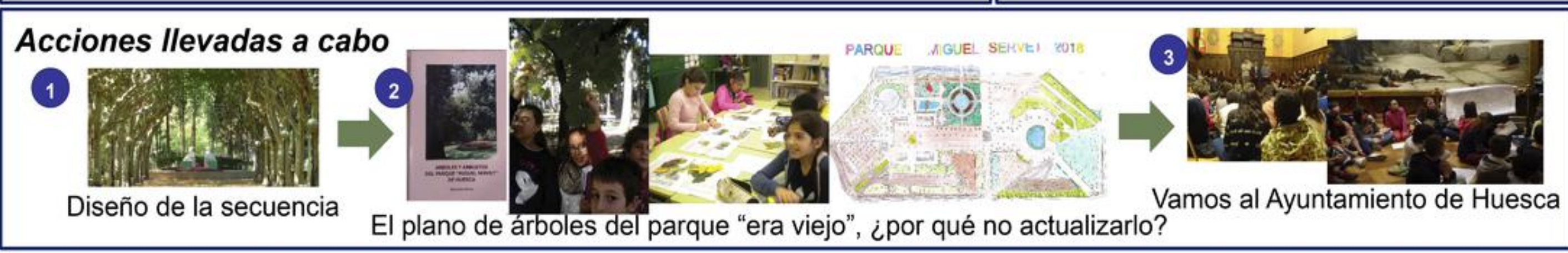

\section{Resultados y conclusiones}

El proyecto realizado tuvo implicaciones para todos los participantes en el mismo, aprendiendo sobre el ApS, tanto maestros como profesores, generando implicación en los estudiantes de primaria al mismo tiempo que aprendían matemáticas, lengua y ciencias. Además se han hecho más fuertes las redes de colaboración entre escuela y universidad.

El plano elaborado ha servido de apoyo al ayuntamiento para la creación de una aplicación móvil sobre el parque Miguel Servet. 


\section{Muestra de Juegos Tradicionales en la Facultad de Educación de Zaragoza}

Fernández Amat, C.; Nadal García, l.; Maestro Guerrero, F.; Balsera Gómez, F. J.; Contreras Sequeira, P.; López Casanova, B.; Alonso Blesa, J. F.

\section{Palabras clave}

Educación musical, musica tradicional, música en la escuela, el juego, aprendizaje lúdico.

\section{Resumen}

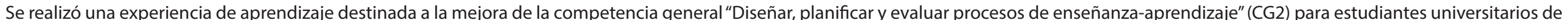

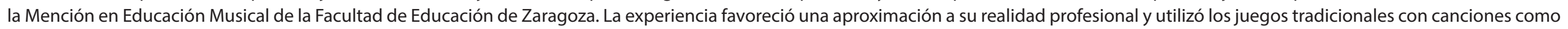

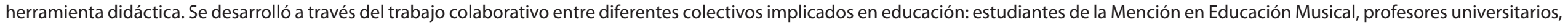

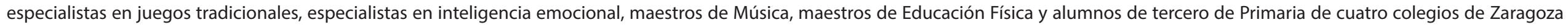

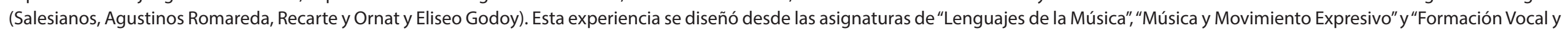

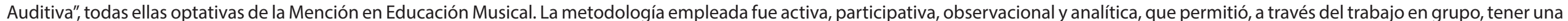

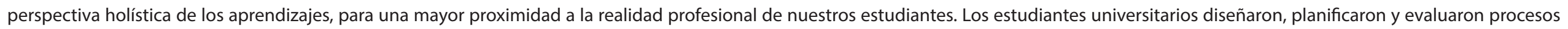

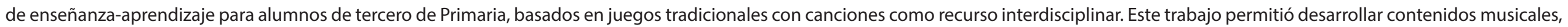

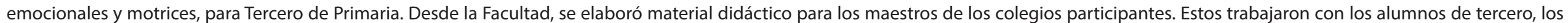

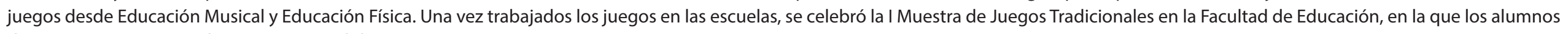
de Tercero compartieron los juegos aprendidos.

Esto permitió, a través de los juegos tradicionales, mejorar la competencia CG2 favoreciendo una aproximación a la realidad profesional de nuestros estudiantes. 


\section{Muestra de Juegos Tradicionales en la Facultad de Educación de Zaragoza}

\section{Carmen Fernández, Icjar Nadal, Fernando Maestro, Francisco José Balsera, Pablo Contreras, Belén López, José Francisco Alonso}

Departamento de Expresión Musical, Plástica y Corporal, cfamat@unizar.es

Contexto: Experiencia para los estudiantes de cuarto curso, pertenecientes a la Mención en Educación Musical de la Facultad de Educación. Desde las asignaturas de "Lenguajes de la Música", "Música y movimiento expresivo" y "Formación vocal y auditiva". Se emplearon juegos tradicionales con canciones para diseñar actividades destinadas a alumnos de tercero de Educación Primaria.

Objetivos: 1.- Facilitar una mejora en el aprendizaje de la competencia general CG2: Diseñar, planificar y evaluar procesos de enseñanza-aprendizaje. 2.- Desarrollar una experiencia innovadora a través de los juegos tradicionales con canciones. 3.- Aproximar a los estudiantes a la realidad profesional de su especialidad. 4.- Celebrar la I Muestra de Juegos Tradicionales.

Metodología: Activa, participativa, observacional y analítica, a través del trabajo en grupo.

Resultados: ¿Esta experiencia te ha servido para:

1.- Aprender a diseñar procesos de enseñanza-aprendizaje?

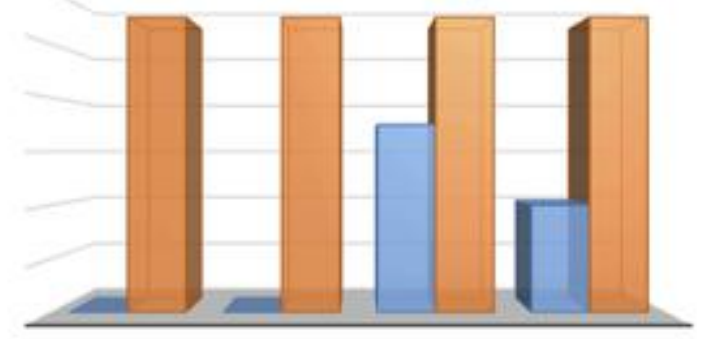

nada - poco - bastante - mucho
2.- Mejorar tu capacidad de planificar actividades en los procesos de enseñanza-aprendizaje?

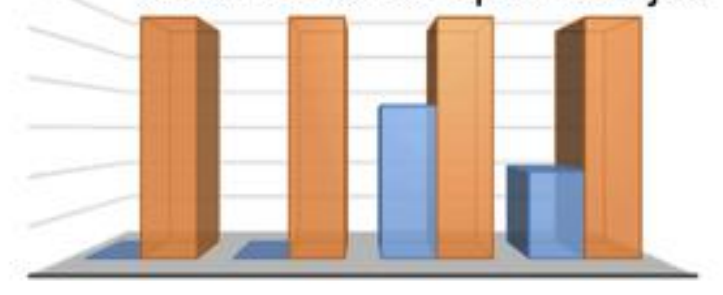

$$
\text { nada - poco - bastante - mucho }
$$

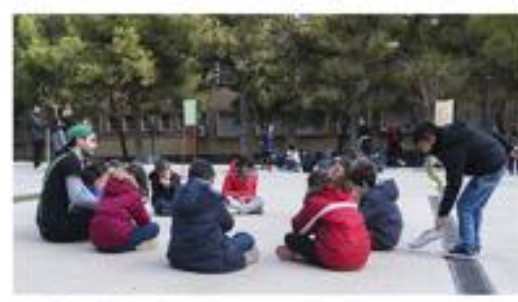

3.- Evaluar actividades para la mejora de los procesos de enseñanzaAprendizaje?

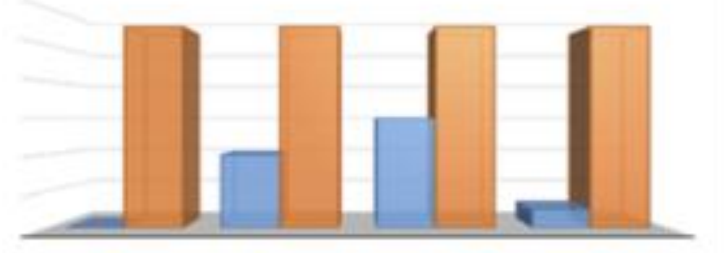

nada - poco - bastante - mucho

Conclusiones: 1.- Los juegos tradicionales permiten trabajar contenidos musicales, emocionales y motrices.

2.- La I Muestra de juegos tradicionales permitió una aproximación a la realidad profesional de la especialidad

3.- Los Juegos Tradicionales permitieron mejorar el aprendizaje de la competencia CG2 


\section{Plan de visibilización del Grado de Información y Documentación: Análisis de factores que inciden en la matrícula de nuevo ingreso, propuesta de estrategias y diseño de un plan de visibilidad}

García Marco, F. J.; Pedraza Gracia, M. J.; Salvador Oliván, J. A.; Martínez Pestaña, M. J.; Ruberte Andreu, S.; Gracia Lafaja, C.

\section{Palabras clave}

Visibilidad de titulaciones, planes estratégicos, satisfacción del estudiante, grado en información y documentación.

\section{Resumen}

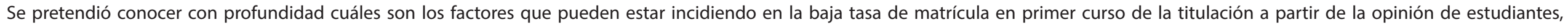

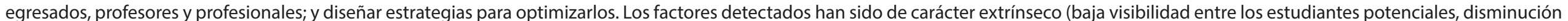

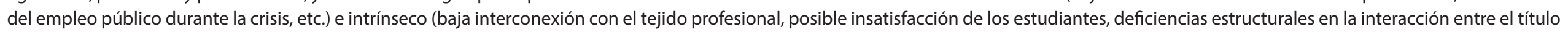

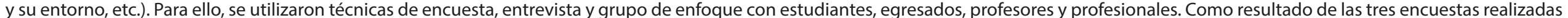

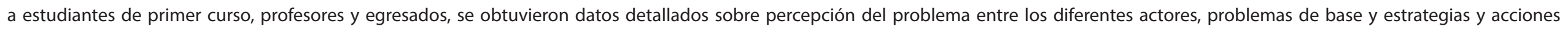

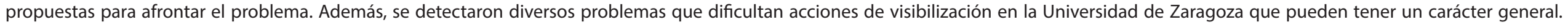

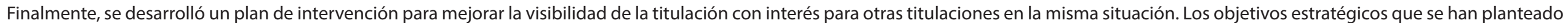

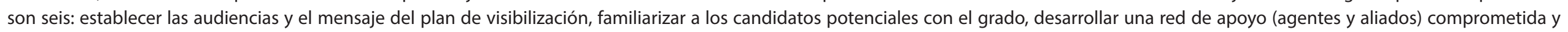

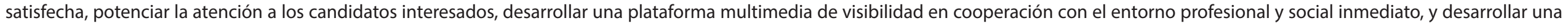
estructura de apoyo a la visibilización. 
Plan de visibilización del Grado de Información y Documentación: Análisis de factores que inciden en la matrícula de nuevo ingreso, propuesta de estrategias y diseño de un plan de visibilidad

García Marco, F. J.; Pedraza Gracia, M. J.; Salvador Oliváin, J. A.; Martinez Pestaña, M. J.; Ruberte Andreu, S.; Gracia Lafaja, C.

Departamento de Ciencias de la Documentación e Historia de la Ciencia, jgarcia@unizar.es)

\section{Contexto}

- Disminución sostenida del ingreso en el grado en

Información y Documentación hasta menos de la mitad de lo previsto en la memoria de verificación

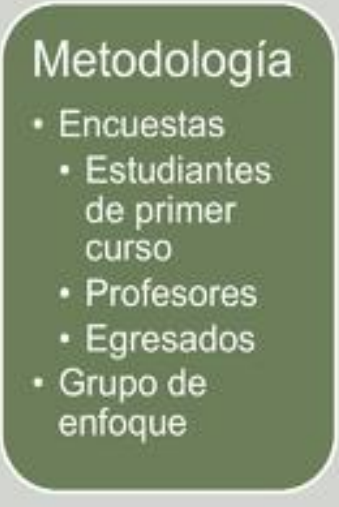

Objetivos

- Inventariar los factores que pueden estar incidiendo en la baja matrícula de estudiantes de nuevo ingreso

- Desarrollar metodologias para estudiar dichos factores.

- Proponer un modelo de interacción

- Producir un documento de diagnóstico de la titulación que pueda ser utilizado para su mejora y para la discusión con las autoridades académicas, representantes profesionales y autoridades de evaluación y certificación.

- Recopilar soluciones propuestas por los diferentes agentes

- Conocer y documentar otros planes de visibilidad

- Producir el borrador de un plan de visibilidad

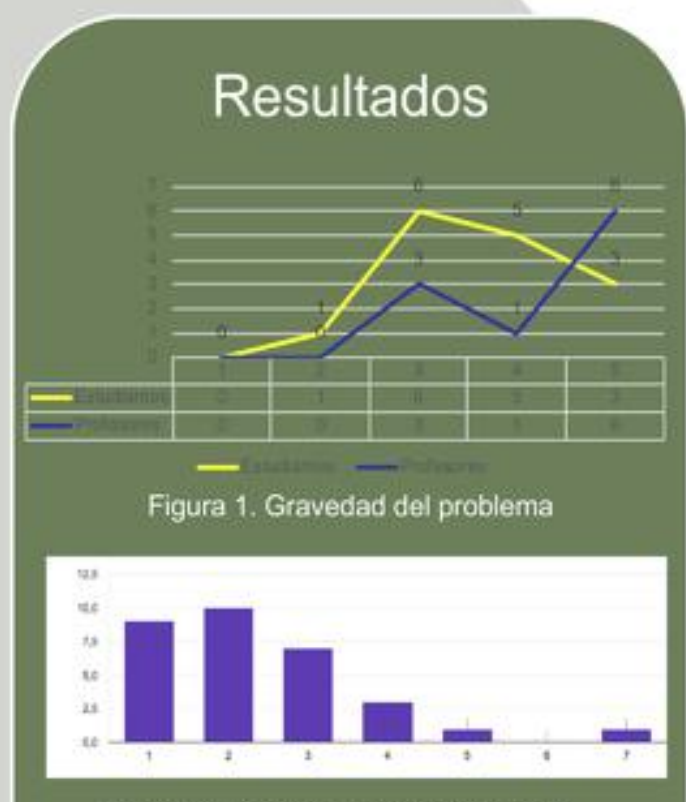

Figura 2. ¿Cuál es tu percepción de la visibilidad del grado?

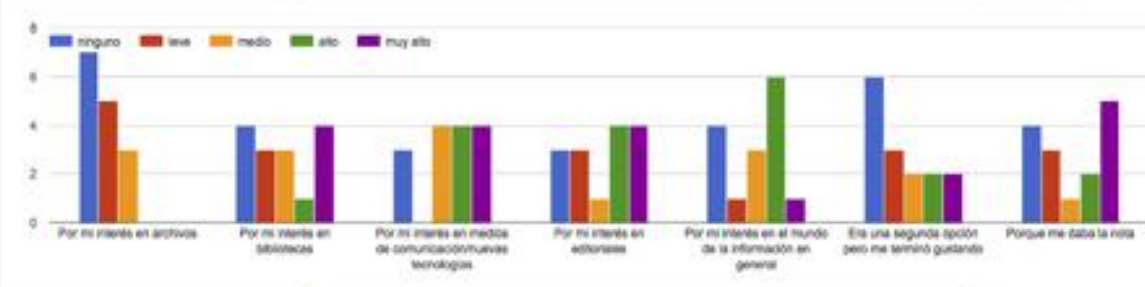

Figura 3. Motivos para cursar el grado
Conclusiones: Borrador de

Plan de

Visibilidad

1.Establecer las audiencias y el
mensaje del plan de visibilización

2.Familiarizar a los candidatos potenciales con el Grado

3.Desarrollar una red de apoyo (agentes y aliados) comprometida y satisfecha 4.Potenciar la atención a los candidatos interesados 5.Desarrollar una plataforma multimedia de visibilidad en cooperación con el entorno profesional y social inmediato 6.Desarrollar una estructura de apoyo a la visibilización 


\section{Reinvent The Classroom: Hacia la transformación del aula}

Sánchez Sansegundo, F. J. ; Gozalo Mandrión, A.

\section{Palabras clave}

Educación, transformación, Innovación, RTC.

\section{Resumen}

El proyecto Reinvent The Classroom (RTC en adelante) tiene su foco en todo el espectro educativo, desde la etapa de infantil hasta la educación superior.

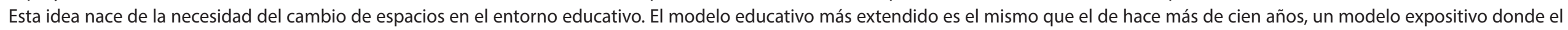

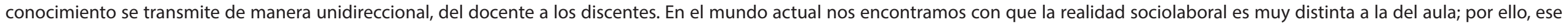

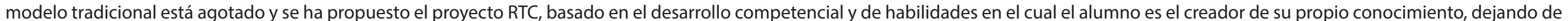
ser meros consumidores.

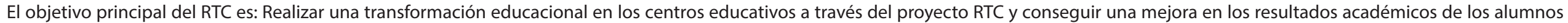
donde se implanten las aulas.

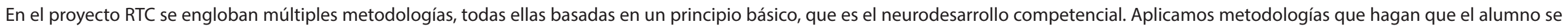
desarrolle en diferentes campos y ejes. El espacio RTC tiene una división interna en espacios según la Filosofía Maker, Design Thinking y el aprendizaje social.

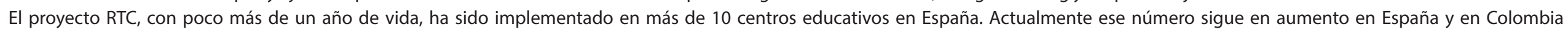
comenzamos a implantarlo.

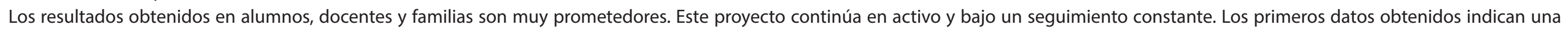
evolución en las competencias y habilidades en alumnado y profesorado. 


\section{Reinvent The Classroom: Hacia la transformación del aula}

\section{Ángel Gozalo, Javier Sánchez}

Grupo Advanced Education, angel@grupo-ae.com

\section{REINVENT THE CLASSROOM}

\section{THINKING}

Investiga

Descubre

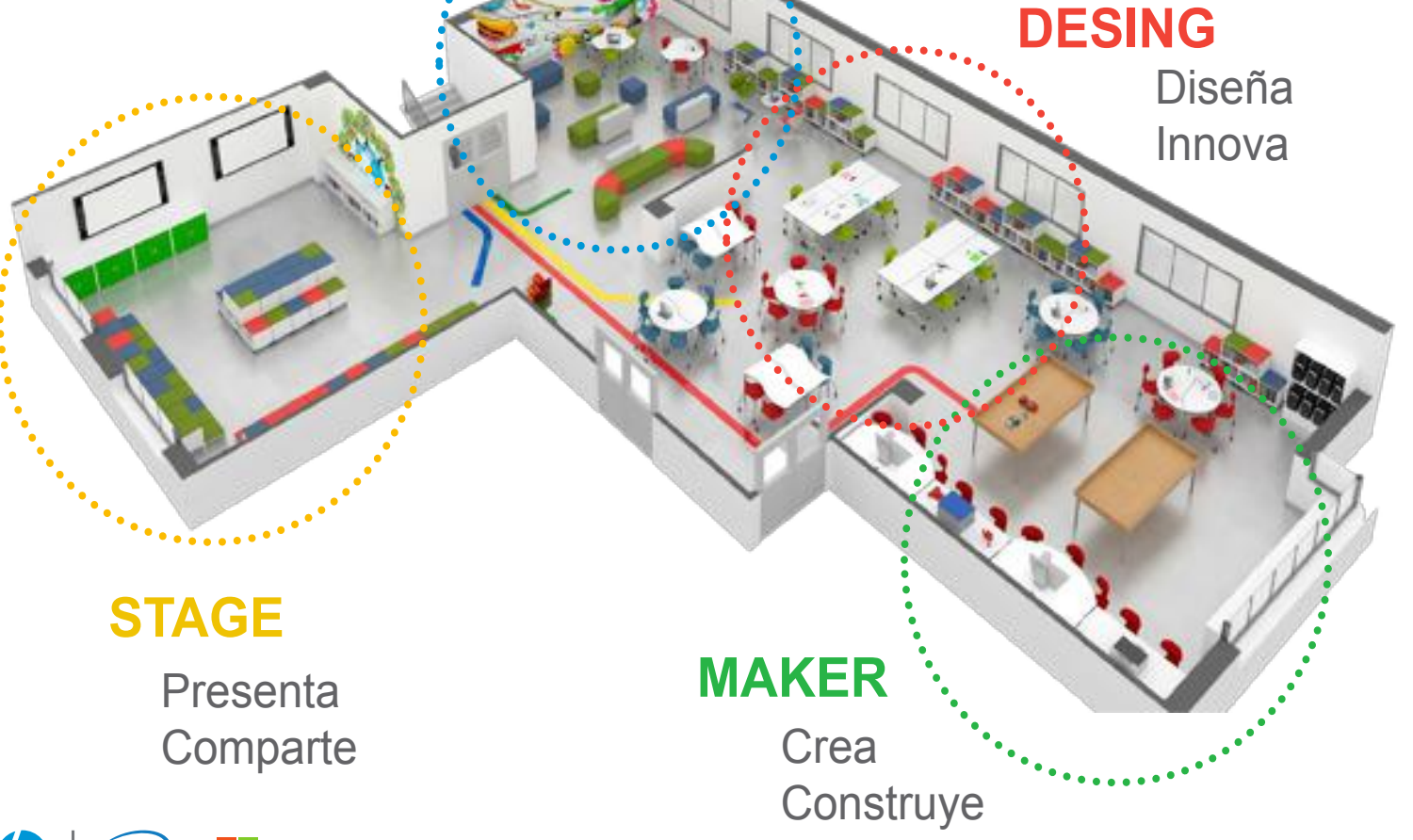

\section{ETAPAS:}

Infantil - Universidad

\section{OBJETIVO:}

Transformar el modelo de espacio educativo.

METODOLOGÍA:

Metodologías activas y críticas que permitan al alumnado desarrollar sus competencias y habilidades.

\section{RESULTADOS:}

- 9 Centros Educativos y 1 Universidad.

- 12 aulas RTC en España.

- 12 aulas en camino.

\section{CONCLUSIÓN:}

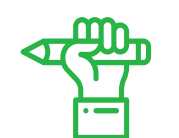
........................ +4000 alumnos 䟿 Alumnos RTC

Profesores formados +600 profesores

\section{해i: Universidad $\underline{\underline{m} \text { Zaragoza }}$}





\section{VI \\ Aplicación de metodologías activas III}




\section{Aplicación de metodologías activas III}

1. Romero Pascual, E.; Artal Sevil, J. S.; Artacho Terrer, J. M.

Analítica del aprendizaje: posibilidades para la docencia universitaria

2. Gil Clemente, E.; García Catalán, R.; Cogolludo Agustín, J. I.; Lizasoain Iriso, I.; Millán Gasca, A.

Aprender matemáticas ¿Qué enseñan los niños con discapacidad intelectual a los maestros en formación?

3. Mitjana Nerin, O.; Medina, J.; Bonastre Rafales, C.; Falceto Recio, M. V.

Creación de un canal propio de Youtube como herramienta de aprendizaje y autoevaluación de las principales técnicas en la clínica reproductiva en el Grado de Veterinaria

4. Nadal García, I.; Casanova López, M. B.; Garrido Rubio, A.; Juan Morera, B.; Fernández Amat, C.; Del Barrio Aranda, L.; Contreras Sequeira, P.

El coro como herramienta inclusiva

5. De Guerrero Manso, M. C.

El humor como recurso didáctico en la enseñanza del Derecho Administrativo General

6. Bordonaba Juste, V.; Fraj Andrés, E.; Gurrea Sarasa, R.; Herrando Soria, C.; Martín de Hoyos, M. J.; Pérez López, R.; Utrillas Acerete, A.

El uso de Códigos QR y Twitter para motivar el aprendizaje activo y colaborativo del alumno fuera del aula

7. Sanz Rubio, M.C.; Marcén Román, Y.; Franco Sierra, M. A.

Empleo de Kahoot en los seminarios del Practicum del Grado en Fisioterapia

8. 8. Serrano Pastor, R. M.; Casanova López, O.

Gamificación educativa con TIC desde el enfoque Flipped Learning en la enseñanza musical universitaria

9. Miqueo, C.

Genealogía profesional para estudiantes universitarios Trabajos dirigidos en el Grado de Medicina: Relatos de vida

10. Romero Pascual, E.; Artal Sevil, J. S.; Garrido Rubio, A.; Valero Gracia, M. S.; Puche Gil, J.; Pérez Sinusía, E.

Introduciendo el "aula invertida" y las nuevas tecnologías en el aula universitaria: red MultiFlipTech

11. Ramos Vallecillo, N.; Murillo Ligorred, V.

Metodología Design Thinking como estrategia en la promoción de pensamiento divergente: una didáctica artística a través de material reciclado 


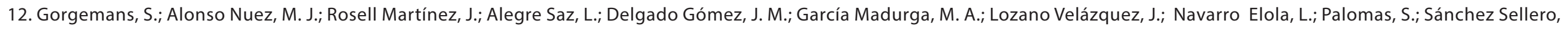
Motivating Engineering students to Improve Teamwork and Time Managemen

13. Artal-Sevil, J. S.; Artacho Terrer, J. M.; Bernues del Río, E.; Romero, E.

Tecnología y Herramientas Interactivas destinadas a la Gamificación. Impacto en el aula universitaria 


\section{Analítica del aprendizaje: posibilidades para la docencia universitaria}

Romero Pascual, E.; Artal Sevil, J. S.; Artacho Terrer, J. M.

\section{Palabras clave}

Analítica del aprendizaje, Google analytics, YouTube.

\section{Resumen}

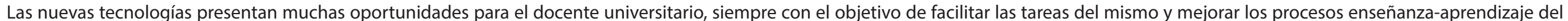

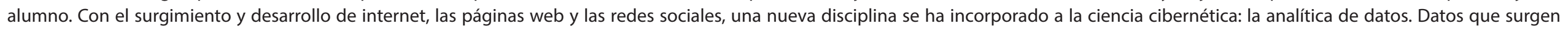

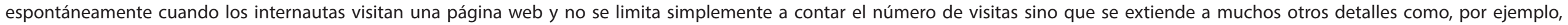
procedencia de los visitantes, tipo de dispositivo que utilizan, enlaces preferidos dentro de la web, tiempo que ven un vídeo, anuncios que visitan...

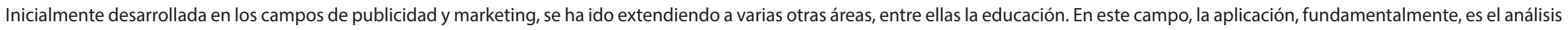

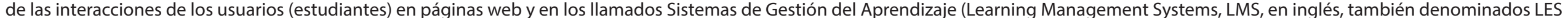

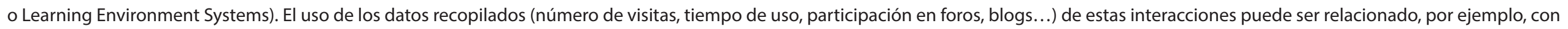

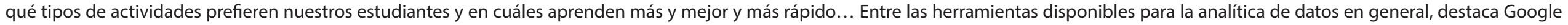
Analytics. Sus ventajas: facilidad de uso, fácil implementación, uso generalizado, múltiples indicadores relevantes...

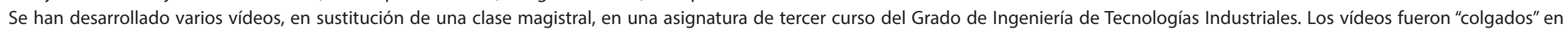

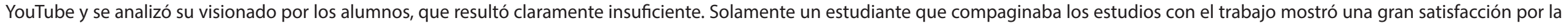
iniciativa. No obstante, una encuesta mostró una gran aceptación en general de las varias TIC empleadas. 


\section{Analítica del aprendizaje: posibilidades para la docencia universitaria}

\section{Enrique Romero, J. Sergio Artal-Sevil, Juan M. Artacho}

Dpto. Ingenieria electrónica y Comunicaciones, jartacho@unizar.es

\section{Google Analytics}

Metodología

SCREENCASt MATIC

\section{- YouTube}

Contexto

Analítica de datos, ¿qué es y qué permite obtener?

Posibilidades en la docencia universitaria

Asignatura: Procesos Químicos Industriales (Ing. Tecnologias Ind.)

\section{Creación de vídeos}

Objetivos

Analizar si son visionados por los alumnos

Analizar cuándo son visionados por los alumnos

\section{Muchos alumnos afirmaron verlos}

Pocas visualizaciones reales, bajo tiempo promedio

Resultados

Un alumno mostró una gran satisfacción

Encuestas generales TIC: muy positivas

Incentivar el visionado

Profundizar en el análisis de los datos 


\section{Aprender matemáticas ¿Qué enseñan los niños con discapacidad intelectual a los maestros en formación?}

Gil Clemente, E.; García Catalán, R.; Cogolludo Agustín, J. l.; Lizasoain Iriso, l.; Millán Gasca, A.

\section{Palabras clave}

Educación especial, síndrome de down, aritmética, geometría.

\section{Resumen}

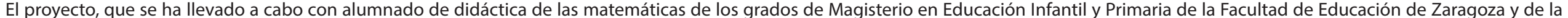

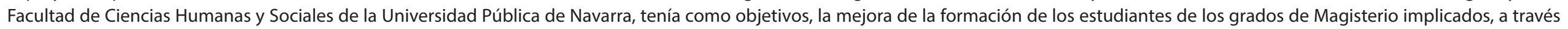

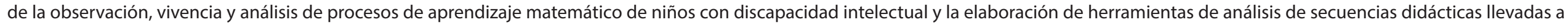
cabo con estos niños.

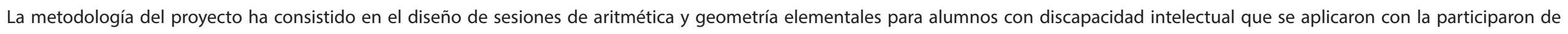
estudiantes voluntarios de ambas universidades. Estas sesiones se grabaron en video, con el fin de facilitar el acceso a la experiencia con los niños a un número mayor de estudiantes.

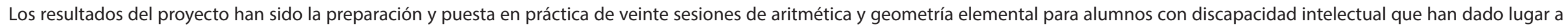

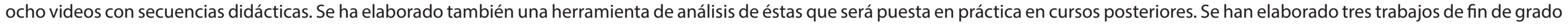
basados en las actividades de estas sesiones.

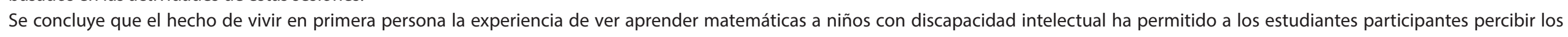

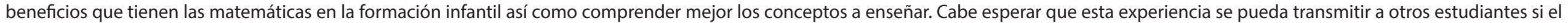
análisis de estas secuencias se puede incluir en los contenidos de las asignaturas de los grados en años venideros. 
Aprender matemáticas ¿Qué enseñan los niños con discapacidad intelectual a los maestros en formación?

\section{Gil Clemente, E; Garcia Catalán, R.; Cogolludo A gustín, J.l.; Lizasoain Iriso, lo; Millán Gasca, A.}

Departamentos de Matemáticas de la Universidad de Zaragoza, de la Universidad Pública de Navarra y de Roma Tre elenagil@unizar.es;

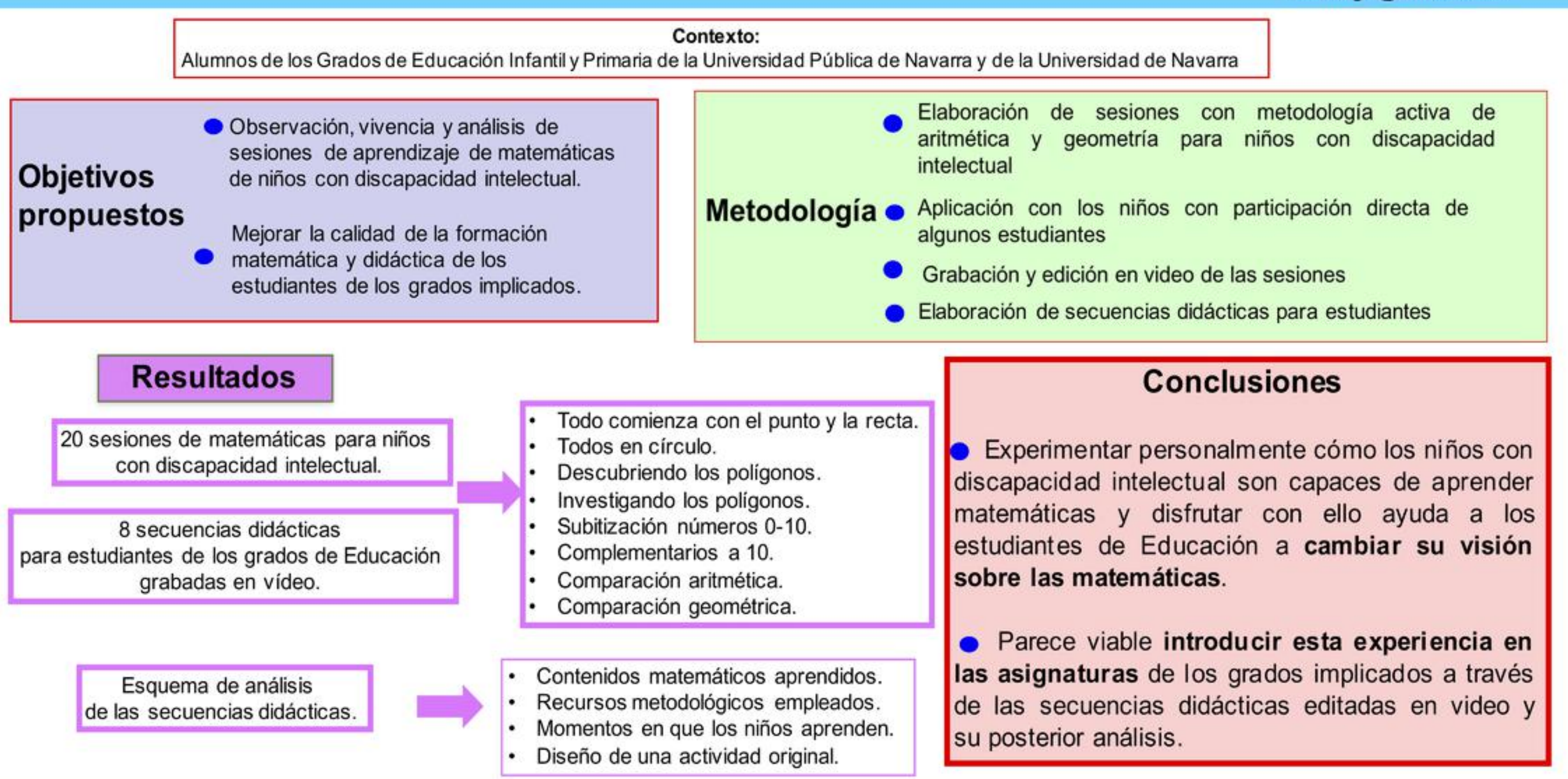

\section{풍 Universidad 쓸 Zaragoza}




\section{Creación de un canal propio de Youtube como herramienta de aprendizaje y autoevaluación de las principales técnicas en la clínica reproductiva en el Grado de Veterinaria}

Mitjana Nerin, O.; Medina, J.; Bonastre Rafales, C.; Falceto Recio, M. V.

\section{Palabras clave}

Autoaprendizaje, audiovisuales, internet, veterinaria.

\section{Resumen}

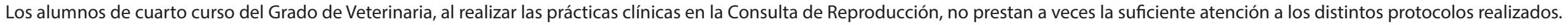

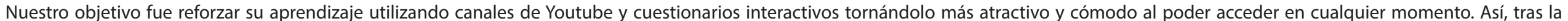

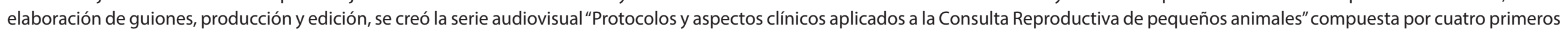

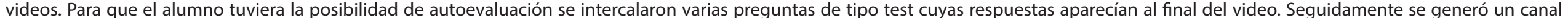

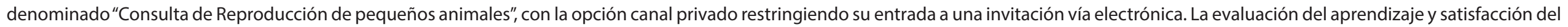

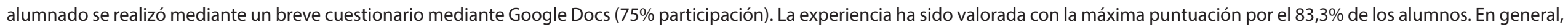

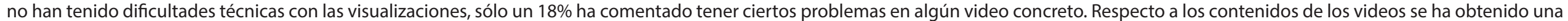

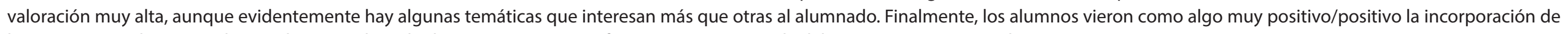
las nuevas tecnologías en el aprendizaje en el Grado de Veterinaria (83,3\%) frente a un 16,7\% que le daba una puntuación media.

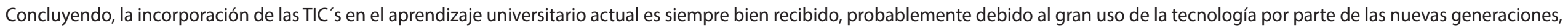
además de considerarlo como una metodología más amena que complementa la enseñanza tradicional 
Creación de un canal propio de Youtube como herramienta de aprendizaje y autoevaluación de las principales técnicas en la clínica

\section{reproductiva en el Grado de Veterinaria}

Olga Mitijana1, Joaquín Medina2, Cristina Bonastre ${ }^{1}$ y Ma Victoria Falceto

1Departamento de Patología Animal, 2Servicio de Audiovisuales de Facultad de Veterinaria, omitjana@unizar.es

\section{(0) 5}

Alumnos de 4 curso de

I Grado de Veterinaria - Prácticas Consulta de Reproducción Integración de Pequeños Animales

$\square$ Refuerzo del aprendizaje gracias a canales de Youtube/cuestionarios interactivos

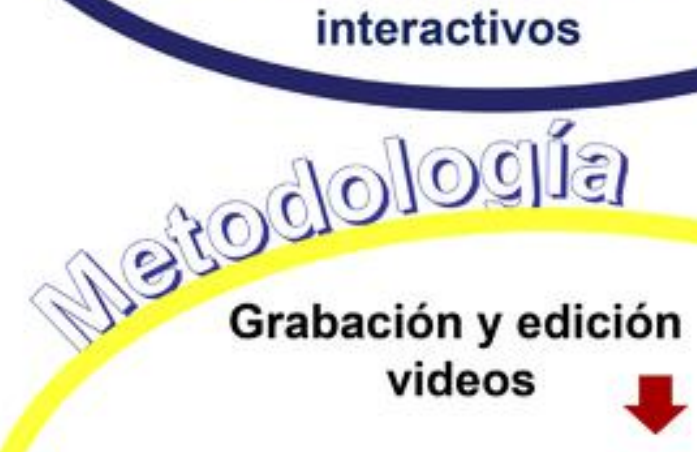

Serie "Protocolos y aspectos clínicos aplicados a la Consulta Reproductiva de pequeños animales"

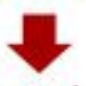
Cuestionarios insertados con Autoevaluación final
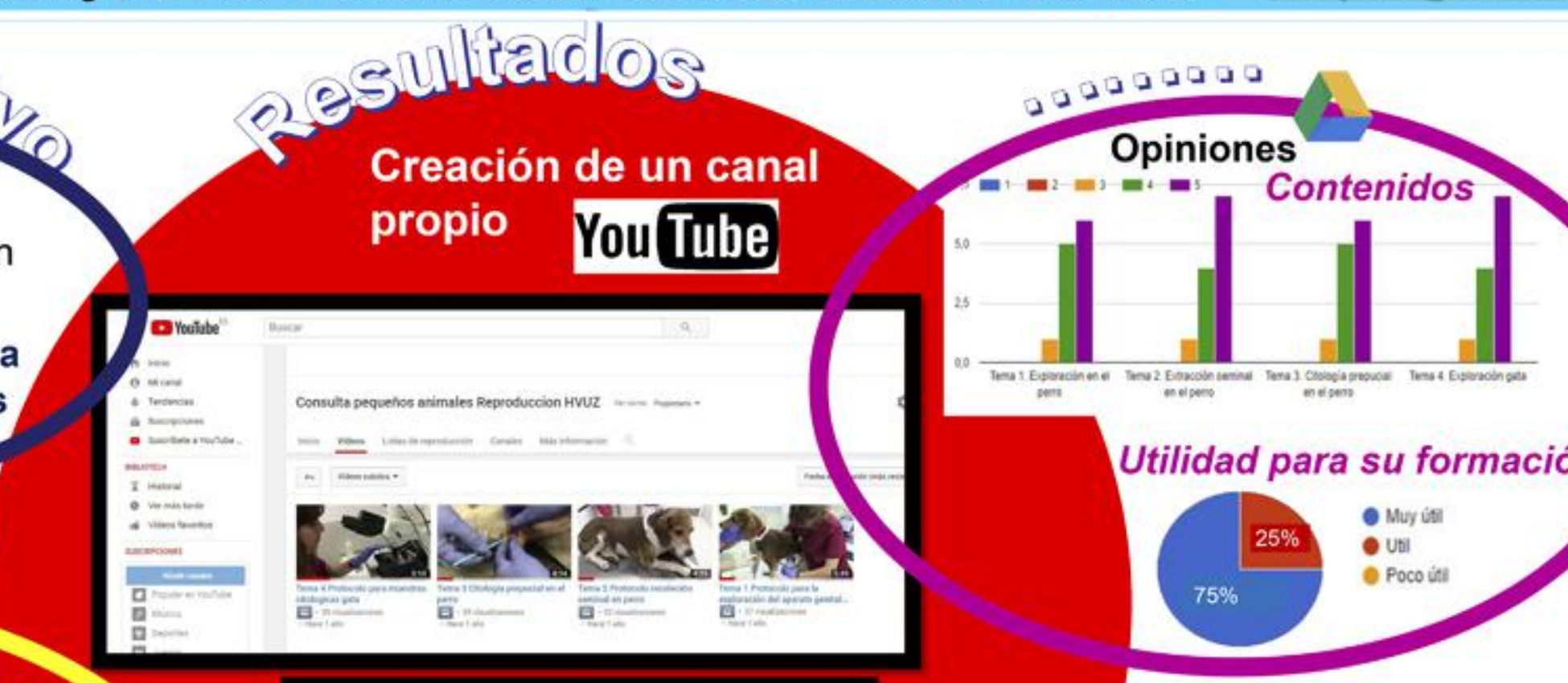

Utilidad para su formación

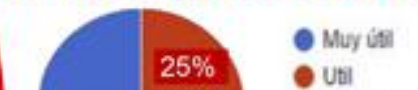

Poco itl

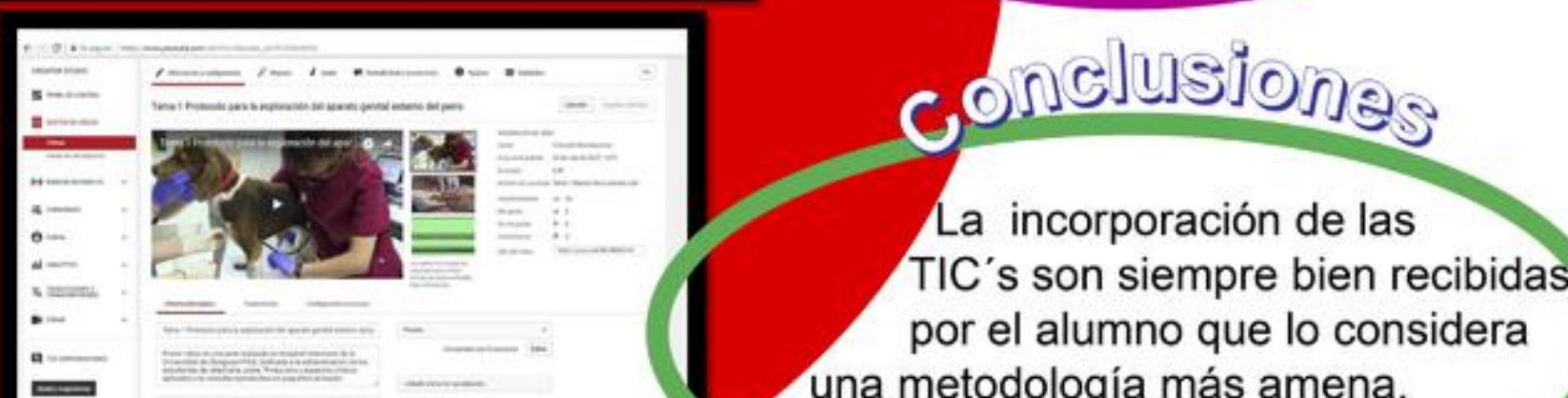

una metodología más amena,

complementaria a la enseñanza tradicional. 


\section{El coro como herramienta inclusiva}

Nadal García, l.; Casanova López, M .B.; Garrido Rubio, A.; Juan Morera, B.; Fernández Amat, C.; Del Barrio Aranda, L.; Contreras Sequeira, P.

\section{Palabras clave}

Actividad coral, inclusión.

\section{Resumen}

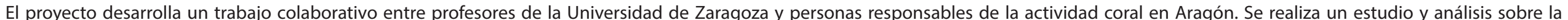

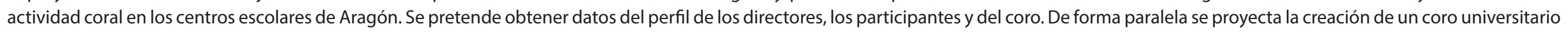

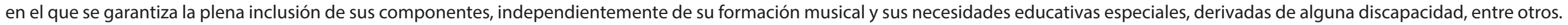

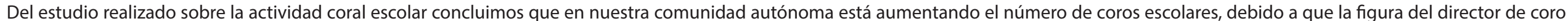

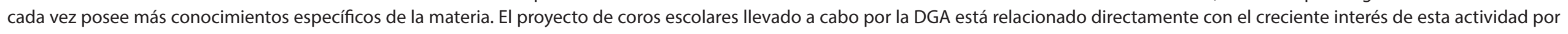

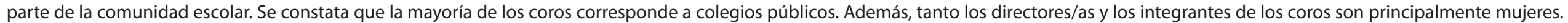

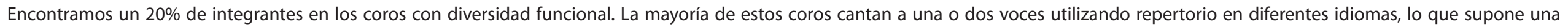

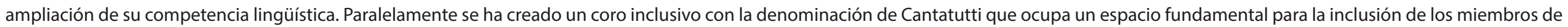

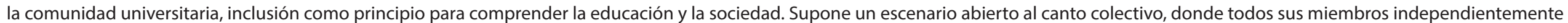

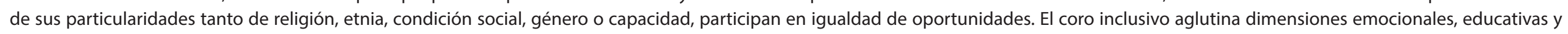
sociales y lo convierten en un modelo social y educativo. El coro ha dado muestra de su trabajo a través de diferentes actuaciones y conciertos. 


\section{El coro como herramienta inclusiva}

Icíar Nadal 1, M. Belén López 1, Ana Garrido2, Borja Juan 1, Carmen Fernández 1, Luis del Barrio1, Pablo Contreras

Departamentos: Expresión Musical, Plástica y Corporal ${ }^{(1)}$ Dirección de Marketing e Investigación de Mercado ${ }^{(2)}$ CC de la Educación iciarnad@unizar.es

Contextualización: Universidad de Zaragoza, coros escolares de centros de Educación Primaria de Aragón; estudiantes de la Universidad de Zaragoza con especial atención a aquellos con necesidades educativas especiales.

Objetivos:

- Estudiar y analizar el perfil de los coros escolares de Aragón.

- Crear un coro universitario inclusivo en el que participen estudiantes con necesidades especiales.

- Analizar y reflexionar sobre la influencia del coro en la adquisición de diferentes competencias a nivel emocional, académico y social.

Metodología: cuestionarios para conocer el perfil de los coros escolares en Aragón.

Recogida de datos y análisis. Talleres formativos y ensayos.

\section{Principales resultados:}

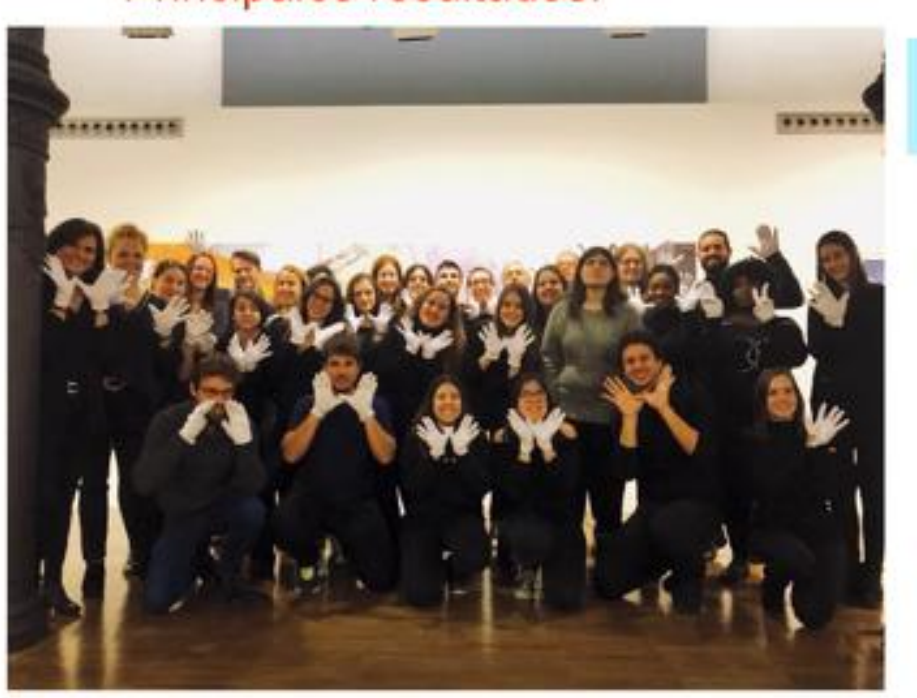

El Coro Cantatutti.

Perfil de sus

componentes
Situación de los coros escolares en Aragón
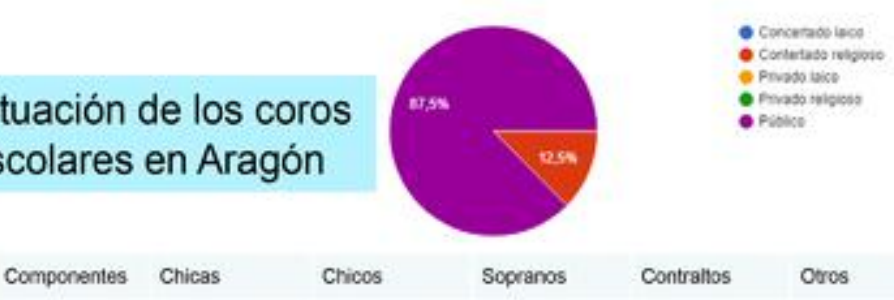

Sopranos

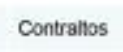

oros

$$
34 \quad 23
$$

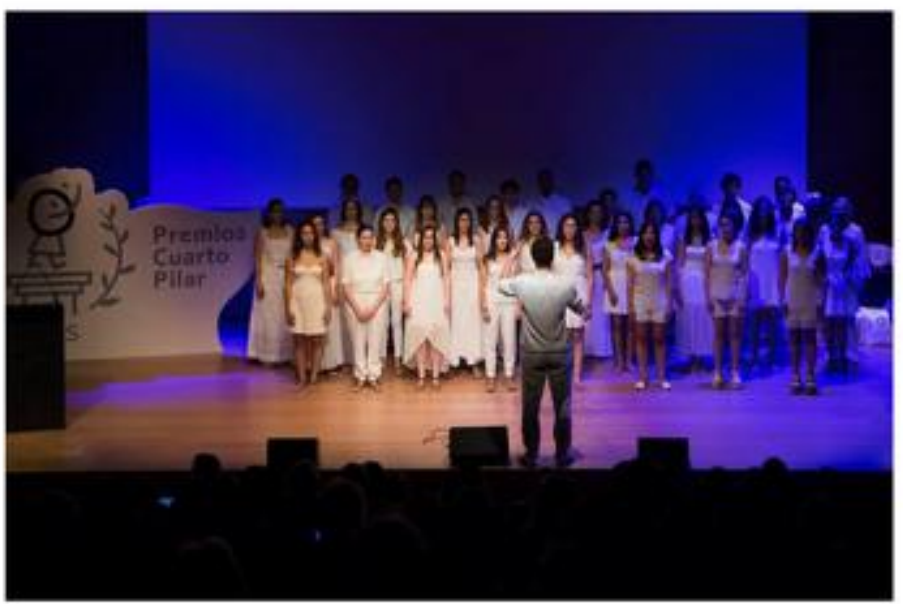

Conclusiones: La mayoría de los coros escolares corresponde a colegios públicos. Además, tanto los directores como los integrantes de los coros son principalmente mujeres. Encontramos un $20 \%$ de integrantes en los coros con diversidad funcional. Paralelamente se ha creado un coro inclusivo Cantatutti que ocupa un espacio fundamental para la inclusión de los miembros de la comunidad universitaria, aglutina dimensiones emocionales, educativas y sociales que lo convierten en un modelo social y educativo. 


\section{El humor como recurso didáctico en la enseñanza del Derecho Administrativo General}

De Guerrero Manso, M. C.

\section{Palabras clave}

Docencia, innovación, motivación.

\section{Resumen}

Se han de mostrado en diversos ámbitos los efectos beneficios que la utilización del humor tiene en el proceso deenseñanza-aprendizaje.

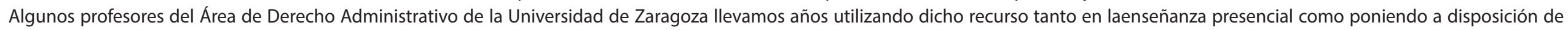

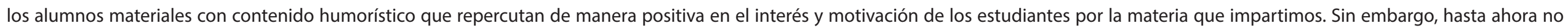

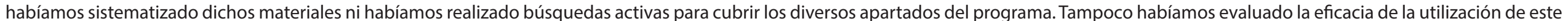
tipo de recursos en el proceso de enseñanza-aprendizaje.

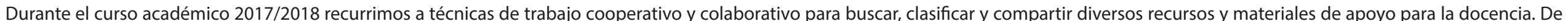
esta manera creamos un repositorio de materiales didáctico y accesible de manera constante y sencilla para los docentes.

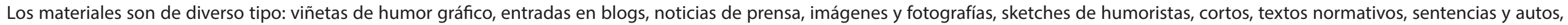
obras literarias, artículos doctrinales, o documentos de diverso tipo.

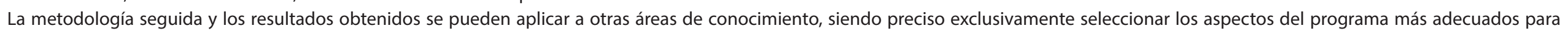
utilizar esta metodología docente basada en el humor y buscar materiales que se adecúen a los contenidos de cada asignatura.

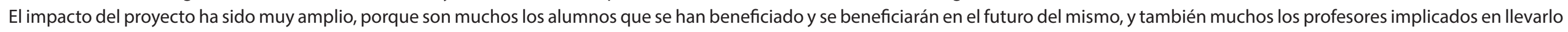
a cabo. Además, resulta muy positivo que la relación tiempo-esfuerzo invertido con los resultados obtenidos ha sido satisfactoria.œ 


\title{
El humor como recurso didáctico en la enseñanza del Derecho Administrativo General
}

\author{
Ma del Carmen De Guerrero Mlanso
}

Departamento de Derecho Público, carmeng@unizar.es

Contexto académico: Doble titulación de Derecho y $\mathrm{ADE}, 2^{\circ}$ curso, Derecho Administrativo Parte General

Objetivos propuestos: mejorar el proceso de enseñanza-aprendizaje de estudiantes que carecen de conocimientos previos de Derecho Administrativo.

Metodología: Se llevaron a cabo 4 fases sucesivas:

1. Selección de los contenidos de mayor complejidad y los que pueden ilustrarse o explicarse de manera adecuada a través del humor.

2. Búsqueda y clasificación de los materiales y recursos que sirvan para presentar o profundizar en los contenidos previamente seleccionados.

3. Confección de un repositorio de materiales didácticos que puedan servir como fundamento o apoyo (según los casos) de las lecciones.

4. Análisis de la eficacia de dichos materiales para transmitir conocimientos o motivar a los alumnos al estudio y comprensión del $D^{\circ}$ Administrativo (encuestas).

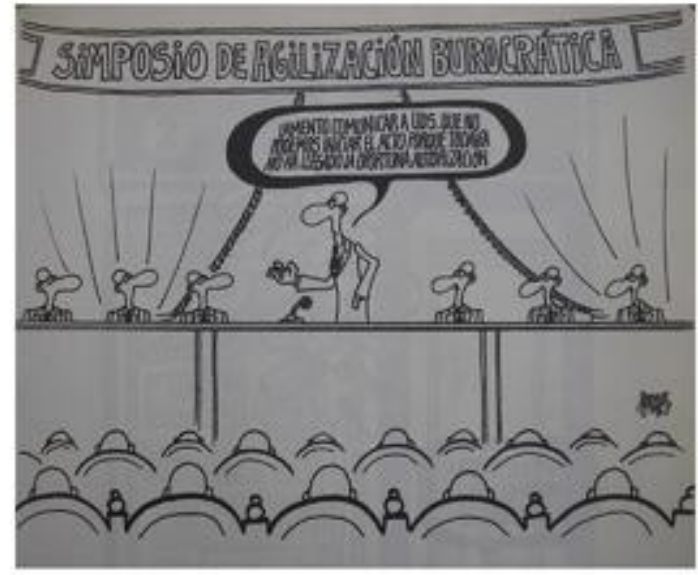

Principales resultados: Creación y sistematización de un repositorio de materiales humorísticos que sirven como apoyo de la docencia.

Grado de satisfacción alto de los alumnos encuestados al final del proyecto.

Conclusiones: Se trata de una metodología eficaz y con una buena ratio de tiempo-esfuerzo invertida por los docentes respecto de los resultados obtenidos. La media de la valoración de los alumnos encuestados es de 8,74 puntos sobre 10 .

En el futuro se pretende implicar de manera más directa a los alumnos en la búsqueda de nuevos materiales. 


\section{El uso de Códigos QR y Twitter para motivar el aprendizaje activo y colaborativo del alumno fuera delaula}

Bordonaba Juste, V.; Fraj Andrés, E.; Gurrea Sarasa, R.; Herrando Soria, C.; Martín de Hoyos, M. J.; Pérez López, R.; Utrillas Acerete, A.

\section{Palabras clave}

Twitter, engagement, satisfacción, rendimiento académico.

\section{Resumen}

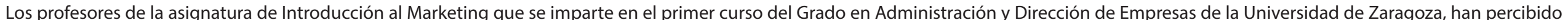

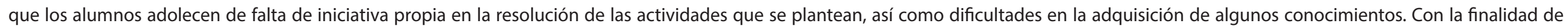

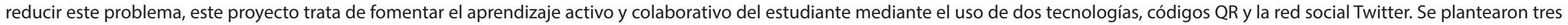

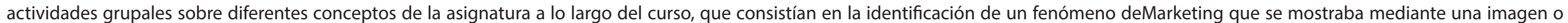

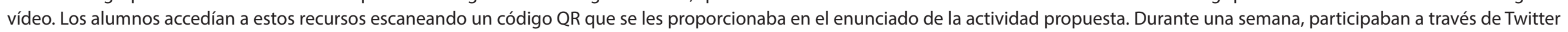

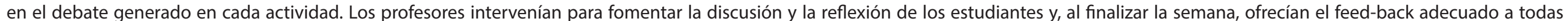

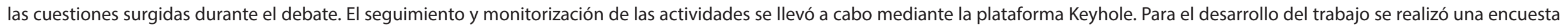

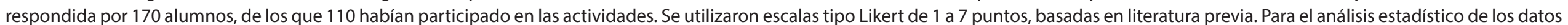

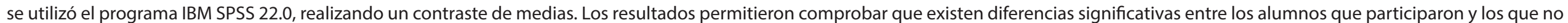
participaron en las actividades. En concreto, los resultados mostraron que estas actividades eran útiles para mejorar el engagement y la satisfacción de losalumnos. 


\section{El uso de Códigos QR y Twitter para motivar el aprendizaje activo y colaborativo del alumno fuera del aula}

Victoria Bordonaba, Elena Fraj, Raquel Gurrea, Carolina Herrando, Ma José Martín, Raúl Pérez, Ana Utrillas

Departamento de Dirección de Marketing e Investigación de Mercados (raperez@unizar.es)

CONTEXTO
OBJETIVO
Introducción al Marketing ( $1^{\circ}$ curso Grado ADE)
Alumnos del curso académico 2017/18
OBjorar el aprendizaje activo y colaborativo
Favorecer el compromiso con la asignatura
Reforzar conocimientos adquiridos en el aula

\section{Diferencias de medias (alumnos participantes y no participantes) \\ RESULTADOS}

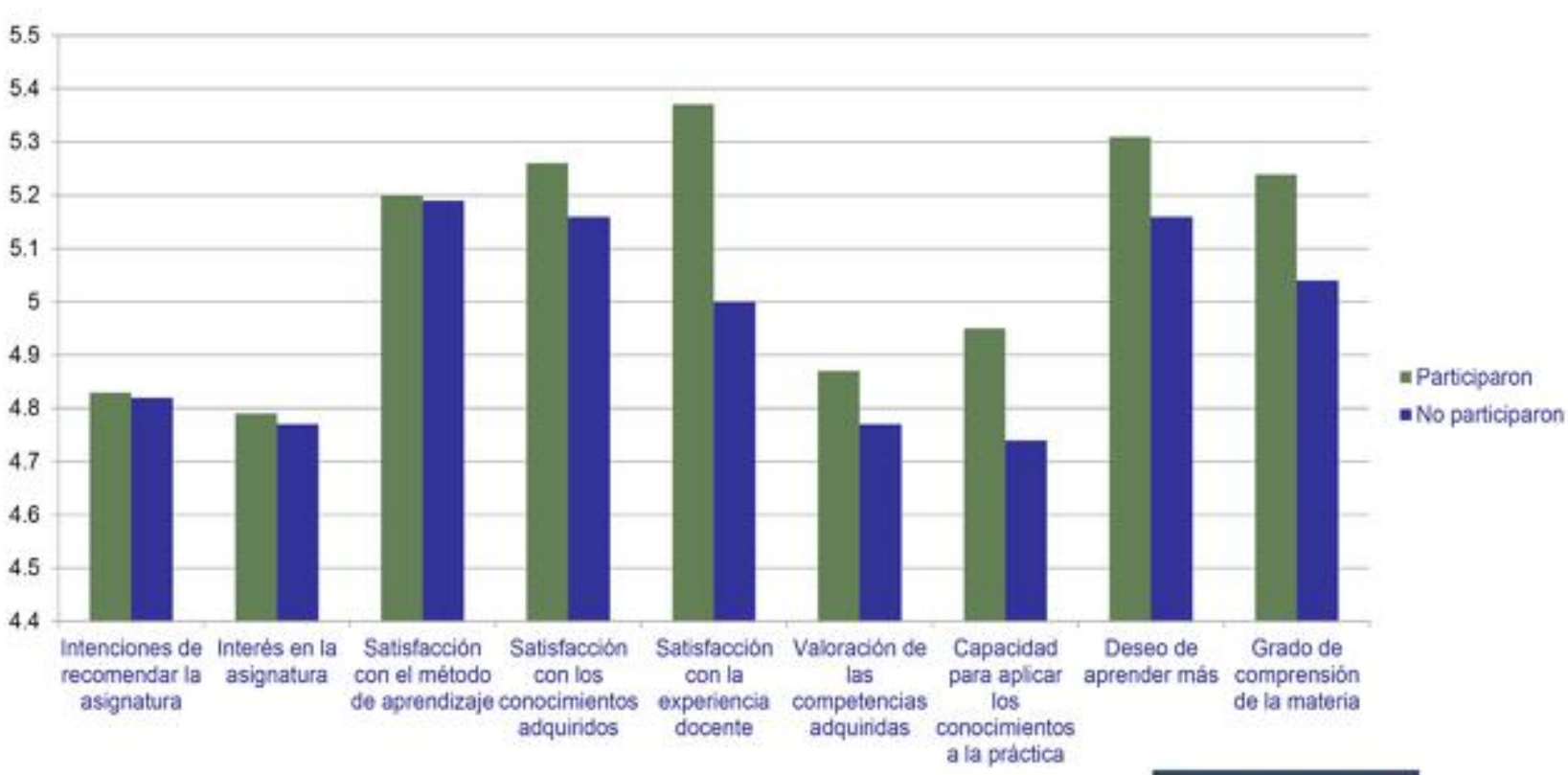

\begin{tabular}{l|l} 
Monitorización de la actividad 1 & KEYHOLE
\end{tabular}

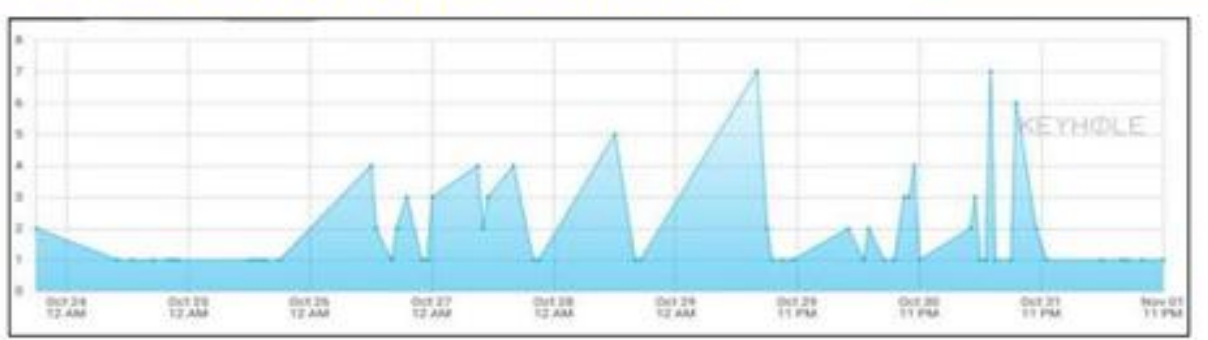

풀 Universidad 쓸 Zaragoza 


\section{Empleo de Kahoot en los seminarios del Practicum del Grado en Fisioterapia}

Sanz Rubio, M. C.; Marcén Román, Y.; Franco Sierra, M.A.

\section{Palabras clave}

Comunicación interactiva, aprendizaje activo, medios educativos.

\section{Resumen}

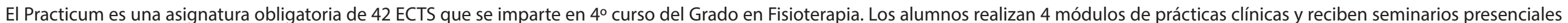

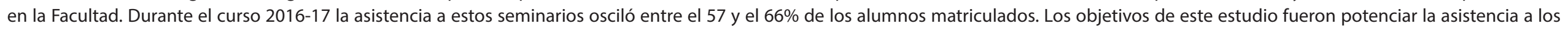

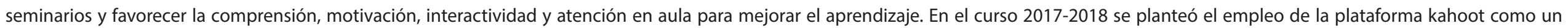

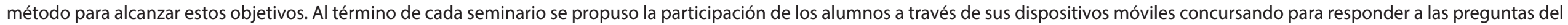
cuestionario sobre cada tema. A final de curso se realizó una encuesta para comprobar la valoración de la actividad por parte de los estudiantes.

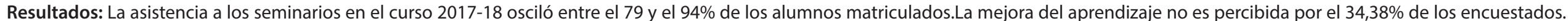

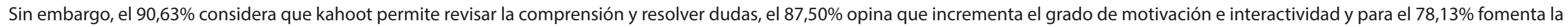

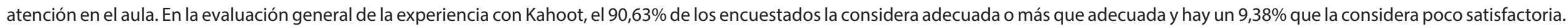

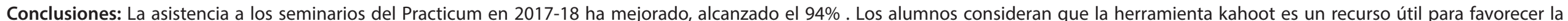

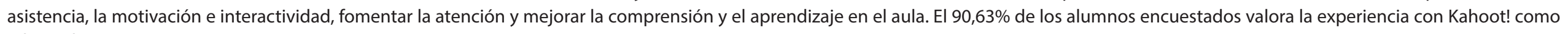
adecuada. 


\section{Empleo de Kahoot en los seminarios del Practicum del Grado en Fisioterapia}

\section{Sanz Rubio, M.C.; Marcén Román, Y.; Franco Sierra, M.A.}

Departamento de Enfermeria y Fisiatria, conchasr@unizar.es

\section{Contexto académico:}

Practicum en el Grado en Fisioterapia: asignatura obligatoria, $42 \mathrm{ECTS} .4^{\circ}$ curso.

Práctica clínica + seminarios presenciales + trabajo no presencial.

Resultados:

La asistencia a los seminarios en 2017-18 fue del 79-94\% de los alumnos matriculados.

КАНООТ permite mejorar el aprendizaje

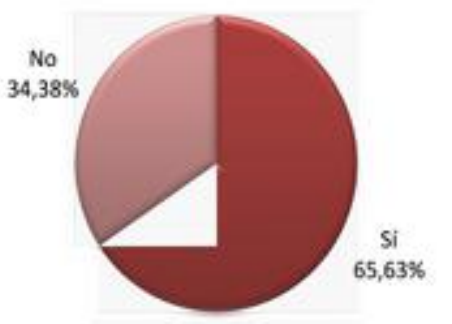

KAHOOT fomenta la atención en el aula

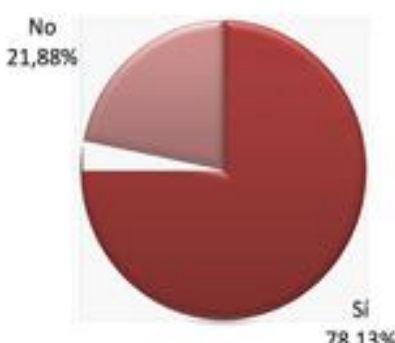

KAHOOT permite revisar la comprensión y resolver dudas

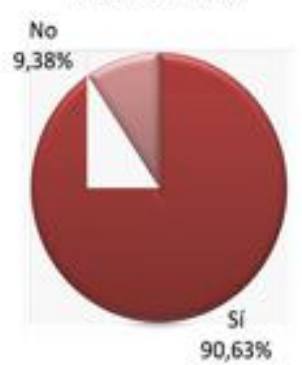

Valoración de la experiencia con KAHOOT

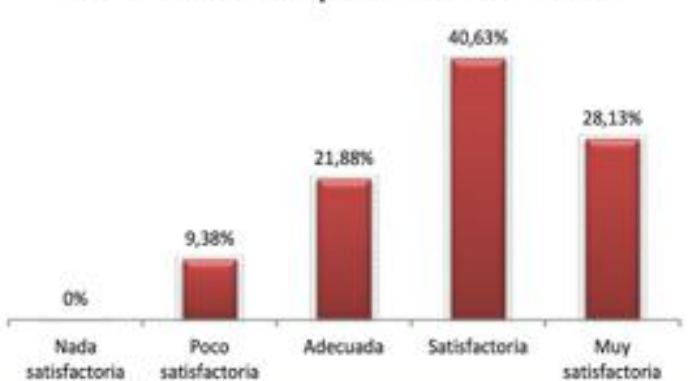

\section{Metodología:}

Curso 2017-18: Al término de cada seminario se propuso la participación de los alumnos a través de sus móviles concursando para responder a las preguntas del cuestionario sobre cada tema en la plataforma Kahoot!. Encuesta a final de curso: valoración de la actividad por parte de los estudiantes.

\section{Conclusiones:}

- La asistencia a los seminarios del Practicum en 2017-18 ha mejorado, alcanzado el $94 \%$ utilizando la herramienta kahoot.

- Kahoot es un recurso útil en el aula, permitiendo mejorar la comprensión e incrementando el grado de motivación e interactividad, y fomentando la atención.

-El $90,63 \%$ de los alumnos encuestados valora la experiencia con Kahoot! como adecuada. 


\section{Gamificación educativa con TIC desde el enfoque Flipped Learning en la enseñanza musical universitaria}

Serrano Pastor, R. M.; Casanova López, O.

\section{Palabras clave}

Educación superior, innovación educativa, juego educativo, aprendizaje inverso, tecnología educativa.

\section{Resumen}

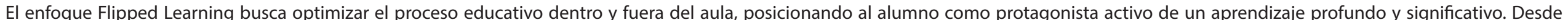

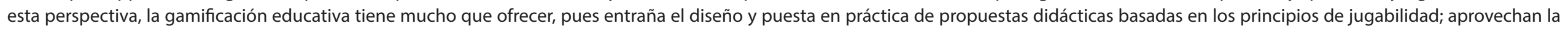
predisposición psicológica hacia el juego y los beneficios en el ámbito de la atención, concentración, interacción y motivación del estudiante.

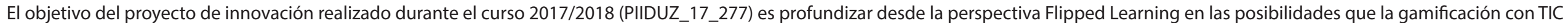
ofrece para favorecer el aprendizaje activo del alumnado.

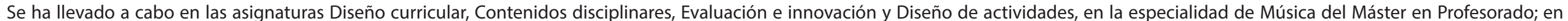
Audición Musical Activa de $4^{\circ}$ del Grado en Magisterio en Educación Primaria y en un grupo de $3^{\circ}$ de Desarrollo de la expresión musical del Grado en Magisterio en Educación Infantil.

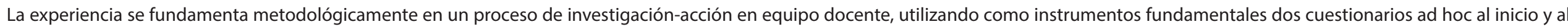

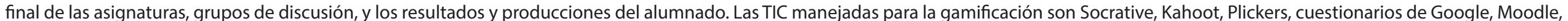
Edpuzzle y PlayPosit.

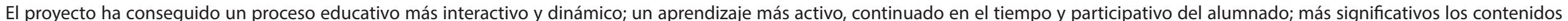
trabajados, así como una mayor atención, concentración y motivación de los estudiantes hacia su propio aprendizaje.

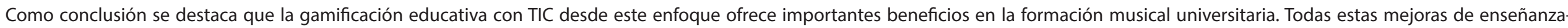
aprendizaje son extensibles a otros contextos. 


\section{Gamificación educativa con TIC desde el enfoque Flipped Learning en la enseñanza musical universitaria}

Rosa IJ. Serrano, Oscar Casanova

Dpto. de Expresión Musical, Plástica y Corporal, rmserran@unizar.es

Objetivo: Analizar las posibilidades de la gamificación educativa con TIC desde el enfoque Flipped Learning

\section{Contexto:}

Máster en Profesorado: Diseño curricular, Contenidos disciplinares, Evaluación e innovación y Diseño de actividades $3^{\circ}$ Grado en Magisterio en E. Infantil: Desarrollo de la E. M. $4^{\circ}$ Grado en Magisterio en E. Primaria: Audición Musical Activa

\section{Metodología:}

Investigación-acción en equipo docente Instrumentos:

- Cuestionarios ad hoc al inicio y al final - Grupos de discusión

- Resultados y producciones del alumnado
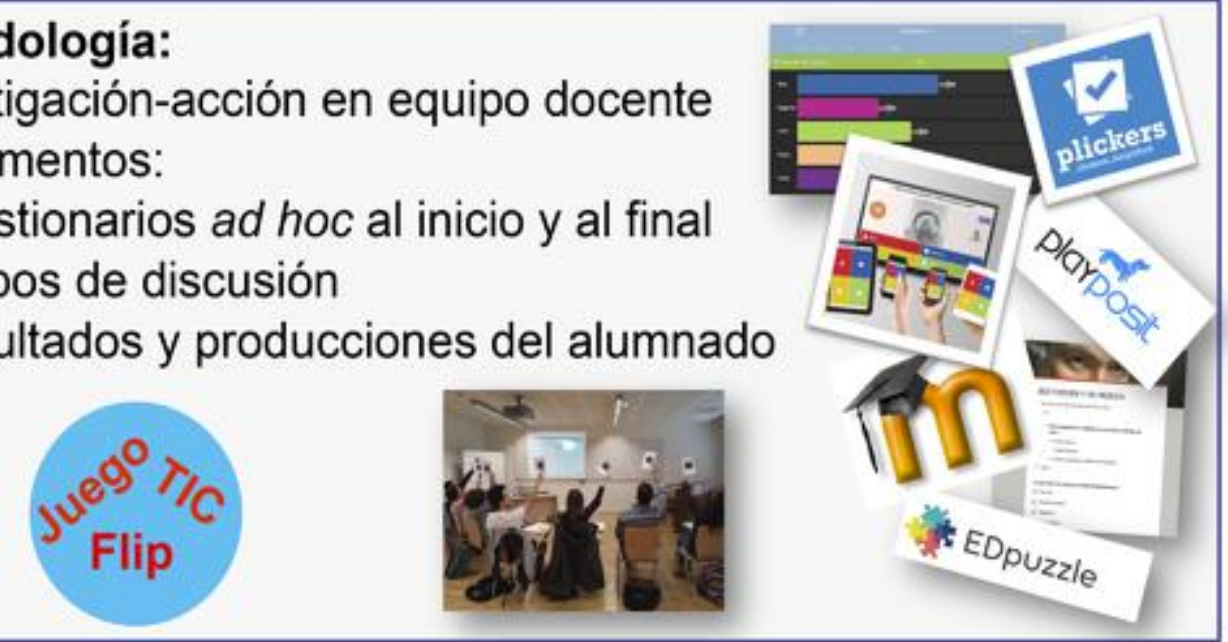

\section{Resultados:}

Proceso educativo dinámico e interactivo

Alumnado: activación, atención, concentración y motivación Aprendizaje: profundo, significativo y continuado en el tiempo

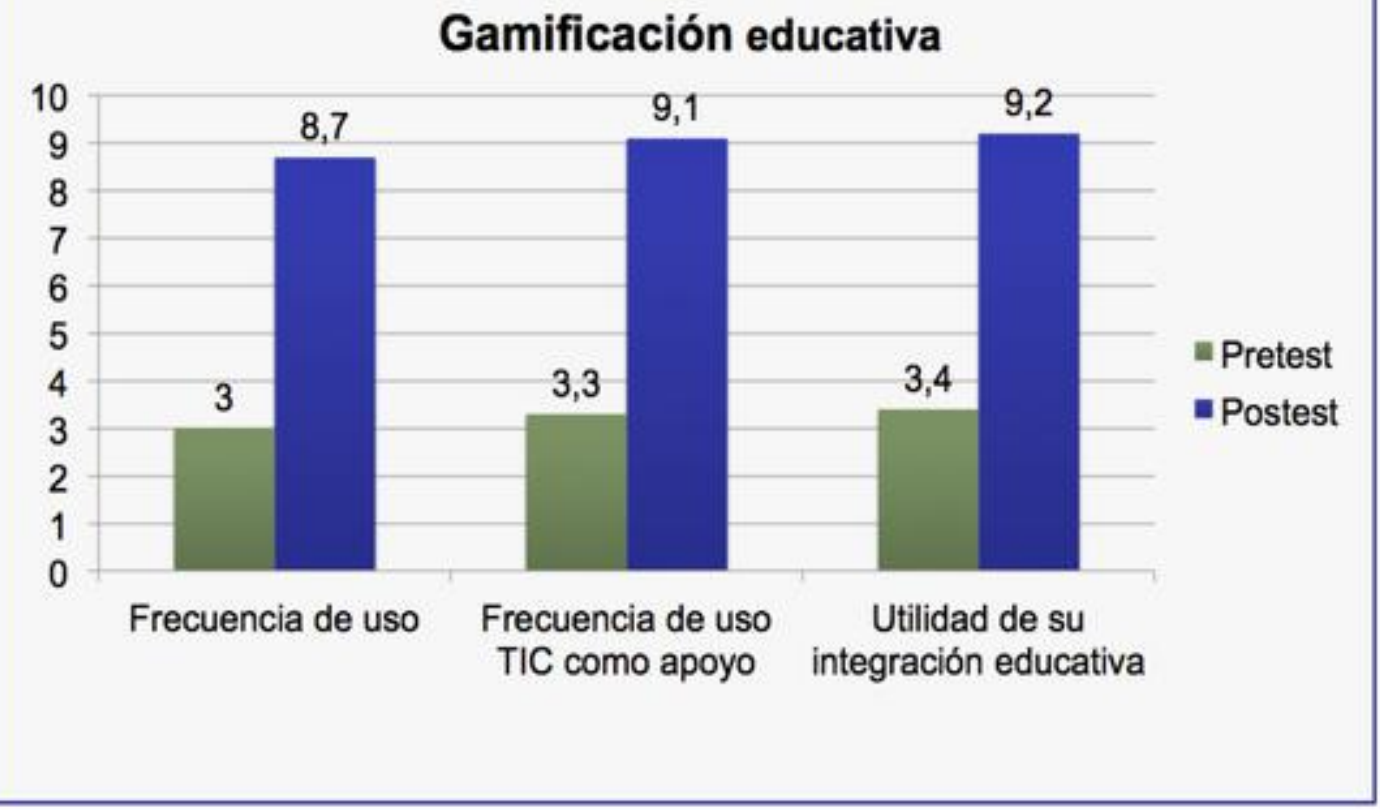

\section{Conclusión:}

La gamificación educativa con TIC desde este enfoque ofrece importantes beneficios en la formación musical universitaria. Todas las mejoras de enseñanza-aprendizaje son extensibles a otros contextos. 


\section{Genealogía profesional para estudiantes universitarios Trabajos dirigidos en el Grado de Medicina: Relatos de vida}

Miqueo, C.

\section{Palabras clave}

Aprendizaje activo, historia oral, historia de la medicina, transición democrática española, biografías médicas.

\section{Resumen}

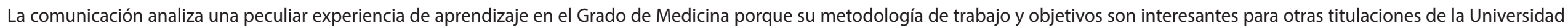
de Zaragoza, y fácilmente replicables.

Objetivos.

sta actividad está integrada en la asignatura troncal Investigación y nuevas tecnología (INT), que sustituyó en 2010 a la de Introducción a la Medicina, y tiene desde su origen un triple objetivo:

1. interesar a los estudiantes de primer curso por la diversidad de salidas profesionales y la evolución natural del contexto socio-laboral, sea en su propio país o en otros;

2. aprender a estimar la metodología cualitativa (absolutamente marginal en la formación de los futuros médicos) junto a la cuantitativa estadística normalizada;

3. adiestrar tempranamente a los jóvenes estudiantes en el diálogo interpersonal (e intergeneracional), en la escucha activa, y en la elaboración de los datos obtenidos -el "relato de vida profesional"- siguiendo la metodología científica al uso.

Pedagógicamente trabajamos para que los estudiantes sientan y acepten que la medicina no es sólo una ciencia.

Metodología.

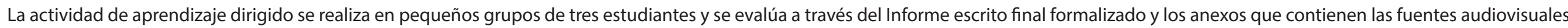

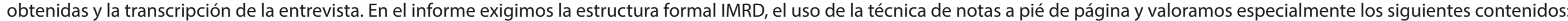

a. el discurso justificativo del contexto y caso;

b. una buena descripción del perfil del informante y la técnica de obtención de datos utilizada: contacto, tipo de entrevista sea en profundidad o semiestructurada, temas claves, y material autobiográfico solicitado y obtenido (fotos, publicaciones, nóminas, certificados, instrumentos médicos, noticias de prensa, etc.);

c. la elaboración de la historia de vida narrada en contraste con la bibliografía recomendada, otras lecturas personalmente elegidas y los marcos teóricos aportadas en las lecciones sobre historia de la profesión y asistencia médica de la asignatura Investigación y Nuevas Tecnologías.

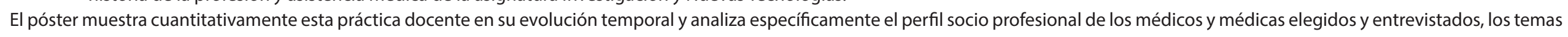

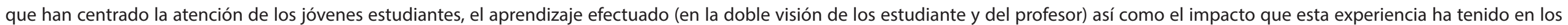
profesionales sanitarios que han participado en el último curso 2017-18. 


\section{Genealogía profesional para estudiantes universitarios Trabajos dirigidos en el Grado de Medicina: Relatos de vida}

\section{Consuelo Mjigueo}

Ciencias de la Documentación e Historia de la Ciencia: cmiqueo@unizar.es

OBJETIVO: presentar una actividad docente replicable en otras titulaciones universitarias.

\begin{tabular}{|c|c|c|c|}
\hline CURSO & $\begin{array}{c}\text { RELATOS } \\
\text { DE VIDA }\end{array}$ & $\begin{array}{c}\text { EsTUDIA } \\
\text { NTE }\end{array}$ & TIPO DE RELATO \\
\hline $2012-13$ & 93 & 93 & vida profesional \\
\hline 2013-14 & 36 & 111 & vida profesional \\
\hline 2014-15 & 35 & 103 & salud sexual \\
\hline 2015-16 & 32 & 98 & $\begin{array}{l}\text { relaciones } \\
\text { interprofesionales }\end{array}$ \\
\hline $2016-17$ & 21 & 68 & $\begin{array}{c}\text { relación medico } \\
\text { enfermo }\end{array}$ \\
\hline 2017-18 & 15 & 50 & vida profesional \\
\hline Total & 232 & 523 & $62,06 \%$ RVP \\
\hline
\end{tabular}

MATERIAL Y MÉTODOS:

Grupos de 3 estudiantes

Guión detallado del proceso: 10 Fases

4 tutorías colectivas según Fases

Evaluación: informe escrito estructurado (IMRDB)

Documentación obligada:

$\checkmark$ Foto entrevista,

$\checkmark$ Autorización firmada

$\checkmark$ Cronograma

$\checkmark$ Audio de entrevista (media: $45 \mathrm{~min}$.)

$\checkmark$ Transcripción (parcial o completa)
INVESTIGACIÓN

Y NUEVAS

TECNOLOGIAS

(INT) // S-1:

evolución de

trabajos

dirigidos de

historia oral

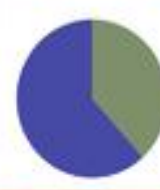

Bibliografia

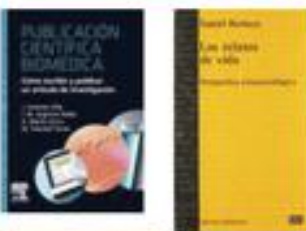

PAPERS

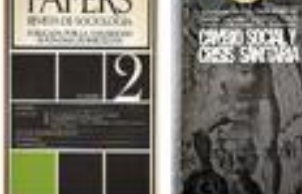

RESULTADOS: Relatos de vida profesional en el mundo rural (APD) de la promoción del 1978
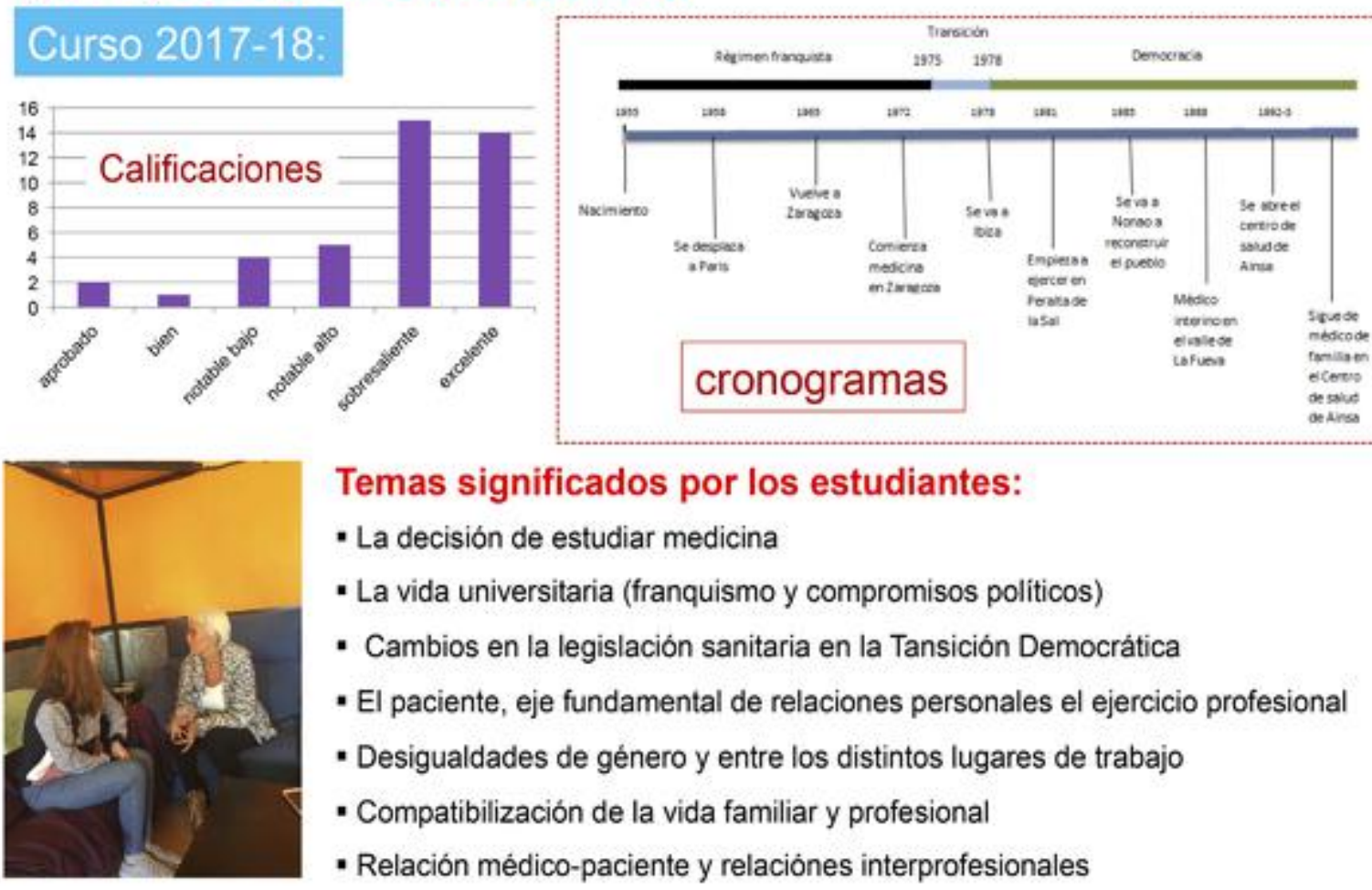

Temas significados por los estudiantes:

- La decisión de estudiar medicina

- La vida universitaria (franquismo y compromisos politicos)

- Cambios en la legislación sanitaria en la Tansición Democrática

- El paciente, eje fundamental de relaciones personales el ejercicio profesional

- Desigualdades de género y entre los distintos lugares de trabajo

- Compatibilización de la vida familiar y profesional

- Relación médico-paciente y relaciónes interprofesionales

- Satisfacción con la decisión de estudiar medicina.

CONCLUSIONES:

1. Estudiantes y médicos aprendieron con la experiencia

2. Interesa analizar otros perfiles profesionales 


\section{Introduciendo el "aula invertida” y las nuevas tecnologías en el aula universitaria: red MultiFlipTech}

Romero Pascual, E.; Artal Sevil, J. S.; Garrido Rubio, A.; Valero Gracia, M. S.; Puche Gil, J.; Pérez Sinusía, E.

\section{Palabras clave}

Flipped, TIC, innovación docente, aula invertida.

\section{Resumen}

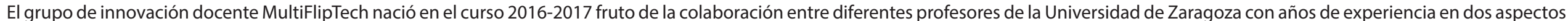

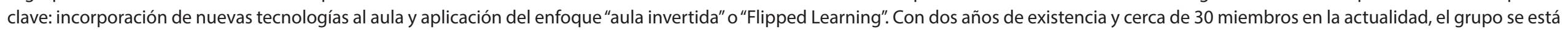

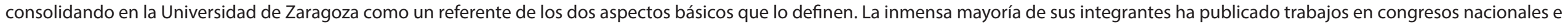

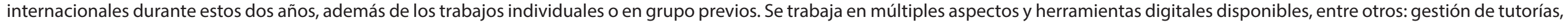

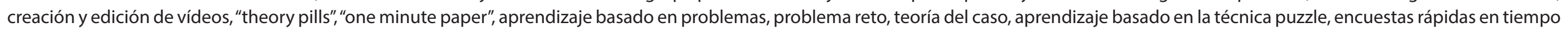
real, formularios, aplicaciones Google varias, entornos de aprendizaje o “LES", itinerarios de aprendizaje, analítica del aprendizaje, etc.

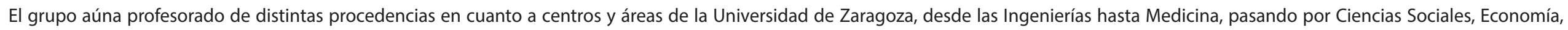

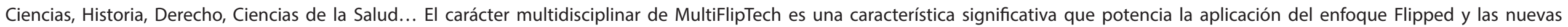
herramientas digitales.

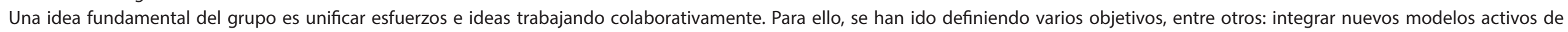

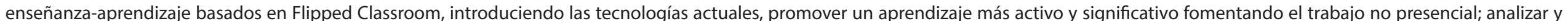

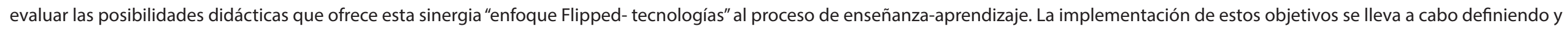
aplicando diferentes actividades concretas prácticas en la docencia. 


\section{Introduciendo el "aula invertida" y las nuevas tecnologías}

en el aula universitaria: red MultiFlipTech

\section{Enrique Romero, J. Sergio Artal-Sevil, Ana Garrido, Marta S. Valero, Javier Puche, Ester Pérez}

Dpto. Ingeniería química y Tecnología del medio ambiente, eromero@unizar.es

Contexto: 26 participantes en la red, unas 40 asignaturas diferentes, 18 titulaciones, más de 800 alumnos.

Áreas implicadas: Ingenierías, Educación, Empresariales, Ciencias, Medicina, Ciencias de la Salud, Derecho.

Objetivos: 1) integrar nuevos modelos activos de enseñanza-aprendizaje basados en Flipped Classroom, introduciendo las tecnologías actuales en el aula, para mejorar el proceso educativo y transferirlo a futuros contextos profesionales 2) visibilizar su aplicación

Metodologías: $\quad$ Aula invertida o Flipped Classroom

\section{feedly}

Herramientas y Recursos Didácticos para fomentar la

aplicación de estrategia Flipped Teaching en el aula

universitaria.

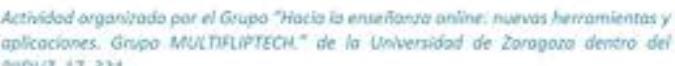

Seminario de divulgación

-4 horas

- 6 charlas

- 1 ponencia invitada

Premind

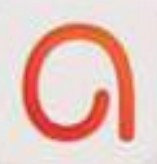

\section{Active Presenter}

Preparación de una macro-encuesta de satisfacción con las nuevas metodologías y herramientas digitales utilizadas

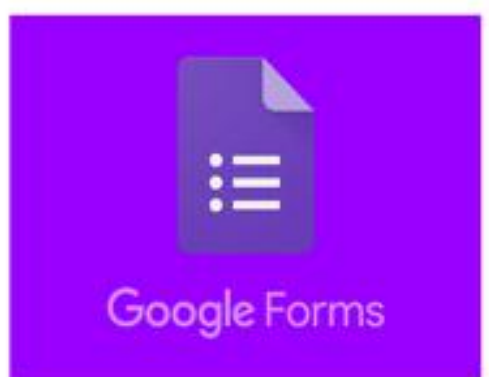

Creación de una página web del grupo

www.multifliptech.unizar.es
Nuevas tecnologías

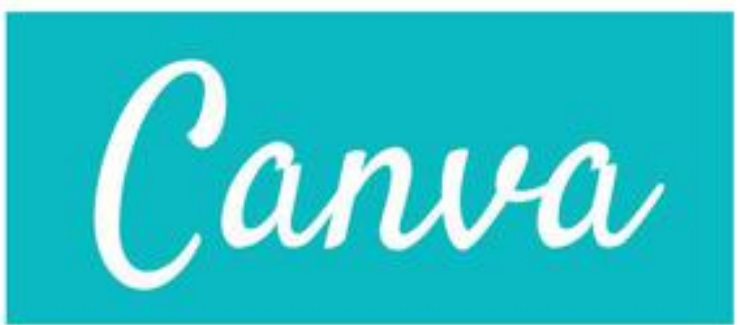

Resultados y

Conclusiones

퓨. Universidad

III Zaragoza 


\section{Metodología Design Thinking como estrategia en la promoción de pensamiento divergente: una didáctica artística a través de material reciclado}

Ramos Vallecillo, N.; Murillo Ligorred, $V$.

\section{Palabras clave}

Design Thinking, pensamiento divergente, material reciclado.

\section{Resumen}

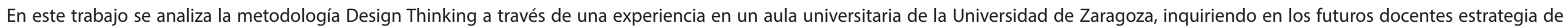

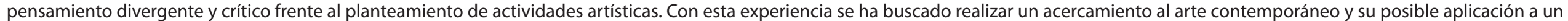
aula infantil, y el desarrollo de todo ello centrado en la estética del reciclaje con el objetivo de fomentar la responsabilidad y autonomía desde las primeras etapas educativas.

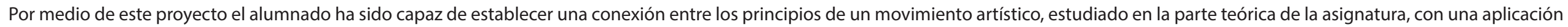
práctica y con utilidad real en el aula de infantil. 


\section{Metodología Design Thinking en la promoción de pensamiento divergente: una didáctica artística a través de material reciclado. (Grados de Maestro)}

Relación de autores: Nora Ramos, Víctor Murillo.

Departamento de expresión musical, plástica y corporal, (noramos@unizar.es)

Contexto de la titulación académica:

$3^{\circ}$ curso del Grado de Maestro en educación infantil.

Área de Didáctica de la Expresión Plástica (Facultad de Educación)

\section{Objetivos de la intervención:}

- Desarrollar la metodología del Desing Thinking -Potenciar el uso del material de reciclaje como elemento para la realización de composiciones creativas en tres dimensiones, aplicadas a la etapa de educación infantil. -Apreciar las creaciones artísticas desde la etapa de educación infantil.

\section{Los principales resultados:}

Utilizando la metodologia Design Thinking hemos logrado en las alumnas un aprendizaje del modo de expresar e interpretar visualmente las ideas. Mediante la aplicación práctica en la resolución del reto planteado se ha posibilitado la asimilación de la parte conceptual que han necesitado para resolverlo.

\section{Metodología:}

Esta propuesta ha sido articulada por el modelo didáctico del ABP. El procedimiento seguido para implementar el Design Thinking en esta experiencia fue en cinco etapas: sentir, definir, idear, prototipar y evaluar. Utilizando esta metodología se ha logrado en el alumnado un aprendizaje del modo de expresar e interpretar visualmente las ideas.

\section{Conclusiones:}

A través del uso de las metodologías aplicadas en la parte práctica de la asignatura, los estudiantes han conseguido mostrar mayor autonomía y gestión del aprendizaje, siendo capaces de integrar los métodos de trabajo artístico para una futura aplicación personal en su aula de infantil.
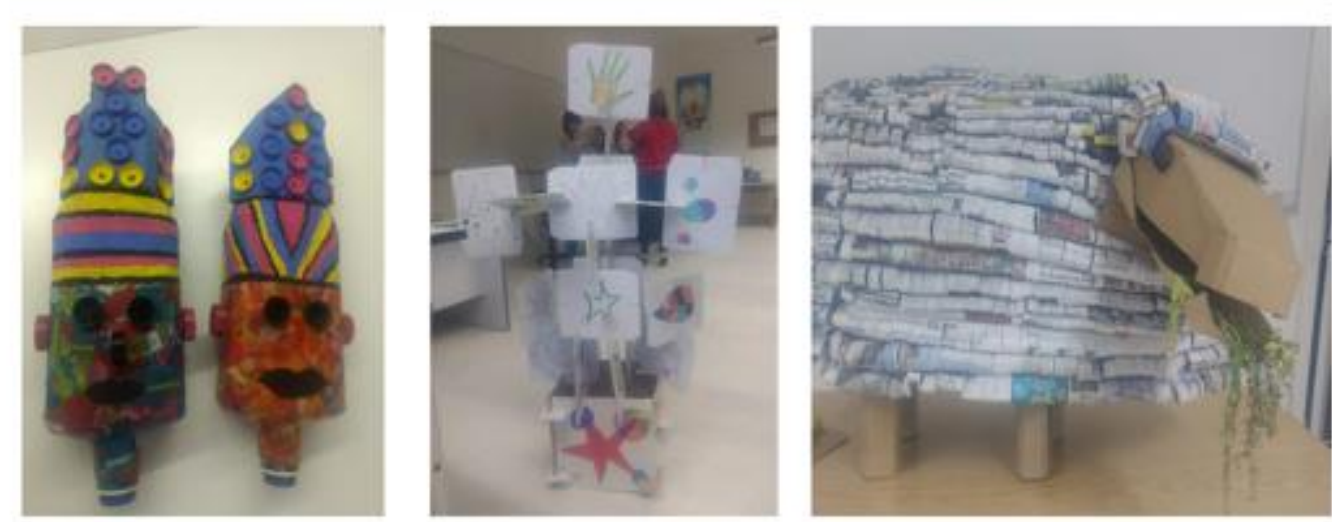


\section{Motivating Engineering students to Improve Teamwork and Time Management}

Gorgemans, S.; Alonso Nuez, M. J.; Rosell Martínez, J.; Alegre Saz, L.; Delgado Gómez, J. M.; García Madurga, M. A.; Lozano Velázquez, J.; Navarro Elola, L.; Palomas, S.; Sánchez Sellero, P.

\section{Keywords}

Teamwork, time management, competences, engineering degrees.

\section{Abstract}

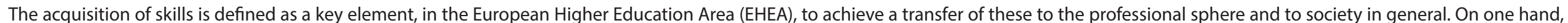

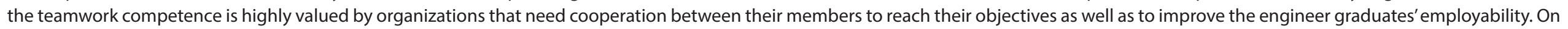

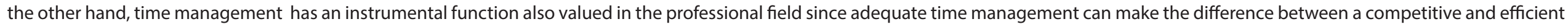

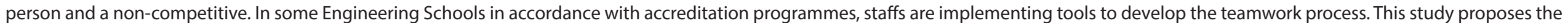

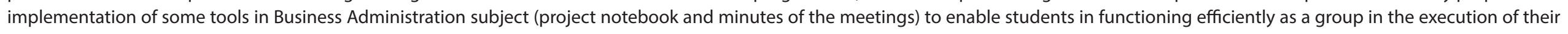

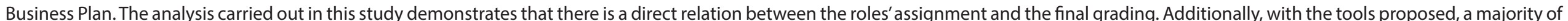

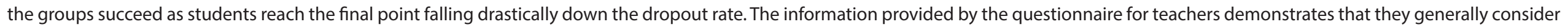

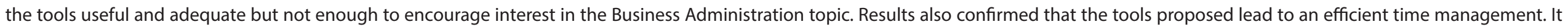

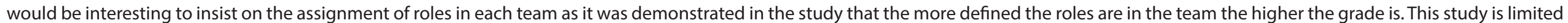
in its scope, but will be soon upgraded through the consideration of the students' point of view.

Acknowledgments to Academic Policy Vice Chancellor for granting of finance to the project PIIDUZ_17_171. 
Motivating Engineering students to Improve Teamwork and Time Management

Gorgemans S.; Alonso Nuez M.J.; Rosell Martinez J.; Alegre Saz L.; Delgado Gómez J.M.; Garcia Madurga M.A.; Lozano Velázquez J.; Navarro Elola L.; Palomas S.; Sánchez Sellero P.

Escuela de Ingeniería y Arquitectura, sgorge@unizar.es

\section{CONTEXT}

- Business Administration 6 ECTS

- Compulsory

- 1,000 students enrolled

- First year of every engeeniring grade

- Continuous evaluation: Business Plan $(20 \%)$

\section{OBJECTIVES}

Introduce tools to improve the teamwork functionning and time management

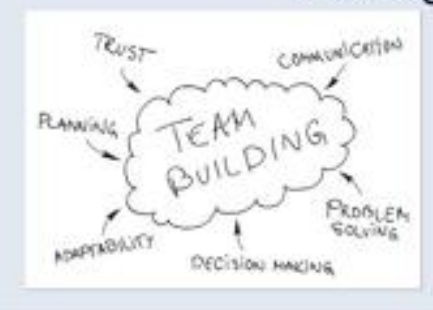

\section{METHOD}

1. Project notebook revised

2. Meeting minute elaboration

3. What about time management? Some tools (Training by Universa)

\section{RESULTS AND CONCLUSIONS}

\section{Sample:}

724 students 108 teams

Answers: $67,8 \%$

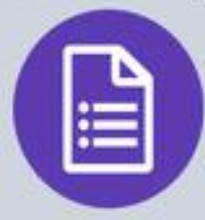

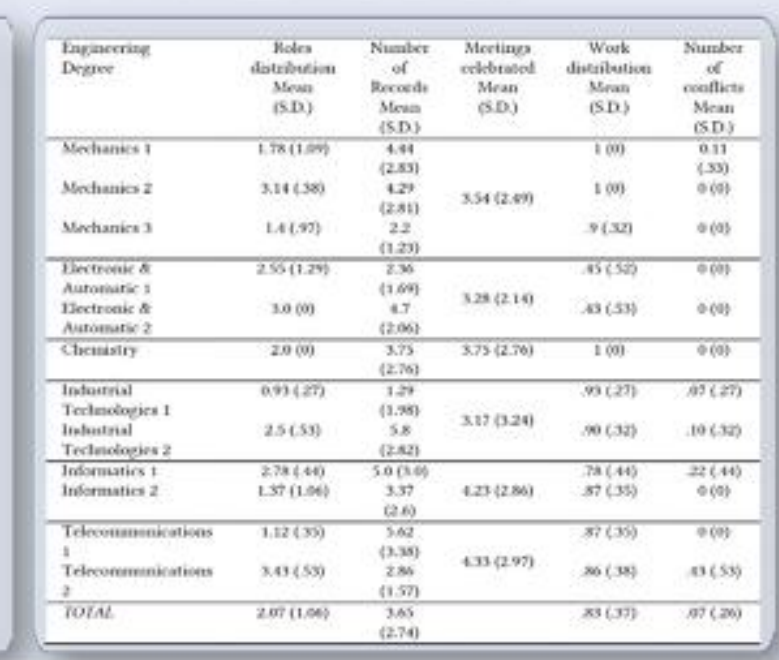

(Organize) (Economize)

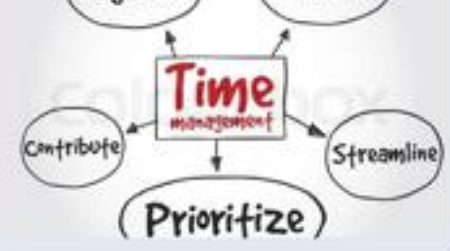

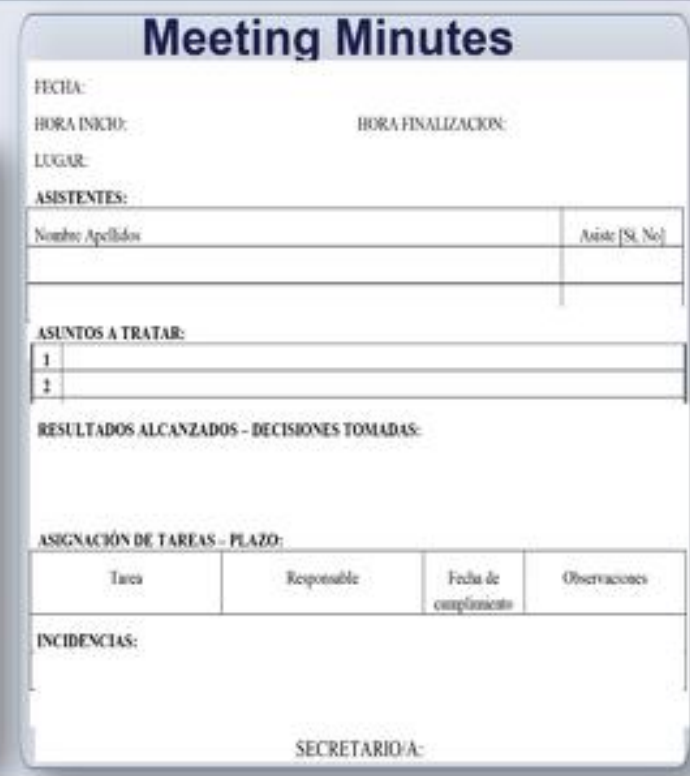

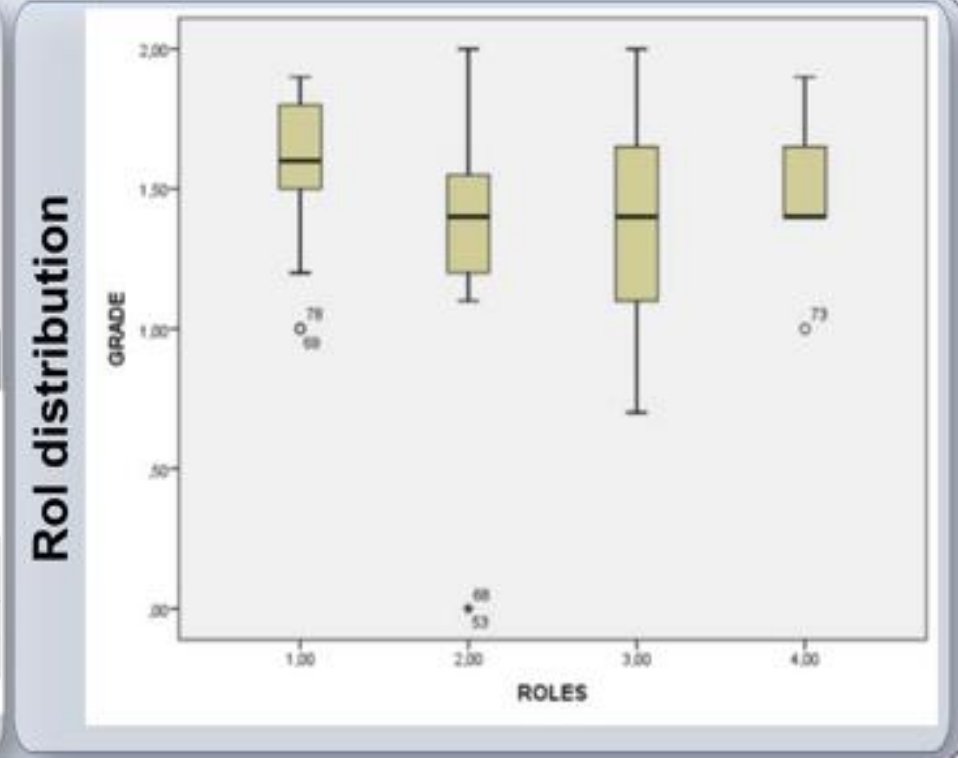

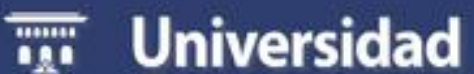
쓸 Zaragoza 


\section{Tecnología y Herramientas Interactivas destinadas a la Gamificación. Impacto en el aula universitaria}

Artal-Sevil, J. S.; Artacho Terrer, J. M.; Bernues del Río, E.; Romero, E.

\section{Palabras clave}

Game-based Learning, Flipped Teaching, eQuestion, recursos TIC, dispositivos móviles.

\section{Resumen}

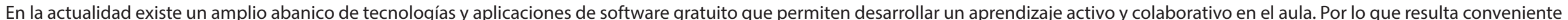

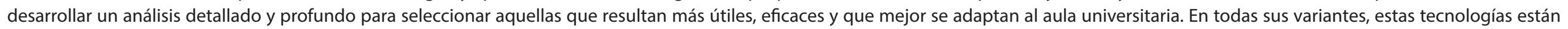

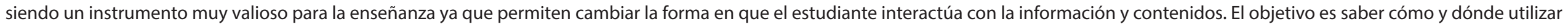

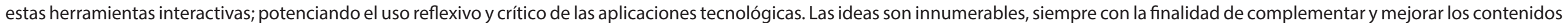

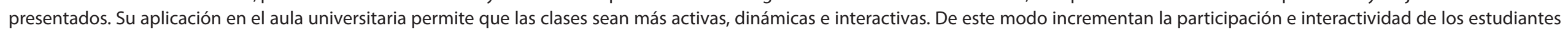

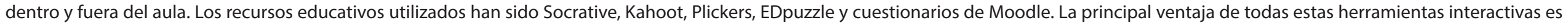
que proporcionan un feedback inmediato al estudiante y profesor.

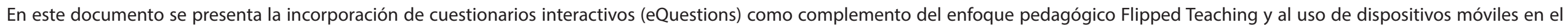

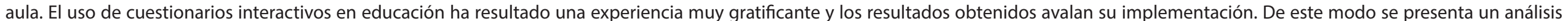

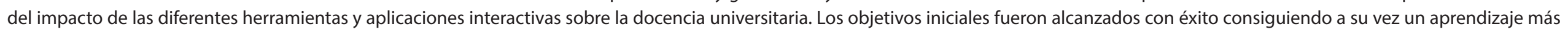

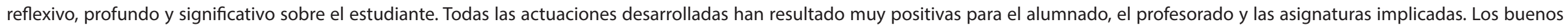
resultados obtenidos muestran la aplicabilidad de la estrategia docente adoptada. 



\section{VII \\ Acciones de Integración y Orientacón de Estudiantes}




\section{Acciones de integración y orientación de Estudiantes}

1. Escanero Marcén, J. F.; Soria Aznar, M. S.; Guerra Sanchez, M.; Lasala Calleja, M. P.; Galindo Ayuda, F.

Autopercepción de la competencia aprender a aprender en estudiantes de Medicina.

2. Santillán Santa Cruz, R.; Martínez Calvo, J.; Villa Torrano, A.

Conceptualización y síntesis como técnicas de aprendizaje en el estudio del Derecho

3. Gargallo Ibort, E.; Dalmau Torres, J. M.; Pérez-Aradros Muro, B.

El emprendimiento como proyección hacia un futuro profesional desde el bachillerato hasta la universidad

4. Oller Benítez, A.

Estrategias para favorecer la inclusión a través del vídeo participativo.

5. Murillo Ligorred, V.; Resano López, J. C.; Sarfson Gleizer, S.; Ramos Vallecillo, N.

Google Apps: los formularios como recurso interactivo para orientar la elección del TFG en Plástica y Música (Grados de Maestro). Itinerarios diferenciados 2.0 para el arte y su educación

6. Jarne Jarne, G.; Minguillón Constante E.; Zabal Cortés, M. T.

Herramientas docentes para el aprendizaje de las Matemáticas

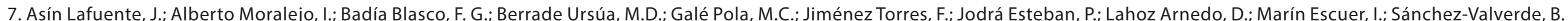
Implementación de un Curso 0 virtual para Estadística y Probabilidad en Ingeniería: La experiencia en la EINA

8. Bretos Fernández, I.; Díaz Foncea, M.; Marcuello Servós, C.; Sarasa Aznar, C.

Los Critical Management Education Studies como prisma teórico y conceptual para una educación empresarial alternative

9. Lizalde Gil, M.; Cortés Pascual, A.

10 MIRRORS: La orientación de los estudiantes de los Grados en Magisterio desde la experiencia contrastada de maestros jubilados

10. Salavera, C.; Usán, P.; Artal, P.; Gómez, J.; Modrego, R.; Suárez H.; Calvo, N.

Percepción del bullying por los estudiantes de la Universidad de Zaragoza

11. Abadia, A. R.; Bueno, C.; Bueso, P.; Fidalgo, A.; Hernández, L.; Sein-Echaluce, M. L.; Ubieto, C.; Ubieto I.

Segunda edición del MOOC "Buenas Prácticas en el Uso Académico de la Propiedad Intelectual" 



\section{Autopercepción de la competencia aprender a aprender en estudiantes de Medicina}

Escanero Marcén, J. F.; Soria Aznar, M. S.; Guerra Sanchez, M.; Lasala Calleja, M. P.; Galindo Ayuda, F.

\section{Palabras clave}

Autorregulación, competencia, aprender a aprender.

\section{Resumen}

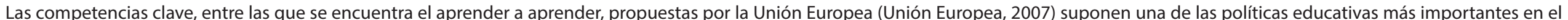

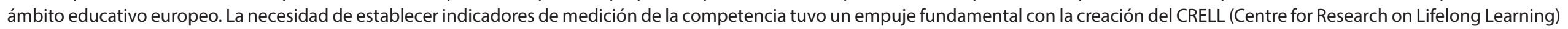

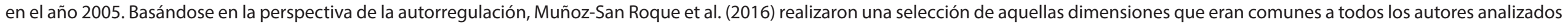

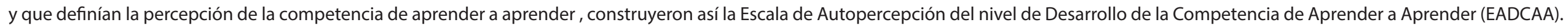

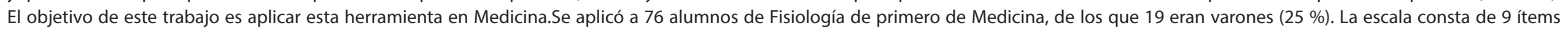

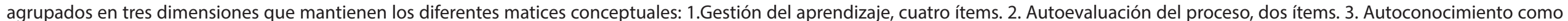

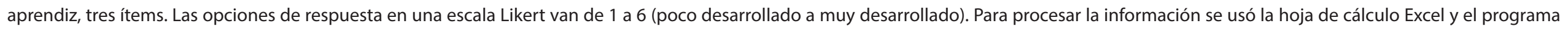
estadístico R Comander.

Los resultados encontrados fueron los siguientes:

- Gestión del aprendizaje (mín.-medio-máx.) = 2,25-4,38-5,75

- Autoevaluación del proceso (mín.-medio-máx.) =3,00-4,43-6,00

- Autoconocimiento como aprendiz (mín.-medio-máx.) = 1,33-4,62-6.00.

- En la baremación de los resultados (de 0 a 2,49, de 2,50 a 4 y de 4,0 a 6) solamente una alumna se encontraba en el primer grupo.

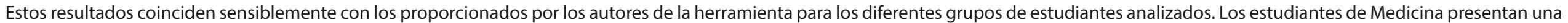

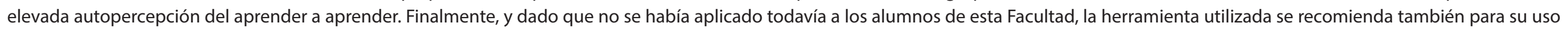
con los alumnos de medicina. 


\section{Autopercepción de la competencia aprender a aprender en estudiantes de}

Medicina.

Escanero Marcén, J.F.; Soria Aznar, M.S.; Guerra Sanchez, M.; Lasala Calleja, M.P.; Galindo Ayuda, F.

Departamento de Farmacología y Fisiología,

Objetivo: aplicar el cuestionario EADCAA en 76 estudiantes de Medicina.

Material y métodos: El cuestionario consta de 9 ítems agrupados en tres dimensiones: 1.Gestión del aprendizaje, cuatro ítems. 2. Autoevaluación del proceso, dos ítems. 3. Autoconocimiento como aprendiz, tres ítems. Las opciones de respuesta en una escala Likert van de 1 a 6 (poco desarrollado a muy desarrollado). Para procesar la información se usó la hoja de cálculo Excel y el programa estadístico R Comander.

\section{Resultados:}

La tabla 1 recoge los resultados de las tres dimensiones; la tabla 2 muestra la baremación para los rangos definidos y la figura las respuestas según el nivel de dificultad de las preguntas.

Tabla1. Valores medios para cada una de las tres dimensiones.

Valores del grupo

Mínimo Media Máximo

Gestión del aprendizaje

Autoevaluación del proceso

Autoconocimiento como aprendiz

\section{2,25}

3,00

4,38

4,43

1,33

$4,62 \quad 6,00$

Tabla 2. Puntuaciones en el rango de baremación definido

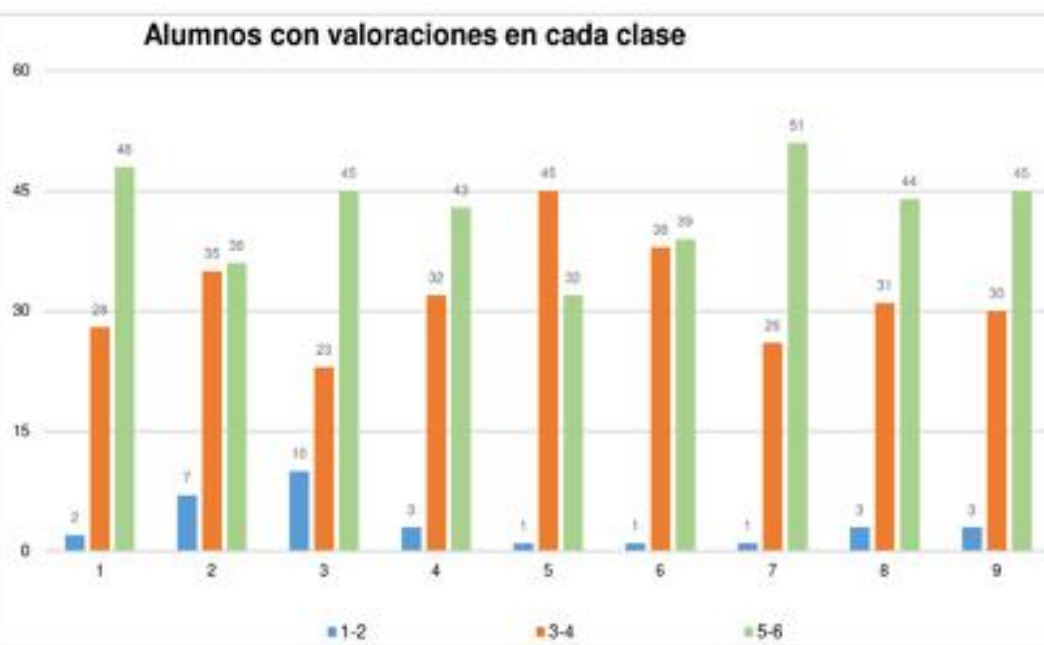

Puntuaciones en el rango de $1,0-2,49 \quad 2,50-4,49 \quad 4,50-6,0$

Gestión del aprendizaje Autoevaluación del proceso Autoconocimiento como aprendiz

$\begin{array}{ll}39 & 38 \\ 35 & 43 \\ 29 & 48\end{array}$

Conclusiones: Estos resultados coinciden con los proporcionados por los autores de la herramienta para los diferentes grupos de estudiantes analizados. Finalmente, y dado que no se había aplicado todavía a los alumnos de esta Facultad, la herramienta utilizada se recomienda también para su uso con los alumnos de medicina.

\section{플 Universidad




\section{Conceptualización y síntesis como técnicas de aprendizaje en el estudio del Derecho}

Santillán Santa Cruz, R.; Martínez Calvo, J.; Villa Torrano, A.

\section{Palabras clave}

Resumen a partir de conceptos, medios de aprendizaje, Moodle, competencias analíticas y sintéticas.

\section{Resumen}

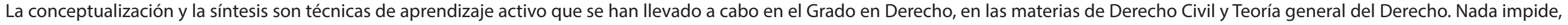
sin embargo, que estas técnicas puedan ser transferidas a otras titulaciones y áreas de conocimiento introduciendo los cambios pertinentes.

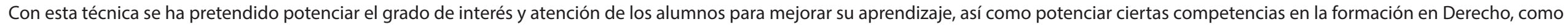
son las habilidades de análisis y síntesis argumentativo.

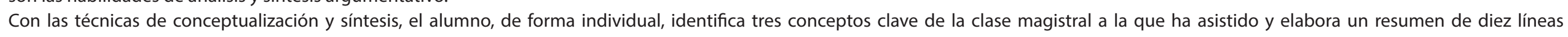

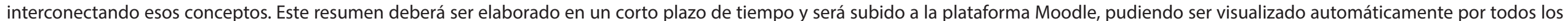

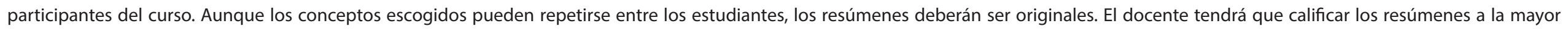
brevedad posible.

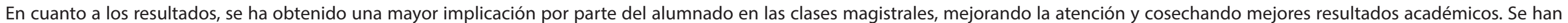
detectado con suficiente antelación problemas de asimilación conceptual, así como una mayor motivación en el alumnado.

Cabe hacer una valoración muy positiva de este proyecto de innovación docente. Conceptualización y síntesis

I. refuerza la capacidad de concentración y retención;

II. permite desarrollar y potenciar la capacidad de análisis y síntesis;

III. incentiva la creatividad u originalidad; i

IV. potencia la capacidad de trabajo síncrono y asíncrono; $y$,

V. fortalece el proceso de enseñanza-aprendizaje, con efectos altamente beneficiosos en el campo de la retroalimentación educativa. 


\title{
Conceptualización y síntesis como técnicas de aprendizaje en el estudio del Derecho
}

\author{
Santillán Santa Cruz, R.; Martinez Calvo, J.; Villa Torrano, A.
}

Departamento de Derecho Privado, Universidad de Zaragoza, rominasantillansc@gmail.com

\section{Contexto académico}

- Derecho Civil: Persona y Bienes.

- Derecho Civil:

Obligaciones y Contratos.

- Teoría del Derecho.

\section{Objetivos}

- Reforzar el grado de atención e interés en las clases magistrales.

- Potenciar la creatividad y la originalidad.

- Potenciar competencias transversales de conceptualización, análisis y síntesis argumentativo.

\section{Metodología}

Tras la clase magistral, en un breve periodo de tiempo, los alumnos de manera individual realizan un resumen de diez líneas interconectando los tres conceptos clave de la sesión, los cuales deben ser identificados por ellos mismos.

Los resúmenes serán subidos a la plataforma Moodle donde serán visibles por el resto de alumnos. EI docente calificará los resúmenes tan pronto como le sea posible con el objetivo de identificar a tiempo problemas de comprensión conceptual.

\section{Resultados}

- Mejora de la atención y motivación del alumnado.

- Detección temprana de problemas de asimilación conceptual.

- Potenciación de la capacidad de trabajo síncrono y asíncrono.

- Fortalecimiento de la retroalimentación educativa.

\section{Conclusiones}

Esta simple técnica de aprendizaje ha demostrado ser una eficiente herramienta con innumerables ventajas. La magnífica aceptación e implicación por parte del alumnado anima a seguir explorándola.

\section{을 Universidad}




\section{El emprendimiento como proyección hacia un futuro profesional desde el bachillerato hasta la universidad}

Gargallo Ibort, E.; Dalmau Torres, J. M.; Pérez-Aradros Muro, B.

\section{Palabras clave}

Emprendimiento escolar-universitario, Learning by doing, FutURemprende.

\section{Resumen}

\section{Contexto:}

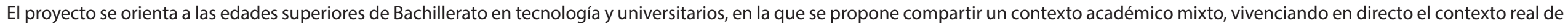

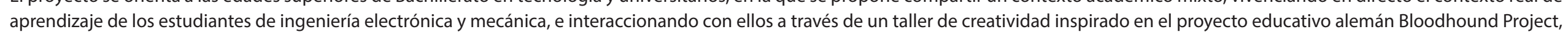

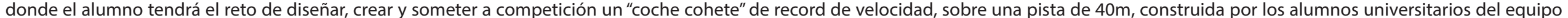

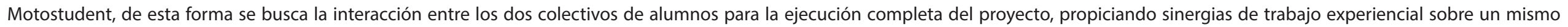
escenario de emprendimiento.

Objetivos:

Atesorar experiencias, compartir vivencias y desarrollar materiales formativos para fomentar la educación emprendedora de los jóvenes estudiantes de Bachillerato y Universitarios.

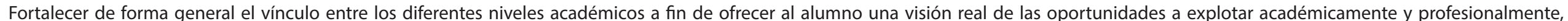
generando al mismo tiempo un efecto de promoción universitaria.

Metodología:

Learning by doing, Aprendizaje basado en problemas (ABP) y Aprendizaje basado en proyectos.

\section{Resultados:}

Aumenta la deseabilidad de los estudiantes por emprender (39\%) Reduce el temor de los alumnos al fracaso $(4,1 \%)$

Los alumnos prefieren las metodologías que les lleva a la practicidad (46\%)

La autonomía y fomento de la creatividad son las acciones estratégicas de motivación para los alumnos (67\%)

Conclusiones:

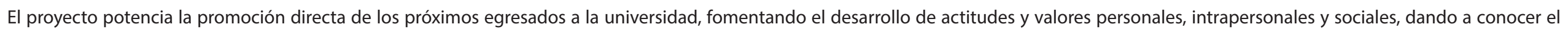
contexto académico universitario así como los proyectos de desarrollo clave de la universidad de referencia. 


\section{El emprendimiento como proyección hacia un futuro profesional desde el Bachillerato hasta la universidad \\ Esther Gargallo, Josep Ma Dalmau, Beatriz Pérez-Aradros, Alberto Falcés}

Departamento Ciencias de La Educación, jose-maria.Dalmau@unirioja.es

\section{Contexto académico}

Primero de Bachillerato/Universitarios

Tecnologia/Ingeniería mecánica-electrónica

\section{Objetivos propuestos}

Movilizar habilidades sociales Desarrollar actitudes personales Generar conocimientos

\section{Metodología empleada}

Learning by doing (Marina, 2012; Contreras; Dewey, 1997)
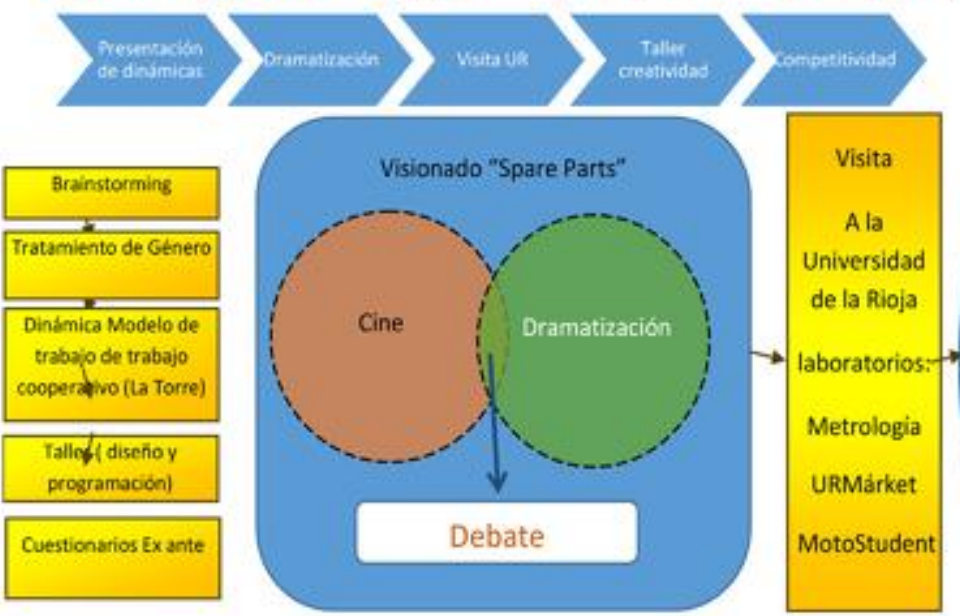

\section{Resultados alcanzados}

Predisposición a emprender

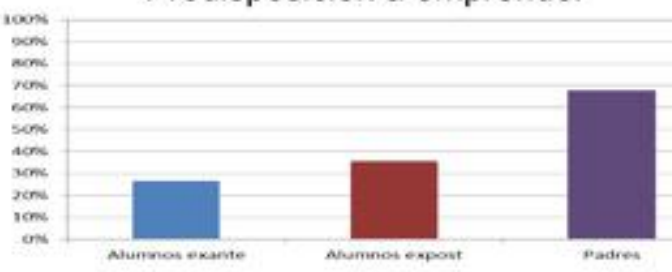

Estilos de aprendizaje

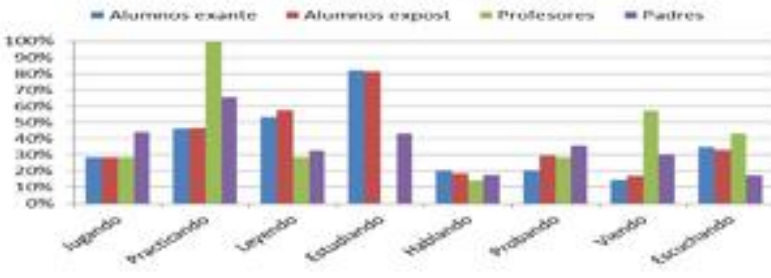

\section{Conclusiones obtenidas}

Aumenta la deseabilidad de los estudiantes para emprender

Reduce el temor de alumnos a fracasar

Potencia una actitud proactiva en los estudiantes

Despierta el interés de los alumnos por el tejido de desarrollo de su entorno y mejora la comunicación entre colectivos

Moviliza el talento individual y potencia el trabajo colaborativo, desarrollando competencias emprendedoras

Promoción de los próximos egresados a la universidad, fomentando el desarrollo de actitudes y valores personales, intrapersonales y sociales, dando a conocer los proyectos clave de la UR

\section{inin Universidad \\ iㅡ Zaragoza}




\section{Estrategias para favorecer la inclusión a través del vídeo participativo}

Oller Benítez, $A$.

\section{Palabras clave}

Inclusión, formación de identidades, recursos audiovisuales, metodologías participativas.

\section{Resumen}

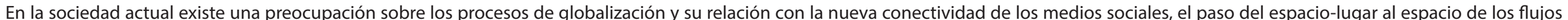

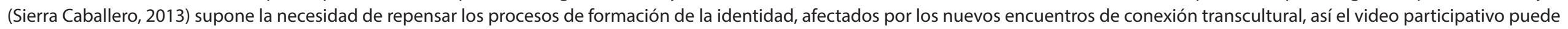

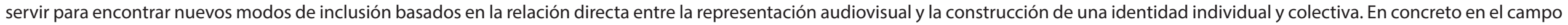

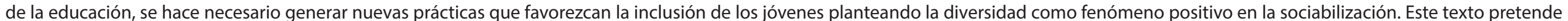

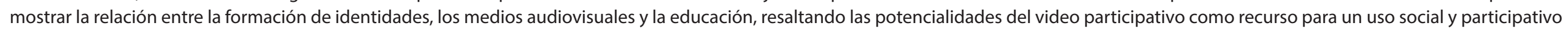
de los medios.

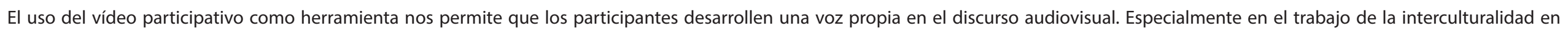

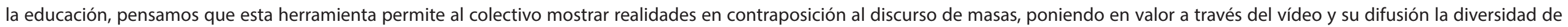
realidades existentes y discursos propios.

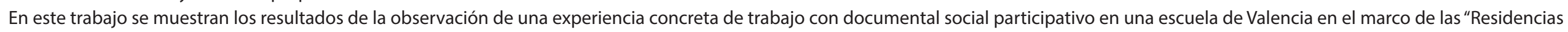
artísticas" promovidas por el Ayuntamiento. Se busca, finalmente, ofrecer recomendaciones a su uso a través de la valoración de la experiencia. 


\section{Google Apps: los formularios como recurso interactivo para orientar la elección del TFG en Plástica y Música (Grados de Maestro). Itinerarios diferenciados 2.0 para el arte y su educación}

Murillo Ligorred, V.; Resano López, J. C.; Sarfson Gleizer, S.; Ramos Vallecillo, N.

\section{Palabras clave}

Google Apps,TFG, educación artística, magisterio.

\section{Resumen}

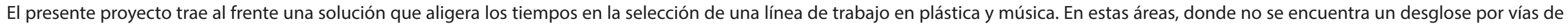

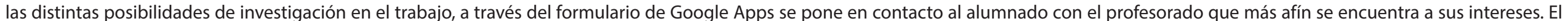

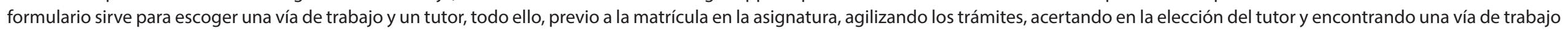

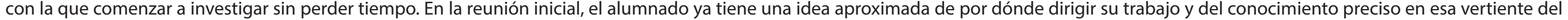
mismo de su tutor/a.

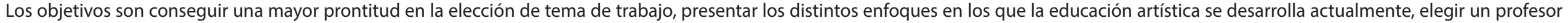
que estudie e investigue esas líneas de trabajo.

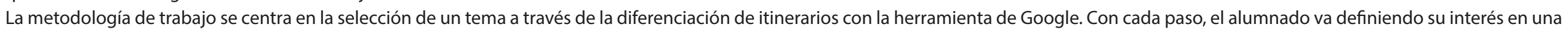
materia en la que no se ha podido profundizar en la asignatura de la carrera. Por ejemplo, educación artística y arte contemporáneo. Educación y museos. Perspectiva de género...

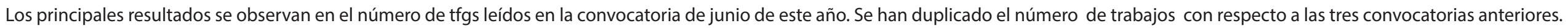
Es una herramienta útil para que el alumnado oriente sus intereses previamente al inicio de la asignatura, con esto, tienen mayor garantía de terminar en junio su proyecto.

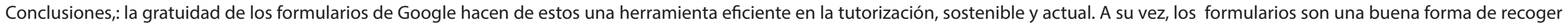

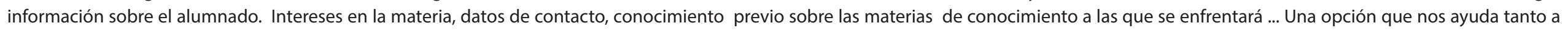

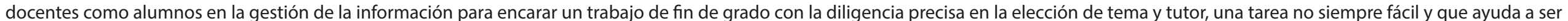
solventada. Los objetivos del proyecto responden a la falta de 


\title{
Google Apps: los formularios como recurso interactivo para orientar la elección del TFG en Plástica y Música (Grados de Maestro).
}

\author{
Itinerarios diferenciados 2.0 para el arte y su educación
}

Relación de autores: Víctor Murillo, Juan Cruz Resano, Susana Sarfson, Nora Ramos

Departamento de expresión musical, plástica y corporal, (vml@unizar.es)

Contexto de la titulación académica:

$4^{\circ}$ curso del Grado de Maestro en educación infantil y primaria. Asignaturas de TFG en el área de didáctica de la expresión Plástica (Facultad de Educación) y el área de Música (Facultad de Ciencias Humanas y de la Educación)

\section{Objetivos de la intervención:}

Definir el interés concreto en una línea de trabajo en didáctica artística: Arte Contemporáneo, Feminismo, Estética,

Conseguir una línea afín a sus intereses.

Elegir un itinerario para obtener un profesor determinado. Acortar los tiempos en la búsqueda de un tutor afín. Seleccionar una línea de trabajo previa al comienzo.

\section{Los principales resultados:}

Tras esta primera experiencia piloto en el departamento y tras la buena acogida del alumnado, asi como su gran aplicabilidad, podemos señalar que será en el futuro una herramienta referente en el área para la orientación de TFG.

En los tres últimos cursos, los TFG leídos en las convocatorias de junio en la Fac. Educación han sido:

2016: 6 - 2017: 5 - 2018: 10

Los intereses concretos de las alumnas/os han sido: 3 alumnas Didáctica/feminismo. 4 alumnas dibujo infantil y creatividad. 3 alumnos/as nuevas audiovisual y videojuegos.

\section{Metodología del PIIDUZ:}

Los formularios de Google Apps son una herramienta útil para evaluar los conocimientos previos del alumnado y orientar sus intereses en su TFG en las áreas de Plástica y Música. A través del recorrido común propuesto a través de un formulario común primero, y las bifurcaciones alcanzadas con las distintas elecciones después, se consigue el objetivo de orientar una línea de trabajo concreta previa, así como un profesor especialista en esos temas. Con las distintas cuestiones, el alumnado alcanza una línea de trabajo afin a sus intereses, asi como idóneo para dirigir su TFG, el cual desarrolla su investigación en los mismos campos en los que el alumnado ha mostrado interés. De este modo se optimiza el tiempo en la elección de tema y tutor.
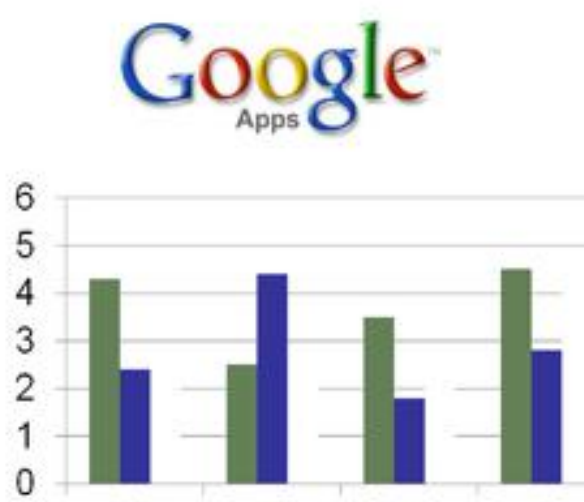

0

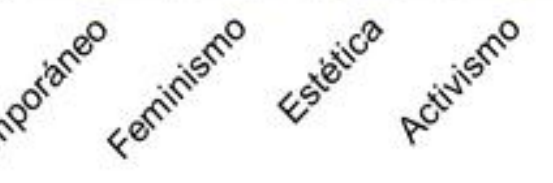

\section{Conclusiones:}

Agilidad de tiempos en la elección de trabajo. Orientación del alumnado en la elección. Visualización de las distintas posibilidades Se duplican los Tfg de junio tras la implantación de la herramienta

Mayor conocimiento de las líneas actuales de trabajo

$$
\begin{array}{r}
\text { = Serie } 1 \\
\text { - Serie } 2 \\
\text { Serie } 3
\end{array}
$$

\section{For Education}

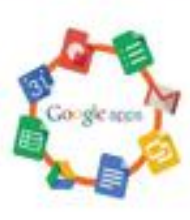




\section{Herramientas docentes para el aprendizaje de las Matemáticas}

Jarne Jarne, G.; Minguillón Constante, E.; Zabal Cortés, M. T.

\section{Palabras clave}

Anillo Digital Docente, autoevaluación, curso cero, descubrimiento de errores, estudio continuado.

\section{Resumen}

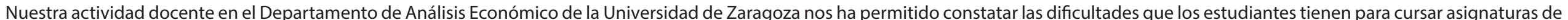

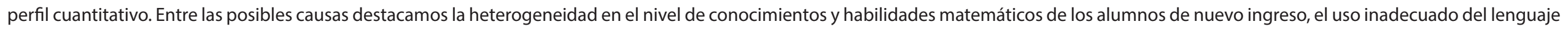
y razonamiento matemático, el desconocimiento de la teoría utilizada en los problemas y la falta de trabajo continuado en la preparación de las asignaturas.

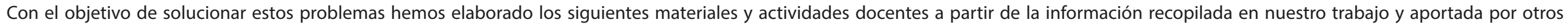
profesores:

1. Un curso cero para nivelar los conocimientos de los estudiantes y que se concreta en:

- Un curso cero presencial de 15 horas impartido en septiembre.

- Un curso cero virtual <http://www.unizar.es/aragon_tres> que permite resolver de forma autónoma dudas matemáticas.

2. Materiales en el Anillo Digital Docente que facilitan el seguimiento de las asignaturas. Son resúmenes teóricos (muy esquemáticos para incentivar la asistencia a clase y el uso de textos recomendados), ejercicios resueltos y para resolver, problemas económicos y exámenes de cursos anteriores.

3. Actividades de aprendizaje a través de descubrimiento de errores <http://www.unizar.es/aragon_tres/errores.htm> que permiten comprobar si los conocimientos se han asimilado adecuadamente.

4. Cuestionarios de autoevaluación en el ADD para evaluar los conocimientos, competencias y habilidades adquiridos en cada tema y cuyos resultados informan al estudiante sobre la conveniencia de repasar el tema.

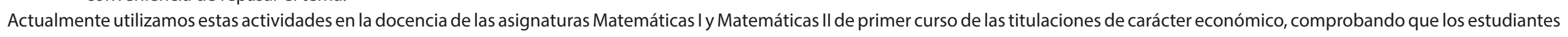
que las usan participan más en clase y están más motivados para el estudio, lo que esperamos se concrete en mejores resultados académicos en el presente curso. 


\section{Herramientas docentes para el aprendizaje de las Matemáticas}

\section{Gloria Jarne, Esperanza Minguillón, Ma Trinidad Zabal}

Departamento de Análisis Económico, gjarne@unizar.es

\section{CONTEXTO}

Estudiantes de primer curso de los Grados de carácter económico-empresarial (ADE, Economía, FICO y MIM) de la Universidad de Zaragoza

\section{OBJETIVOS}

- Mejorar el proceso de enseñanza-aprendizaje de las asignaturas de Matemáticas

- Motivar el estudio continuado incidiendo en la relevancia de los contenidos teóricos

- Evitar el absentismo en las clases presenciales y mejorar las tasas de éxito y rendimiento

\section{METODOLOGÍA}

- Detección y análisis de las dificultades

- Elaboración de materiales y actividades online

\section{CONCLUSIONES}

- Mejora la práctica docente de las asignaturas que utilizan herramientas cuantitativas

- Aumenta la participación del estudiante en clase
Nivela conocimientos previos 


\section{Implementación de un Curso 0 virtual para Estadística y Probabilidad en Ingeniería: La experiencia en la EINA}

Asín Lafuente, J.; Alberto Moralejo, I.; Badía Blasco, F. G.; Berrade Ursúa, M. D.; Galé Pola, M. C.; Jiménez Torres, F.; Jodrá Esteban, P.; Lahoz Arnedo, D.; Marín Escuer, I.; Sánchez-Valverde, B.

\section{Palabras clave}

Auto-evaluación, trabajo autónomo, plataforma Moodle.

\section{Resumen}

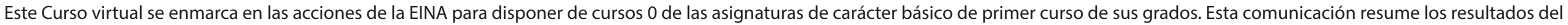

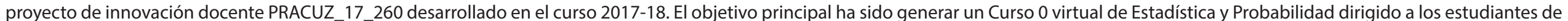
nuevo ingreso en los Grados de Ingeniería.

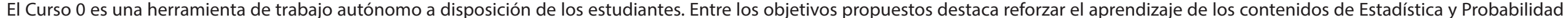
incluidos en Secundaria y Bachillerato y facilitar la adquisición de las nuevas competencias formuladas en las asignaturas de Estadística.

Las etapas han sido:

1. Revisar las competencias que los estudiantes adquieren según el currículo de Matemáticas durante Secundaria y Bachillerato.

2. Determinar el conocimiento previo necesario que facilite el aprendizaje y la adquisición de las competencias de la asignatura Estadística.

3. Elaborar materiales que incluyan recursos teóricos y actividades de autoevaluación atendiendo a los resultados de las etapas anteriores.

4. Proporcionar experiencias de aplicación de la Estadística cercanas al ejercicio profesional de la Ingeniería y que revelen el interés de esta materia.

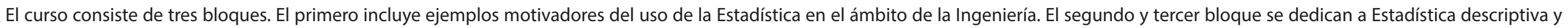

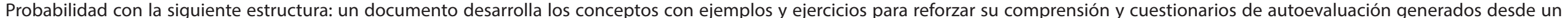
banco de preguntas. Los estudiantes pueden añadir datos a encuestas e interpretar los resúmenes estadísticos que proporciona Moodle.

El Curso 0 está disponible en la plataforma Moodle (NR_23426) para los estudiantes de nuevo ingreso de la EINA del curso 2018-19. 
Implementación de un Curso 0 virtual para Estadística y Probabilidad en Ingeniería: La experiencia en la EINA

Asín Lafuente, J.; Alberto Moralejo, L,; Badía Blasco, F. G.; Berrade Ursúa, M.D.; Galé Pola, M.C.; Jiménez Torres, F.; Jodrá Esteban, P.; Lahoz Arnedo, D.; Marín Escuer, J.; Sánchez-Valverde, B.

Dpto. Métodos Estadísticos. E-mail: jasin@unizar.es

Contexto y objetivo: Se ha implementado un Curso 0 dirigido a los estudiantes de nueva entrada en la EINA como recordatorio de los conceptos de Probabilidad y Estadistica estudiados en Enseñanza Secundaria y Bachillerato.

Metodologia: Se realizó el proyecto de innovación docente PRACUZ_17_26 para diseñar e implementar el Curso 0 en la plataforma Moodle de la UZ.

El diseño incluye la presentación de los conceptos básicos junto con ejemplos, la propuesta de ejercicios de entrenamiento y tests que permiten la autoevaluación por parte de cada estudiante.

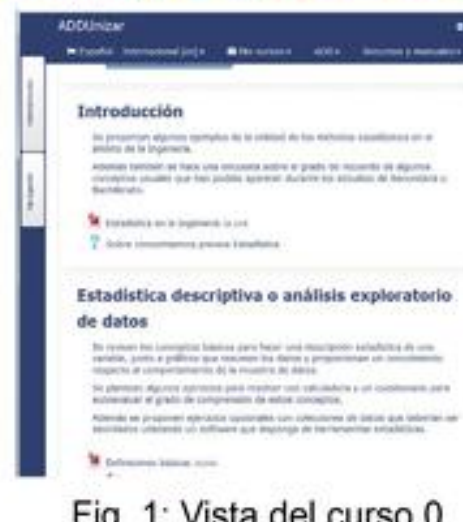

Resultados: El curso está activado desde julio de 2018. Hasta inicio de septiembre, 85 estudiantes lo han visitado. La frecuencia de visitas por parte de cada alumno es muy variable, como indica el histograma de la Figura 3, izd. En cuanto al momento de uso del curso, destaca que se produce con mayor frecuencia el domingo que el resto de dias y también las últimas horas del dia.

A partir de las respuestas al cuestionario sobre conceptos previos, el $83 \%$ conoce la desviación típica, $67 \%$ la regla de Bayes y $58 \%$ las distribuciones binomial y normal. Por el contrario, solo un $8 \%$ conoce la recta de regresión.

Conclusiones: El desarrollo del proyecto ha permitido la revisión de las herramientas de Probabilidad y Estadística que han aparecido en Secundaria y Bachillerato.

Los materiales son susceptibles de ser ampliados, para paliar lagunas que se detecten en los estudiantes de nuevo ingreso.

Fig. 2: Pregunta de cuestionario de autoevaluación
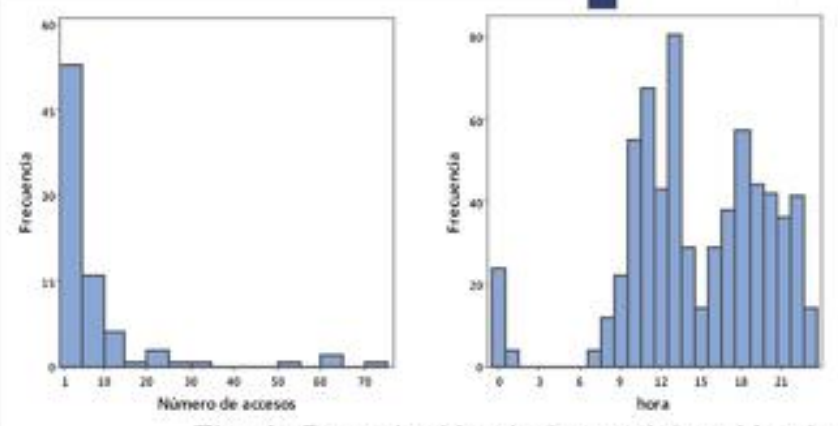

Fig. 1: Vista del curso 0

Fig. 3: Descripción de la participación de los estudiantes 


\section{Los Critical Management Education Studies como prisma teórico y conceptual para una educación empresarial alternativa}

Bretos Fernández, I.; Díaz Foncea, M.; Marcuello Servós, C.; Sarasa Aznar, C.

\section{Palabras clave}

Co-creación de conocimiento, organizaciones alternativas, organización y gestión, pedagogía crítica, universidad.

\section{Resumen}

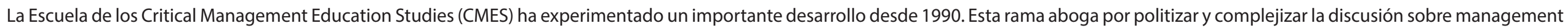

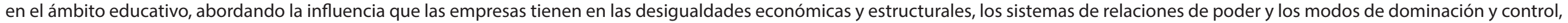
con el objetivo último de imaginar y generar formas de gestión más democráticas, humanistas, emancipadoras y socialmente responsables (Alvesson \& Willmott 1992).

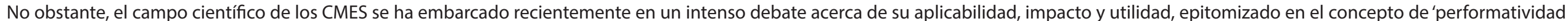

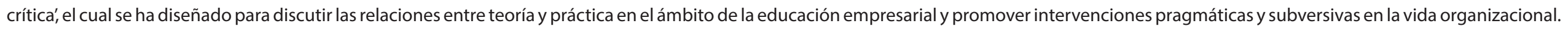

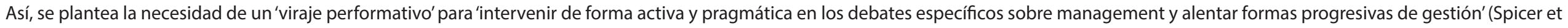
al. 2009: 537).

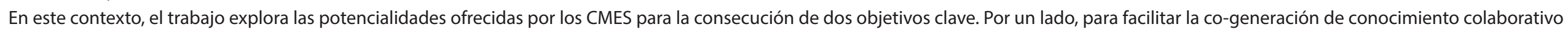

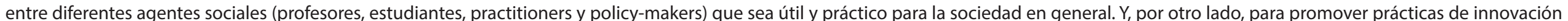

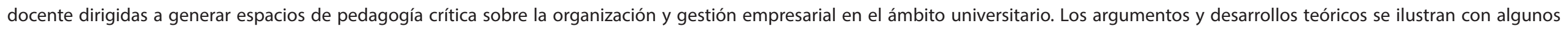
ejemplos prácticos de experiencias e intervenciones educativas llevadas a cabo en la Universidad de Zaragoza.

Alvesson, M., \& Willmott, H. (1992). Critical management studies. London: Sage.

Spicer, A. et al. (2009). Critical performativity: The unfinished business of CMS. Human Relations, 62(4): 537-560. 


\title{
Los Critical Management Education Studies como prisma teórico y conceptual para una educación empresarial alternativa
}

\author{
Ignacio Bretos, Millán Díaz Foncea, Carmen Marcuello, Clara Sarasa
}

Dpto. de Dirección y Organización de Empresas; ibretos@unizar.es; millan@unizar.es; cmarcue@unizar.es; clarasarasa@gmail.com

\begin{tabular}{|l|}
\hline $\begin{array}{l}\text { Contexto académico } \\
\text { Grado ADE y Grado } \\
\text { Economía (UZ) }\end{array}$ \\
\hline \multicolumn{1}{|c|}{ Objetivos } \\
\hline - Reducir el gap entre \\
teoría y práctica \\
- Promover educación \\
alternativa en \\
economía/empresa \\
\hline \hline \multicolumn{1}{|c|}{ Metodología } \\
- Learning-by-doing \\
- Aprendizaje-Servicio \\
\hline \hline Marco teórico: CMES \\
- Co-generación de \\
conocimiento entre \\
diferentes agentes \\
Herramientas docentes \\
para imaginar y generar \\
formas alternativas de \\
organización y gestión \\
económica
\end{tabular}

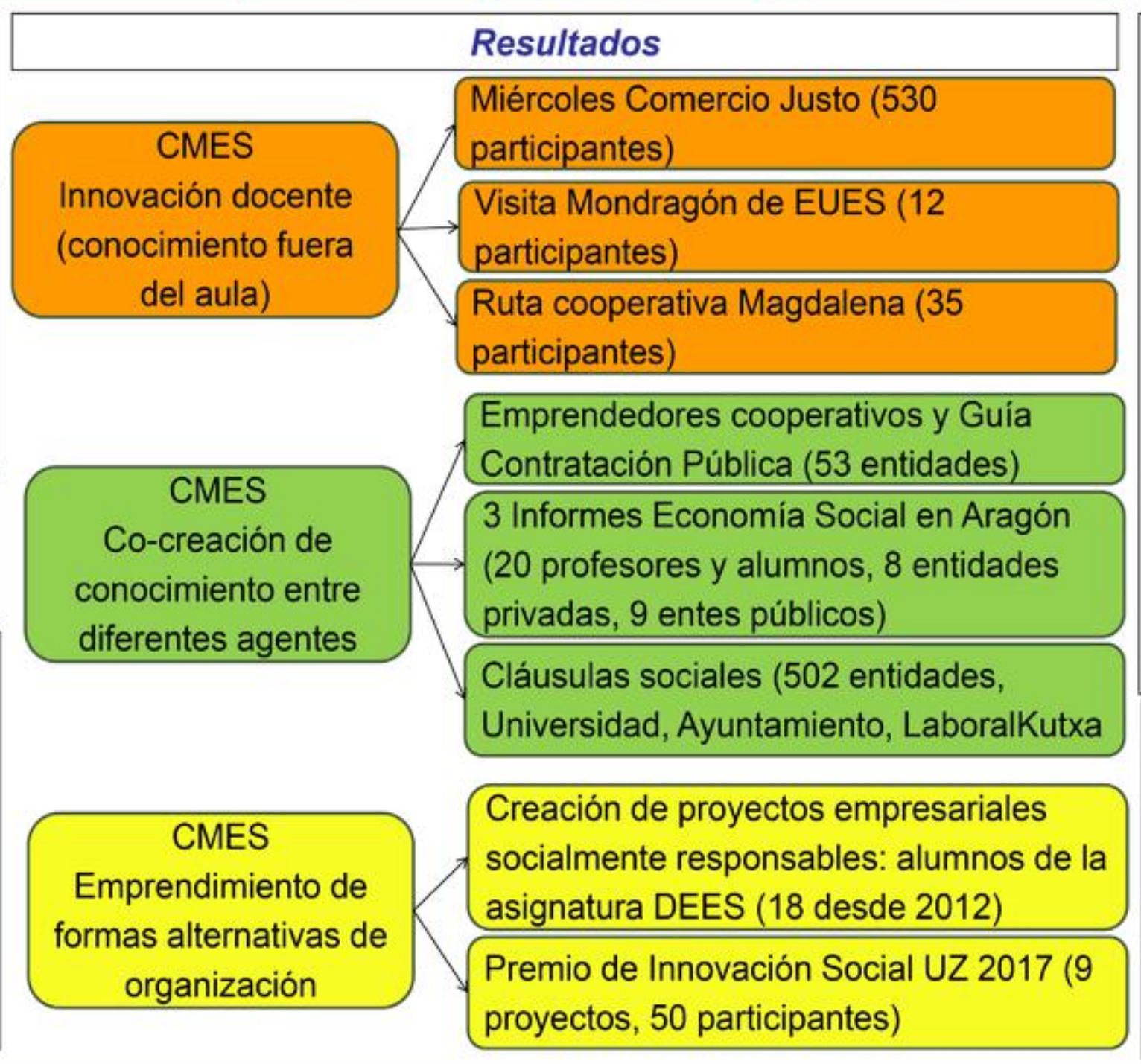

\begin{tabular}{|l|}
\hline \multicolumn{1}{|c|}{ Conclusiones } \\
- Difusión entre la comunidad \\
universitaria de experiencias de \\
organización basadas en la \\
democracia, solidaridad y \\
compromiso con el entorno. \\
- Herramientas de innovación \\
docente para reducir gap \\
teoría-práctica (conocimiento \\
fuera del aula, emprendimiento \\
por alumnos, etc.) \\
- Co-generación de conocimiento \\
entre profesores, alumnos, \\
practitioners y policy-makers. \\
\hline \hline \multicolumn{1}{c}{ Bibliografía } \\
- Alvesson, M., \& Willmott, H. \\
(1992). Critical management \\
studies. London: Sage. \\
- Spicer, A. et al. (2009). Critical \\
performativity: The unfinished \\
business of CMS. Human \\
Relations, 62(4): 537-560. \\
\hline
\end{tabular}

\section{.win Universidad $\underline{\text { III }}$ Zaragoza}




\section{MIRRORS: La orientación de los estudiantes de los Grados en Magisterio desde la experiencia contrastada de maestros jubilados}

Lizalde Gil, M.; Cortés Pascual, A.

\section{Palabras clave}

Orientación universitaria, mentoría, empleabilidad.

\section{Resumen}

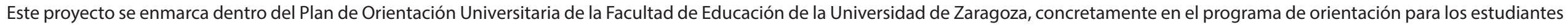

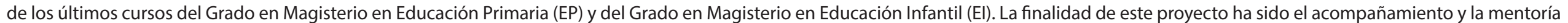

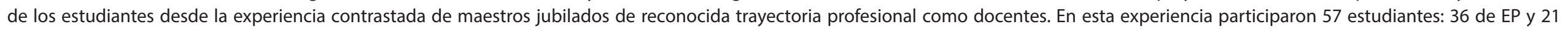

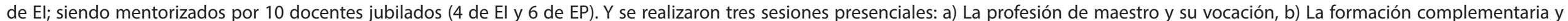

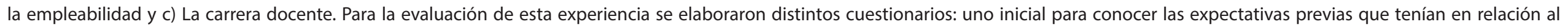

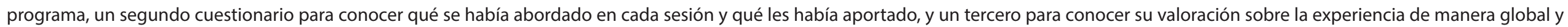

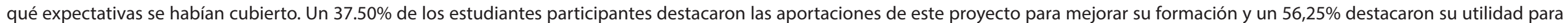

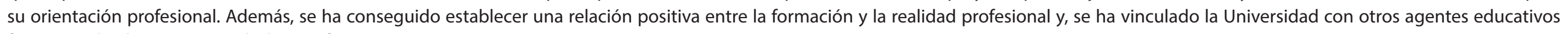
favoreciendo el impacto social y la transferencia. 


\section{MIRRORS: La orientación de los estudiantes de los Grados en Magisterio desde la experiencia contrastada de maestros jubilados \\ Lizalde Gil, M.1 ; Cortés Pascual, A²}

1Dpto. de Expresión Musical, Plástica y Corporal, mboston@unizar.es, 2Dpto. de Ciencias de la Educación, alcortes@unizar.es

Objetivo: Orientar a los estudiantes en el desarrollo de su formación académica, en su desarrollo competencial y en empleabilidad desde su experiencia personal y profesional. .

Contexto: Facultad de Educación. Grado Metodología, acciones e hitos

en Magisterio en Educación Primaria y 1.Selección de los maestros mentores (enero-febrero, 2018)

Grado en Magisterio en Educación 2.Presentación del proyecto a los estudiantes y selección de los participantes (febrero, 2018) Infantil.

3.Panel de expertos (febrero, 2018)

57 estudiantes de $3^{\text {er }}$ y $4^{\circ}$ curso. 10 mentores maestros jubilados

4.Desarrollo de las tres sesiones obligatorias de mentoria (marzo-mayo, 2018)

5.Seminario de discusión y evaluación (junio, 2018)

\section{Resultados}
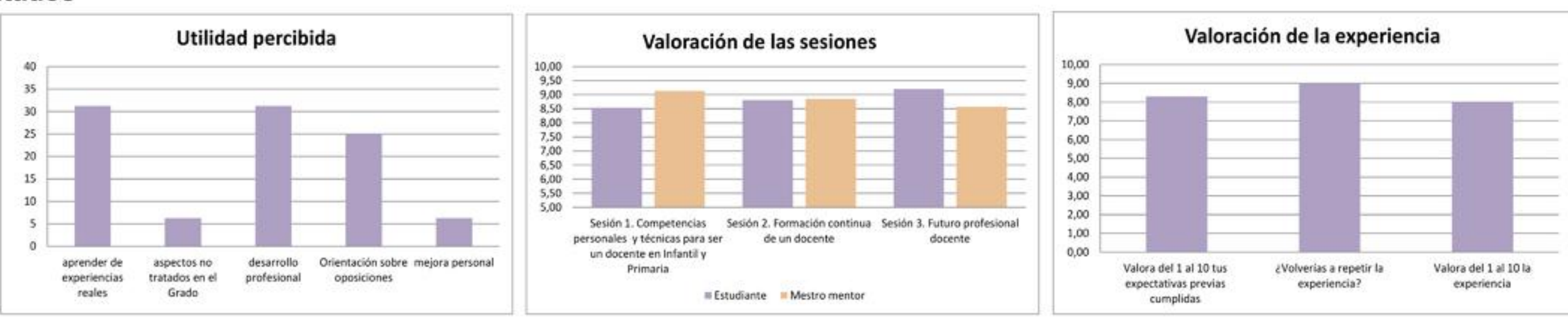

Conclusiones: Tanto las necesidades iniciales de los estudiantes de seguir mejorando su formación, a través de las experiencias reales de los maestros jubilados, como sus inquietudes por conocer como es el desarrollo profesional de una maestro/a se han visto satisfechas. Además, se ha conseguido establecer una relación positiva entre la formación y la realidad profesional y, se ha vinculado la Universidad con otros agentes educativos favoreciendo el impacto social y la transferencia. 


\section{Percepción del bullying por los estudiantes de la Universidad de Zaragoza}

Salavera, C.; Usán, P.; Artal, P.; Gómez, J.; Modrego, R.; Suárez H.; Calvo, N.

\section{Palabras clave}

Acoso escolar, estudiantes, primaria, secundaria, universidad.

\section{Resumen}

\section{Contexto:}

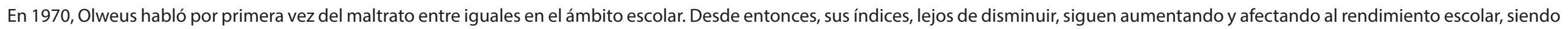
uno de los factores más determinantes en el fracaso escolar y posterior abandono de las aulas, en el que nuestro país, desgraciadamente, ocupa uno de los primeros puestos.

Las numerosas investigaciones que se han realizado, abarcan generalmente la etapa de Educación Secundaria, con alguna incursión en Primaria, pero sin abordar el tema desde la Universidad.

Objetivos:

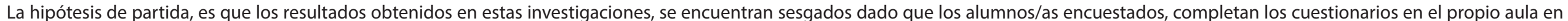

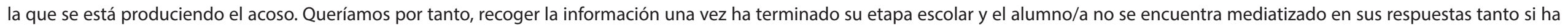
sido victima, acosador/a o espectador/a.

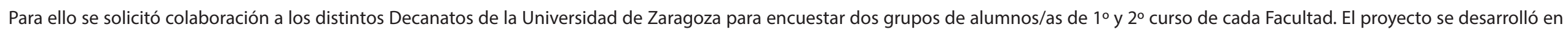

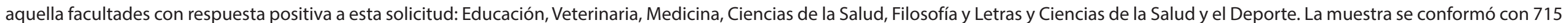
personas ( $31,2 \%$ hombres), de entre 18 y 70 años $(x=22,55)$ y un $97,1 \%$ menores de 45 años.

\section{Resultados:}

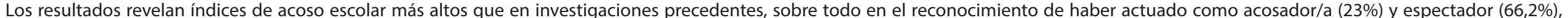
siendo las víctimas un $43,2 \%$

Conclusiones:

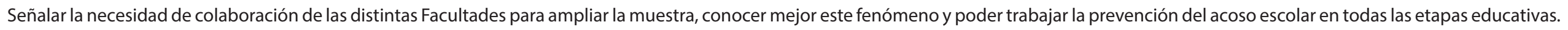




\section{Percepción del bullying por los estudiantes de la Universidad de Zaragoza}

\section{Carlos Salavera, Pablo Usán, Pedro Artal, Jennifer Gómez, Rocio Modrego, Helena Suárez y Noelia Calvo}

Departamento de Psicologia y Sociologia. Contacto: salavera@unizar.es

El propósito de este proyecto, consistía en medir en estudiantes de $1^{\circ}$ y $2^{\circ}$ de Grado, el acoso escolar en las etapas de Primaria y Secundaria una vez superada la etapa escolar y libre el alumno/a de presiones sociales a la hora de manifestar si había sido víctima, agresor o espectador en situaciones de acoso escolar; un segundo objetivo era evaluar si había situaciones de acoso entre iguales en la Universidad.

Los resultados muestran como un $27.7 \%$ conocen situaciones de violencia con insultos y amenazas, un $7.8 \%$ maltrato físico, un $24.47 \%$ rechazo y un $10.90 \%$ violencia de genero. Respecto al bullying, un $43.2 \%$ ha sido victima de acoso escolar, un $23 \%$ ha realizado alguna vez bullying a sus compañeros/as y un $66.2 \%$ ha sido espectador de situaciones de acoso.

Como conclusiones, la necesidad de ampliar la muestra a otras Facultades, para conocer y trabajar mejor este fenómeno a lo largo de las diferentes etapas educativas.
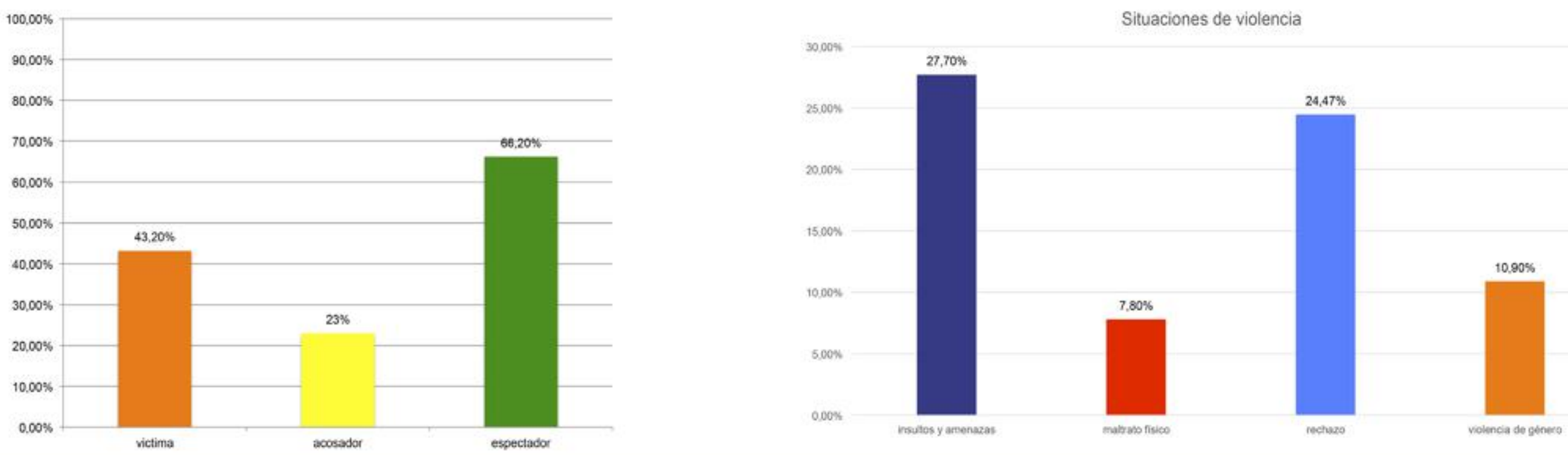


\section{Segunda edición del MOOC "Buenas Prácticas en el Uso Académico de la Propiedad Intelectual"}

Abadia, A. R.; Bueno, C.; Bueso, P.; Fidalgo, A.; Hernández, L.; Sein-Echaluce, M. L.; Ubieto, C.; Ubieto I.

\section{Palabras clave}

Derechos de autor, MOOC, e-learning.

\section{Resumen}

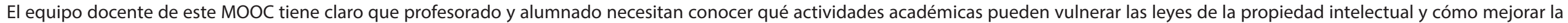
calidad de los trabajos académicos (como los TFG y TFM), no solo en contenidos propios sino en el respeto a la propiedad intelectual ajena utilizada en los mismos.

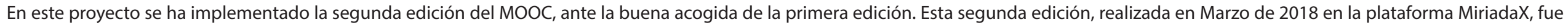
revisada y mejorada a partir de las opiniones de los participantes en la primera edición.

La tasa de finalización del curso se sigue manteniendo por encima del 50\%, mucho mayor que la media obtenida en este tipo de cursos masivos.

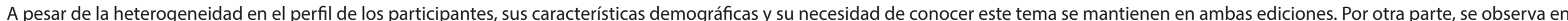
los resultados de las encuestas que hay un muy alto grado de satisfacción de los participantes en cuanto a la utilidad del curso y en cuanto al conocimiento que han adquirido.

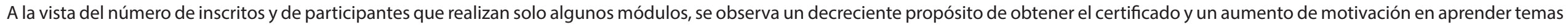
de interés, por el mero hecho de aprender, lo que incide en la calidad del aprendizaje de este curso masivo.

En la segunda edición se observa un aumento del número de estudiantes universitarios entre los participantes.

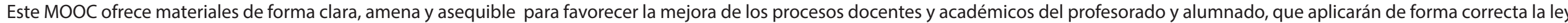
de propiedad intelectual. 
Segunda edición del MOOC 'Buenas Prácticas en el Uso Académico de la Propiedad Intelectual'

\section{Ana Rosa Abadia, Concha Bueno, Pedro Bueso, Angel Fidalgo, Lola Hernández,} Marisa Sein-Echaluce, Clara Ubieto, Isabel Ubieto

Depto. Farmacología y Fisiología, arabad@unizar.es

$\begin{array}{ll} & = \\ \text { URL: https://miriadax.net/web/buenas-practicas-en-el-uso-academico-de-la-propiedad- } & \text { implementado en Marzo de } 2018 \text { en la plataforma MiriadaX } \\ \text { intelectual-2-edicion-/inicio (acceso libre para consulta de los materiales hasta la }\end{array}$

8. Implementar la segunda edición del MOOC con materiales y diseño mejorado a partir de las opiniones de los participantes en la primera edición. Analizar los datos de participación y los resultados de las encuestas inicial y final sobre perfil demográfico y de conocimiento previo, así como la satisfacción de los participantes respecto a la utilidad y calidad de los contenidos.
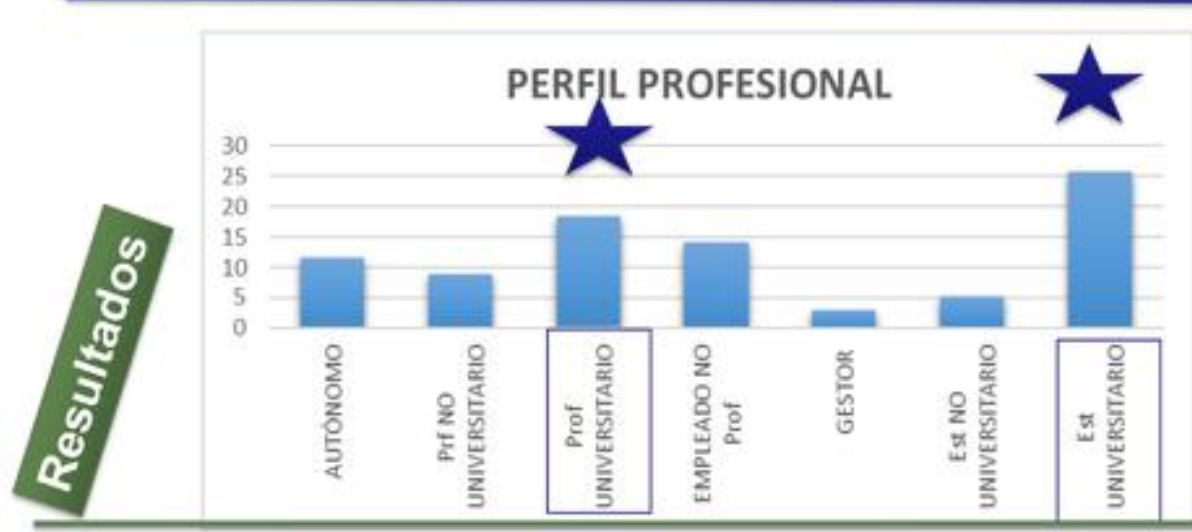

En tu actividad laboral ctienes la necesidad de conocer los fundamentos éticos y legales de la Propiedad Intelectual?

sion Altas tasas de finalización, altísima percepción sobre utilidad y calidad del curso y necesidad de

conocimientos sobre la Propiedad Intelectual aconsejan la difusión y uso de este MOOC para mejorar los procesos docentes en profesorado y alumnado y, en particular, en la elaboración de los TFG y TFM.

\section{Universidad}

Iî. Zaragoza 



\section{Índice de autores}




\section{Índice de Autores}

Abadia, A. R. .

196,218

Abecia Martínez, B.

Abián Vicén, M.

16,24

Abrego Garrués, J.

17,42

Acero-Ferrero, M.

50,64

Acero Fraile, I.

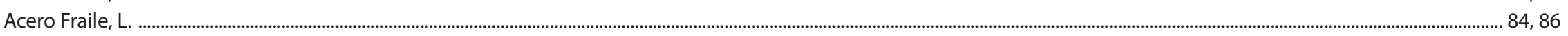

Agudo Valiente, J. M. .

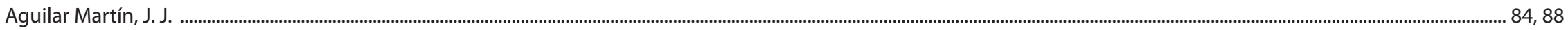

Aibar Solana, A.

140,154

Aísa Arenaz, J.

$84,85,88,104$

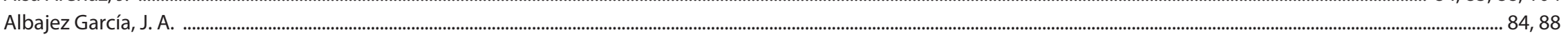

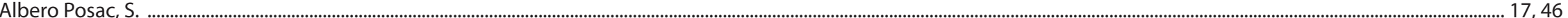

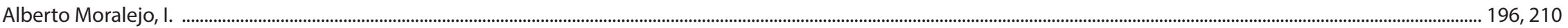

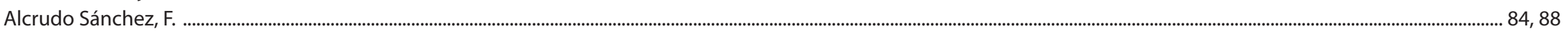

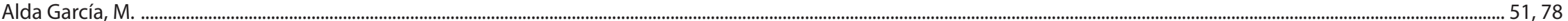

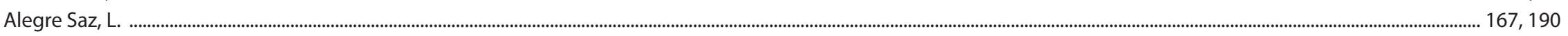

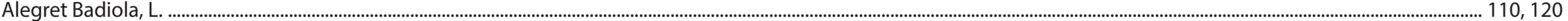

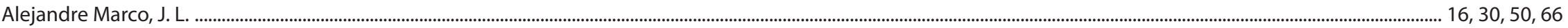

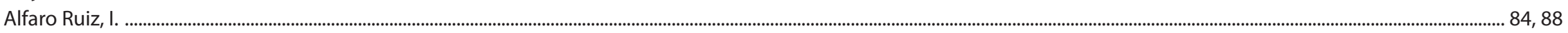

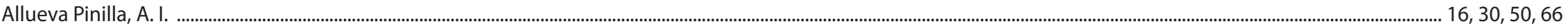

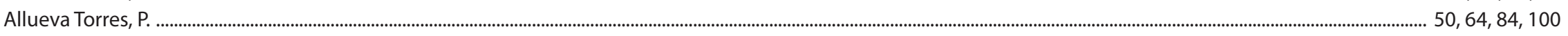

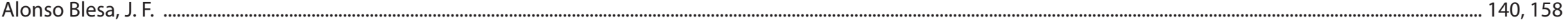

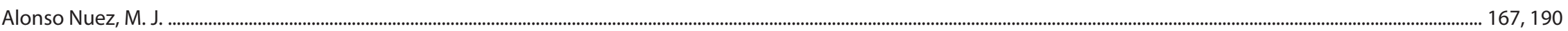

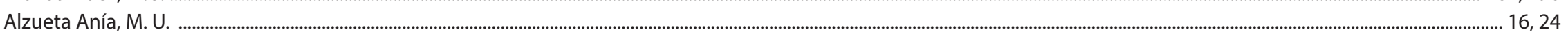

Arauzo Perez, I. .

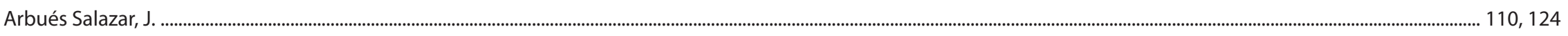

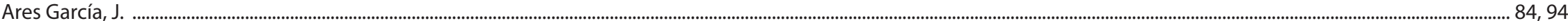

Artacho Terrer, J. M. ............................................................................................ 166, 167, 168, 192 
Artal, P.

Artal Sevil, J. S.

$66,167,168,186,192$

Artero Escartín, I.

$16,32,110,128$

Asensio Martínez , A

110,126

Asín Lafuente, J.

196,210

Asún Dieste, $\mathrm{S}$.

... 50,68

Atienza Martínez, M

$16,28,140,142$

Ayensa Vázquez, J. A

110,130

Aznar Villacampa, M. P.

Badía Blasco, F. G.

Balsera Gómez, F. J.

140,158

del Barrio Aranda, L.

$140,146,166,174$

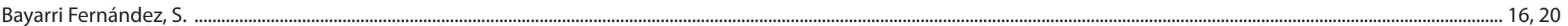

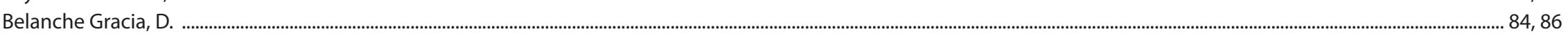

Bernad Morcate, $C$. 84,86

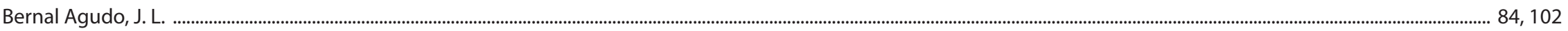

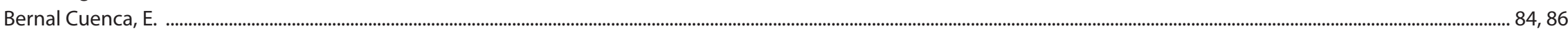

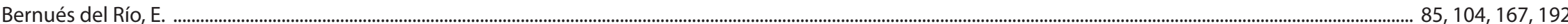

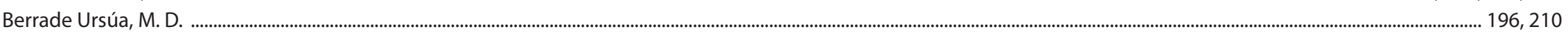

Biel lbáñez, P.

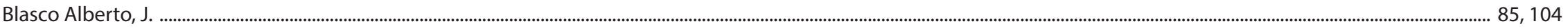

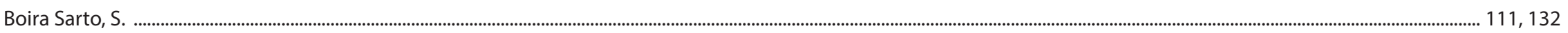

Bonastre Rafales, C .

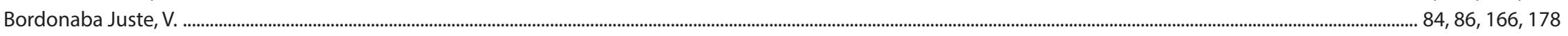

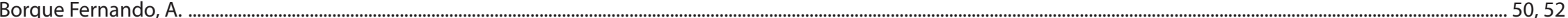

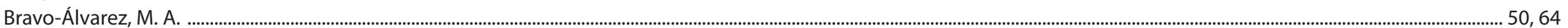

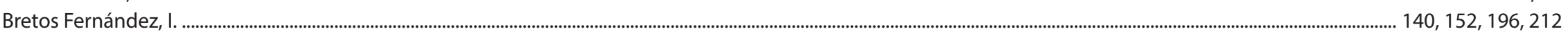

Bueno García, C. ............. 50, 64, 196, 218

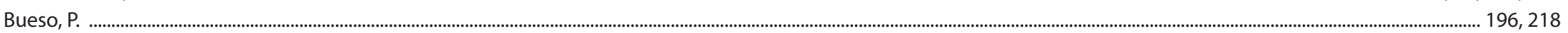

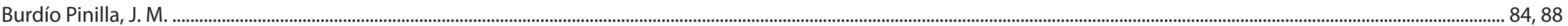

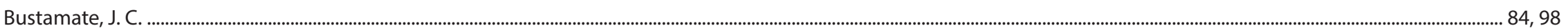


Cabanés Cacho, B.

Cadena González, A.

17,38

Callejas Bermejo, A.

$6,17,28,42$

Calvo López, B.

110,118

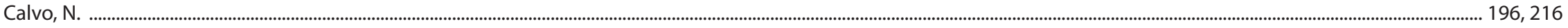

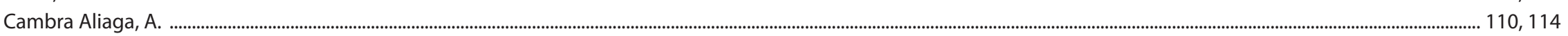

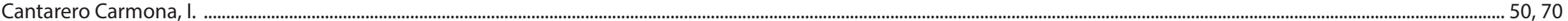

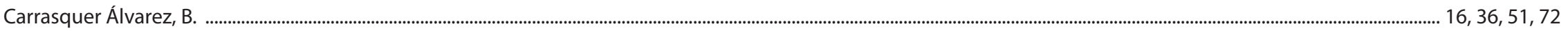

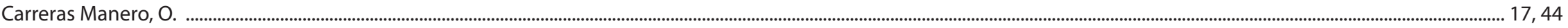

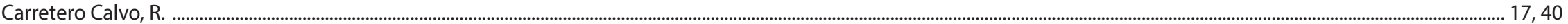

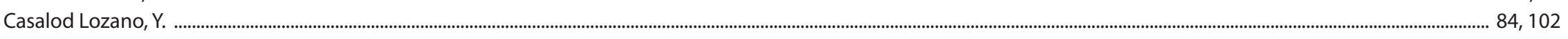

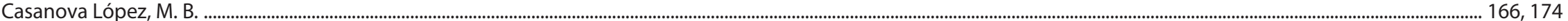

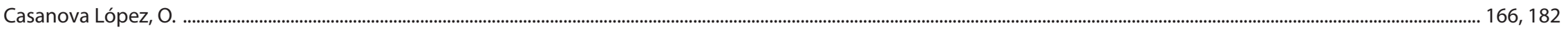

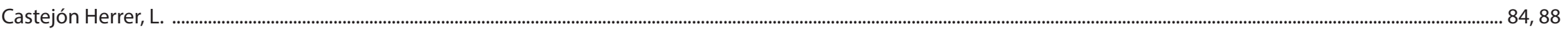

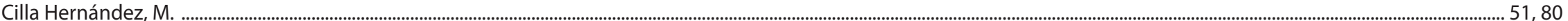

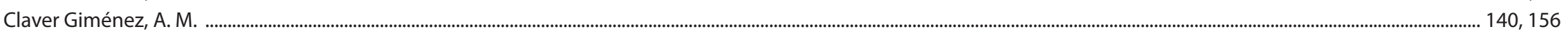

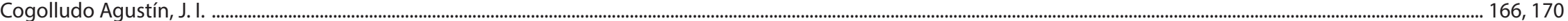

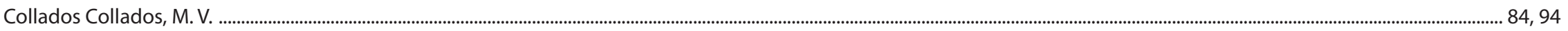

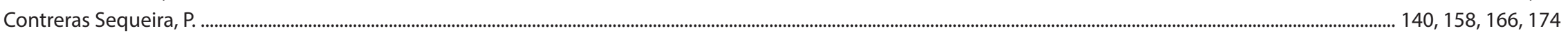

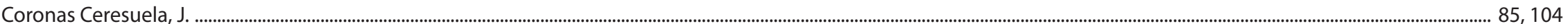

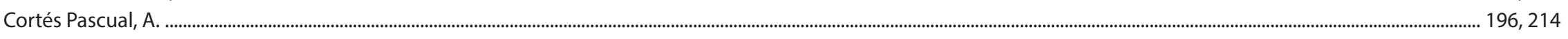

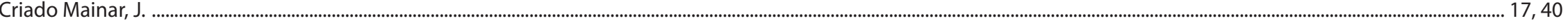

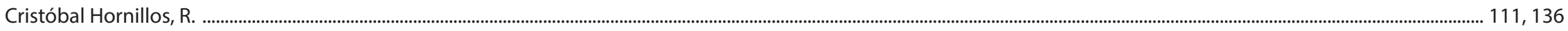

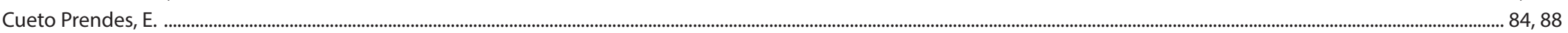

Cuevas Salvador, J. ........................-. - 
Díaz Foncea, M. ...

$84,86,140,152,196,212$

Domeque Claver, $\mathrm{N}$

110,128

Duarte Pac, R. .. 50, 56

E

Echeverría Domingo, J.

140,148

Elduque Viñuales, D.

.. 84,88

Elia Guedea, N. ....

... 84,94

Embid López, M. S.

... 84,90

Escanero Marcén, J. F.

196,198

Escolano Pérez, E. .

$50,64,84,100$

Esteban Sánchez, A. L.

Falceto Recio, M. V.

Fernández Amat, $\mathrm{C}$.

$111,132,166,172$

$140,158,166,174$

dez-Turrado, $\mathrm{T}$ ... 84,98

Fidalgo, A.

196,218

Fraj Andrés, E. ...

$84,86,166,178$

Francés Pérez, E. ..

$84,88,140,142$

Franco Sierra, M. A

$50,54,166,180$

Galé Pola, M. C.

$84,88,196,210$

Galindo Ayuda, F.

196,198

Gállego Lanau, M.

16,22

Gálvez Ruiz, P.

50,64

Garcés-Ayerbe, $C$.

50,62

García Campayo, J.

111,132 
García Casarejos, N.

$84,86,111,134$

García Catalán, R.

166,170

García-Cebrián, L.

84,96

167,190

40,160
51,74

García Nieto, L.

196,202

Gargallo Ibort, E.

$66,174,186$

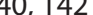

Gea Galindo, G. .......

140,154

Gil Clemente, E. ..

166,170

Gil Huerta, L.

51,76

Gil Lacruz, A. I.

$.84,88$

Gil Lalaguna, N.

$16,28,140,142$

Gil Sanz, M. J.

50,52

Gil, V.

50,64

Gómez, J. .....................196, 216

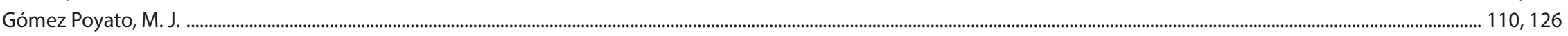

González Campo, F. de Asís .........................................

Gonzalo Ciria, L.

110,114

Gorgemans, S.

$88,167,190$

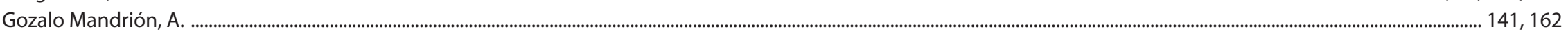

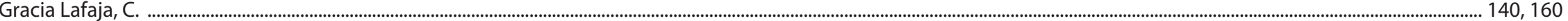

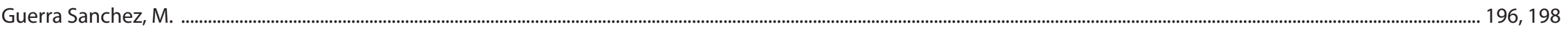

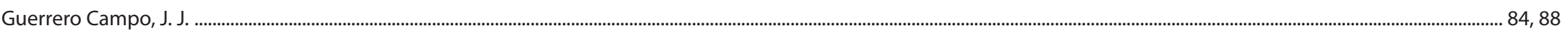

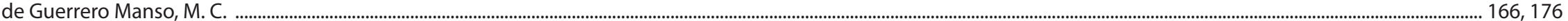

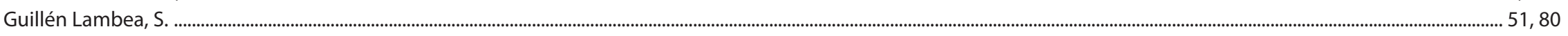

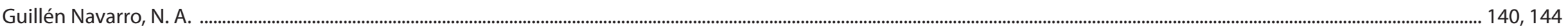

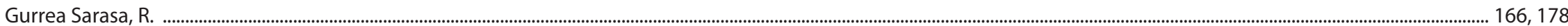


Hernández Ortega, B.

Herrando Soria, C.

166,178

Herrero Nivela, M. L.

$50,64,84,100$

Huertas Talón, J. L.

Jarne Jarne, G.

Jiménez Torres, $\mathrm{F}$.

Jodrá Esteban, P.

196,210

Juan Morera, B.

166,174

Julián Clemente, J. A

$\mathbf{L}$

Labarta Aizpún, C.

85,104

Laborda, A.

111,132

Laborda Soriano, A. A

110,114

Lahoz Arnedo, D.

196,210

Laliena Cantero, D.

17,38

Lanchares Sancho, E.

16,20

Larramona Bailarín, $\mathrm{G}$

84,86

Larrodé Pellicer, E.

... 84,88

Lasala Calleja, M. P. ....

196,198

Latorre Cosculluela, $C$

110,124

Lázaro Gistau, R.

16,20

Leris López, M. D.

$16,28,50,64$

Lidón López, I. 
Liesa Orús, M

110,124

Lizalde Gil, M.

196,214

Lizasoain Iriso, I.

... 166,170

Llera Sastresa, E. M.

$16,26,110,112$

Lobera Viñau, E.

16,32

López Casanova, M. B.

$140,146,158$

... 84,94

López del Hoyo, Y.

111,132

85,104

López Forniés, L

16,18

López Nicolás, G.

84,88

López Pellicer, F. J.

84,88

López Pérez, F. .

17,44

López Sánchez, C.

16,32

Lozano Velázquez, J.

167,190

Lucha López, P.

140,156

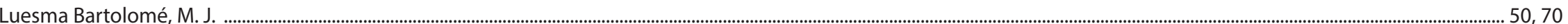

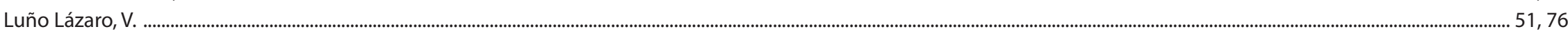

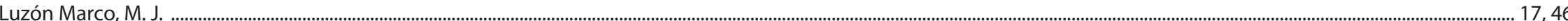

Maestro Guerrero, F.

Magallón Botaya, R.

110,126

Majarena Bello, A. C.

Manchado Pérez, E. .

16,18

Marcellán Vidosa, M. C. 84,94

Marcén Román, Y $50,54,166,180$

Marco Sanjuán, I.

Marcuello Servós, C.

140, 152, 196, 212

196,210

Márquez Marzal, A

110,118

Martí Jimenez, J. I.

Martín de Hoyos, M. J. 
Martínez Asensio, F.

Martínez Barca, M. A. . . . ...... 84, 88

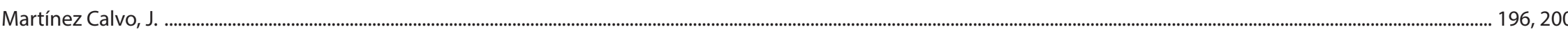

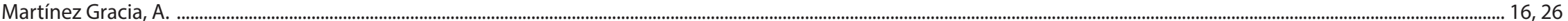

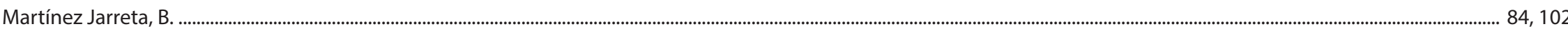

Martínez Pestaña, M. J. .................................................................................................................................................................................................................................................................. 140, 160

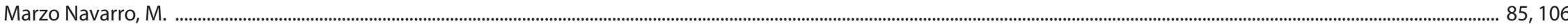

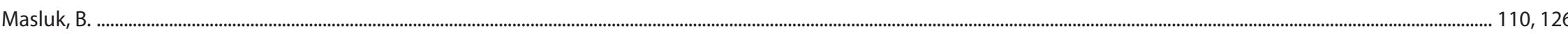

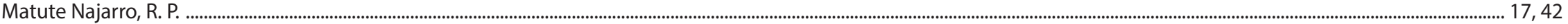

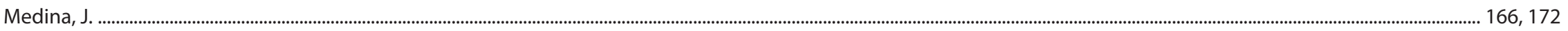

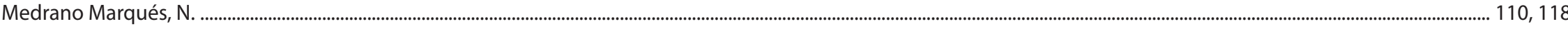

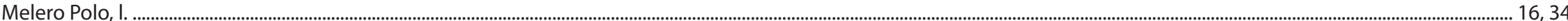

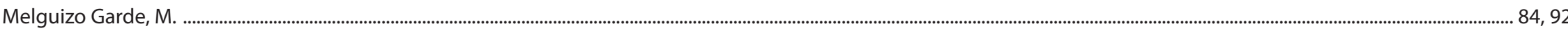

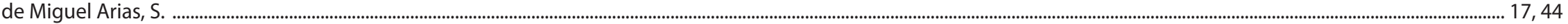

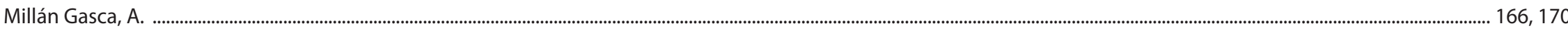

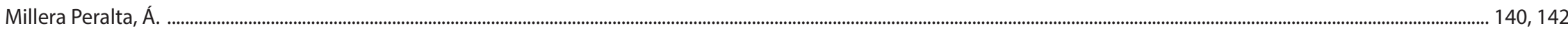

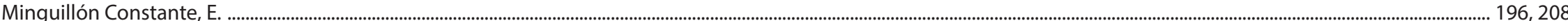

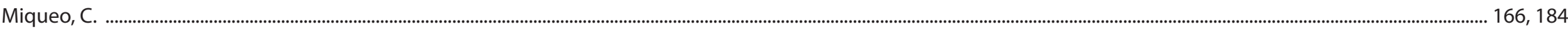

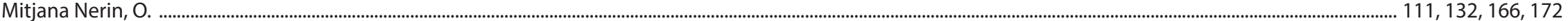

Modrego, R. .

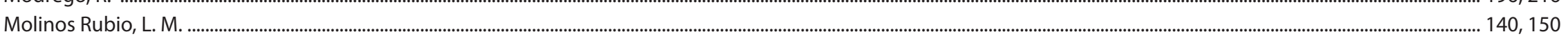

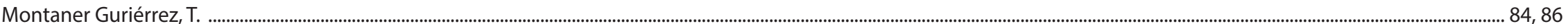

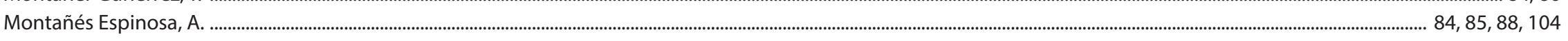

Mosteo Abad, R. ...

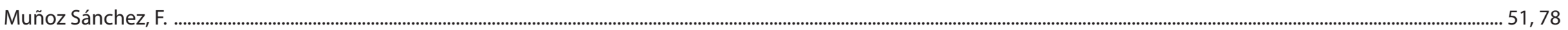

$50,64,110,116$

Mueñas, M. P.

$16,17,28,42,84,88$

$110,122,166,188,196,206$

140,154

Pardo, B.

110,128 
Navarro Elola, L.

Palomas, S.

167,190

Pardos Martínez, E.

Pasamar Alzuria, G.V.

140,150

Pastor-

Pedraja Iglesias, $M$

85,106

Pedraza Gracia, M. J.

140,160

Pellicer Ortín, S.

110,116

Peña Pellicer, B.

$16,26,110,112$

Perchés Barrena, $\mathrm{S}$.

.. 84, 94

Pérez-Aradros Muro, B.

196,202

Pérez Arquillué, $C$.

16,20

Pérez Bailón, J.

110,118

Pérez López, R.

166,178

Pérez Sinusía, E.

166,186

Pessoa de Oliveira, A. K.

$50,60,84,86$

Ponz Miranda, A

$16,36,51,72$

Puche Gil, J.

166,186

Pueo Arteta, M.

51,80

Puértolas Marcén, A. 
Ramos Vallecillo, N.

166, 188, 196, 206

Rapún López, M.

50,68

Rebollar Rubio, R.

... 84,88

Remacha Andrés, $\mathrm{M}$.

84,90

Remón Martín, L.

... 84,94

Resano Ezcaray, J. J.

85,104

$10,122,196,206$

Revilla Carrasco, A

17,38

Rico Letosa, S.

16,32

Rivera-Torres, P. . .

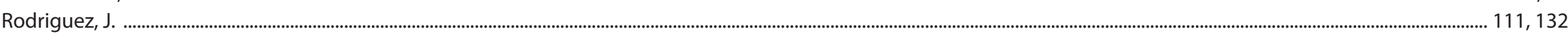

Rodríguez Martínez, A. . 110, 124

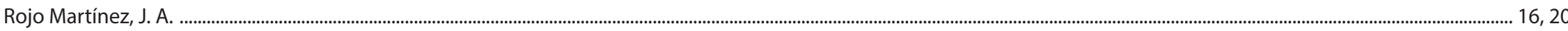

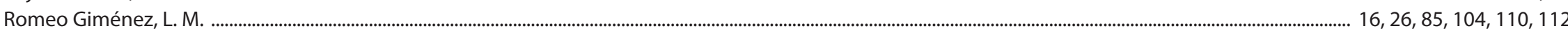

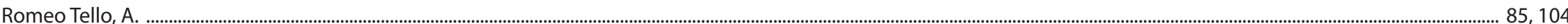

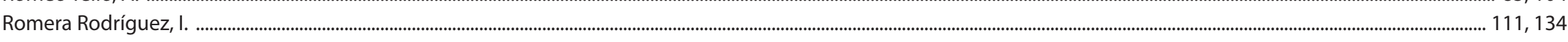

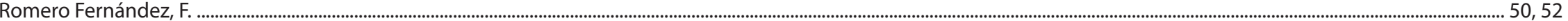

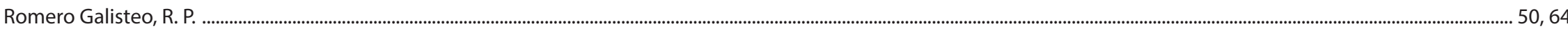

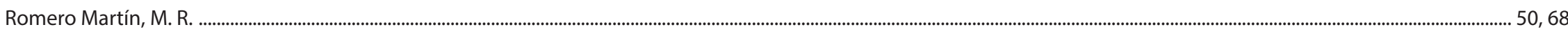

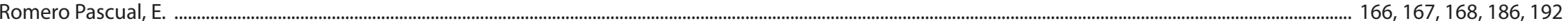

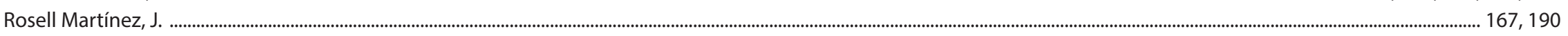

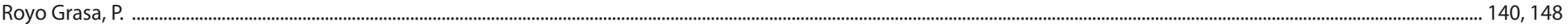

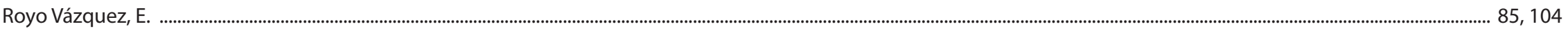

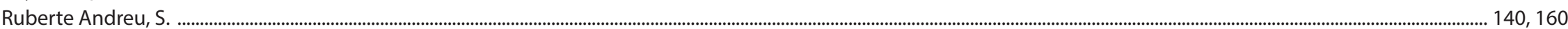


Sánchez Sellero, P.

Sánchez-Valverde, B.

196,210

Sancho Anel, D.

.... 50, 56

Sanjuán Alvarez, M.

111,136

Santillán Santa Cruz,

196,200

Sanz del Pozo, M.

$. .50,52$

Sanz Rubio, M. C.

$50,54,166,180$

Sanz Segura, R.

16,18

Sanz Valer, P. .

110,114

Sarasa Alonso, J.

17,42

Sarasa Aznar, C.

$140,152,196,212$

Sarasa Fernández, C. . .

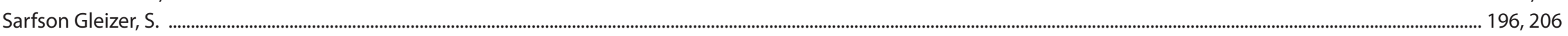

Sayago García, F. J.

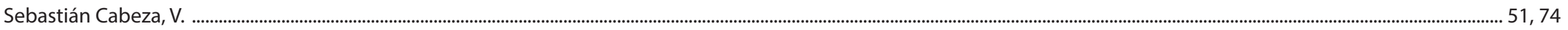

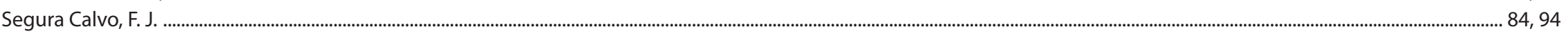

Sein-Echaluce, M. L. _................. 196, 218

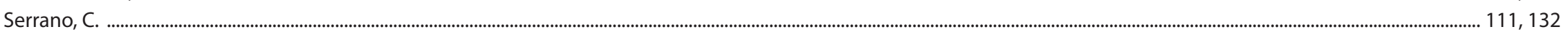

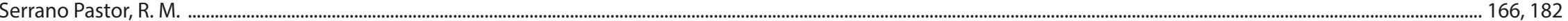

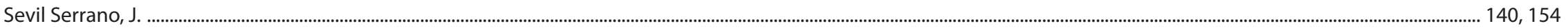

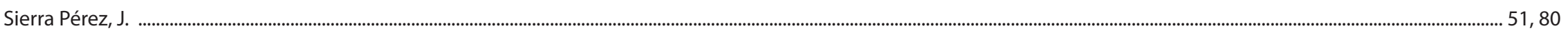

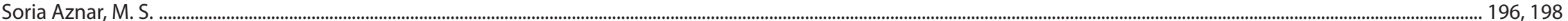

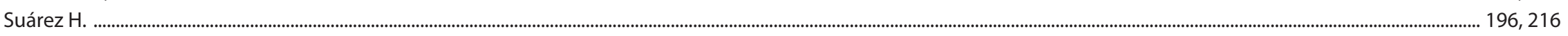

Suárez-Perales, I. ...................................................... 50, 62

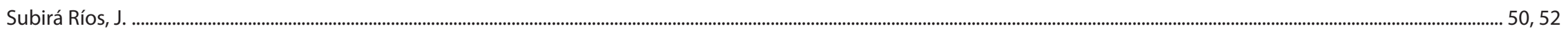

Tormo Blanes, J. 
Ubieto, C

196,218

Ubieto I.

196,218

Usán, P.....

... 196, 216

Usón Gil, S.

$16,26,110,112$

166,178

Valero-Gil, J.

$16,20,50,62$

Valero Gracia, M. S.

$16,20,166,186$

Vallés Brau, J. A.

.. 84,94

Vargas Magallón, M.

51,78

Vázquez Toledo, S.

110,124

Vélez Jiménez,

140,150

... 17, 46

Vicente Reñé, $R$.

51,78

Vicente Romero, J.

140,150

Vidal Sánchez, M. I.

110,114

Villagrasa Rozas, M. M.

16,32

Villanueva Roa, J. D.

111,136

Villa Torrano, A

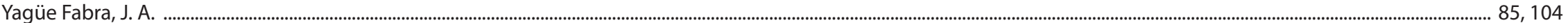

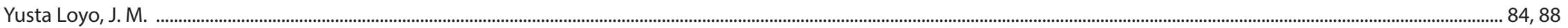




ISBN 978-840906315-4

|| |||||| ||| || ||||||||

(1)

g $788409 \|_{063154}$ 